NUREG/CR-5759

EGG-2640

RG

\title{
Risk Analysis of Highly Combustible Gas Storage, Supply, and Distribution Systems in PWR Plants
}

Manuscript Completed: November 1992

Date Published: June 1993

Prepared by

G. P. Simion', R. L. VanHorn, C. L. Smith,

K. D. Bulmahn², J. H. Bickel, M. B. Sattison

Idaho National Engineering Laboratory

Managed by the U.S. Department of Energy

EG\&G Idaho, Inc.

Idaho Falls, ID 83415

\section{Prepared for}

Division of Safety Issue Resolution

Office of Nuclear Regulatory Research

U.S. Nuclear Regulatory Commission

Washington, DC 20555

NRC FIN D6198

Under DOE Contract No. DE-AC07-76ID01570

'Currently with Science Applications International Corp., Albuquerque, NM 87110

2Scientech, Inc., Idaho Falls, ID 83415 


\begin{abstract}
This report presents the evaiuation of the potential safety concerns for pressurized water reactors (PWRs) identified in Generic Safety Issue 106, Piping and the Use of Highly Combustible Gases in Vital Areas. A Westinghouse four-loop PWR plant was analyzed for the risk due to the use of combustible gases (predominantly hydrogen) within the plant. The analysis evaluated an actual hydrogen distribution configuration and conducted several sensitivity studies to determine the potential variability among PWRs. The sensitivity studies were based on hydrogen and safety-related equipment configurations observed at other PWRs within the United States. Several options for improving the hydrogen distribution system design were identified and evaluated for their effect on risk and core damage frequency. A cost/benefit analysis was performed to determine whether alternatives considered were justifiable based on the safety improvement and economics of each possible improvement.
\end{abstract}

FIN No. D6198 Generic Safety Issue 106, Piping and the Use of Highly Combustible Gases in Vital Areas 


\section{CONTENTS}

ABSTRACT $\ldots \ldots \ldots \ldots \ldots \ldots \ldots \ldots \ldots \ldots \ldots \ldots \ldots \ldots \ldots \ldots$ iii

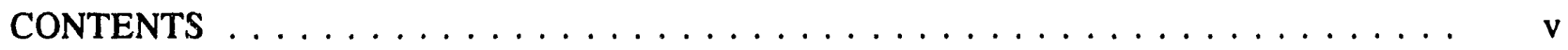

LIST OF FIGURES $\ldots \ldots \ldots \ldots \ldots \ldots \ldots \ldots \ldots \ldots \ldots \ldots \ldots \ldots \ldots$

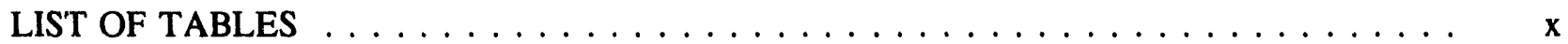

EXECUTIVE SUMMARY $\ldots \ldots \ldots \ldots \ldots \ldots \ldots \ldots \ldots \ldots \ldots \ldots \ldots \ldots$

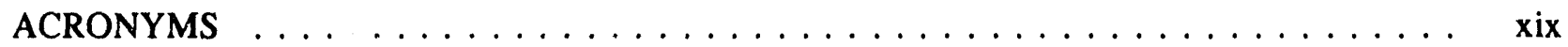

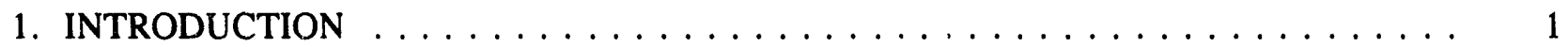

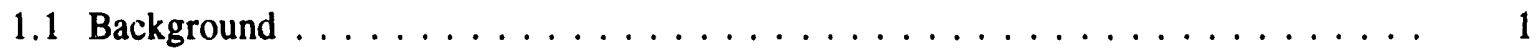

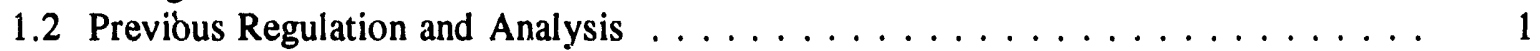

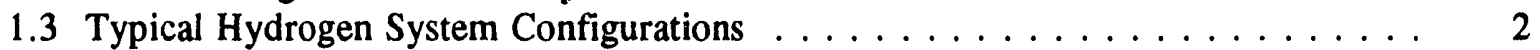

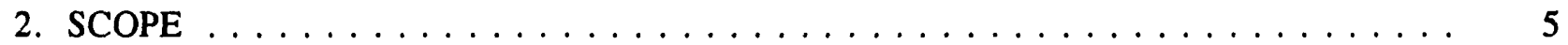

3. NUCLEAR INDUSTRY EXPERIENCES INVOLVING HYDROGEN $\ldots \ldots \ldots \ldots$

3.1 Review of U.S. Nuclear Power Plant Hydrogen Events $\ldots \ldots \ldots \ldots \ldots \ldots$

3.1.1 Electrical Generator Events . . . . . . . . . . . . . . . . . 9

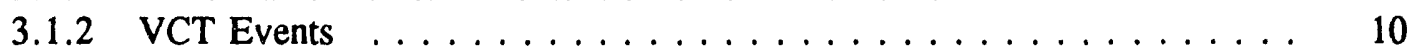

3.1 .3 Waste Gas Events . . . . . . . . . . . . . . . . . . . 10

3.1.4 Hydrogen Storage Facility Events . . . . . . . . . . . . 10

3.1 .5 Battery Events . . . . . . . . . . . . . . . . . 10

3.2 Review of Foreign Nuclear Power Plant Hydrogen Events . . . . . . . . . . . . 10

3.3 Summary of Review of Hydrogen Events $\ldots \ldots \ldots \ldots \ldots$

4. SCREENING ANALYSIS OF POTENTIAL SOURCES OF

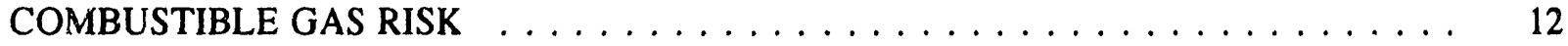

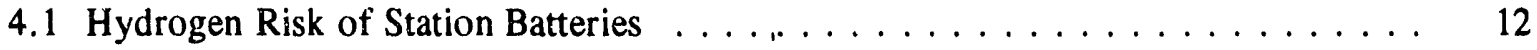

4.2 Risk of Portable Gas Bottle Use and Storage Areas f . . . . . . . . . . . . . 16

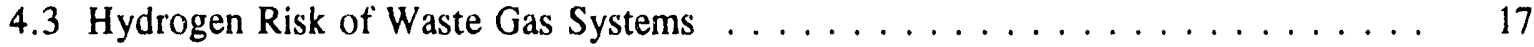

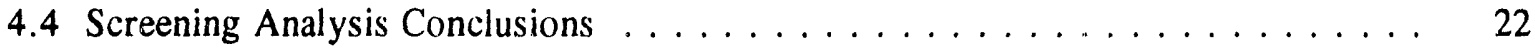




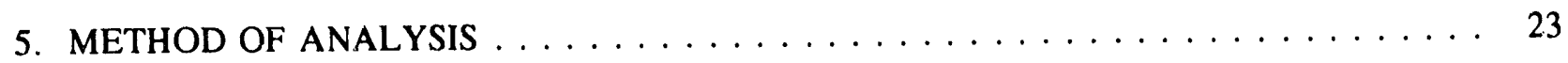

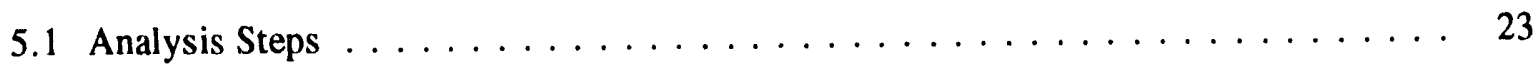

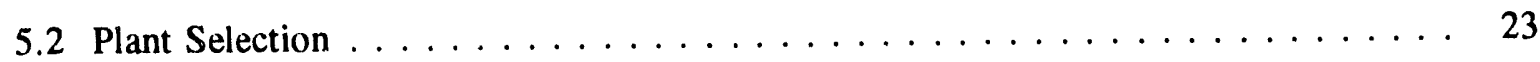

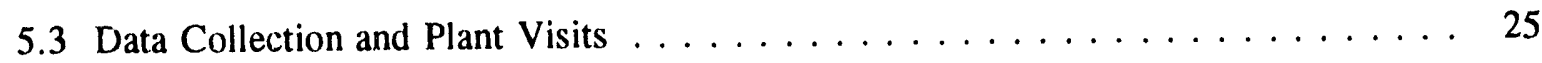

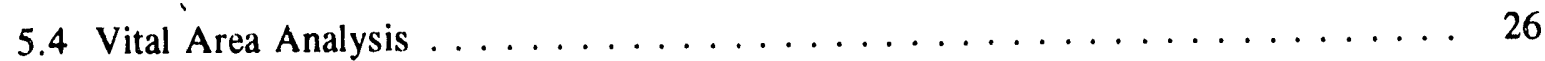

5.5 Seismic Interaction Analysis $\ldots \ldots \ldots \ldots \ldots \ldots \ldots \ldots \ldots$

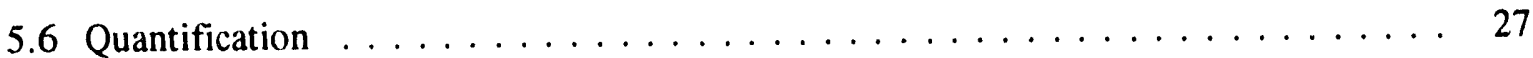

5.7 Uncertainty Analysis $\ldots \ldots \ldots \ldots \ldots \ldots \ldots \ldots \ldots \ldots \ldots$

5.8 Generic Analyses $\ldots \ldots \ldots \ldots \ldots \ldots \ldots \ldots \ldots \ldots \ldots$

5.9 Plant Improvement Analysis $\ldots \ldots \ldots \ldots \ldots \ldots \ldots \ldots \ldots \ldots$

5.10 Analysis Limitations and Assumptions . . . . . . . . . . . . . . . . 29

6. ANALYSIS OF A WESTINGHOUSE FOUR-LOOP PLANT $\ldots \ldots \ldots \ldots \ldots$

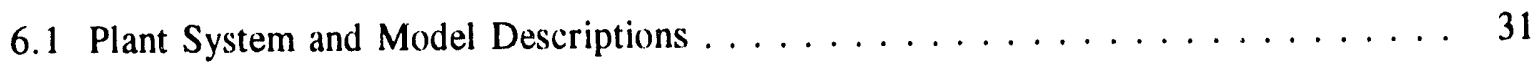

6.2 Turbine Building Analysis $\ldots \ldots \ldots \ldots \ldots \ldots \ldots \ldots \ldots \ldots \ldots$

6.2.1 Turbine Building Hydrogen Gas System Configuration . . . . . . . . 31

6.2 .2 Turbine Building Vital Area Analysis . . . . . . . . . . . . . 35

6.2.3 Transients with Loss of Decay Heat Removal - Turbine Building . . . . . . 36

6.2.4 Transient-Induced Loss-of-Coolant Accident - Turbine Building . . . . . 39

6.3 Auxiliary Building Analysis $\ldots \ldots \ldots \ldots \ldots \ldots \ldots \ldots \ldots$

6.3.1 Auxiliary Building Hydrogen Gas System Configuration . . . . . . . . . . 44

6.3.2 Auxiliary Building Vital Area Analysis . . . . . . . . . . . . . . 47

6.3.3 Transients with Loss of Decay Heat Removal - Primary Auxiliary Building ...................... 48

6.3.4 Transient-Induced Loss-of-Coolant Accident - Primary Auxiliary Building ...................... 51

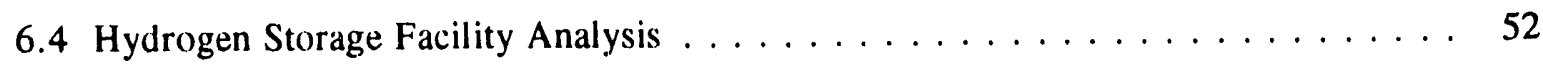

6.4 .1 Hydrogen Storage Facility Description . . . . . . . . . . . . 52

6.4 .2 Hydrogen Storage Facility Vital Area Analysis . . . . . . . . . . . . 53

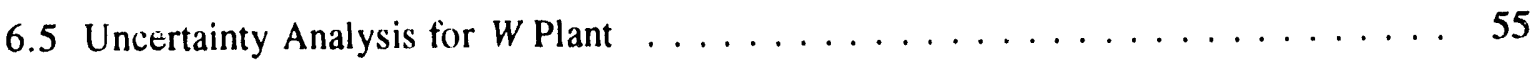


$6.6 W$ Plant Analysis Results $\ldots \ldots \ldots \ldots \ldots \ldots \ldots \ldots$

6.7 Hydrogen Events During Operating Modes Other Than Full Power . . . . . . . . 55

7. GENERIC ANALYSES $\ldots \ldots \ldots \ldots \ldots \ldots \ldots \ldots \ldots \ldots$

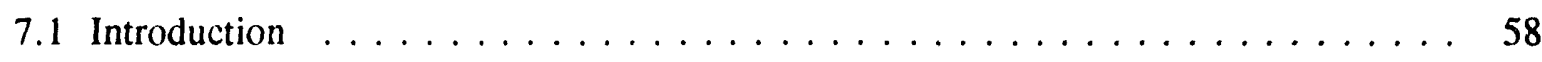

7.2 Methodology for Generic Plant Analysis $\ldots \ldots \ldots \ldots \ldots \ldots$

7.2.1 Methodology Utilized for Evaluating In-plant Hydrogen Supply and

Distribution System Risk . . . . . . . . . . . . . . . . 58

7.2.2 Methodology Utilized for Evaluating Hydrogen Storage Facility Risk . . . 60

7.3 Transients with Loss of Decay Heat Removal . . . . . . . . . . . . . . . . 62

7.3.1 Turbine Building Nonseismic Analysis . . . . . . . . . . . . 62

7.3.2 Turbine Building Seismic Analysis $\ldots . \ldots \ldots \ldots 66$

7.3.3 Uncertainty Analysis for Turbine Building T/DHR Scenarios . . . . . . . 66

7.3 .4 Auxiliary Building Nonseismic Analysis . . . . . . . . . . . . 68

7.3.5 Auxiliary Building Seismic Analysis . . . . . . . . . . . . . . . . 69

7.3.6 Uncertainty Analysis for Auxiliary Building T/DHR Scenarios . . . . . 69

7.3.7 Summary of Transients with Loss of Decay Heat Removal . . . . . . . 71

7.4 Transient-Induced Loss-of-Coolant Accident $\ldots \ldots \ldots \ldots \ldots \ldots$

7.4.1 Turbine Building Nonseismic Analysis .............. 71

7.4 .2 Turbine Building Seismic Analysis ... . . . . . . . . . 72

7.4.3 Uncertainty Analysis for Turbine Building T/LOCA Scenarios . . . . . . 73

7.4.4 Auxiliary Building Nonseismic Anal,/sis 74

7.4.5 Auxiliary Building Seismic Analysis ... . . . . . . . . . 76

7.4.6 Uncertainty Analysis for Auxiliary Building T/LOCA Scenarios . . . . . 76

7.4.7 Summary of Transient-Induced Loss-of-Coolant Accidents . . . . . . . . 77

7.5 Plant-Specific Hydrogen Storage Facility Analysis . . . . . . . . . . . . . 78

7.5.1 Hydrogen Storage Facility Explosion Analysis . . . . . . . . . . . . . 78

7.5.2 Hydrogen Storage Facility Leakage into Air Intakes Analysis . . . . . . . 80

7.6 Summary of Plant Generic Analyses $\ldots \ldots \ldots \ldots \ldots$

8. COST/BENEFIT ANALYSIS $\ldots \ldots \ldots \ldots \ldots \ldots \ldots \ldots \ldots$

8.1 Alternatives Considered $\ldots \ldots \ldots \ldots \ldots \ldots \ldots \ldots \ldots$

8.1.1 Alternatives Considered for the Turbine Building . . . . . . . . . 84

8.1.2 Alternatives Considered for the Auxiliary Building . . . . . . . . . 85

8.1.3 Alternatives Considered for the Hydrogen Storage Facility . . . . . . . . 85 
8.2 Core Damage Frequency Results $\ldots \ldots \ldots \ldots \ldots$

8.2.1 Delta CDF for Turbine Building Alternatives . . . . . . . . . . 86

8.2.2 Delta CDF for Auxiliary Building Alternatives . . . . . . . . . . 88

8.2.3 Delta CDF for Hydrogen Storage Facility Alternatives . . . . . . . . 88

8.3 Consequence Analysis $\ldots \ldots \ldots \ldots \ldots \ldots \ldots \ldots$

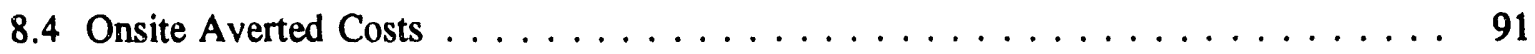

8.5 Cost Estimating Methodology $\ldots \ldots \ldots \ldots \ldots \ldots \ldots \ldots$

8.5.1 Assumptions . . . . . . . . . . . . . . . . . 94

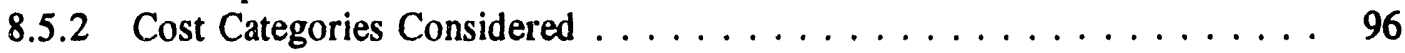

8.5.3 Key Cost Parameters . . . . . . . . . . . . . . . . . 96

8.5 .4 NRC Costs . . . . . . . . . . . . . . . . . 97

8.5.5 Cost estimating uncertainty $\ldots \ldots \ldots \ldots \ldots \ldots \ldots$

8.6 Plant Alternative Cost Estimate . . . . . . . . . . . . . . . . . . . . . . 99

8.6.1 Alternatives Considered for the Turbine Building . . . . . . . . . . 99

8.6.2 Alternatives Considered for the Auxiliary Building . . . . . . . . . 102

8.6.3 Alternatives Considered for the Hydrogen Storage Facility . . . . . . 105

8.7 Total Cost Results . . . . . . . . . . . . . . . . . . . . . . . 109

8.8 Cost/Benefit Uncertainty Discussion $\ldots \ldots \ldots \ldots \ldots$

8.9 Uncertainty Analysis Results $\ldots \ldots \ldots \ldots \ldots \ldots \ldots \ldots \ldots$

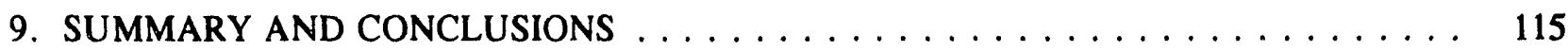

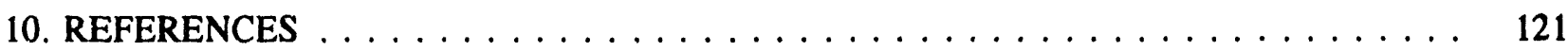

APPENDIX A-REPORTS OF HYDROGEN EXPERIENCE AT COMMERCIAL REACTORS

APPENDIX B-UNCERTAINTY ESTIMATE CALCULATIONS

APPENDIX C-OTHER PLANT OPERATING MODES

APPENDIX D-WESTINGHOUSE PLANT DESCRIPTION

APPENDIX E-WESTINGHOUSE BASE CASE PLANT PRA MODEL

APPENDIX F-COST/BENEFIT UNCERTAINTY ANALYSIS

viii 


\section{LIST OF FIGURES}

1. Example of a hydrogen distribution system for PWRs $\ldots \ldots \ldots \ldots$

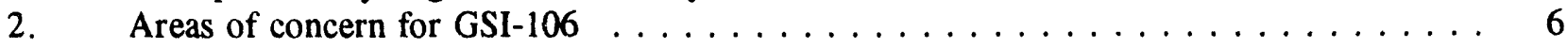

3. Total hydrogen events for BWRs and PWRs $(1969-1989) \ldots \ldots \ldots \ldots \ldots$

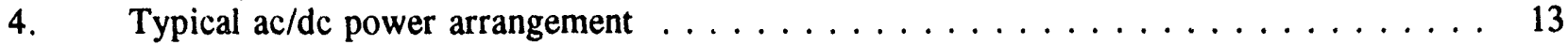

5. Typical uninterruptible power supply arrangement $\ldots \ldots \ldots \ldots \ldots \ldots \ldots$

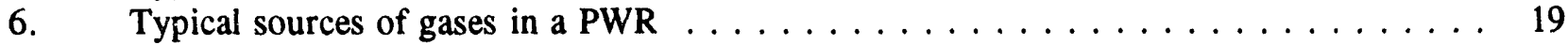

7. Turbine building elevation $15-\mathrm{ft}$ Zone 21 hydrogen seal oil reservoir area $\ldots \ldots \ldots 32$

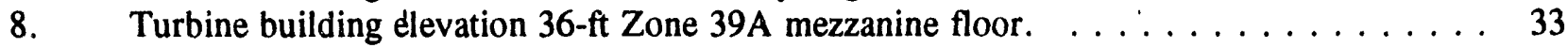

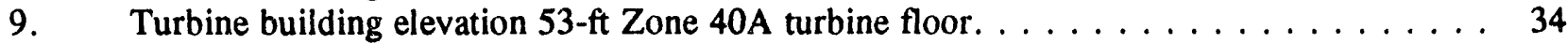

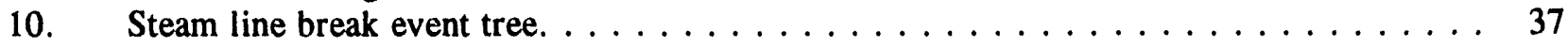

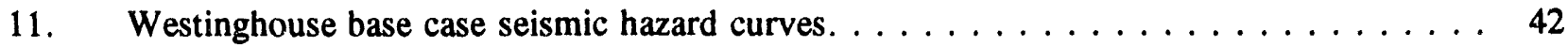

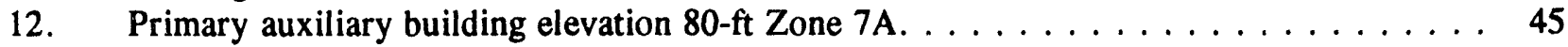

13. Primary auxiliary building elevation $98-\mathrm{ft}$ Zone $27 \mathrm{~A} \ldots \ldots \ldots \ldots \ldots$

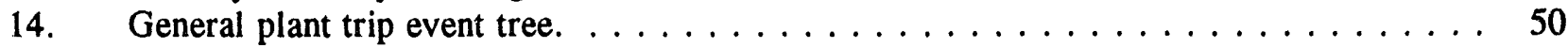

15. Generic PWR containment event tree. . . . . . . . . . . . . . . . . . 89 


\section{LIST OF TABLES}

1. Summary of the hydrogen events in each plant location $\ldots \ldots \ldots \ldots \ldots$

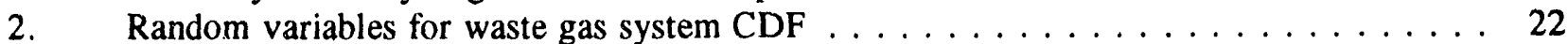

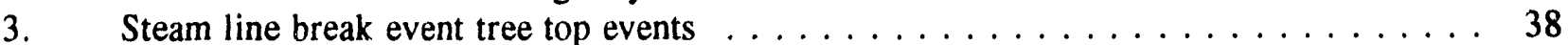

4. PAB fire zones considered in base case plant analysis . . . . . . . . . . . . . . 47

5. General turbine trip event tree top events $\ldots \ldots \ldots \ldots \ldots \ldots \ldots \ldots \ldots$

6. W plant generator hydrogen storage facility comparison with EPRI separation criteria . . 53

7. $\quad W$ plant VCT hydrogen storage facility comparison with EPRI separation criteria $\ldots \ldots .54$

8. $\quad W$ plant truck skid comparison with EPRI separation criteria $\ldots \ldots \ldots \ldots \ldots \ldots$

9. Random variable for $W$ base case $C D F \ldots \ldots \ldots \ldots \ldots \ldots$

10. Analysis results for $W$ base case $\mathrm{CDF} \ldots \ldots \ldots \ldots \ldots \ldots \ldots \ldots$

11. Generic plant configurations $\ldots \ldots \ldots \ldots \ldots \ldots \ldots \ldots$

12. Various feed and bleed failure rates from PRAs. . . . . . . . . . . . . . . . 64

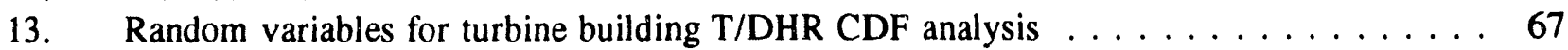

14. Random variables for auxiliary building T/DHR CDF analysis $\ldots \ldots \ldots \ldots$

15. Random variables for turbine building T/LOCA CDF analysis $\ldots \ldots \ldots \ldots$

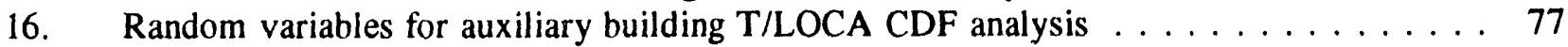

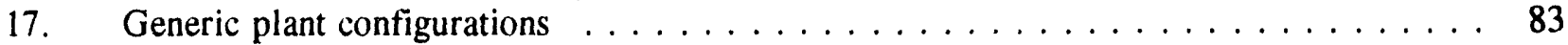

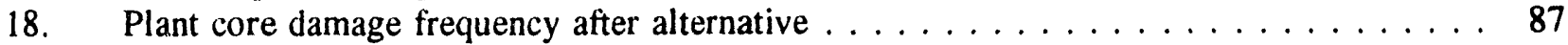

19. PWR accident sequence to release category mapping $\ldots \ldots \ldots \ldots \ldots$

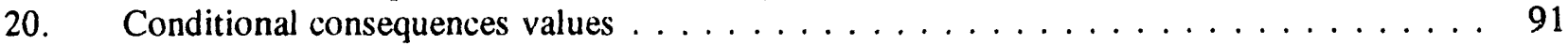

21. Total offsite dose by PWR configuration (person-rem for 20 year PWR plant

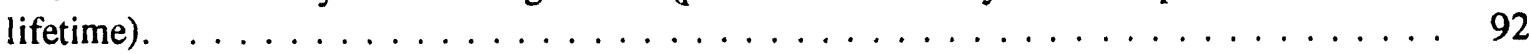

22. Onsite Averted Costs (by PWR configuration) $\ldots \ldots \ldots \ldots \ldots \ldots \ldots \ldots$

23. Turbine building Alternative 1 cost breakdown $\ldots \ldots \ldots \ldots \ldots \ldots$

24. Turbine building Alternative 2 cost breakdown $\ldots \ldots \ldots \ldots \ldots \ldots 1$

25. Turbine building Alternative 3 cost breakdown $\ldots \ldots \ldots \ldots \ldots \ldots$

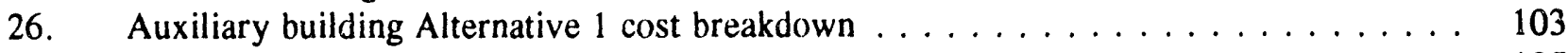

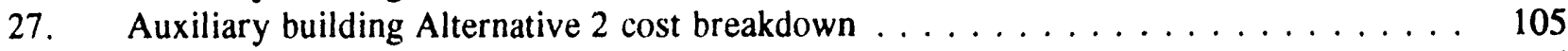

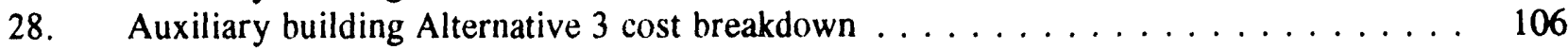

29. Hydrogen storage facility Alternative 1 cost breakdown $\ldots \ldots \ldots \ldots \ldots$

30. Hydrogen storage facility Alternative 2 cost breakdown $\ldots \ldots \ldots \ldots \ldots$

31. Hydrogen storage facility Alternative 3 cost breakdown $\ldots \ldots \ldots \ldots \ldots$

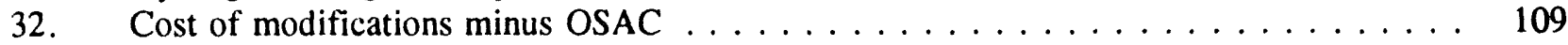

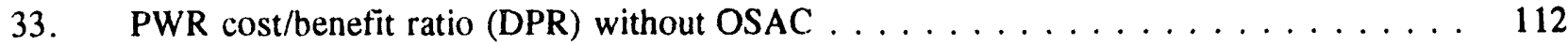

34. PWR cost/benefit ratio (DPR) with OSAC $\ldots \ldots \ldots \ldots \ldots \ldots \ldots$

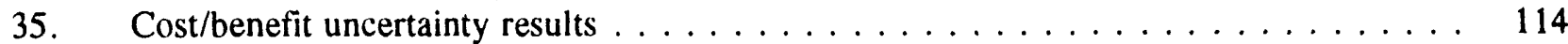

36. Comparison of base case analysis results $\ldots \ldots \ldots \ldots \ldots \ldots \ldots$

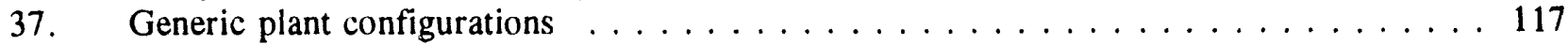

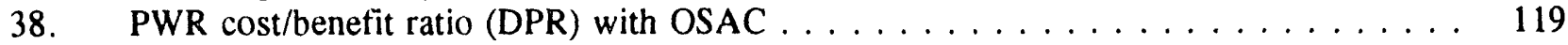

39. PWR cost/benefit ratio (DPR) without OSAC $\ldots \ldots \ldots \ldots \ldots \ldots$ 


\section{EXECUTIVE SUMMARY}

Generic Safety Issue 106 addresses the risk impact of the use of highly combustible gases within nuclear power plants. In the context of Generic Safety Issue 106 in pressurized water reactors (PWRs), combustible gases can be released in six basic areas: station batteries, portable gas bottle storage areas, gaseous waste systems, the volume control tank (VCT), the main generator cooling system, and in large onsite hydrogen storage facilities. Based on an extensive survey of the US PWRs, the existing hydrogen system configurations, although comprised of similar type components, are very plant-specific. Hydrogen gas tank farm locations with respect to various safety-related structures varies from plant to plant. Analogous conclusions can be drawn for hydrogen system lines inside the turbine and auxiliary buildings.

This report documents the risk analysis of these gases (predominantly hydrogen) in PWRs. To conduct a realistic risk assessment, an actual plant configuration was analyzed. The plant chosen for the base case in this study was a Westinghouse four-loop PWR that went into commercial operation in 1974. This choice was based on the availability of a completed Level III probabilistic risk assessment (PRA) with a fire analysis, and a nuclear steam supply system design that represented a large fraction of the PWR population.

To address different reactor vendor designs and balance of plant arrangements, the plant-specific PRA analysis was supplemented with a comprehensive series of sensitivity analyses.

The technical findings of this evaluation are summarized for both the qualitative and quantitative aspects of this generic safety issue:

- Based on a screening analysis and other considerations, station batteries, portable gas bottle storage areas, and gaseous waste systems pose a negligible level of risk when compared to other sources.

- Based on the Westinghouse plant (base case) analysis, the effects of hydrogen releases and subsequent burns are relatively small contributors to the overall core melt risk. Table ES-1 summarizes the full power (Mode 1) base case core melt frequencies (mean values) due to internal events, seismic events, fires, etc., and the additional core melt frequency due to various hydrogen release scenarios. The consideration of a hydrogen release during reactor shutdown (Modes 2-5) is not expected to be significant to risk because of a number of operational considerations.

- The relatively low core melt frequency risk (base case analysis) is attributed to the following features:

- The location of the auxiliary feedwater (AFW) system away from possible hydrogen sources.

- The feasibility of feed and bleed core cooling in the event AFW became unavailable.

- The quantity of hydrogen that can empty inside the auxiliary building is limited. 
Table ES-1. Comparison of base case analysis results.

\begin{tabular}{ccc}
\hline & & Core Damage Frequency \\
Document & Scenarios & $7.9 \times 10^{-5}$ \\
\hline & Internal events & $7.7 \times 10^{-6}$ \\
Licensee's PRA & Seismic events & $1.4 \times 10^{-5}$ \\
& Fire events & $3.6 \times 10^{-5}$ \\
& High winds & $1.4 \times 10^{-4}$ \\
\hline This base case study & Total & $7.1 \times 10^{-7}$ \\
\hline
\end{tabular}

- The location of vital support systems or auxiliaries [diesels, component cooling water (CCW), service water (SW)] in different locations away from possible hydrogen sources.

- Recognizing the specific issues that caused the low risk for the base case plant analysis, it was possible to identify different reactor vendor design features and balance of plant equipment arrangements that would pose significantly larger risks. These include:

- PWR plants with the AFW system physically located in the turbine building or auxiliary building.

- Combustion Engineering PWRs that have either marginal or no capabilities of using feed and bleed core cooling in the event AFW becomes unavailable.

- $\quad$ PWR plants with diesels, component cooling water, or other vital support systems located near major potential hydrogen sources.

- The core melt frequency risks associated with hydrogen release scenarios for the above design features are summarized in Table ES-2. These risks are clearly larger than found in the base case analysis.

- To address the hydrogen-related risks a number of possible alternatives were considered. These included:

\section{Turbine Building Alternatives}

Alternative 1: Install an excess flow cheok valve on the hydrogen line header and a check valve on the hydrogen supply line at the generator. This hydrogen system alternative would require the placement of one excess flow check valve just downstream of the pressure regulator, and one check valve on the hydrogen supply line at the generator. If properly sized, an excess flow check valve would limit the amount of 
Table ES-2. Generic plant configurations.

\begin{tabular}{|c|c|c|c|}
\hline Configuration & Plant Applicability & $\begin{array}{l}\text { Important Accident Scenarios } \\
\text { Applicable to Configuration }\end{array}$ & $\begin{array}{c}\text { Core } \\
\text { Damage } \\
\text { Frequency } \\
(/ \text { ry }) \\
\end{array}$ \\
\hline I & $\begin{array}{l}\text { All PWRs with AFW and vital } \\
\text { equipment outside of turbine and } \\
\text { auxiliary buildings }\end{array}$ & $\begin{array}{l}\text { T/DHR } \\
\text { T/LOCA }\end{array}$ & $3.4 \times 10^{-8}$ \\
\hline II & $\begin{array}{l}\text { Babcock \& Wilcox and } \\
\text { Westinghouse with AFW in turbine } \\
\text { building distribution system level }\end{array}$ & $\begin{array}{l}\text { T/DHR } \\
\text { (Feed and bleed credited) }\end{array}$ & $7.3 \times 10^{-7}$ \\
\hline III & $\begin{array}{l}\text { Fombustion Engineering with AFW } \\
\text { in turbine building distribution } \\
\text { system level }\end{array}$ & $\begin{array}{l}\text { T/DHR } \\
\text { (Feed and bleed not credited) }\end{array}$ & $9.4 \times 10^{-6}$ \\
\hline IV & $\begin{array}{l}\text { All PWRs with vital equipment in } \\
\text { turbine building distribution system } \\
\text { level }\end{array}$ & $\begin{array}{l}\text { T/LOCA } \\
\text { (Station ac blackout, or loss of } \\
\text { CCW, SW) }\end{array}$ & $9.4 \times 10^{-6}$ \\
\hline v & $\begin{array}{l}\text { All PWRs with vital equipment in } \\
\text { turbine building generator floor level }\end{array}$ & $\begin{array}{l}\text { T/LOCA } \\
\text { (Station ac blackout, or loss of } \\
\text { CCW, SW) }\end{array}$ & $5.2 \times 10^{-6}$ \\
\hline VI & $\begin{array}{l}\text { Babcock \& Wilcox and } \\
\text { Westinghouse with AFW in auxiliary } \\
\text { building }\end{array}$ & $\begin{array}{l}\text { T/DHR } \\
\text { (Feed and bleed credited) }\end{array}$ & $2.0 \times 10^{-7}$ \\
\hline VII & $\begin{array}{l}\text { Combustion Engineering with AFW } \\
\text { in auxiliary building }\end{array}$ & $\begin{array}{l}\text { T/DHR } \\
\text { (Feed and bleed not credited) }\end{array}$ & $4.7 \times 10^{-6}$ \\
\hline VIII & $\begin{array}{l}\text { All PWRs with vital equipment in } \\
\text { auxiliary building }\end{array}$ & $\begin{array}{l}\text { T/LOCA } \\
\text { (Loss of CCW, sW) }\end{array}$ & $4.7 \times 10^{-6}$ \\
\hline
\end{tabular}


hydrogen released due to a pipe break to a concentration level easily dissipated, either by outside air or by building ventilation. The check valve on the hydrogen line at the generator will prevent backflow out of the generator given a hydrogen supply line pipe break.

Alternative 2: Periodic hydrogen makeup to the generator. This hydrogen system alternative would require changing plant procedures to allow periodic hydrogen makeup to the generator. This procedure was estimated to be an approximately 1/2-hour task for two people each day. This alternative would allow the isolation of the hydrogen supply from the turbine building to the generator for the remaining 23-1/2 hours of the day.

Alternative 3: Enclose the safety-related equipment in a blast-proof structure. This hydrogen system alternative is for those plants whose turbine building configuration is considered at higher risk from hydrogen-initiated events. It includes the cost of the engineering evaluation and the cost of performance of an alternative identified by the evaluation.

\section{Auxiliary Building Alternatives}

Alternative 1: Install an excess flow check valve in the hydrogen supply line leading to the VCT. This hydrogen system alternative would require the placement of one excess flow check valve (sized for $150 \%$ of the maximum daily hydrogen flow) downstream of the pressure regulator in the hydrogen distribution line for the VCT. The excess flow check valve (if properly sized) would restrict hydrogen flow out of a broken line to a level that could be easily dissipated by the building ventilation.

Alternative 2: Limit the hydrogen supply to a three 250-scf hydrogen storage facility for the VCT. This hydrogen system alternative would require the removal of three of the six existing 250 scf hydrogen tanks present in the auxiliary building and the removal of the supply piping connection to the main hydrogen storage facility. The three remaining 250 scf tank would be reconnected to form a limited supply day tank for the VCT. Limiting the amount of hydrogen in the auxiliary building would reduce the potential of a hydrogen storage facility emptying a large volume of hydrogen inside safety-related structures.

Alternative 3: Periodic hydrogen makeup to VCT. This hydrogen system alternative would require changing plant procedures to allow periodic hydrogen makeup to the VCT. This procedure was estimated to be an approximately $1 / 2$-hour task for two people each day. This alternative would allow the isolation of the hydrogen supply from the auxiliary building to the VCT for the remaining 23-1/2 hours of the day.

\section{Hydrogen Storage Facility Alternatives}

Alternative 1: Relocate the hydrogen storage facility to a distance within EPRI NP5283-SR-A guidelines. This hydrogen system alternative would relocate the storage facility to a distance meeting EPRI NP-5283-SR-A safe separation criteria. This would eliminate any potential of damage to safety-related equipment presently located near the hydrogen storage facility. 
Alternative 2: Install a hydrogen blast wave deflection shield. This hydrogen system alternative would install a blast wave deflection shield. By deflecting the blast wave from a hydrogen detonation, a blast shield can greatly lessen the blast impact.

Alternative 3: Install hydrogen analyzer-actuated air intake louvers. This hydrogen system alternative would require the installation of automatic shutters controlled by hydrogen analyzers. This alternative would eliminate the ingress of a flammable (or detonable) hydrogen mixture into safety-related structures via air intake pathways.

- When averted onsite costs were factored into the cost/benefit analysis, dollar-to-personrem averted ratio (DPR) results were obtained. Table ES-3 presents these DPR values. A regative DPR value for an alternative indicates an overall cost saving. Table ES-4 presents the DPR values for the case where the averted onsite cost was not factored into the cost/benefit analysis. 


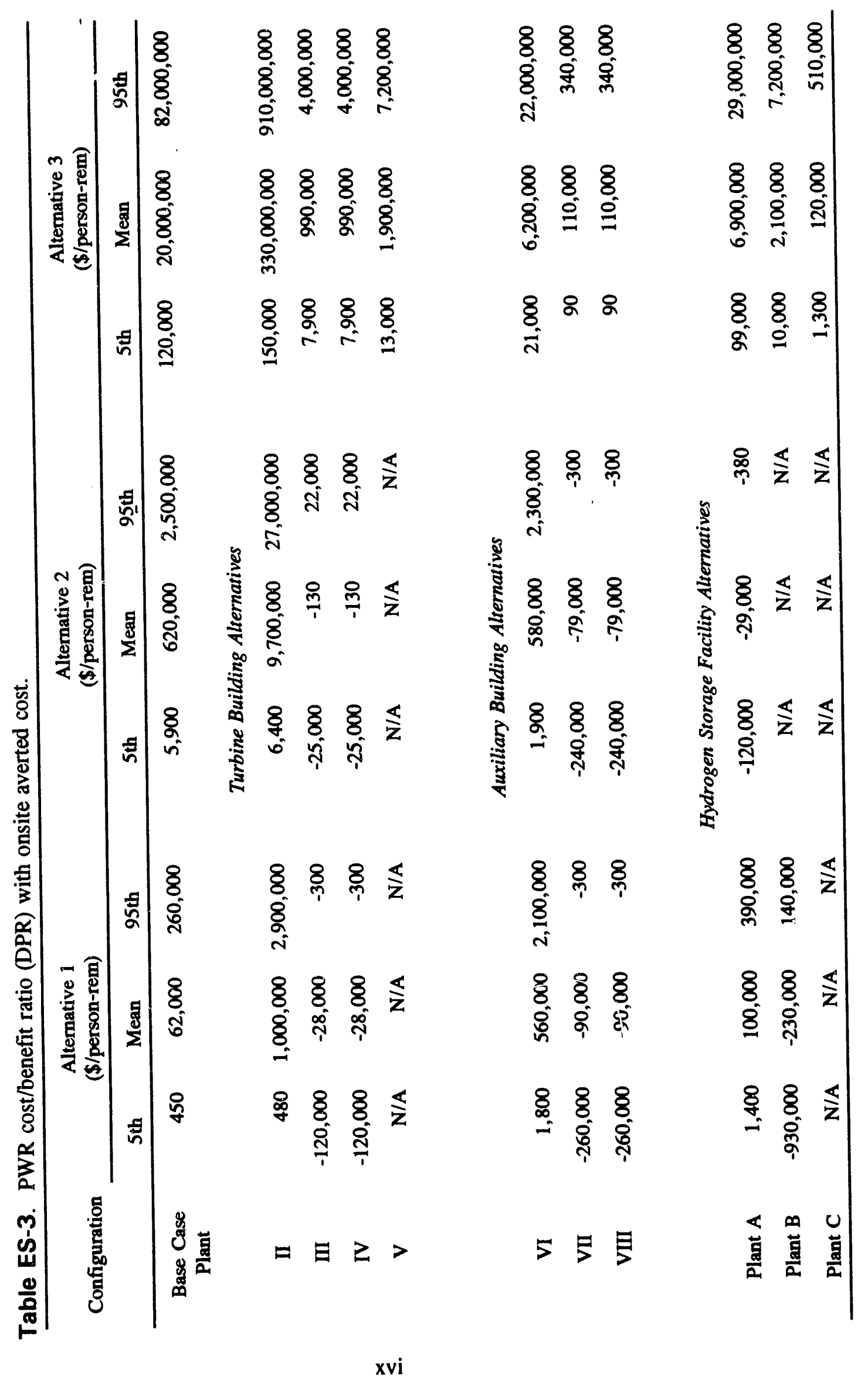




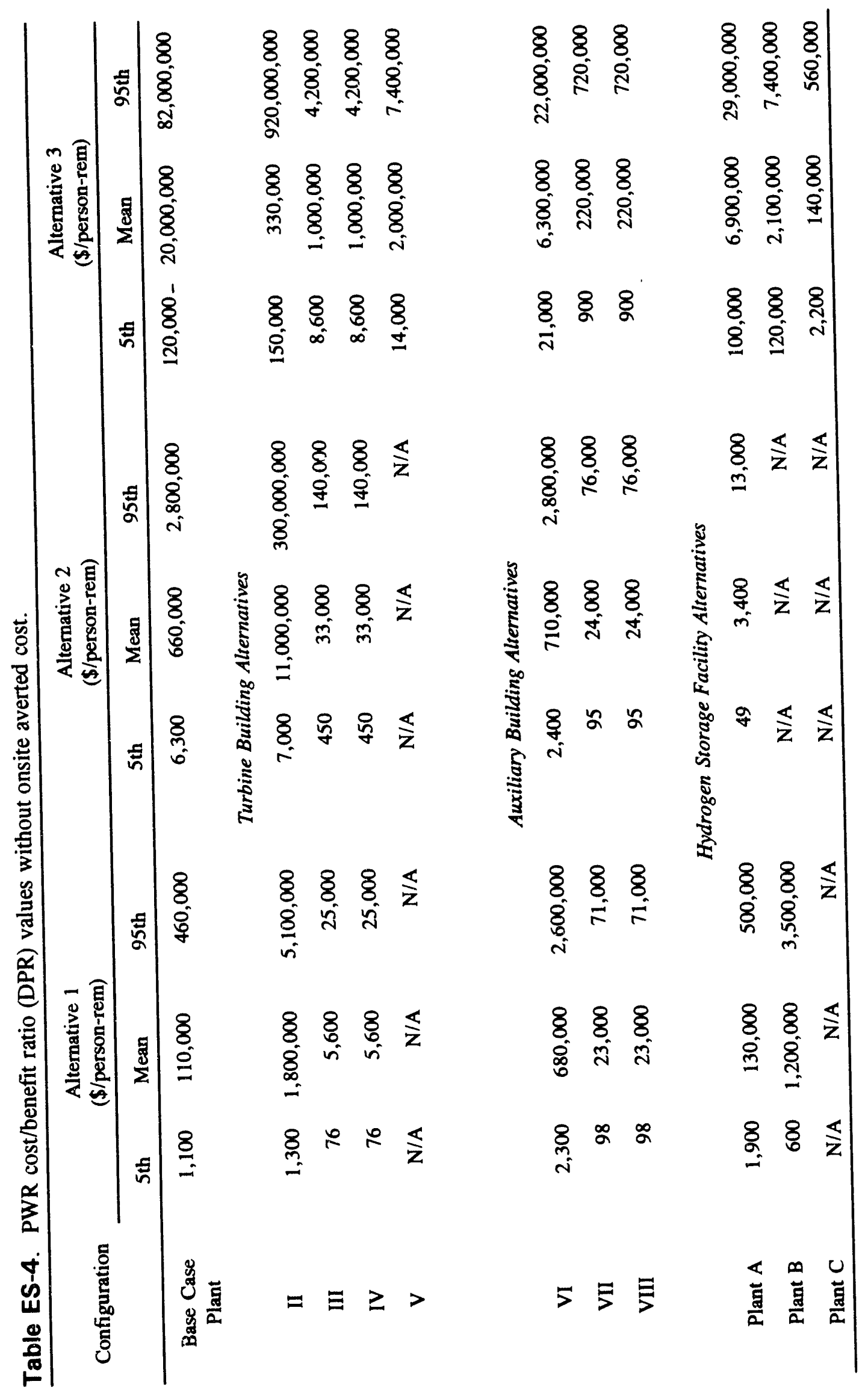

xvii 


\section{ACRONYMS}

\begin{tabular}{|c|c|}
\hline AFW & auxiliary feed water \\
\hline B\&W & Babcock \& Wilcox \\
\hline BWR & boiling water reactor \\
\hline $\mathrm{CCW}$ & component cooling water \\
\hline $\mathrm{CDF}$ & core damage frequency \\
\hline $\mathrm{CE}$ & Combustion Engineering \\
\hline CET & containment event tree \\
\hline CRAC & Calculation of Reactor Accident Consequences \\
\hline CSF & conditional split fraction \\
\hline CVCS & chemical and volume control system \\
\hline DHR & decay heat removal \\
\hline DPR & dollar-to-person-rem averted ratio \\
\hline EEDB & Energy Economic Data Base \\
\hline EPRI & Electric Power Research Institute \\
\hline $\mathrm{F} \& \mathrm{~B}$ & feed and bleed \\
\hline FSAR & final safety analysis report \\
\hline GSI & generic safety issue \\
\hline HPI & high pressure injection \\
\hline HSF & hydrogen storage facility \\
\hline HVAC & heating, ventilating, and air conditioning \\
\hline IE & initiating event \\
\hline INEL & Idaho National Engineering Laboratory \\
\hline
\end{tabular}




\begin{tabular}{|c|c|}
\hline IRRAS & Integrated Reliability and Risk Analysis System \\
\hline LER & licensee event report \\
\hline LOCA & loss-of-coolant accident \\
\hline LOSP & loss-of-offsite power \\
\hline MFW & main feedwater \\
\hline NRC & Nuclear Regulatory Commission \\
\hline NRR & Office of Nuclear Reactor Regulation \\
\hline NSSS & nuclear steam supply system \\
\hline OSAC & onsite averted costs \\
\hline $\mathrm{PAB}$ & primary auxiliary building \\
\hline PORV & power-operated relief valve \\
\hline PRA & probabilistic risk assessment \\
\hline PWR & pressurized water reactor \\
\hline $\mathrm{QA} / \mathrm{QC}$ & quality assurance/quality control \\
\hline $\mathrm{RCS}$ & reactor coolant system \\
\hline RWST & refueling water storage tank \\
\hline ry & reactor year \\
\hline SLB & steam line break \\
\hline SRP & Standard Review Plan \\
\hline SSE & safe shutdown earthquake \\
\hline SSS & support system state \\
\hline SW & service water \\
\hline T/DHR & transient-induced loss of decay heat removal \\
\hline T/LOCA & transient-induced loss-of-coolant accident \\
\hline
\end{tabular}


Three Mile Island

TS

Technical Specification

VCT

volume control tank

W

Westinghouse

WGS

waste gas system

xxi 


\section{RISK ANALYSIS OF HIGHLY COMBUSTIBLE GAS STORAGE, SUPPLY, AND DISTRIBUTION SYSTEMS IN PRESSURIZED WATER REACTOR PLANTS}

\section{INTRODUCTION}

\subsection{Background}

Combustible gases such as hydrogen, propane, acetylene, and methane are used in various capacities during normal operation of nuclear power plants. Hydrogen is the most prevalent combustible gas. It is used as a coolant for th? main electrical generator in both pressurized water reactors (PWRs) and boiling water reactors (BWRs). In PWRs, it is fed to the volume control tank (VCT) in the chemical volume and control system to control the dissolved oxygen concentration in the reactor coolant system (RCS). In BWRs, hydrogen water chemistry control systems are being installed for the same purpose. Hydrogen is also present in the waste gas systems (WGS) as a product of water dissociation during operation.

Generic Safety Issue (GSI) 106, entitled Piping dnd the Use of Highly Combustible Gases in Vital Areas, was identified in NUREG-0705. ${ }^{1}$ This GSI addresses the safety issue resulting from the use of hydrogen, propane, acetylene, methane, and other combustible gases in operating nuclear power plants. While the distribution and storage systems for these gases are not typically safety related (e.g., seismic category 1), it became apparent that leakage resulting from failures of these systems (e.g., leaks, breaks) in areas containing or adjacent to safety-related equipment have the potential to significantly impact safety system operability and overall plant risk.

This analysis investigates the potential impact of failure of combustible gas systems on the core damage frequency (CDF) for PWRs, identifies possible improvements, and assesses their cost/benefit.

\subsection{Previous Regulation and Analysis}

GSI-106 was first identified in 1981. The Nuclear Regulatory Commission (NRC), following a prioritization evaluation in November 1987, directed its staff to resolve GSI-106. Originally, GSI-106 technical work was focused only on the hydrogen piping inside safety-related (vital) areas. The scope was later expanded to include additional concerns like the hydrogen storage facilities.

On April 20,1987, the NRC issued Information Notice 87-20.2 This notice addressed the discovery of a hydrogen leak in the auxiliary building at the Vogtle Nuclear Power Plant. The leak was due to the use of a conventionally designed globe valve instead of a valve designed specifically for hydrogen use. The recipients of the notice were expected to review the information for applicability to their facilities and consider actions if applicable. No specific action or written response was required.

The potential safety problems associated with nuclear plant hydrogen storage facilities became more apparent during an NRC team visit at the Trojan Nuclear Plant on April 17, 1989. The NRC 
inspectors identified that the hydrogen storage facility (composed of four tanks, each containing 8000 standard cubic feet of hydrogen gas) was located on the roof of the control building. This finding escalated concerns about similar hazards in the storage of hydrogen at other nuclear plants. The NRC issued Information Notice 89-44, ${ }^{3}$ entitled "Hydrogen Storage on the Roof of the Control Room," on May 2,1989 , in which it requested all utilities to review the information for applicability to their facilities and consider actions if applicable. In addition, an informal survey by NRC staff provided information on hydrogen storage facilities (i.e., volume of hydrogen stored onsite and distance from nearest safety-related structure and air intake) present at nuclear plant sites. This' information was then used to determine the number of plants not meeting the Electric Power Research Institute (EPRI) separation criteria for hydrogen storage near safety-related structures and air intakes. ${ }^{4}$

Current NRC regulations and guidelines consider the use and storage of highly flammable gases and liquids within the plant. Specifically, 10 CFR 50 Appendix $R^{5}$ regulations explicitly require plants to establish administrative controls that "prohibit the storage of combustibles in safety-related areas or establish designated storage areas with appropriate fire protection." Standard Review Plan (SRP), Section $9.5 .1,6$ reiterates the above control measures and provides recommendations for the design and safety features of hydrogen systems.

Recent utility evaluations concerning the risks associated with fires within the plants have addressed events involving hydrogen. Yankee Rowe, in its Individual Plant Examination (IPE), ${ }^{7}$ specificall;'; identified fire accidents initiated by hydrogen line breaks in the turbine building and in the upper level primary auxiliary building (PAB) as very important to plant risk and a source of major uncertainty. To reduce the potential for large fires or explosions, the utility proposed installing excess flow check valves (and associated check valves) on the two hydrogen system headers supplying the volume control tank and electric generator.

\subsection{Typical Hydrogen System Configurations}

Two typical hydrogen storage arrangements are found at PWRs. One case uses a single hydrogen storage system to supply all the plant's hydrogen needs. The other case uses two separate hydrogen storage systems, one supplying the electrical generator and the other supplying the VCT. A typical hydrogen storage and distribution system contiguration for the electrical generator (with a single hydrogen storage facility) is shown in Figure 1.

The hydrogen gas in the hydrogen storage system is contained at high pressures (between 1500 and $2,400 \mathrm{psig}$ ) inside pressure vessels. The hydrogen distribution system feeding the turbine building and the PAB consists mainly of small piping and valves (less than 2 in. in diameter). Generic design information for the pressure vessel supply, discharge headers, pressure regulation and reduction, and other components included in the hydrogen system has been included in a previous report. ${ }^{8}$ Variations in the supply systems for the turbine-generator building and the PAB are presented in Section 6.

The plant-specific portion of this evaluation of the CDF contributions of combustible gas fire and explosion events is based on the configuration of a Westinghouse (W) four-loop PWR considered representative of a large portion of the PWRs. This $W$ reactor (the predominant PWR type) went into commercial operation in 1974 (a period when a large number of nuclear power plants went into service in the United States). 


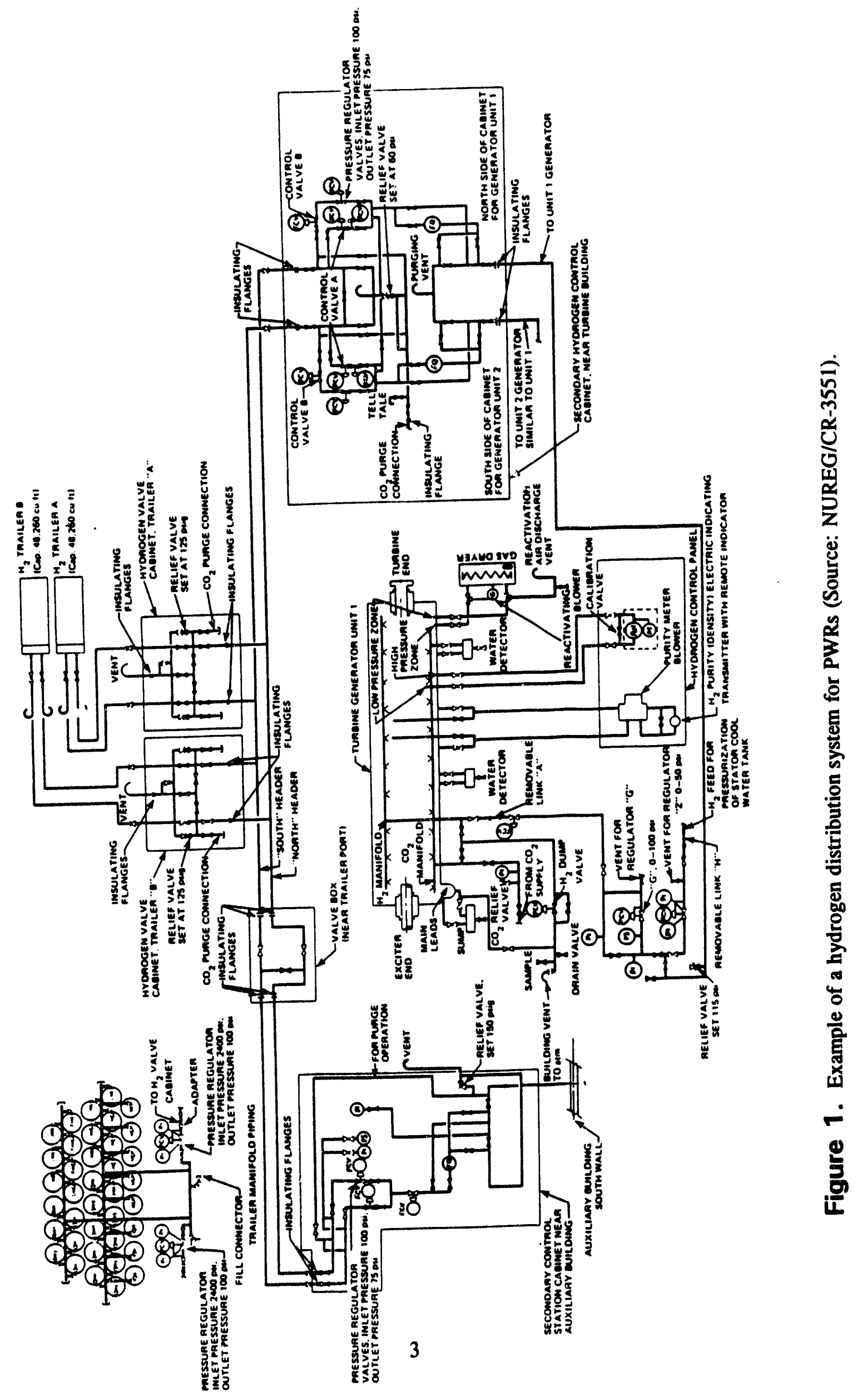


Preliminary research, including walk-through tours of 15 different PWRs, indicated that hydrogen was the prevalent combustible gas in use. All other gases, such as acetylene, are used in small amounts and on an infrequent basis under strict plant administrative controls (e.g., work permit required, fire watch posted, no smoking allowed in the work area, bottles physically-anchored to a fixed structure, etc.). Subsection 4.2 discusses the use of portable gas bottles, which is the most commonly found form of combustible gases other than hydrogen. None of the PWR plants visited was using large sources of propane gas for such activities as the plant auxiliary boiler. 


\section{SCOPE}

The purpose of this study is to develop quantitative estimates of the generic risks associated with the storage, distribution, and use of combustible gases in or near the vital areas of PWRs in the United States. Additionally, this study is intended to assist in a determination of whether the risk of combustible gas usage warrants any generic plant modifications to reduce risks based on a cost/benefit analysis.

At the outset of this program it was recognized that it was not practical to develop quantitative risk estimates for all U.S. PWRs. This would have required data collection, plant walk-downs, and detailed analysis for over 70 nuclear power plants. Because of this limitation, a generic risk model was developed based on a $W$ four-loop PWR with a peer-reviewed PRA model. ${ }^{9}$ This PRA model was subsequently upgraded by the Idaho National Engineering Laboratory (INEL) to incorporate modeling of events where combustible gas fires and/or explosions initiated transients and impacted event mitigation. Recognizing that there are differences between the selected plant design and those of the other U.S. PWRs, sensitivity studies were performed with the intent of representing the effects of different designs and combustible gases used. The choice of specific design features to be modeled and analyzed was based on plant information obtained during visits at 15 PWRs, ${ }^{8}$ reviews of final safety analysis reports (FSARs) and safety evaluation reports for an additional number of PWRs (to determine the location of safety-related equipment with respect to combustible gases in the plant), and other PRA-related documentation (e.g., plant fire hazard analyses).

The types of combustible gases considered in the scope of this program include normal hydrogen supplies and distribution systems used for main generator cooling and water chemistry control in the VCT, hydrogen found in gaseous waste systems, and hydrogen evolved in the normal operation of station batteries.

The technical issues associated with the hydrogen generation and combustion during severe reactor core damage accidents have been addressed extensively in numerous NRC-sponsored studies ${ }^{10}$ and thus, are beyond the scope of this program. Safety issues regarding large cryogenic propane systems at nuclear power plants have been addressed by GSI-136. Also, the consideration of gaseous fuels for building or hot water heating is beyond the scope of this program.

Several areas of concern in GSI-106 have been identified. Figure 2 illustrates the six areas that are evaluated in the orders of the quantity of hydrogen involved. For each area, two accident scenario categories are investigated: a transient-induced loss of decay heat removal (T/DHR) and a transientinduced loss-of-coolant accident (T/LOCA). 


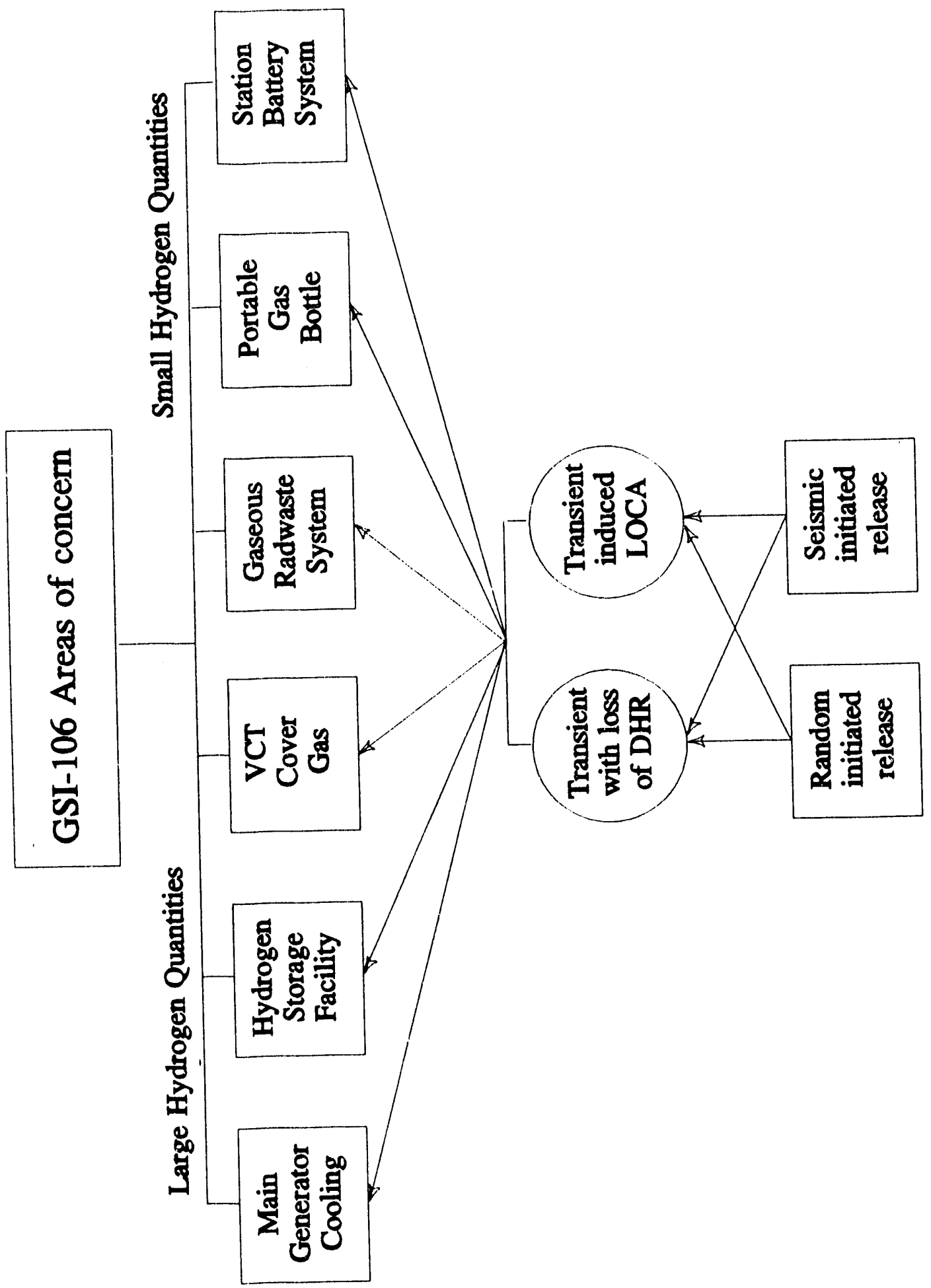

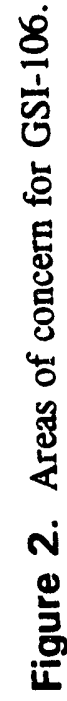




\section{NUCLEAR INDUSTRY EXPERIENCES INVOLVING HYDROGEN}

\subsection{Review of U.S. Nuclear Power Plant Hydrogen Events}

A literature search was conducted to identify hydrogen events at U.S. nuclear power plants that resulted in fires, leaks, explosions, or potentially explosive concentrations. Various sources of information were searched to determine nuclear power plant hydrogen events pertinent to GSI-106. The events were then grouped into several categories for later evaluation of their impact on plant operation. These hydrogen events were organized into three major plant systems for the BWRs: off-gas, electrical generator, and hydrogen storage facility, and into four systems for the PWRs: electrical generator, VCT, waste gas, and hydrogen storage facility. A further ordering was performed by event date. Each event was evaluated to determine if actual damage to safety-related system had occurred.

The primary source of information was Technical Evaluation Report on Recommendations for Hydrogen Safety Features for the Hydrogen Distribution System in PWR Plants. ${ }^{11}$ This report compiled event information from diverse sources for both PWR and BWR plants. Additional sources of information used in this study include the following documents: PWR Plant Hydrogen Gas Supply and Distribution System Information for Risk Analysis to Assess P'ant Damage from Potential Hydrogen Gas Explosions/Burns, ${ }^{8}$ Guidelines for Permanent BWR Hydrogen Water Chemistry Installations, ${ }^{12}$ Safety Implications Associated with In-Plant Pressurized Gas Storage and Distribution Systems in Nuclear Power Plants, ${ }^{13}$ licensee event reports (LERs), operating plant experience data, pertinent National Aeronautics and Space Administration and industry safety reports, and other NRC and industry literature. This report was updated and supplemented by additional searching of Nuclear Documents System - Advanced Design (NUDOCS/AD) ${ }^{14}$ and Nuclear Power Experience (NPE). ${ }^{15}$ The NUDOCS/AD data base containing LERs was searched for hydrogen events from January 1, 1988, through April 30, 1990 . Other documents related to hydrogen topics were searched for additional events. NUREG/CR-5088 ${ }^{16}$ identified a hydrogen fire unreported elsewhere that occurred in the electrical generator while the plant was at full power. Appendix A contains a summary of hydrogen events sorted by plant area (e.g., generator, VCT).

Based on information obtained from a search of the LER data base, all pertinent GSI-106 hydrogen events have been tabulated. A hydrogen event is identified as a hydrogen leak, fire, or explosion, and in the case of the rad-waste gas system, includes hydrogen concentrations above technical specifications (potentially combustible mixtures).

The review of PWR and BWR hydrogen events in the United States determined that 83 fit the criteria established (i.e., hydrogen leak, explosion, fire, or potentially dangerous concentration in the plant). Of the 83 hydrogen events, 49 resulted in either a fire and/or explosion. The other 34 events were primarily hydrogen leaks reported for the safety-related systems interfacing with the VCT and electrical generator, and potential explosive conc ntrations of hydrogen in the waste-gas system. None of the hydrogen events damaged plant safety-related 'equipment. Forty-five hydrogen events have occurred at BWRs, while PWRs have experienced 38 hydrogen events (see Figure 3). ${ }^{\mathrm{a}}$ Included is a

\footnotetext{
a It should be noted that Figure 3 shows the number of reported events. It does not consider the number of existing reactor plants which generated the events. The appearance of an increase in reported PWR events starting in 1981 is primarily the result of an increase in the number of operating PWRs during the 1981 to 1989 time period. (Source: NRC Information Digest, NUREG-1350, Vol. 3, 1991 edition, p.24)
} 


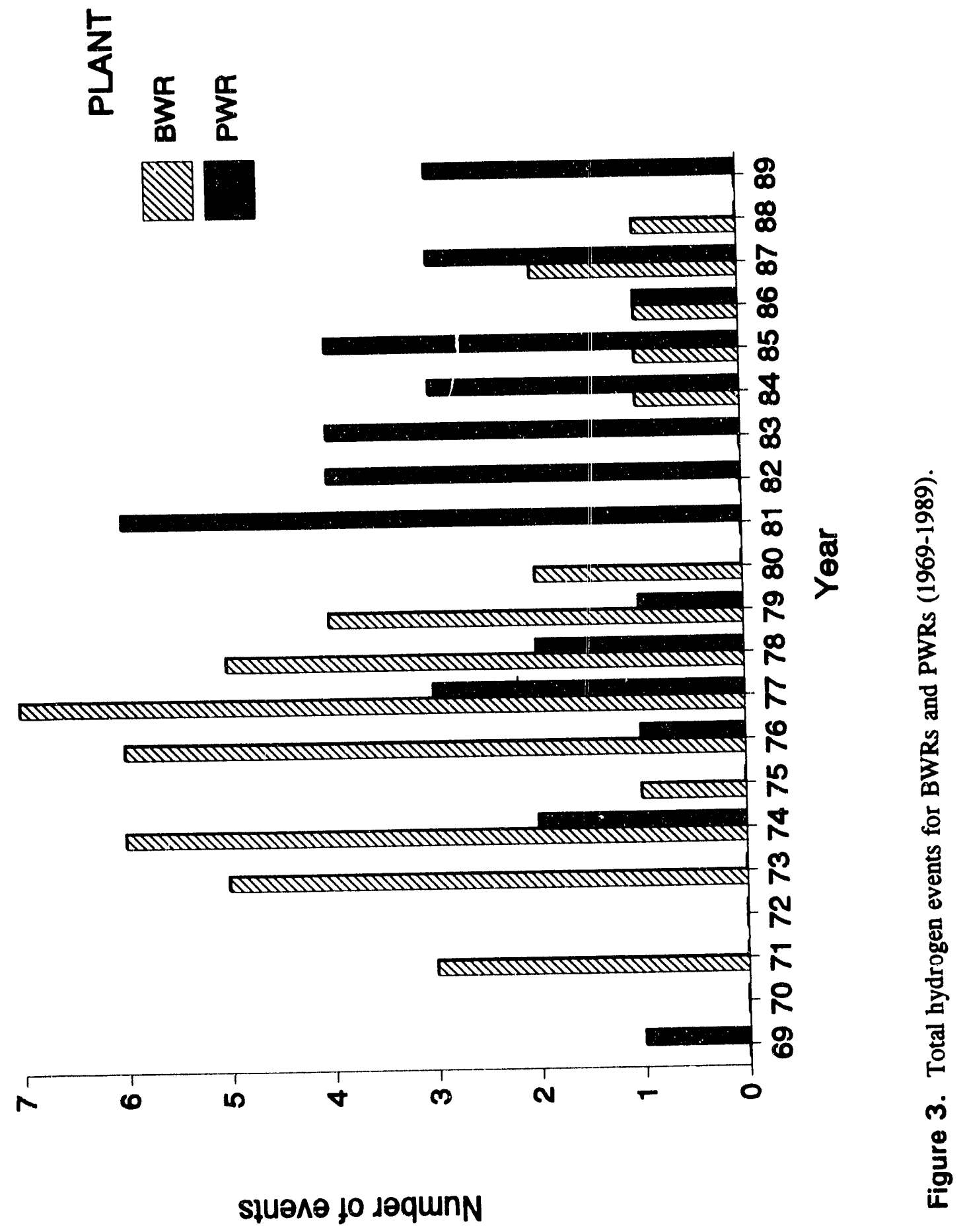


PWR plant report of two battery cells failing as a 1 ssult of a maintenance error igniting the hydrogen inside the cells. Table 1 lists the number of hydrogen events for the different plant locations that are considerad in this study (see Appendix A for a complete summary, including event date). The table excludes those hydrogen events that have occurred in BWR off-gas systems (considered in a similar study performed for BWR plants).

Table 1. Summary of the hydrogen events in each plant location.

\begin{tabular}{cccccc}
\hline $\begin{array}{c}\text { Event Location } \\
\text { (in reactor years) }\end{array}$ & $\begin{array}{c}\text { Explosion } \\
\text { Events }\end{array}$ & $\begin{array}{c}\text { Fire } \\
\text { Events }\end{array}$ & $\begin{array}{c}\text { Uncombusted } \\
\text { Leak }\end{array}$ & $\begin{array}{c}\text { Other } \\
\text { Events }\end{array}$ & $\begin{array}{c}\text { Total } \\
\text { Events }\end{array}$ \\
\hline $\begin{array}{c}\text { Turbine Building } \\
(1424 \text { BWR/PWR) } \\
\text { VCT in PAB } \\
\text { (S17 PV/R) }\end{array}$ & 2 & 7 & 7 & 0 & 16 \\
$\begin{array}{c}\text { Rad-Waste Ga: System in } \\
\text { PAB (917 PWR) }\end{array}$ & 1 & 0 & 11 & 0 & 11. \\
$\begin{array}{c}\text { Hydrogen Storage System } \\
\text { (1424 BWR/PWR) }\end{array}$ & 2 & 0 & 1 & 0 & 3 \\
$\begin{array}{c}\text { Batteries } \\
\text { (1424 BWR/PWRs) }\end{array}$ & 1 & 1 & 0 & 0 & 10 \\
\hline $\begin{array}{c}\text { Total Hydrogen Lvents } \\
\text { a Hydrogen concuntrations above technical specifications. }\end{array}$ & 6 & 0 & 19 & 8 & 41 \\
\hline
\end{tabular}

3.1.i Electrical Generator Events. There were 14 PWR events and 2 BWR events invclving hydrogen associated with generator cooling (including the supply piping within the turbine-generator building). Only 7 of these 16 events were reported to involve fires and only 2 of the 16 events were reported to involve explosions. It is possible that some of the events reported as fires actually involved an initial explosion with a subsequent hydrogen fire. Out of the nine fires or explosions that occurred in PWRs, six occurred while the plants were at greater chan $90 \%$ power, which lead to a turbine and/or reactor trip. The other seven events involved only small uncombusted leaks.

Neither of the two events reported for the BWRs resulted in a fire or explosion. The one event in 1971 was a leak and the other event in 1987 reported increased hydrogen concentration in the generator neutral bushing. Experience frot. BWRs is included in this analysis since the equipment and operations for generator cooling systems are the same for both plant types. Hydrogen fires are not normally considered to have the potential to directly ir.pact safety-related equipment due to the large separation distance typical of turbine buildings. However, a hydrogen fire could potentially spread to the seal oil system or could ignite the turbine lube oil. In the Vandellos-1 fire, ${ }^{17}$ a hydrogen fire ignited large volumes of oil, resulting in a major turbine building fire. 
3.1.2 VCT Events. Through mid-1990 there was a total of 11 events involving hydrogen associated with the VCT cover-gas system (including the supply piping within the PAB). Only experience from PWRs is included for the VCT since BWRs do not utilize a comparable system. None of these 11 events resulted in either a tire or an explosion. All 11 reported leaks were detecied by the associated radioactivity (xenon, krypton, etc.). Ten of the leaks were hardware related, while one was caused by inadequate sampling procedures. Of the hardware-related events, one was caused by a leaking diaphragm in the hydrogen supply regulator, seven were valve related, and two were incidents of the VCT vent header leaking. All hydrogen leaks reported were small and some did not even reach concentrations in the lower flammability limit for hydrogen in air (i.e., 4.1\%).

3.1.3 Waste Gas Events. Of the 52 total waste gas and off-gas system events, 10 were reported in PWRs. From 1981 to 1987 , eight events were reported concerning concentrations of hydrogen that exceeded technical specifications in the waste gas hold-up, storage, or decay tanks. In 1981 an explosion occurred at the San Onofre Plant when air leakage into the nitrogen system resulted in a buildup of oxygen and hydrogen, and in 1977 a leak (uncombusted) during system maintenance occurred.

3.1.4 Hydrogen Storage Facility Events. There was a total of three events involving hydrogen associated with hydrogen storage facilities (includes the supply piping between the hydrogen storage facilities and the turbine or PAB building). Two events have occurred at PWRs and one has occurred at a BWR. Only one of the cirree events was reported to involve an explosion, and the other two events were only reported to invólve fires. It is also possible that the events reported as fires actually involved an initial explosion with a subsequent fire. There were no reported catastrophic uncombusted hydrogen releases. None of the three events resulted in damage to any safety-related equipment or structures.

3.1.5 Battery Events. While taking battery voltage readings during a battery equalizing charge, two cells in No. 2 station battery failed as a result of hydrogen combustion inside the cells. The details on this event are from limited information available in an LER. The battery was subsequently taken out of service to permit jumpering of the defective cells. Both battery chargers for battery bus No. 2 were in operation as required by Technical Specification (TS) 3.7.2.4. This event is reportable per TS 6.9.2.b.2. Battery voltage and capacity with two jumpered cells are within specifications. This event caused no damage to facility, no personnel exposures or injuries, and the plant remained at $100 \%$ power.

\subsection{Review of Foreign Nuclear Power Plant Hydrogen Eivents}

Several turbine building fires that have occurred at foreign nuclear power plants have been extremely large and caused significant damage to balance-of-plant systems and structures. The fires at Vandellos-1, Spain, at Maanshan, Taiwan, and at Muehleberg, Switzerland, did extensive damage to the turbine building's systems and required considerable expenditures in order to become fully operational. The first two events mentioned above did involve hydrogen as a participant in the fires. Unfortunately, not enough information is available on foreiga hydrogen systems and the number of years of system operating experience to make an evaluation of the frequency of large hydroger. releases and large fires. 'The applicability of foreign data in light of differing regulation and design requirements for safety equipment train separation and fire protection systems must be considered before using the data to investigate U.S. commercial reactor systems. 


\subsection{Summary of Review of Hydrogen Events}

The LER summaries, spanning the nuclear power plant reactor operating years, are used as the basis for the hydrogen event frequency derivation. Information on the number of nuclear power plant reactor years was available from the UNITINFO data base developed at EG\&G Idaho, Inc., for the NRC using information consolidhated from the Commercial Nuclear Power Plants ${ }^{18}$ report and the Headquarters Daily Reports (obtained from the National Institute of Health).

The low power license data (i.e., pre-commissioning) for the PWR and BWR nuclear power plants included in the data base were subtracted from April 30,1990, (cutoff date for this study) or the date of plant decommission, as appropriate, to obtain total reactor operating days. The plant reactor-days from both PWRs and BWRs were summed and divided by 365 resulting in a total of 1424 reactoroperating years (ry) including shutdowns. (The shutdown times were included because some events occurred while the plants were in shutdown or refueling mode.) The same procedure was used to calculate a total of 917 ry for just PWR operation.

Even though hydrogen fires and explosions have occurred, none of the events have resulted in damage to any safety-related equipment or structures.

The initiating event frequency calculations for hydrogen events associated with the generator cooling, the VCT, and the hydrogen storage facilities are presented in Sections 6 and 7. 


\section{SCREENING ANALYSIS OF POTENTIAL SOURCES OF COMBUSTIBLE GAS RISK}

To properly assess the risk significance due to the use of combustible gases in a PWR, a search was conducted to find all uses and sources of combustible gases. The results of this search determined the following uses or sources of combustible gases to be worthy of further investigation (see Figure 2 in Section 2):
- $\quad$ Station batteries
- Portable gas bottle storage areas (mostly acetylene and hydrogen)
- Waste gas systems
- Hydrogen distribution system for cover gas for the volume control tank
- Hydrogen distribution system for main generator cooling
- Hydrogen storage facilities (tank farms).

A preliminary investigation screened the first three sources from a detailed analysis. The following subsections discuss these screening investigations.

\subsection{Hydrogen Risk of Station Batteries}

The station batteries can become a source of hydrogen gas during charging operations. To date there have been no major accidents involving hydrogen gas in the battery rooms at nuclear plants. A search of the LER data base for battery-related hydrogen events found one event of a hydrogen explosion involving two cells of a station battery at the Palisades Nuclear Power Plant in 1979. Damage was caused by maintenance error and was limited to the two battery cells. The two damaged battery cells were jumpered out, leaving the station battery operational.

During normal plant operation, the station batteries are floating on the dc power system with the actual dc loads being supplied by the ac power distribution system through an uninterruptible power supply (see Figure 4). The uninterruptible power supply (UPS) typically consists of transformers and rectifiers for conversion of ac power to dc power and inverters to convert dc power to ac (see Figure 5). A $125 \mathrm{Vdc}$ battery system consists of four banks of 60 lead antimony or lead calcium storage cells. Typically, each bank is mounted in two rows of battery racks and located in its own battery room. Some very small amounts of hydrogen may be generated during normal operation. To prevent a sufficient buildup of hydrogen to present a hazard, several features and controls are in place at all PWRs. Federal regulation 10 CFR 50 Appendix $R^{5}$ requires separation, ventilation, and monitoring for the station batteries and all licensed plants must affirm compliance as directed in Generic Letter 86-10. ${ }^{19}$ Also, battery-generated hydrogen concerns are addressed and the impact on the plant is analyzed in each 


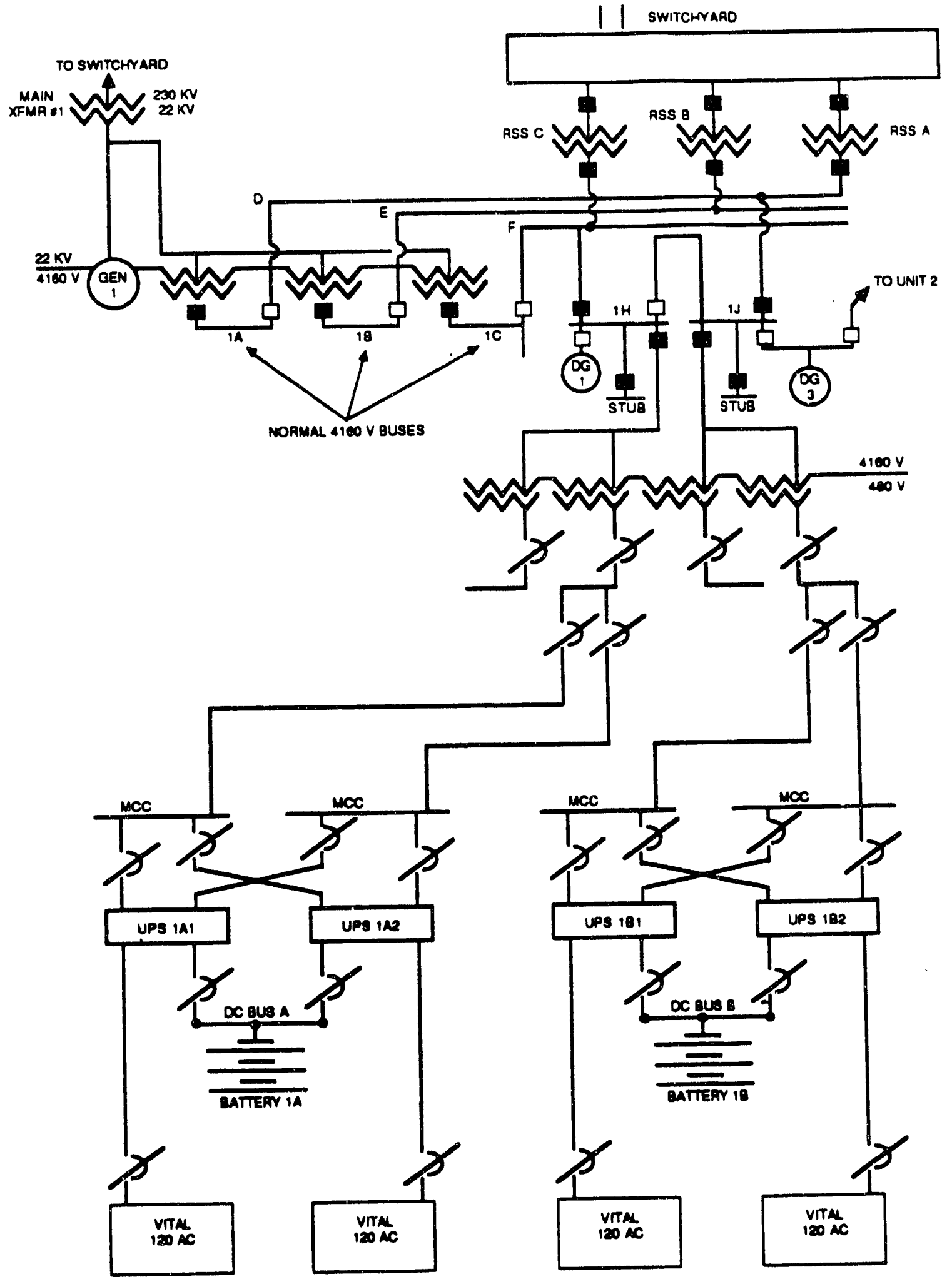

Figure 4. Typical ac/dc power arrangement. 


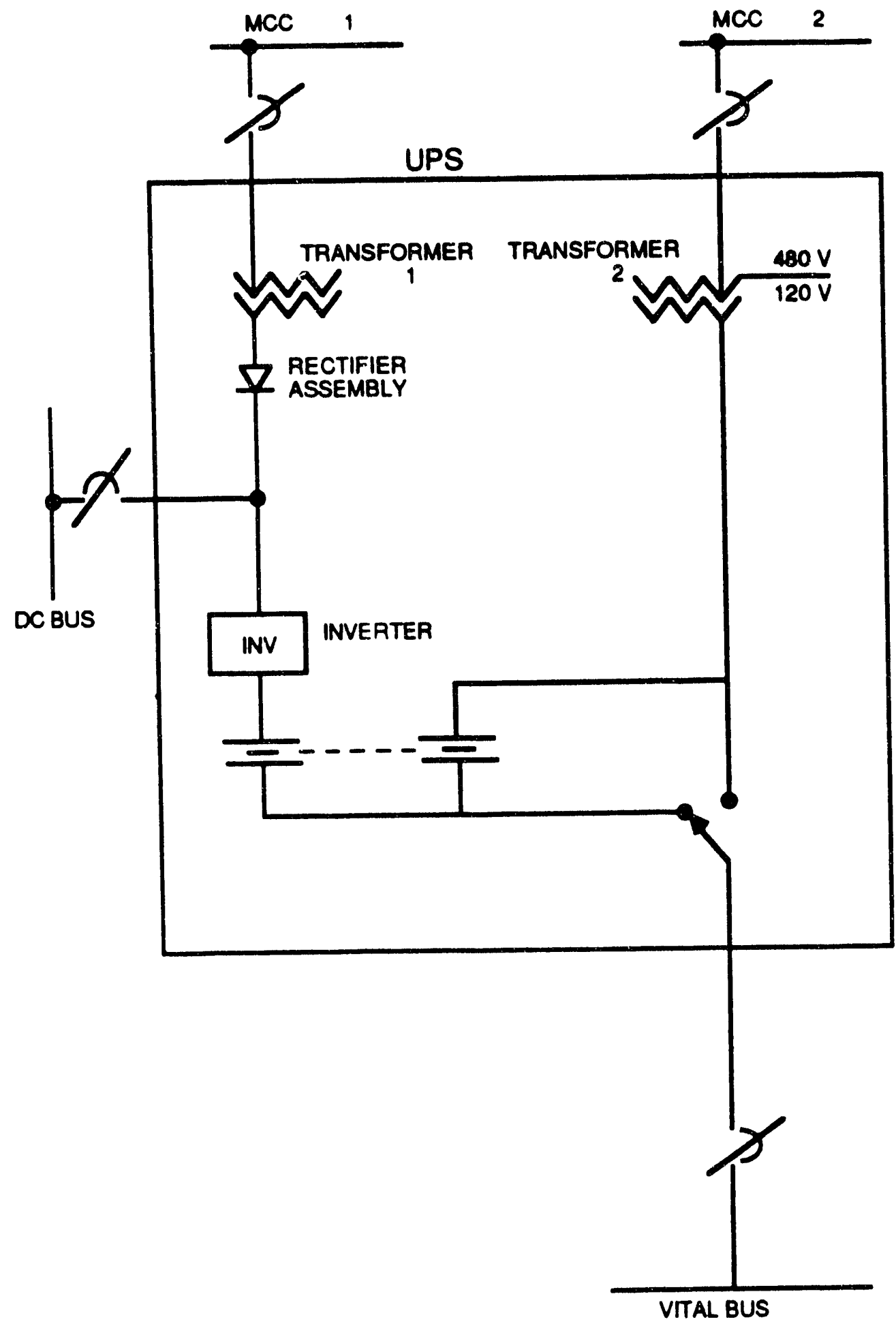

Figure 5. Typical uninterruptible power supply arrangement. 
plant-specific Fire Hazard Analysis Report. The Chemical Engineering Branch (CMEB) of the NRC's Office of Nuclear Reactor Regulation, in its Branch Technical Position (BTP) 9.5-1 [Section 7(g)], ${ }^{6}$ provides information that may be used by nuclear power plant licensees to protect safety-related battery rooms against hydrogen fires and explosions. First, the batteries are isolated from other areas of the plant by dedicated rooms or cubicles. These spaces are maintained at a slight negative pressure to prevent the spread of any generated hydrogen. Second, the ventilation system for the battery rooms is independent from the rest of the building ventilation, with separate supply and exhaust paths. The exhaust is typically vented to the atmosphere outside the building. Finally, the battery room ventilation is monitored for proper operation. This monitoring may be a continuous hydrogen detector with alarm in the control room, a continuous ventilation flow ratemeter with alarm, or once-a-shift ventilation flow readings by a roving plant operator. These design features and controls have allowed only one small, localized battery gas event and have prevented any such events from presenting a hazard to plant safety.

The batteries remain in a charged condition at all times except in situations involving a sustained loss of the normal and onsite emergency ac power supply (station blackout followed by ac power recovery). Immediately after onsite power is restored, the battery is recharged. During normal operation, as the batteries change chemical energy to electrical energy, the acid content of the electrolyte becomes depleted and batteries must be recharged. This is done by giving an equalizing charge to the battery at a higher voltage per cell than the float charge. During the charging process, some of the water molecules in the electrolyte are broken down by electrolysis into their chemical components of hydrogen and oxygen, which bubble to the surface of the solution as gases. The only time when significant hydrogen can be produced is during equalizing charge operations. The information obtained from two major US nuclear power plant battery manufacturers states that during the equalizing charge process, the hydrogen gen'ration rate for lead antimony batteries is about $15 \mathrm{scf}$ per hour (at a battery room temperature of $77^{\circ} \mathrm{F}$ ). This rate is about 10 to 20 times higher than that of lead calcium batteries. ${ }^{20}$ Typically, each station battery is given an equalizing charge once every three months for about 96 hours. Nuclear power plant operators have to follow written procedures on this type of maintenance activity, such as ensuring that (a) battery room ventilation is available and is adequate, (b) there are no open flames (or smoking) in the proximity of the battery room, (c) sparkless tools are used, etc.

The risk significance of hydrogen generated during equalizing charge operations can be evaluated by considering the following conditions:

- A hydrogen explosion must occur in the safety-related battery room, necessitating a plant shutdown

- The explosion must cause safety-related equipment needed to shutdown the reactor or remove decay heat to become unavailable.

The PRA Procedures Guide, NUREG/CR-2300, Vol. 1,21 outlines two basic methods for analyzing data to estimate constant failure rates (based on an underlying Poisson distribution of the failures): the classical method and the Bayesian method. Initiating event frequency calculations were performed using the noninformative prior Bayesian method for impact assessment since the Bayesian method provides slightly higher mean frequencies than the classical method. 
The Bayesian 5th percentile, mean, 95th percentile, and variance for a noninformative prior distribution are defined for $\mathrm{n}$ events in $\mathrm{T}$ years by:

$$
\begin{aligned}
\lambda_{.05} & =\frac{\chi_{0.05}^{2}(2 n+1)}{2 T} \\
\text { mean } \lambda & =\frac{(2 n+1)}{2 T} \\
\lambda_{.95} & =\frac{\chi_{0.95}^{2}(2 n+1)}{2 T} \\
\text { variance } \lambda & =\frac{(2 n+1)}{2 T^{2}}
\end{aligned}
$$

where $\chi_{0.95}^{2}(2 n+1)$ is from the chi-square statistic for $2 n+1$ degrees of freedom and $95 \%$ probability level.

Using the above equation for the mean, the initiating event frequency for a hydrogen event sufficient enough to disable an entire battery inside the battery room was calculated to be $1.1 \times 10^{-3} / \mathrm{ry}$. Appendix B contains the uncertainty derivation for the frequency calculations.

Nuclear power plants typically have two safety-related batteries, each supplying dc power to a train of safety-related equipment. Each battery is contained in its own dedicated room. Since equalizing charge operations are performed only for one battery at a time, a hydrogen explosion/fire can only cause loss of a single safety-related battery (i.e., dc bus). This particular accident initiator, "Non-Recoverable Loss of dc Bus" (abbreviated $T_{5}$ ), has been analyzed and documented in the NUREG-1150 study for the Sequoyah and Surry PWR plants. ${ }^{22,23}$ The following assumption was made in the NUREG-1150 study regarding this transient initiating event: Loss of dc bus will cause a reactor trip and disable an entire train of safety equipment.

In the NUREG-1150 analyses, the CDF contribution from the $\mathrm{T}_{5}$ accident sequences were estimated to be between $3.5 \times 10^{-7}$ and $1.4 \times 10^{-7}$ per reactor year (less than $1 \%$ of the total plant $\mathrm{CDF}){ }^{23}$ The $\mathrm{T}_{5} \mathrm{CDF}$ assumed an initiating event frequency of $5 \times 10^{-3} / \mathrm{ry}$. The calculated initiating event frequency for battery hydrogen events [see Equation (1)] is almost a factor of five lower than the NUREG-1150 $\mathrm{T}_{5}$ accident initiating event frequency. Therefore, the risk posed by hydrogen-induced fires or explosions in nuclear power plant battery rooms is considered to be insignificant and does not warrant any further investigation.

\subsection{Risk of Portable Gas Bottle Use and Storage Areas}

Bottled gases are used on an infrequent basis throughout the plant for various reasons. The major bottled gases of concern are acetylene, oxygen, and hydrogen. These gases are used for cutting and welding operations, and for calibration of flame photometers. These operations are performed infrequently when the plant is at power and are very transitory in nature. During the visit to 15 nuclear 
power plants, there was not one instance of these types of activities in progress. Compliance with Appendix R and SRP 9.5.1 requires that strict administrative controls (e.g., no smoking, securing gas bottles) be in place for these types of operations.

An individual bottle of combustible gas contains about 200 to $250 \mathrm{scf}$ of gas. In discussions with INEL explosion experts, this amount of hydrogen could cause only local damage and, if confined in a small room, could breach barriers such as fire doors and concrete block walls. However, all the energy would be dissipated in doing so and would not cause any widespread damage. As stated above, the use of other combustible gases (e.g., acetylene) is strictly controlled by the SRP $9.5 .1^{6}$ and by National Fire Protection Association guidelines.

While the amount of combustible gas in a single bottle may not pose a risk to plant safety, the portable bottle storage area could contain enough to cause a larger explosion. 10 CFR 50 Appendix $R$ regulations and SRP 9.5.1 explicitly require plants to establish administrative controls that "prohibit the storage of combustibles in safety-related areas or establish designated storage areas with appropriate fire protection."

A review of historical experience did not identify a single incident involving the explosion of a portable gas bottle in a safety-related (vital) area of a nuclear power plant. To ensure the continuing safe handling and storage of combustible gas bottles at nuclear plant sites, existing industry codes, standards, practices, and procedures must be strictly followed.

Based on the aforementioned site visits, event data base search, and limited evaluation, it is judged that the risk to plant safety due to fires or explosions in portable gas bottle storage areas is insignificant and does not warrant further investigation.

\subsection{Hydrogen :isk of Waste Gas Systems}

In the RCS of a PWR, various gases are produced as a result of the fission process or are introduced to control water chemistry. Hydrogen is one of these gases. Hydrogen and oxygen are produced by the radiolytic decomposition of water due to the high radiation fields present in the fuel region. At the operating temperature and pressure of a PWR, oxygen is corrosive to reactor internal materials and is partially scavenged by the deliberate introduction of excess hydrogen as part of the control of water chemistry. The addition of excess hydrogen (about $25 \mathrm{~cm}^{3} / \mathrm{kg}$ coolant) shifts the equilibrium of the reaction toward the water side of the reaction

$$
2 \mathrm{H}_{2} \mathrm{O} \rightleftarrows 2 \mathrm{H}_{2}+\mathrm{O}_{2}
$$

During reactor operation, a small fraction of the reactor coolant water (about 5 to $75 \mathrm{gpm}$ ) is continuously removed via a let-down line. This water is cooled and let down in pressure to allow processing and then is returned to the RCS. The processing maintains control of water chemistry via the chemical and volume control system (CVCS), removes boron for reactivity control via the boron recovery system, and removes radioactive materials via the radwaste system. A second source of gas is the pressurizer. The pressurizer and letdown systems contain various liquid tanks, evaporators, and/or gas 
strippers at pressures generally near 1 atmosphere. Dissolved gases are released from the liquid into the vapor space in these liquid tanks or in the gas strippers. Each tank has a hard-piped line to a waste gas header that sends the waste gases to the WGS. Figure 6 is a schematic diagram of a typical PWR RCS showing the major sources of gases. An inert cover gas, usually nitrogen, is maintained on most of the tanks and piping to dilute the hydrogen and oxygen and to allow the tank levels to fluctuate. An exception is the VCT in the CVCS. At the VCT, hydrogen gas is added to the reactor coolant to control corrosion. The hydrogen supply to the VCT is analyzed in a separate section of this report.

A study conducted by Brookhaven National Laboratory for the NRC and documented in NUREG/CR- $0603^{24}$ evaluated the risk from a large number of specific Class 3 through 8 accident scenarios, including releases from PWR WGSs. The methods used to investigate risk in this study were similar to those used in WASH-1400. ${ }^{25}$ NUREG/CR-0603. concluded that, "Class 3 to 8 accidents, as reviewed in this report, provide a small contribution to risk in comparison with Class 9 (core damage) accidents." (Note: This comparison takes in consideration the source term (radioactivity) inventories available and released by each accident clas s. The source term associated with the waste decay tanks is significantly lower than that of a nuclear $r$,dctor core.) Therefore, as a source of risk to the public, the major concern for the WGSs in PWRs is the explosion of combustible gases causing degradation or failure of nearby safety-related systems, and not direct releases of radioactive materials.

To pose a risk, the following conditions must exist simultaneously:

- An explosion in the WGS must occur, necessitating a plant shutdown

- The explosion must damage redundant safety-related equipment needed to shutdown the reactor or remove decay heat.

The potential for explosions in PWR waste gas systems was analyzed in a study conducted for the NRC in 1984.26 This study gathered information on existing waste gas systems, waste gas concentrations, and gas monitoring instrumentation for six operating nuclear power plants. A comparative risk evaluation was performed for several generic types and configurations of PWR waste gas systems. Some of the major conclusions pertaining to risk that can be inferred from this study are:

- Operational experience shows that PWR WGSs exhibit less likelihood of explosion than BWR off-gas systems

- $\quad$ Most WGSs use diaphragm or water-sealed vane compressors (rather than piston pumps) to reduce the likelihood of friction initiated fires

- The major potential ignition source is the presence of a catalytic recombiner

- If hydrogen and oxygen concentrations are kept below 4 and $5 \%$ respectively, then a safe condition always exists regardless of the potential ignition sources

- Continuous monitoring for both hydrogen and oxygen provides early warning of the onset of potentially hazardous conditions. 


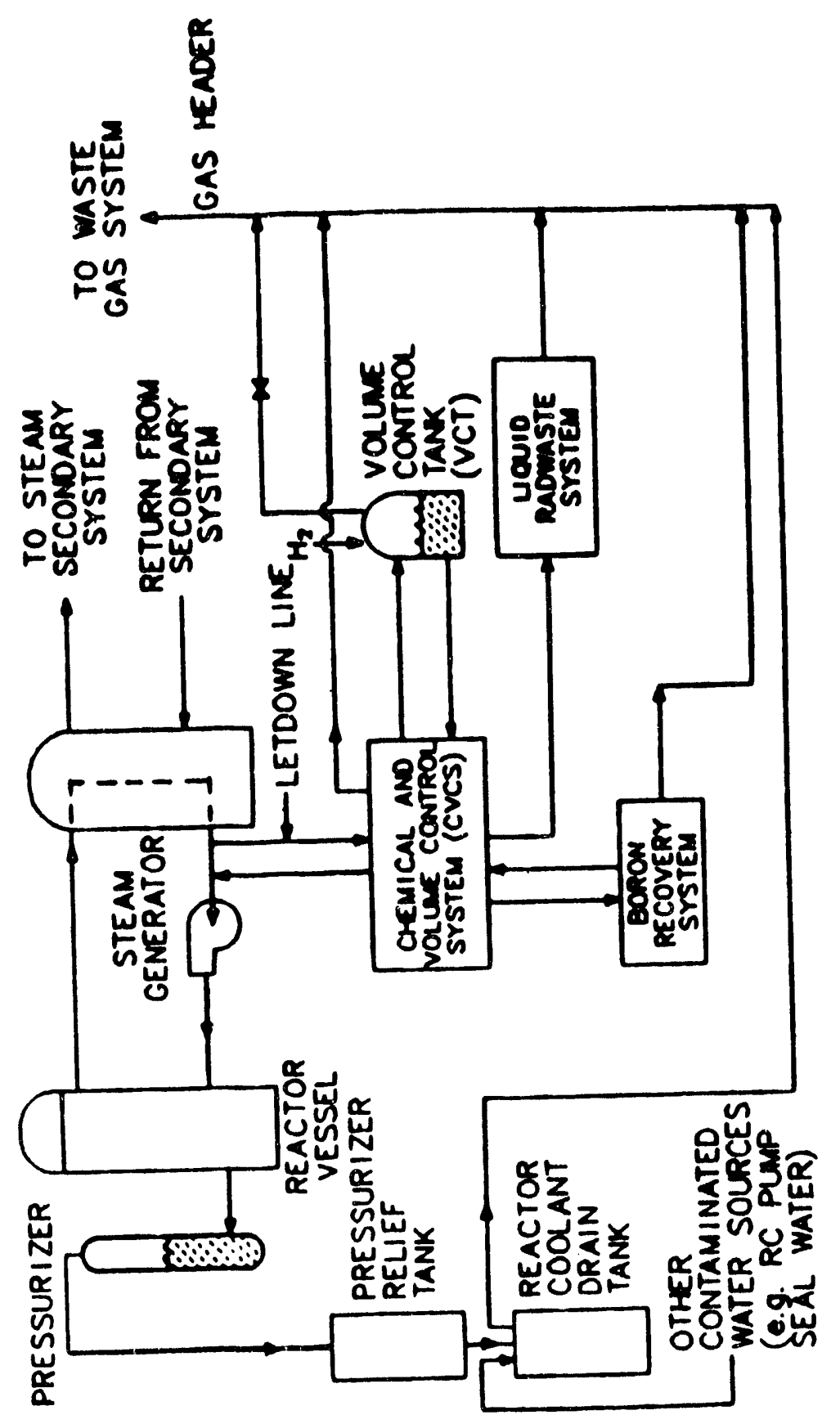

 
The design of most hydrogen recombiners calls for a maximum design capacity of $3 \%$ oxygen. This value is well below the $5 \%$ limit for oxygen (5\% oxygen is the minimum level at which oxygen will support combustion). Therefore, the hydrogen recombiner should not be online as an ignition source when higher oxygen concentrations exist. Generic Letter $89-01^{27}$ reaffirms the radiological effluent technical specifications requirement for maintaining the oxygen concentration below $2 \%$ and for continuous monitoring of the gas concentrations in the WGS. Thus, by system design and administrative controls the potential for explosions is minimized.

To keep radiation exposure as low as reasonably achievable, many plant designs have located major portions of the WGS (e.g., gas decay tanks) with the other auxiliary systems and generally away from safety-related systems. Therefore, if a hydrogen explosion did occur, the plant response in most cases would be a controlled shutdown initiated by the operating staff.

Most safety-related systems are normally in standby. Exceptions are support systems such as electric power and cooling water to operating components. These systems are not normally in the area of the WGS. If the explosion damaged a standby safety-related system, the plant operators would conduct an orderly reactor shutdown due to the invocation of a limiting condition of operation. The likelihood that an explosion in the WGS would take place during an existing transient that required a standby safety system is negligible since independent unlikely events occurring simultaneously are even more unlikely than one event occurring by itself.

This study concentrated on transients initiated by hydrogen explosions in the WGS. If some bounding numerical values are used, an estimate of the potential for contribution to risk can be made. Based on the data collected between 1963 and 1982 by NUREG/CR-3237, ${ }^{26}$ and updated to 1990 through a LER search, the frequency of an explosion or fire in a PWR WGS is [from the constant failure rate Bayesian analysis, Equation (1)] estimated as:

$$
f\left(W G S H_{2} \text { event }\right)=\frac{2(10)+1}{2(917 r y)}=1.1 \times 10^{-2} / r y
$$

For demand-driven failure rates, such as the probability of hydrogen explosion given that there is a leak, the PRA Procedures Guide ${ }^{21}$ provides the following Bayesian equations for a noninformative prior distribution, given $n$ events in $D$ demands.

$$
\begin{gathered}
P_{.05}=\frac{n+0.5}{n+0.5+(D-n+0.5) F_{0.05}(2 D-2 n+1,2 n+1)} \\
\text { mean } P=\frac{(n+0.5)}{(D+1)}
\end{gathered}
$$




$$
P_{.95}=\frac{n+0.5}{n+0.5+(D-n+0.5) F_{0.95}(2 D-2 n+1,2 n+1)}
$$

variance $P=\frac{(n+0.5)(D-n+0.5)}{\left[(D+1)^{2}(D+2)\right]}$

where $F_{0.95}(2 D-2 n+1,2 n+1)$ is the F-statistic for $2 D-2 n+1$ and $2 n+1$ degrees of freedom and $95 \%$ probability level.

Of the 10 WGS hydrogen events, only one led to a fire or explosion. Thus, using the demand failure rate Bayesian update [Equation (2)], the mean conditional probability of a tire or explosion given a hydrogen event in the WGS is:

$$
P\left(\text { WGS fire or explosion } \backslash \mathrm{H}_{2} \text { event }\right)=\frac{1+0.5}{10+1}=0.14
$$

A review of the LER information shows no case of a fire or an explosion in the WGS causing a plant transient. Using Equation (2), the mean conditional probability of a transient given a hydrogen fire or explosion in the WGS is:

$$
P\left(\text { plant transient } \mathrm{H}_{2} \text { fire or explosion }\right)=\frac{0+0.5}{1+1}=0.25
$$

Visits to 15 reactor plants revealed that WGSs are not typically located in areas near safety-related equipment. None of the 15 plants visited had located multiple trains of redundant safety-related systems (such as the cable spreading room or electrical tunnel) in the proximity of the WGS system. A review of FSAR drawings (available to INEL) for 26 additional PWR plants has not identified a single plant that had located redundant safety-equipment in a room adjacent to the waste decay tanks.

The failure of a single safety-related system would not normally lead directly to core damage. However, if multiple safety systems (i.e., redundant safety trains) are unavailable to respond to a transient condition and recovery actions are not possible, core damage can occur. Therefore, for transients initiated by a hydrogen explosion in the WGS and assuming that none of the 41 PWRs could have redundant trains of safety-related equipment damaged by the explosion (based on plant visits and FSAR information review), the safety-related equipment vulnerability [using Equation (2)] is:

$$
P(\text { safety related equipment vulnerability })=\frac{0+0.5}{41+1}=1.2 \times 10^{-2}
$$


The CDF due to a PWR WGS hydrogen fire or explosion event is calculated by:

$$
\begin{aligned}
f\left(\begin{array}{c}
\text { damaging safety } \\
\text { related equipment }
\end{array}\right)= & f\left(\begin{array}{c}
\mathrm{H}_{2} \text { WGS } \\
\text { event }
\end{array}\right) P\left(\text { WGS fire or explosion } \mathrm{H}_{2} \text { event }\right) \\
& P\left(\text { plant transient } \mathrm{H}_{2} \text { fire or explosion }\right) \\
& P(\text { safety related equipment vulnerability }) \\
= & \left(1.1 \times 10^{-2} / r y\right)(0.14)(0.25)\left(1.2 \times 10^{-2}\right) \\
= & 4.6 \times 10^{-6} / r y
\end{aligned}
$$

For the uncertainty calculation of the waste gas system CDF, the distributions for each parameter were loaded into the @RISK ${ }^{28}$ Monte Carlo program. Table 2 shows each random variable, the distribution, and the associated parameters. The results from the uncertainty analysis are:

$$
\begin{array}{ll}
C D F_{\text {sth }}=9.4 \times 10^{-10} / r y & C D F_{50 \text { th }}=6.2 \times 10^{-7} / r y \\
C D F_{9 S_{\text {ih }}}=2.5 \times 10^{-5} / r y & C D F_{\text {mean }}=5.0 \times 10^{-6} / r y
\end{array}
$$

Table 2. Random variables for waste gas system CDF.

\begin{tabular}{ccc}
\hline Random Variable & Distribution & Parameters \\
\hline f(WGS $\mathrm{H}_{2}$ event) & Gamma & $\alpha=10.5$ \\
& (constant failure rate) & $\beta=1.09 \times 10^{-3} / \mathrm{ry}$ \\
$\mathrm{P}(\mathrm{WGS}$ fire or & Beta & $\alpha_{1}=1.5$ \\
explosion $\mathrm{H}_{2}$ event) & (demand failure rate) & $\alpha_{2}=9.5$ \\
$\mathrm{P}\left(\right.$ plant transient $\backslash \mathrm{H}_{2}$ fire & Beta & $\alpha_{1}=0.5$ \\
or explqsion) & (demand failure rate) & $\alpha_{2}=1.5$ \\
$\mathrm{P}($ safety related equipment & Beta & $\alpha_{1}=0.5$ \\
vulnerability) & (demand failure rate) & $\alpha_{2}=41.5$ \\
\hline
\end{tabular}

\subsection{Screening Analysis Conclusions}

Based on the relatively low CDF results obtained in this conservative screening analysis, and the existence of appropriate regulatory guidance and licensee programs, the combustible gas risks associated with station battery operation, portable gas bottle storage, and gaseous waste systems are considered to be very low and do not warrant further detailed analysis. The combustible gas risks associated with hydrogen storage and distribution systems for the volume control tank, main generator cooling, and the external hydrogen storage facilities are potentially higher and cannot be eliminated by a simple conservative screening analysis. These areas are studied in more detail in the following sections. 


\section{METHOD OF ANALYSIS}

The general methodology used in this study to evaluate the base case PWR plant is based on the use of a vital area analysis. Such an analysis is a means by which the plant response logic, as modeled by typical probabilistic risk assessment (PRA) event trees and fault trees, can be used to identify whick areas of the piant are vital with respect to the issue of concern. In this study, a "vital area" is a location in the plant where a hydrogen explosion or fire could occur and thereby reduce the availability of one or more safety systems to the point that the conditional probability of core damage associated with hydrogen release scenarios is significant.

Vital area analyses nave been used in several external events analyses conducted by Sandia National Laboratories for the U. S. Nuclear Regulatory Commission (NRC), including the fire analyses for NUREG $150 . .^{29}$

\subsection{Analysis Steps} as follows:

The method used to evaluate the issue of combustible gases in PWRs is a seven-step approach,

1. Select a plant to analyze

2. Collect plant data via a plant visit

3. Perform a vital area analysis

4. Quantify PRA models to determine the contribution to core damage

5. Perform sensitivity studies to assess the effects of different PWR configurations

6. Perform an uncertainty analysis to more fully characterize the risk profile

7. Identify possible corrective actions that have the potential to be cost effective.

These steps are documented in this report. A cost/benefit analysis was performed to evaluate the potentially cost-effective corrective actions. Tr::s NUREG/Cr. documents the entire PWR hydrugen risk research work, and will bring together information presented in this report and several other reports related to this project.

\subsection{Plant Selection}

The selection of a PWR to be used in this analysis was based on evaluations of candidate plants against a set of criteria. These criteria are listed below:

- $\quad$ Completed Level 3 PRA. The Level 3 PRA will be used in the cost/benefit analysis to determine a change in the risk to the public. 
- $\quad$ Completed and Detailed Fire Analysis. The fire analysis contains useful information concerning the spatial configuration of the plant (explanations of fire zones and their contents). Fewer resources are consumed when more information is readily obtained from previously conducted analyses.

- Peer Reviewed PRA. There are many steps taken during the PRA process to ensure that correct analysis methods and sound ergineering judgments have been used. Upon completion, a PRA is peer reviewed by either an external expert panel or by a national laboratory team. Any inconsistencies are then resolved. Peer review also gives the particular PRA more credibility and acceptance. It is desirable that this research be based on previously accepted work. The original PRA study performed for the base case plant has been peer reviewed by Sandia National Laboratories. ${ }^{30}$

- $\quad$ Other criteria. Several other factors are important to this work. The plant analyzed should represent a large portion of the PWR population with regard to vintage and reactor vendor. Plant specific details such as hydrogen system and ventilation system specifics were obtained for the plant selection process. Fifteen PWRs were visited, hydrogen storage and distribution systems were walked down, and available plant documentation was coliected and documented. ${ }^{8}$

PRA analysts use two main approaches for accident sequence analysis and quantification. These two approaches are referred to as (a) the large fault tree/small event tree or fault-tree linking approach, and (b) the small fault tree/large event tree or event tree with boundary conditions method (sometimes called the PL\&G method). ${ }^{9}$ Both methods use event trees in conjunction with fault trees. Both approaches require some assumptions and approximations to be practical.

In the fault tree linking technique, the event trees are constructed at a high level in terms of the function or system success or failure definition. Each event tree has the systems as headings or top events. Any support systems and subsystems interdependencies are accommodated entirely within the fault trees. This method will result in both large and complex fault trees. This is the methodology used with four of the five NUREG-1150 plants. $^{29}$

In the event tree with boundary conditions method, the more elaborate event trees are broken down to explicitly display the significant dependencies. The resultant fault trees (or reliability block diagrams) for the event tree top events are thus simpler and can be analyzed by hand without resorting to computer assisted fault tree reduction. Heavy reliance is placed on the analyst to identify and separate the dependencies in the event tree modeling. More time is spent in understanding the systems and their dependencies at the beginning of the analysis. This method commonly yields many more sequences because of its evaluation for the various mutually exclusive support system states. This is the methodology used for the $W$ plant specific analysis, and is discussed more fully in this section.

Event trees provide the unifying structure for the PRA. An event tree is a graphical description of a group of sequences. It conventionally proceeds from left to right, calling out and showing how the systems (top events) are reacting to the initiating event (on the left). On the right-hand side, the plant core damage states are defined. Each path through the event tree defines a specific accident sequence. The sequence analysis proceeds through this path, with the success or failure of a top event at each branch of the tree. In the large event tree approach, the systein or top events are narrowly defined and 
the important dependencies between top events are shown explicitly in the event tree. Each top event has a probability of failure and probability of success (probability of success $=1.0$ - probability of failure).

In the $W$ plant PRA, ${ }^{9}$ reliability block diagrams were used to model the various plant systems and operator actions. For the vital area analysis, it was necessary to develop the system fault trees. When such a fault tree is quantified it yields a probability of system failure, the conditional split fraction (CSF). This is the split fraction for that top event conditional on the path through the event tree by which that top event is reached. Fault trees were then modified and requantified to produce the CSF applicable to the varying conditions potentially present in the plant due to different initiating events, availability of systems, and support system states. A small loss-of-coolant accident (LOCA) event tree, for example, may require only one of two high pressure injection (HFI) trains to keep the core covered, while a medium LOCA event tree may require both HPI trains. Each of these conditions will be modeled by a similar fault tree that has been modified to reflect these differing requirements, and has a different CSF probability upon quantification.

For the $W$ plant PRA, an event tree was created for each initiating event category [e.g., large LOCA, small LOCA, turbine trip, loss of off-site power (LOSP)]. The status of the support systems (primarily electric power) was modeled separately and resulted in different support system states. The support system dependencies are defined in degraded states for which the event tree is evaluated. That is, the top event (also called the conditional split fraction or branch point) probabilities will have one set of values for full electric power and another set for a degraded state in which one bus or a combination of buses is unavailable.

A typical accident sequence from the plant PRA has the general form of an initiating event frequency, multiplied by a support system state probability, multiplied by combinations of successful and failed event tree top event CSFs:

$$
\mathrm{Acc}=\mathrm{IE} \cdot \mathrm{SSS}_{\mathrm{n}} \cdot \overline{\mathrm{TE}_{\mathrm{i}}} \cdot \mathrm{TE} 2_{\mathrm{j}} \cdot \ldots
$$

where IE equals the initiating event frequency, $\mathrm{SSS}_{\mathrm{n}}$ equals the system support state probability, $\mathrm{TE}_{\mathrm{i}}$ equals the $i$ 'th CSF for the first top event, and TE2 ${ }_{j}$ equals the $j$ 'th CSF for the second top event. The bar over the CSF designator indicates the success of that event or action (an up branch on the event tree).

\subsection{Data Collection and Plant Visits}

To prepare for the visit to the selected plant, the analysis team studied as much documentation about the selected plant as possible. The collected material included the FSAR, plant drawings and schematics, the PRA report and any backup information, and the Appendix $R$ analyses. From this information, the analysis team prepared data packages for each fire zone. These packages contained drawings of the zones, lists of equipment in the zones, details concerning barriers between zones, and any other information deemed pertinent. These packages were used to guide the team members through the plant walk-downs. 
Visits were made to the selected plant to obtain first-hand knowledge about the layout of the hydrogen and safety-related systems. Tasks performed during the plant visits included:

- Walk-through tours of each of the accessible fire zones

- Determination of the hydrogen system configuration from the tank farm to the turbine and auxiliary buildings

- Determination of the physical arrangement of the hydrogen system and safety-related equipment within each fire zone

- Identification of potential paths for hazard propagation between fire zones

- Identification of uses and locations for portable hydrogen bottles and any other combustible gases in the plant

- Discussions with plant experts in the areas of operations, maintenance, and fire protection regarding hydrogen system operation and maintenance practices and histories.

\subsection{Vital Area Analysis}

With the information collected before and during the plant visits and the logic models from the PRA, the vital area analysis could be started. The steps involved in this work were:

1. Identification of Applicable Accident Sequences from the Original PRA to. Use as a Basis for the Vital Area Analysis. The original $W$ plant PRA analyzed the plant response to a large number of initiating events. For the vital area analysis, the appropriate event tree from the PRA was identified to use in the analysis. The vital area analysis uses the information in the PRA and assumptions about the effects of new hazards on relevant equipment to establish the plant system response to those new hazards. A hydrogen explosion or fire in the turbine building, for example, is assumed to generate a turbine trip. (Data on past hydrogen fires and explosions, such as the recent Maine Yankee hydrogen fire, support this assumption). ${ }^{31}$ The turbine trip event tree is then used in the analysis. The top event fault trees are modified as necessary to reflect the effects of the explosion on any safety-related equipment called on to mitigate core damage. The event tree accident sequences that become important for these scenarios are identified and quantified.

2. Determination of Impacted Safety-Related Equipment. This step examines each fire zone containing hydrogen for a potential point of origin of hydrogen fires and explosions. Each postulated fire and explosion is analyzed for equipment damage in that zone, the potential for breaching zone barriers, failure of equipment caused by zone barrier failure, and failure of equipment in adjacent zones. 
3. Development of New Accident Sequences. The event tree identified will now have a hydrogen fire and/or explosion as the initiating event. Potential damage to safety-related equipment is identified and new accident sequences are developed as follows. The safetyrelated equipment failed by a postulated fire or explosion is compared to the equipment called for in the plant PRA transient sequences. Each instance where one or more pieces of required equipment is disabled can change the CSF probability. If, as in some instances a top event system has completely failed, then the success side sequence will be eliminated (probability of success is zero). Furthermore, should the fire or explosion impact the reliability of any equipment modeled in the support system states, new support system state probabilities must also be calculated. Different accident sequences will now become prominent as the CSF probabilities change and sequences are eliminated. These modified sequences, with hydrogen fire or explosion as the initiating event, are the new sequences created by the vital area analysis.

\subsection{Seismic Interaction Analysis}

Seismic interactions with the hydrogen supply systems, generator cooling system, and VCT were also addressed. The seismic interactions were analyzed with the same analysis techniques discussed above in Subsection 5.4, but with different assumptions to account for seismic initiators. Safety-related systems designed to withstand the safe shutdown earthquake (SSE) were assumed to function properly to those acceleration levels. Previous seismic studies ${ }^{32}$ have shown that most safety-related system failures occur in the range of two to four times the SSE level. The hydrogen distribution systems at U.S. nuclear power plants consist of small bore piping and valves (less than 3 in. in diameter) of high quality industrial grade. The pipe can have threaded joints, be welded, or include a combination of both. At some plants visited, the hydrogen pipe is seismically supported in areas containing safety-related system components. The features and seismic response characteristics of hydrogen distribution systems are similar to those of dry small bore pipe utilized in balance of plant (BOP) systems and fire protection systems. Based on those considerations, the hydrogen gas system fragility was assumed to be similar to that estimated for a dry, small bore fire protection piping system installed at the base case plant. ${ }^{33}$ Sections 6 and 7 present the seismic interaction analysis for $W$ and the generic plant configurations.

\subsection{Quantification}

The entire W plant PRA was loaded into the Integrated Reliability and Risk Analysis System (IRRAS). ${ }^{34}$ This included all the event trees, initiating events, CSFs, and the probabilistic data associated with the quantification and uncertainty analysis. The new accident sequences, initiating event frequencies, and CSFs were developed and added to the plant data base. IRRAS was used to perform the sequence quantification using the CSF method and to determine the CDF contribution of the new accident sequences, which are summarized in Subsections 6.6 and 7.6.

\subsection{Uncertainty Analysis}

The results of this risk analysis study include upper and lower uncertainty bounds around the mean value. The bounds represent the maximum (to some degree of confidence) expected variation of the outcome (i.e., mean) due to the randomness of events which are included in the model. 
For models with random event values based strictly on historical experience (e.g., hydrogen fires and explosions inside turbine building), uncertainty distributions and bounds were determined using techniques recommended by the PRA Procedures Guide, NUREG/CR-2300, Vol. 1. ${ }^{21}$ However, for plant analyses which contain significant uncertainty due to modeling assumptions or due to parameter values which are not based on historical experience (e.g., conditional probability of hydrogen gas not igniting immediately following a large discharge inside the turbine building, probability of completely damage redundant safety system components) a different approach was used. It subjectively (based on engineering judgment) chose numerical uncertainty limits for modeling uncertainties and then calculated an overall accident sequence uncertainty, treating modeling uncertainties as statistical uncertainties. A large error factor (i.e., ratio of the 95th percentile upper bound to the median) was assigned to these modeling parameters.

The plant PRA data base contained the original PRA uncertainty distribution information for initiating events and CSFs. This information, along with distributions developed for any new initiating events and CSFs, were used to propagate uncertainty through the accident sequence models. This analysis was performed using the Monte Carlo sampling techniques built into the statistical @RISK program.

\subsection{Generic Analyses}

Sensitivity studies were performed with the intent of representing the effects of different plant designs and combustible gas location with respect to safety-related equipment. The choice of specific design features to be modeled and analyzed was based on plant information obtained during visits at 15 PWRs, ${ }^{8}$ reviews of final safety analysis reports and safety evaluation reports for an additional number of PWRs (to determine the location of safety-related equipment with respect to combustible gases in the plant), and other PRA-related documentation (e.g., plant fire hazard analyses). The PWR plants visited and reviewed represent a good cross-section of the PWR population. The sensitivities reflect the plant-toplant variability in routing of hydrogen lines, location of safety-related equipment, and major differences between nuclear steam supply system (NSSS) designs. Section 7 provides the details of these generic analyses.

\subsection{Plant Improvement Analysis}

This analysis evaluates selected plant hardware and/or procedural improvements and then estimates the reduction in the CDF that could result if they were to be implemented. This is accomplished by estimating the reduction in hydrogen fire/explosion frequency or re-evaluating the damage caused by hydrogen fires/explosions and requantifying the accident sequences. For each of the plant areas investigated, three alternatives were considered. Most of the hardware and procedural alternatives considered in this study reflect existing arrangements found at some of the U.S. nuclear power plants visited (e.g., excess tlow check valves in the hydrogen supply pipe headers, periodic hydrogen make-up to the VCT or generator). Other alternatives, such as air intake louvers actuated by hydrogen analyzers and hydrogen detonation wave deflection shield, have been considered in the EPRI NP-5283-SR-A 12 (topical report on hydrogen storage facilities) and by the INEL hydrogen detonation experts. ${ }^{35}$ The alternatives considered include (by plant area): 
- Auxiliary Building

- Install an excess flow check valve in the hydrogen supply line leading to the VCT

- Limit the hydrogen supply for the VCT to a three bottle storage facility (each containing $250 \mathrm{scf}$ )

- Perform periodic hydrogen make-up to the VCT

- Turbine Building

- Install an excess flow check valve on the hydrogen supply line header and a check valve on the hydrogen line at the generator

- Perform periodic hydrogen make-up to the electrical generator

- Enclose safety-related equipment in a blast-proof structure

- Hydrogen Storage Facility

- $\quad$ Relocate hydrogen storage facility (i.e., tank farm) to a distance within EPRI NP-5283SR-A guidelines ${ }^{12}$

- Install a hydrogen blast wave deflection shield

- Install air intake louvers that are actuated by hydrogen analyzers.

Section 8 of this report presents a detailed discussion of the above listed alternatives, including examples of specific features and characteristics of these alternatives that are currently implemented at some operating nuclear power plants.

\subsection{Analysis Limitations and Assumptions}

The following limitations and assumptions were employed in this analysis:

- The detailed analysis is limited to the impacts of combustible gas fires and explosions with the reactor at full power. It was beyond the scope of this study to quantitatively determine the risks associated with hydrogen events during modes of operation other than Mode 1. However, various power-state dependent factors are discussed and a qualitative assessment was performed of the risk associated with off-power conditions (see Appendix $\mathrm{C}$ for details). The following conclusions can be made regarding the hydrogen risk associated with reactor shutdown modes: 
- Power operation through hot standby (Modes 1 through 3) risks should be bounded by the full power operating cases presented previously. This conclusion is based upon system operability requirements, decay heat loads, RCS coolant inventory, RCS coolant makeup capacity, containment integrity, and operability of vital auxiliaries.

- Hydrogen-induced events during hot standby (Mode 4), cold shutdown, and refueling (Modes 5 and 6) are considered to have insignificant impact on the reactor core. This conclusion is based upon the consideration that hydrogen is typically absent from in-plant distribution systems, the significant reduction in decay heat loads, the increased coolant inventories, and the lower coolant temperatures (all of which allow more time for recovery of damaged systems).

- It was assumed that a major fire or explosion will cause a plant trip, either automatically or by operator action. The basis for this assumption is that plant procedures dictate plant shutdown for major off-normal conditions, such as major plant fires or explosions.

- Any combustible gas fire or explosion caused by an earthquake is assumed to be accompanied by an LOSP. This is consistent with the plant PRA modeling of the fragile nature of the ceramic insulators in the off-site power distribution system.

- An explosion inside an enclosed space is assumed to disable all unshielded safety-related equipment in that space. Credit is taken for missile barriers, protruding walls, and large open distances when appropriate.

- An explosion sufficient to breach a solid zone barrier (such as a wall) is assumed to have caused failure of any piping or cabling penetrating that barrier. Safety-related equipment mounted to that barrier is also assumed to be disabled.

- Statistical uncertainties have been addressed in all analyses. However, since plantspecific equipment modeling (e.g., seismic fragilities for hydrogen distribution system, hydrogen fire/explosion causing safety equipment damage) has not been performed for all U.S. PWRs, model uncertainties still exist. In this study, the modeling uncertainties have been treated as statistical uncertainties and large error factors were assigned to parameter values.

- No mechanistic analysis were performed to evaluate: (a) the hydrogen detonation impact on safety-related equipment, (b) the feasibility of delayed ignition of leaking hydrogen, (c) the propagation of the blast wavefront, or (d) hydrogen stratification and transport. 


\section{ANALYSIS OF A WESTINGHOUSE FOUR-LOOP PLANT}

\subsection{Plant System and Model Descriptions}

The PWR unit under analysis employs a four-loop nuclear steam supply system furnished by Westinghouse Electric Corporation. Westinghouse $(W)$ was the primary contractor and had responsibility for the design, construction, testing, and initial startup of the facility. The company had contracted with United Engineers and Constructors as architect-engineer to provide engineering assistance in the design and construction of the structural and civil works. The reactor is presently licensed to operate until September 28, 2013, at a thermal power of $3071.4 \mathrm{MW}(\mathrm{t})$ that corresponds to a design turbine-generator output of $971 \mathrm{MW}(\mathrm{e})$ net. Appendix D provides a detailed description of the plant and systems.

A full-scale Level 3 PRA was conducted on the $W$ plant in $1982 .^{9}$ This PRA was performed by Pickard, Lowe, and Garrick, Inc. The PRA utilized the large event tree, small fault tree method of performing PRA. The PRA consisted of large event tree models of the various accident initiator groups, fault tree models of the required safety systems and actions, and a support system model to establish support system states. Appendix E provides more details of the PRA models.

\subsection{Turbine Building Analysis}

6.2.1 Turbine Building Hydrogen Gas System Configuration. The $W$ plant hydrogen gas system $^{36}$ supplying the main generator begins with a 45-bottle hydrogen storage facility located about 135 $\mathrm{ft}$ west of the turbine building and approximately $300 \mathrm{ft}$ south of the service water pumps at the $15-\mathrm{ft}$ elevation (ground level). Eighteen bottles are online as the active supply. Another 18 bottles supply the reserve manifold, and 9 bottles supply the emergency reserve manifold. Each bottle contains about 1150 standard cubic feet (scf) of hydrogen at a pressure of about 1500 psig. A hydrogen fill connection is located at the front of the hydrogen storage facility enclosure.

The hydrogen storage facility is protected under a concrete roof and is open to the outside on three sides. Also located under the concrete roof are a pressure reducing station (and associated valves) and portions of the hydrogen piping system.

A 1.5-in. diameter line runs from the hydrogen storage facility to the west wall of the turbine building. This line is underground at the 9-ft elevation. Once the line is under the turbine building, it comes up through the floor of the 15-ft elevation just inside the west wall in fire zone 44A (FZ-44A). After going through a flow totalizer, the line goes up into the overhead of the 15-ft level (34-ft elevation), turns east once again, and proceeds through fire zones 21 (FZ-21) and 43A (FZ-43A) to a point under the main generator. The hydrogen feed line then goes up through the mezzanine level (FZ-39A on the 36- $\mathrm{ft}$ 9-in elevation) to the main generator on the 53-ft level (FZ-40A). Out of the main generator are 0.5 -in. purity sample lines going to a hydrogen control panel in FZ-43A. Coming off the hydrogen feed line and various smaller lines are vent lines that collect in a 3-in. vent header that rises up the east wall of the turbine building and terminates above the building roof. Figures 7 to 9 show schematics of the hydrogen pipe run through the turbine building, and the fires zones within the turbine building that contain hydrogen gas system pipe lines. 


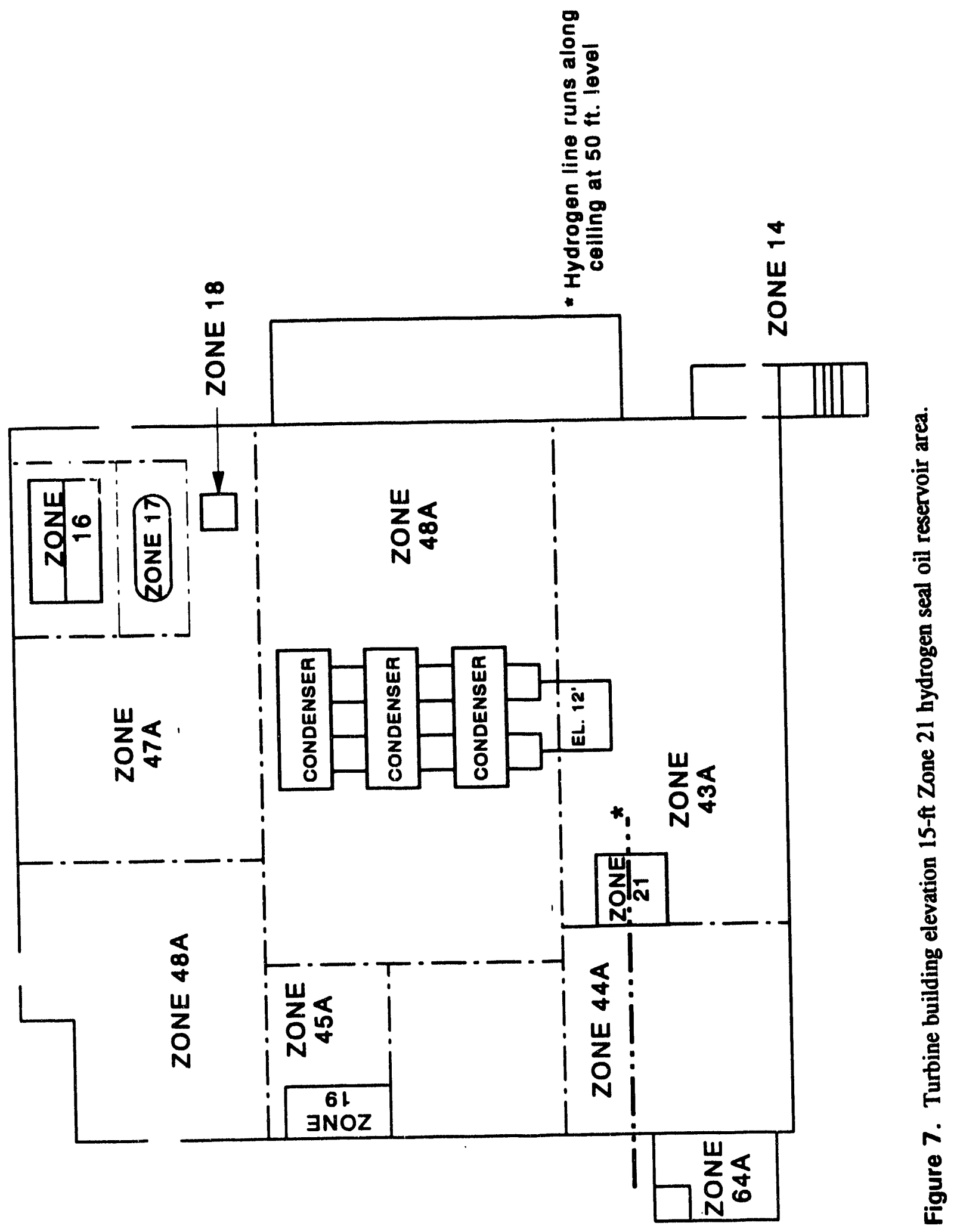




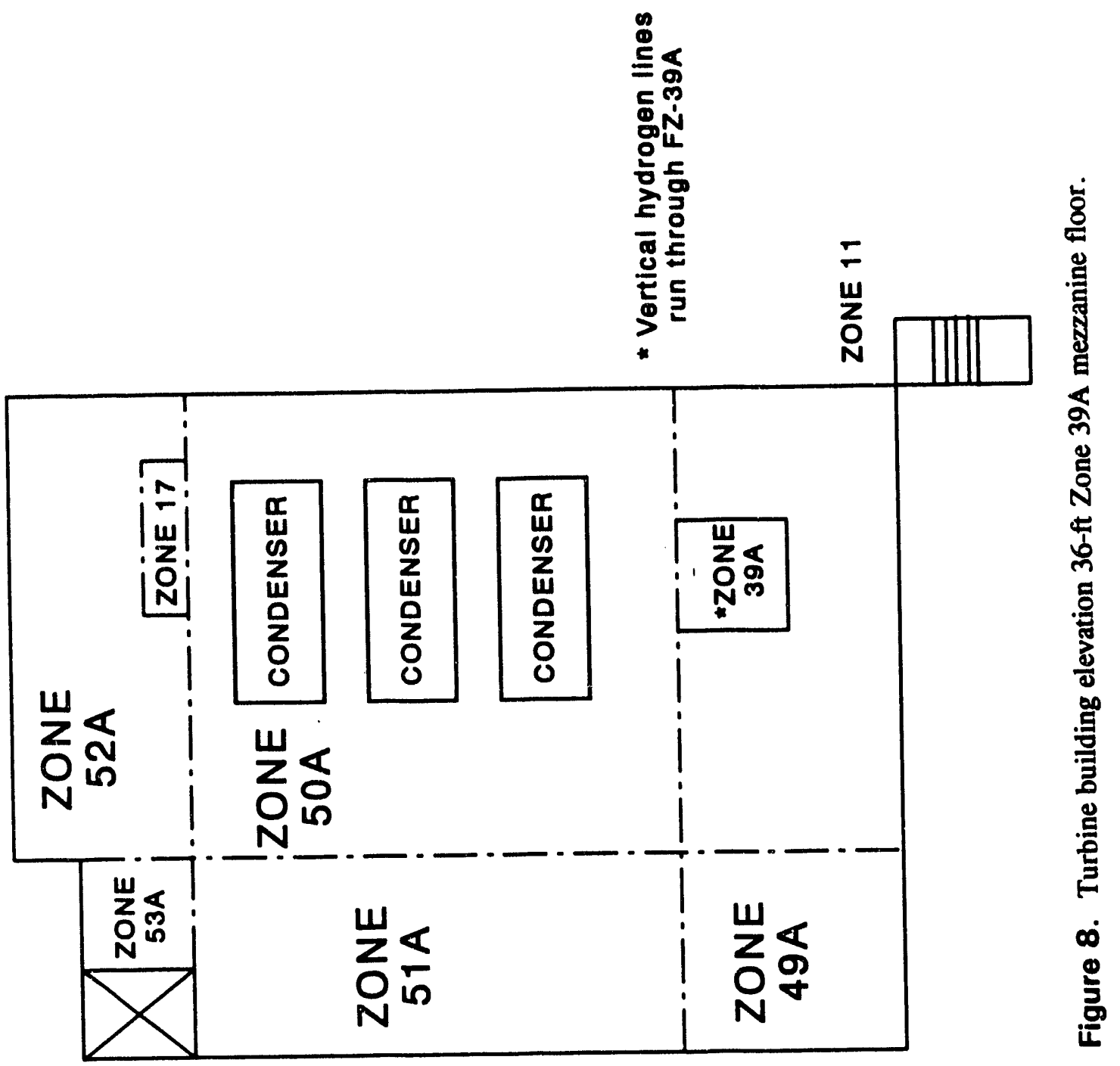




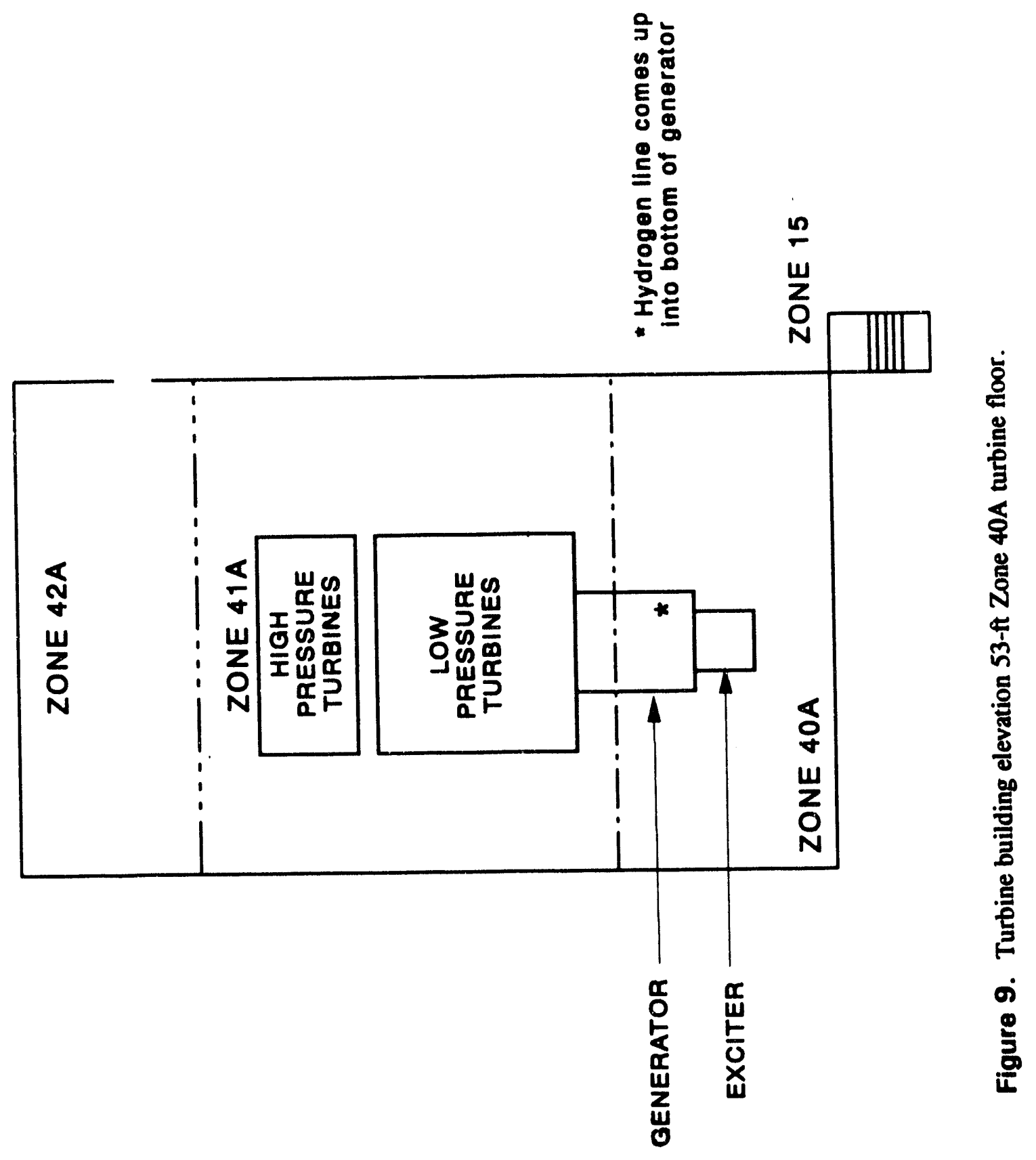


The hydrogep distribution system for the generator is not equipped with an automatic excess flow check valve or a similar device designed to prevent a large uncontrolled hydrogen discharge into the turbine building due to a leak or rupture of the distribution system.

6.2.2 Turbine Building Vital Area Analysis. The following fire zones in the turbine building contain portions of the hydrogen gas system:

- 15-ft elevation

- FZ-44A Main supply line

- FZ-21 Hydrogen seal oil unit

- FZ-43A Main supply line, sample lines, vent

lines, $\mathrm{H}_{2}$ control panel

- 36-ft 9-in. elevation

- FZ-39A' Main supply line, vent lines

- 53-ft elevation

- FZ-40A Main generator.

On each elevation, the fire zones are not separated by any physical barriers, but are actually one large open area divided into fire zones for convenience. Different elevations are separated by concrete floors. None of the zones containing hydrogen gas lines have safety-related equipment in them.

The closest fire zones containing safety-related equipment are in the control building, directly adjacent to the southeast corner of the turbine building. Fire zones of potential interest in the control building are:

- $\quad 15 \mathrm{ft}$ elevation

- FZ-14 Switchgear room containing the vital $480-\mathrm{V}$ Buses $2 \mathrm{~A}, 3 \mathrm{~A}, 5 \mathrm{~A}$, and $6 \mathrm{~A}$ and power/control cables for most safetyrelated pumps.

- $\quad 33 \mathrm{ft}$ elevation

- FZ-11 Cable spreading room containing power and/or control cables for most safetyrelated pumps and valves. 
$53 \mathrm{ft}$ elevation

- FZ-15 Control room containing the control panels and instrumentation for most safety-related systems.

On the 15-ft elevation, the control building is separated from the turbine building by an 8-in.thick concrete block wall and the hydrogen lines are approximately $100 \mathrm{ft}$ away.

On the 33-ft level, the wall between the cable spreading room and the turbine building is partially 1-ft-thick brick with the remainder being constructed of insulated metal sandwich panels with a three-hour fire barrier rating. The hydrogen lines in the turbine building on this level are about $60 \mathrm{ft}$ away from the cable spreading room.

The wall between the turbine building and the control room ( $53 \mathrm{ft}$ elevation) is constructed of 8in. block or brick. The closest turbine building hydrogen lines are about $80 \mathrm{ft}$ away. In addition to the wall separation, a stairwell provides further separation for a portion of the zone barrier on each elevation.

The turbine building has an open volume of approximately 4 million $\mathrm{ft}^{3}$. In the event of an explosion in the turbine building, it is anticipated that much of the energy would be dissipated in this large, open volume. The largest volume of hydrogen in the turbine building resides in the main generator itself. The main generator is on the 53-ft elevation. This is the largest open area in the entire plant with the roof being about $100 \mathrm{ft}$ above the turbine hall floor. Portions of the walls are constructed of insulated metal sandwich panels and contain a number of large windows for natural lighting. An explosion in this area would likely blow out these windows and walls before breaching the control building wall.

A large fire fueled by the main generator hydrogen supply and the turbine lube oil inventory, such as the fire at Vandellos 1 in October 1989, could cause major destruction of the turbine building. In that fire, electrical supplies to a shutdown heat removal system were burned and the expansion joint for the cooling water supply to the main condenser was ruptured. The layout of the $W$ plant turbine building does not contain cabling for safety-related equipment. Destruction of the condenser cooling water supply could happen, but there are still many ways for supplying feedwater and secondary cooling with the condenser cooling water supply disabled.

As introduced in Section 2 of this report, two categories of hydrogen-initiated accident scenarios were considered and quantified as part of $W$ plant turbine building analysis: a transient with loss of decay heat removal (T/DHR) and a transient-induced loss-of-coolant accident (T/LOCA). The following subsections detail the two accident scenarios as applicable to the base case analysis.

6.2.3 Transients with Loss of Decay Heat Removal-Turbine Building. The T/DHR accident scenario considered assumes a large explosion in the turbine building (at the generator floor level) causes the steam supply line to the main turbine to rupture. This presents a challenge to the reactor that is modeled in the original plant PRA under the initiating event of "Steam Line Break (SLB) Outside Containment" (see Figure 10). 


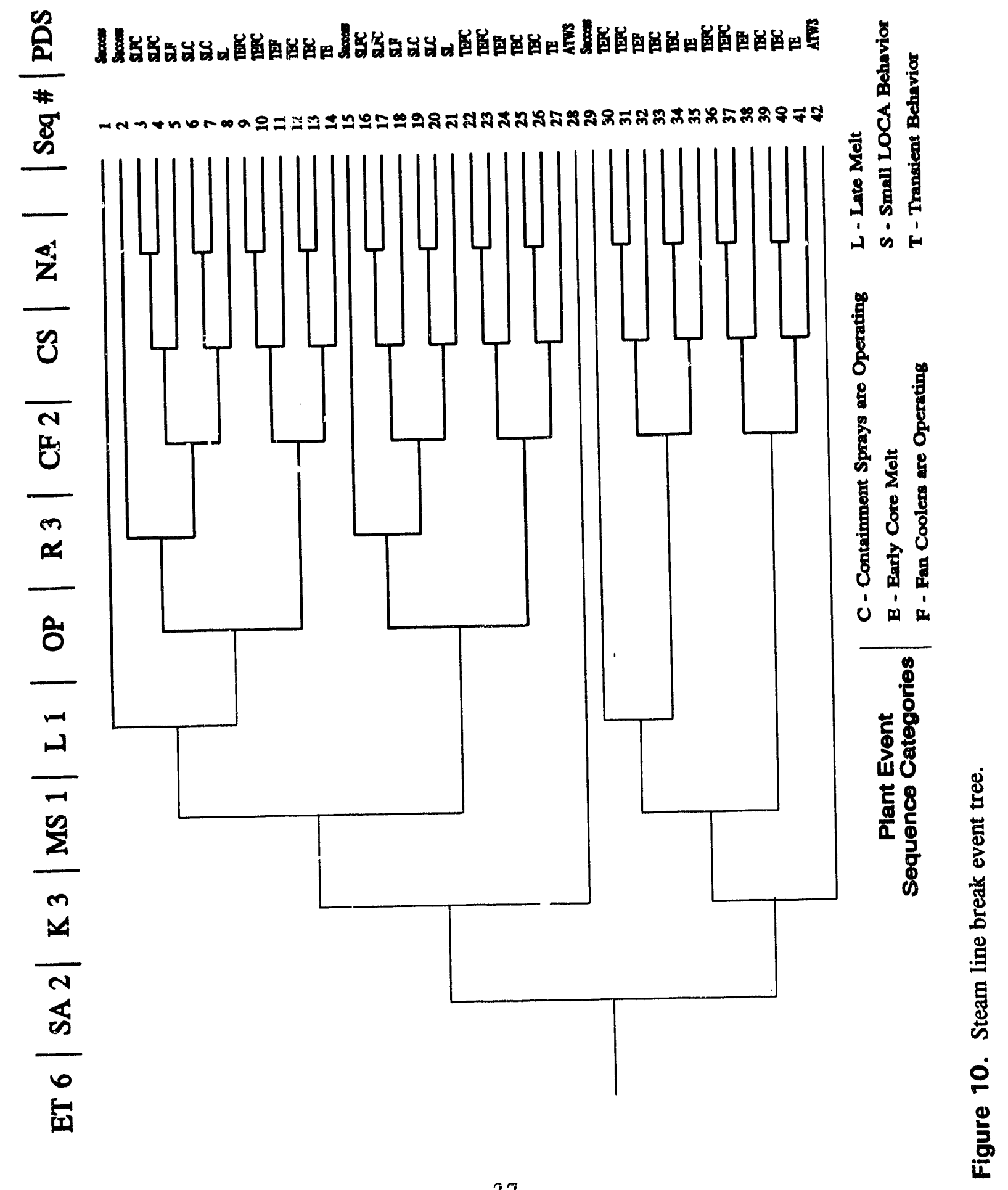


The functions and systems modeled by the top events (with failure probabilities from the $W$ base case PRA) are described in Table 3.

Table 3. Steam line break event tree top events.

Name Probability Description

SA-2 $1.3 \times 10^{-4} \quad$ Failure probability of safety injection signal and high load pump

$\mathrm{K}-3 \quad 2.0 \times 10^{-5} \quad$ Reactor trip

MS-1 $1.5 \times 10^{-2} \quad$ Main steam isolation valve trip

L-1 $\quad 1.9 \times 10^{-5} \quad$ Failure probability of auxiliary feedwater and secondary cooling

OP $6.1 \times 10^{-3} \quad$ Failure probability of primary cooling feed and bleed (F\&B)

R-3 $5.0 \times 10^{-4} \quad$ Failure probability of recirculation cooling

CF-2 $5.0 \times 10^{-6} \quad$ Failure probability of containment fan coolers

CS $\quad 8.1 \times 10^{-5} \quad$ Failure probability of containment spray system

NA $9.6 \times 10^{-4} \quad$ Failure probability of the sodium hydroxide addition system

The mean initiator frequency for the steam line break event was calculated to be $1.95 \times 10^{-3} / \mathrm{ry}$. This frequency was developed using the available data at the time of the PRA and supposedly covers all causes. However, assuming that hydrogen fire and explosions were not included, a new initiating event for hydrogen-induced SLBs can be calculated.

The frequency of hydrogen fire or explosion events at the generator level in the turbine building is estimated from the Bayesian analysis of a noninformative prior distribution [see Equation (1)]. All hydrogen explosions and fires that have occurred at the generator level in the turbine building are included in the frequency estimation. The mean initiating event frequency is calculated as:

$$
f\left(\mathrm{H}_{2} \text { fire or explosion at generator floor level }\right)_{T B}=\frac{2(8)+1}{2(1424 r y)}=6.0 \times 10^{-3} / r y
$$

To date, there have been eight turbine building explosions or fires at the generator level and none have caused a steam line rupture. Using Equation (2), an estimate of the mean probability that, given 
a turbine building fire or explosion, a steam line will be ruptured is:

$$
P\left(S L B \backslash H_{2} \text { fire or explosion }\right)=\frac{0+0.5}{8+1}=0.06
$$

Thus, the steam line rupture frequency due to hydrogen events only is:

$$
\begin{aligned}
f(S L B)_{T B}= & f\left(H_{2} \text { fire or explosion at generator floor level }\right) \\
& P\left(S L B \backslash H_{2} \text { fire or explosion }\right) \\
= & \left(6.0 \times 10^{-3} / r y\right)(0.06)=3.6 \times 10^{-4} / r y
\end{aligned}
$$

This initiating event frequency is multiplied by the base case conditional core damage probability to obtain a hydrogen-induced CDF. The original PRA conditional core damage probability from SLBs is $1.02 \times 10^{-4} /$ ry. Thus, the CDF from hydrogen-initiated SLBs is estimated to be:

$$
\begin{aligned}
C D F_{S L B \text { (nonseismic) }} & =f(S L B) P(\text { core damage } L L B) \\
& =\left(3.6 \times 10^{-4} / r y\right)\left(1.02 \times 10^{-4}\right) \\
& =3.7 \times 10^{-8} / r y
\end{aligned}
$$

\subsubsection{Transient-Induced Loss-of-Coolant Accident - Turbine Building}

6.2.4.1 Turbine Building T/LOCA Nonseismic Analysis. The T/LOCA accident scenario considered assumes a large explosion in the turbine building (at the hydrogen system floor level) causing extensive damage to the plant's cable spreading room (closest safety-related fire zone, located inside the control building). As described in the Subsection 6.2.2, the cable spreading room is the most susceptible to hydrogen fires or explosions. At the 33-ft level, the wall between the cable spreading room and the turbine building is partially 1 -ft-thick brick with the remainder being constructed of insulated metal sandwich panels. The hydrogen lines in the turbine building on this level are about $60 \mathrm{ft}$ away from the cable spreading room. Because the hydrogen distribution system for the generator is not equipped with an automatic excess flow check valve, a large uncontrolled hydrogen discharge into the turbine building due to a leak or rupture of the distribution system is possible. Based on the configuration of the turbine building, the distance between turbine building area containing hydrogen lines and control building fire zone containing safety-related equipment, the types of fire barriers and wall structures present at the base case plant, and the large volume of hydrogen (about $40,000 \mathrm{scf}$ ) that could be available from the storage facility, it was judged that a hydrogen-initiated large fire or explosion in the turbine building could potentially impact the safety-related system components in the cable spreading room (CSR). 
The initiating event frequency is calculated using Equation (1). To date only one hydrogen explosion and fire has occurred in the turbine building at the hydrogen distribution system level. Therefore the mean initiating event frequency is calculated as:

$$
f\left(H_{2} \text { fires or explosions at distribution system level }\right)_{T B}=\frac{2(1)+1}{2(1424 r y)}=1.1 \times 10^{-3} / r y
$$

To determine the probability of a sufficiently large hydrogen fire or explosion damaging multiple safety-related equipment via mechanistic analysis is beyond the scope of the present analysis. One can develop a value based on engineering judgment by considering the scenario required to yield a hydrogen fire or explosion of sufficient magnitude to breach the wall separating the turbine building from the CSR, and then causing damage to the safety equipment present in the room. Development of this value would involve two items:

- Assuming a major release of hydrogen, the early ignition of the leaking hydrogen would not occur

- Given the continued accumulation and eventual delayed ignition of the released hydrogen, the propagation of a detonation wave or fire front throughout the turbine building floor would proceed in such a manner that cable spreading room fire zone (FZ-11) boundaries are breached, totally damaging the enclosed equipment.

The probability of the first item, $\mathrm{P}$ (delayed ignition), is assessed to be less than $1 \times 10^{-1}$ for the turbine building environment at the hydrogen distribution system level. The large number of operating electrical equipment (e.g., pump motors, fan motors) in the turbine building provides an ignition source necessary for early ignition of the released hydrogen.

The probability of the second item, $\mathrm{P}$ (blast propagation), is assessed to be less than $1 \times 10^{-1}$. This takes into consideration spatial interactions (i.e., location of hydrogen sources in the turbine building with respect to safety-related equipment inside cable spreading room) and the likelihood of the blast wave damaging safety-related equipment following zone boundary breach.

Thus, while uncertainties clearly exist in building designs and explosive potential, a mean value of $1 \times 10^{-2}$ may be assumed to be reasonable for the conditional probability of disabling multiple safetyrelated equipment in the cable spreading room. If no recovery actions are taken, it is postulated that core damage will occur from loss of coolant inventory through the failed reactor coolant pump (RCP) seals (T/LOCA accident scenario).

For this analysis, it is postulated that the CSR is damaged by the hydrogen fire or explosion. The frequency of this event is the frequency of turbine building hydrogen fires and explosions that are large enough to cause damage to the CSR. To date there have been no hydrogen-related fires or explosions in the U.S. that have impacted safety-related equipment. Even though, it was assumed that those hydrogen events that were reported as fire or explosions in the data base would have the potential to have released large amounts of hydrogen (assuming early ignition did not occur). Thus, these values were 
used in the frequency calculation of a large hydrogen release in the turbine building at the distribution system level. Therefore, the frequency of a large release is similar to the hydrogen fire or explosion frequency calculation, which results in:

$f\left(H_{2} \text { large release event at distribution system level }\right)_{T B}=\frac{2(1)+1}{2(1424 r y)}=1.1 \times 10^{-3} / r y$

Recognizing that, in the event of a large fire inside the CSR, power and control cables for most safety-related equipment (e.g., high pressure injection pumps, component cooling water pumps, residual heat removal and recirculation pumps) could be damaged, an alternate safe shutdown system (ASSS) was installed at the base case plant during the 1982-1984 time frame. The ASSS provides the capability to perform the following critical safety functions: maintenance of reactor subcriticality, core cooling for hot shutdown (through natural circulation and primary system pressure and inventory control), reactor coolant system integrity, secondary heat removal for hot shutdown, long-term decay heat removal, and process monitoring. The power and control cables for the ASSS are routed independently of the CSR. The ASSS is designed to function given a loss of offsite power. Therefore, recovery of critical safetyrelated equipment (given that a large hydrogen fire or explosion damages cabling inside CSR) is possible through the use of ASSS. A probability of nonrecovery [P(ASSS nonrecovery)] from a T/LOCA condition, using the installed ASSS, was obtained from the original base case plant fire PRA. ${ }^{9}$ The calculated mean value of $P$ (ASSS nonrecovery) was estimated to be $4.6 \times 10^{-2}$. This value is comprised of both human error contributions $\left(3.9 \times 10^{-2}\right)$ and hardware-related failures $\left(7 \times 10^{-3}\right)$. This nonrecovery value was developed in the base case PRA fire analysis and modeled the operator action during high-stress level activities.

Thus, the CDF due to failures of the generator hydrogen supply system that lead to damage of the cable spreading room (T/LOCA scenario) is estimated as:

$$
\begin{aligned}
C D F_{C S R \text { (nonseismic) }}= & f\left(H_{2} \text { large release event at distribution system level }\right) P(\text { delayed ignition } \\
& \text { at distribution system level }) P(\text { blast propagation }) P(\text { ASSS nonrecovery) }) \\
= & \left(1.1 \times 10^{-3} / r y\right)\left(1 \times 10^{-1}\right)\left(1 \times 10^{-1}\right)\left(4.6 \times 10^{-2}\right) \\
= & 5.1 \times 10^{-7} / r y
\end{aligned}
$$

6.2.4.2 Turbine Building T/LOCA Seismic Analysis. The generator hydrogen distribution system at the base case plant consists of small bore piping and valves (less than 3 in. in diameter) of high quality industrial grade. The piping system includes both portions that have threaded joints, as well as portions that are welded. The features and seismic response characteristics of the generator hydrogen distribution system are similar to those of small bore pipe utilized in balance of plant (BOP) systems and dry fire protection systems (FPS). Based on those considerations, the hydrogen gas system fragility was assumed to be similar to that estimated for a dry, small bore fire protection piping system installed at the base case plant. ${ }^{33}$ The probability of seismic-induced failure for the hydrogen 
distribution system is evaluated by convolving the seismic hazard probability distribution with the seismic fragility of the hydrogen supply system. If the seismic hazard and fragility are known with certainty, there will be a single hazard curve and a single fragility curve, and the result of the convolution is a single value of the annual frequency of hydrogen system failure. The Lawrence Livermore National Laboratory seismic hazard curve results (from NUREG/CR-5250-V2) ${ }^{37}$ for the $W$ plant site were used for the base case seismic analysis. The $W$ seismic hazard curve is presented in Figure 11.

As previously stated, the generator hydrogen gas system fragility at the $W$ plant is similar to that of dry, small bore pipe with threaded joints. Its fragility estimate is shown below: ${ }^{33}$

$$
\begin{aligned}
\text { HCLPF } & =0.34 \mathrm{~g} \\
\hat{\boldsymbol{A}} & =1.1 \mathrm{~g} \\
\boldsymbol{\beta}_{c} & =0.5
\end{aligned}
$$

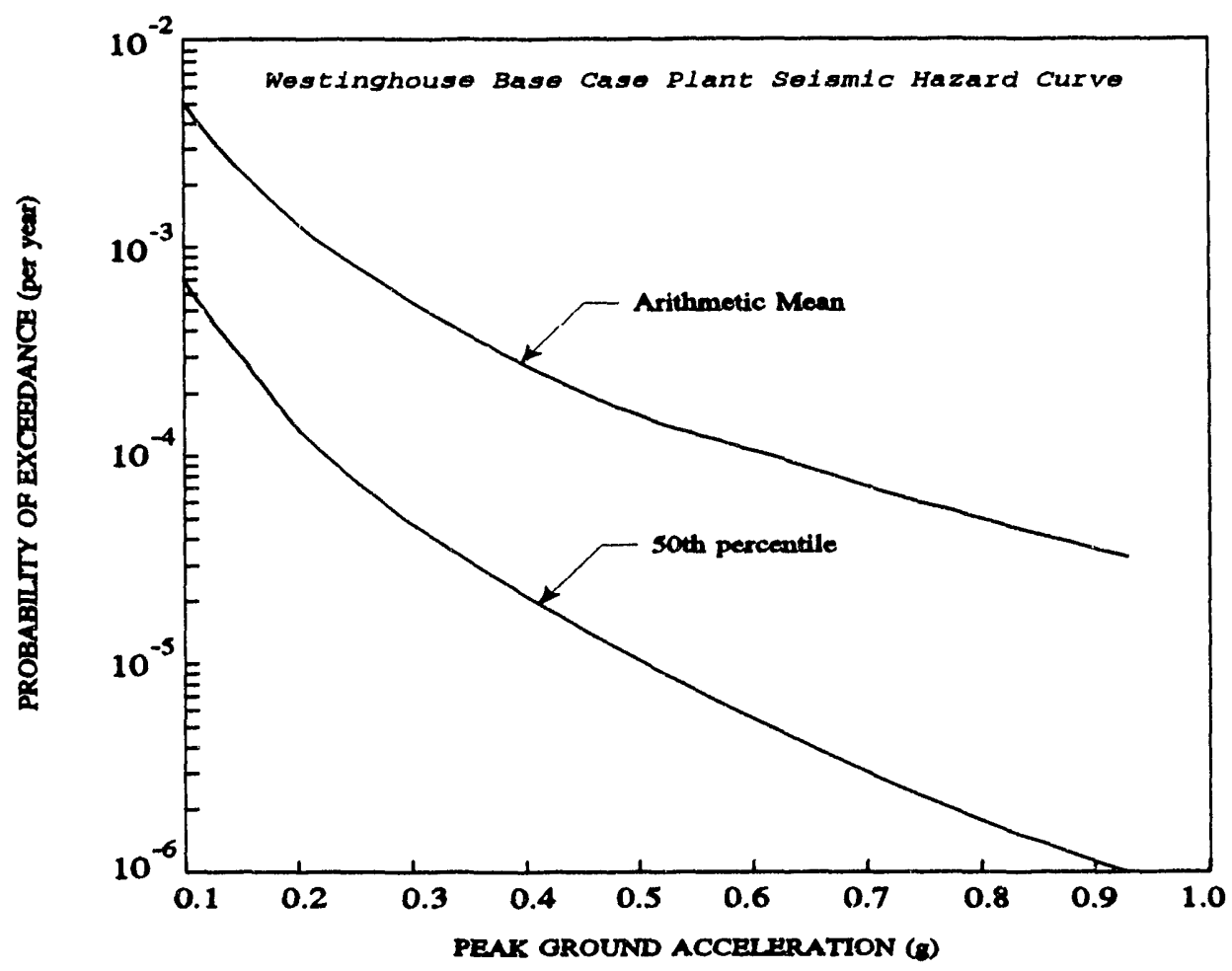

Figure 11. Westinghouse base case seismic hazard curves. 
where

HCLPF = high confidence low probability of failure [peak ground acceleration level (g) below which pipe failure will not occur (with an upper bound confidence)]

$\hat{\boldsymbol{A}} \quad=\quad$ median ground acceleration capacity for the hydrogen pipe

$\beta_{c} \quad=\quad$ logarithmic standard deviation associated with the randomness and uncertainty of the capacity $\hat{A}$.

The probability of pipe failure, $\mathrm{P}_{\mathrm{f}}(\mathrm{g})$, for a given peak ground acceleration level is obtained from:

$$
P_{f}(g)=\Phi\left(\frac{\ln (g / \hat{A})}{\beta_{c}}\right)
$$

where $\Phi$ is the standard Gaussian cumulative distribution function, and $g, \hat{A}$, and $\boldsymbol{\beta}_{c}$ are defined above.

The annual frequency of seismic-induced failure for the hydrogen distribution system at the $W$ plant was evaluated by integrating the composite pipe failure probability and frequency of specific $\mathrm{g}$ levels as recommended in NUREG/CR-2300 21 as:

$$
F_{g}=\int P_{f}(g) f(g) d g
$$

This results in a mean seismic pipe failure frequency of $5.3 \times 10^{-5} /$ year.

The conditional probability of disabling multiple safety-related equipment in the cable spreading room and the probability of seal LOCA nonrecovery using the ASSS are assumed to be similar to those presented in Subsection 6.2.4.1 (i.e., $1 \times 10^{-2}$ and $4.6 \times 10^{-2}$, respectively).

Thus, the CDF due to seismically-induced failures of the hydrogen supply system that lead to damage of the cable spreading room safety equipment is estimated to be:

$$
\begin{aligned}
C D F_{C S R \text { (seismic) })=} & f(\text { seismic pipe failure in turbine building }) \\
& P(\text { delayed ignition at distribution system level }) \\
& P(\text { blast propagation }) P(\text { ASSS non-recovery }) \\
= & \left(5.3 \times 10^{-5} / r y\right)\left(1 \times 10^{-1}\right)\left(1 \times 10^{-1}\right)\left(4.6 \times 10^{-2}\right) \\
= & 2.4 \times 10^{\circ} / r y
\end{aligned}
$$


In the original $W$ base case PRA, ${ }^{9}$ the total CDF from seismic-caused events was calculated to be $7.7 \times 10^{-6} / \mathrm{ry}$. When compared against this value, a seismic-induced hydrogen fire or explosion in the turbine building was judged to be an insignificant contributor to $W$ plant total CDF.

\subsection{Auxiliary Building Analysis}

6.3.1 Auxiliary Building Hydrogen Gas System Configuration. The hydrogen gas system supplying the VCT is independent of the electrical generator supply system. It consists of a 12-bottle hydrogen storage facility located adjacent to the north wall of the primary auxiliary building (PAB) on the 80-ft elevation, which is also ground level for that side of the PAB. A hydrogen truck skid, stationed approximately $200 \mathrm{ft}$ from the 12-bottle hydrogen storage facility, provides refilling capability through a 1-in. diameter, field-run pipe. The bank is for normal service and the truck (which is typically isolated) is used as a backup. The hydrogen storage facility is housed in a metal shed open to outside air circulation. The metal shed provides weather protection and could also act as a blowout panel in the event of a hydrogen explosion, thus reducing the impact on the PAB wall. Located inside the metal shed are a pressure reducing station (and associated valves) and portions of the hydrogen piping system.

The system does not have excess flow check valves or any flow limiting device other than the pressure regulator. Each bottle contains about $200 \mathrm{scf}$ of hydrogen at a pressure of about $2000 \mathrm{psig}$. The gas bottles are interconnected (via a header) to form an active bank (six bottles) and a reserve bank (six bottles). The header's pressure (after it is reduced) is maintained in the range of 90 to $100 \mathrm{psig}$. It is protected from overpressurization by a relief valve. The atmospheric side of the relief valve is fitted with a flame arrester. Various plant administrative controls are implemented to prevent hydrogen fires or explosions when working in the vicinity of the hydrogen gas cylinders and lines (e.g., use of sparkless tools, posting "no smoking" and other signs). The hydrogen storage area is toured by auxiliary operators on their shift tours.

After leaving the hydrogen storage facility, the hydrogen pipe enters the PAB corridor, fire zone 7A (FZ-7A), at the 92- $\mathrm{ft}$ elevation, runs through a portion of FZ-7A for about $25 \mathrm{ft}$, then enters and runs through the pipe chase (FZ-30A) for approximately $20 \mathrm{ft}$, and finally enters the VCT cubicle and tank (FZ-23A at the $98 \mathrm{ft}$ elevation of the PAB). Figures 12 and 13 show a schematic of the hydrogen storage facility, the hydrogen pipe run through the $\mathrm{PAB}$, and the fire zones within the $\mathrm{PAB}$ that contain hydrogen gas system pipe lines. Inside the PAB the hydrogen pipe is seismically anchored.

Inside the VCT, for charging pumps operation, the hydrogen blanket is maintained at a pressure of $15 \mathrm{psig}$ or greater by a pressure regulator. During plant operation, the hydrogen concentration inside the VCT is greater than $90 \%$ by volume. The Technical Specifications (TS) maximum allowable oxygen concentration in the VCT vapor is $2 \%$ by volume (TS 3.9.B.6). Typically, the nominal oxygen concentration is much less than $2 \%$ by volume. 


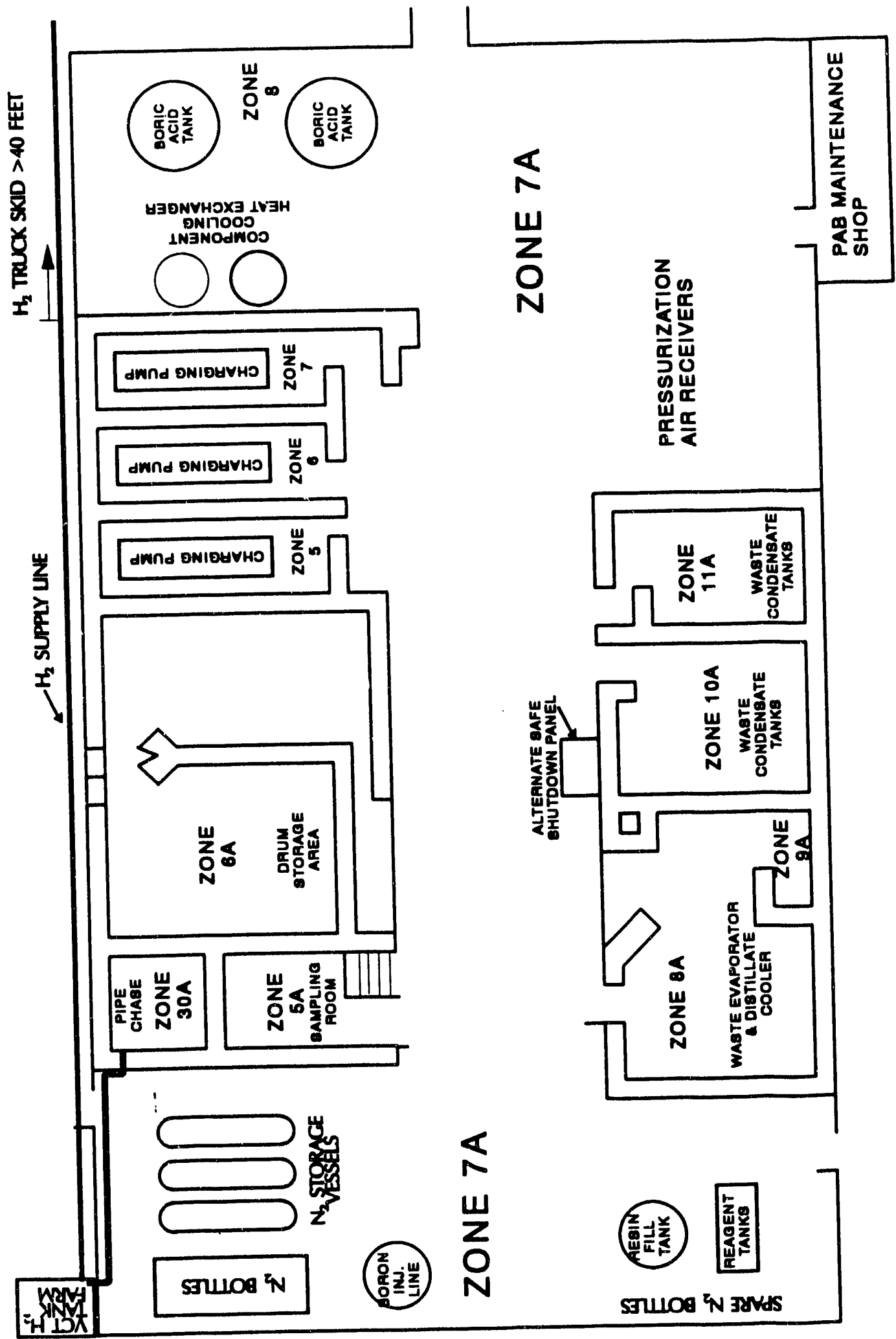

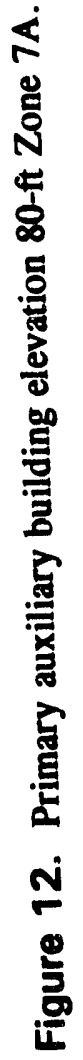




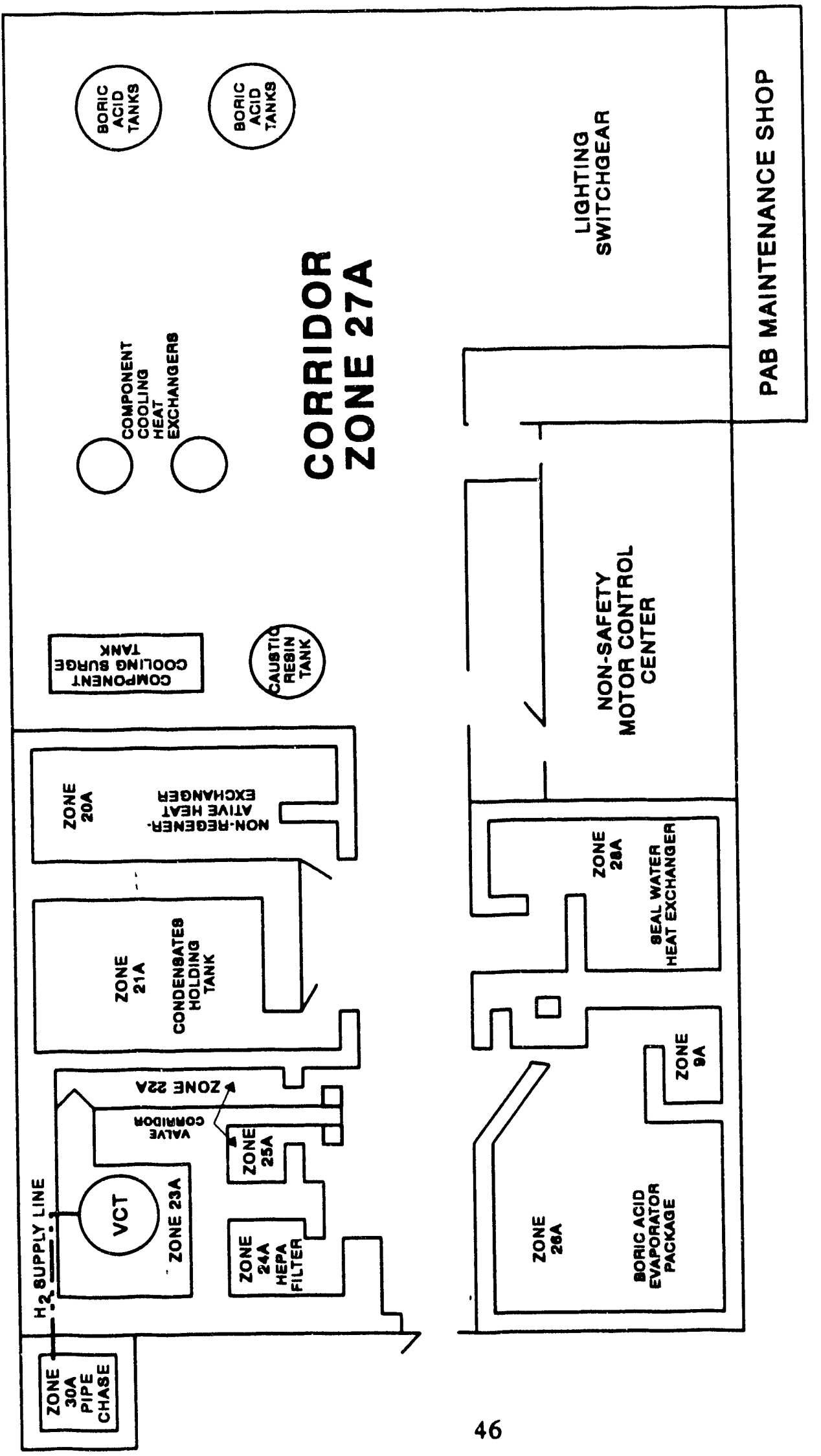

సิ 
6.3.2 Auxiliary Building Vital Area Analysis. In a vital area analysis, an area in the plant is characterized as vital if the result of failure of some or all the components in the area causes core damage. For the base case plant, this was accomplished by identifying the zones containing hydrogen lines and then mapping safety-related components to areas (fire zones) in the PAB in which they reside. Physical zone boundaries were examined and most fire zones were screened out based on the following criteria:

1. No safety-related components are present in fire zone

2. Fire zone containing safety equipment was located two or more floor levels below zone containing hydrogen lines.

Table 4 presents the locations inside the PAB (fire zones) containing the hydrogen gas distribution system. Included in the table is information on the amount of hydrogen pipe system present in each fire zone, safety-related components present in each zone, and their location with respect to the hydrogen lines.

Table 4. PAB fire zones considered in base case plant analysis.

\begin{tabular}{|c|c|c|}
\hline & & PAB Fire Zones \\
\hline $\begin{array}{l}\text { PAB Zone } \\
\text { with } \mathrm{H}_{2}\end{array}$ & $\begin{array}{c}\text { Percent of } \mathrm{H}_{2} \\
\text { System in } \\
\text { Zone }^{\mathrm{a}}\end{array}$ & $\begin{array}{c}\text { Safety-Related Components and Their Approximate } \\
\text { Distance from } \mathrm{H}_{2} \text { Lines }\end{array}$ \\
\hline \multicolumn{3}{|c|}{$80 \mathrm{ft}$ Elevation } \\
\hline$F Z-7 A^{b}$ & 12.5 & $\begin{array}{l}\text { Electrical cables for charging pumps }(@ 30 \mathrm{ft}) \\
\text { Alternate shutdown panel (@ } 70 \mathrm{ft}) \\
\text { Component cooling water (CCW) heat exchangers (HXs) } \\
\text { (@100 ft) } \\
\text { Boric acid tanks (@120 ft) }\end{array}$ \\
\hline FZ-30A & 10.0 & Service water piping (@ $50 \mathrm{ft}$ ) \\
\hline \multicolumn{3}{|c|}{$98 \mathrm{ft}$ Elevation } \\
\hline FZ-23A & 50.0 & None \\
\hline \multicolumn{3}{|c|}{ a The remaining $27.5 \%$ of the $\mathrm{H}_{2}$ piping system is outside of the PAB. } \\
\hline \multicolumn{3}{|c|}{$\begin{array}{l}\text { b The most critical safety-related components in FZ-7A are CCW HXs. Their loss would lead to } \\
\text { core damage due to reactor coolant pump (RCP) seal LOCA. }\end{array}$} \\
\hline
\end{tabular}


As indicated in Table 4, the PAB fire zones containing portions of the hydrogen gas system are FZ-7A, FZ-23A, and FZ-30A. The following determinations were made based on the plant vital area analysis:

FZ-7A. (1) The most critical safety-related conponents in FZ-7A are CCW heat exchangers. Their loss would lead to core damage due to reactor coolant pump (RCP) seal LOCA. However, given the large distance (about $100 \mathrm{ft}$ ) separating the hydrogen lines and the $\mathrm{CCW}$ heat exchangers, the concrete walls (each at least $2 \mathrm{ft}$ thick) that are present between the hydrogen pipe and $\mathrm{CCW}$ heat exchangers (see Figure 12), and the relatively small quantity of hydrogen $(2400 \mathrm{scf})$ available online from the hydrogen storage facility, it is concluded (based on engineering judgment) that a hydrogen explosion at the 80-ft elevation of the PAB would not lead to the loss of the CCW heat exchangers.

(2) The safety-related components located closest to the hydrogen gas lines are the electric (control) cables for charging pumps 21,22 , and 23. Since these pumps are of positive displacement type, the original base case plant PRA did not take any credit for these pumps in its analysis (i.e., pumps are assumed not being used for any accident mitigation functions). This is a conservatism in the plant PRA analysis and in the INEL's evaluation.

FZ-23A. This fire zone contains the VCT. There are no safety-related components inside the zone or in any of the adjacent zones. The VCT is enclosed in a concrete cubicle with walls approximately 3.5 - $\mathrm{ft}$ thick.

FZ-30A. Piping bay and tunnel (pipe chase) are represented by this fire zone. The 1-in. diameter hydrogen pipe enters the pipe chase at the $92-\mathrm{ft}$ elevation and exits at the 108- $\mathrm{ft}$ elevation. The only safety-related components present in the zone are some of the service water piping lines (less than 6 in. in diameter). The service water piping is seismic category I (i.e., it is fully anchored). The pipes are made of steel (schedule 80 or above) and are not susceptible to fire damage. In addition to the service water piping, the pipe chase contains numerous nonsafety piping in a very compact configuration. Air circulation is provided to the pipe chase by the primary auxiliary building ventilation system. Because the service water lines, located about 40 to $50 \mathrm{ft}$ from the 1-in. hydrogen gas pipe (going up to the VCT), are seismically supported, and the vertical pipe chase is well ventilated (which prevents hydrogen gas buildup in the event of a pipe leak or rupture), it is very unlikely for a hydrogen event to have an impact on the plant safety functions (and equipment). Should a localized hydrogen concentration in the pipe chase occur, there are no ignition sources there. Additionally, with such a small volume of hydrogen, all the available energy would be dissipated in breaching the fire zone barriers, causing only local damage.

6.3.3 Transient with Loss of Decay Heat Removal-Primary Auxiliary Building. Based on 917 reactor-year industry experience (PWRs only), there have been 11 events involving the VCT hydrogen system (refer to Section 3 and Appendix A for details). All events were small hydrogen leaks and most occurred either through the pressure regulator or other valves associated with the VCT 
hydrogen system. One event was caused by human error (inadequate sampling procedures). Some of the events were discovered following alarms on the radiation monitoring system (i.e., they also involved releases of radioactive xenon 133 and 135 gases). None of the events reported hydrogen concentration readings near or above the lower flammability limit for hydrogen (about $4.1 \%$ by volume in air).

The review of the auxiliary building hydrogen events indicates the following:

- No fires or explosions have ever occurred inside the auxiliary buildings from events associated with the VCT hydrogen supply system

$\bullet$ No safety-related components (or their functions) were ever affected by hydrogen fires or explosions inside the PAB

- Hydrogen events (e.g., leaks) that have occurred while the plant was at power did not lead to a turbine/reactor trip (shutdown).

6.3.3.1 Auxiliary Building T/DHR Nonseismic Analysis. One possible scenario postulated for the base case PAB analysis assumes a small hydrogen fire or explosion in the auxiliary building as the accident initiator. The turbine trips automatically or is manually initiated by plant personnel (out of tolerance condition). The direct damage caused by the hydrogen event does not prevent the use of any of the plant safety systems that reside or pass through the three fires zones containing portions of the hydrogen system. The new accident sequences for fire zones $7 \mathrm{~A}, 23 \mathrm{~A}$, and $30 \mathrm{~A}$, are modeled using the general turbine trip event tree.

The general turbine trip event tree is illustrated in Figure 14. The first four top events determine the accident sequences that lead to core damage. The last three top events establish the plant damage state given that the core suffers damage. The plant damage state categories influence the release of radioactive material to the containment and therefore have an impact on the potential risk to the public. Appendix E provides a detailed descriptions of the event tree top events. The functions and systems modeled by the top events are briefly described in Table 5 .

Using Equation (1), the mean frequency for this hydrogen fire or explosion initiating event is calculated to be $5.5 \times 10^{-4} /$ ry (see discussion in Appendix B). Since no changes occur in the availability of the safety-related components (from that modeled in the original PRA), the original CSFs values were used for the event tree top events.

The core damage sequences for this scenario sum to less than $1 \times 10^{-9} / \mathrm{ry}$. This represents an insignificant increase when compared to both the mean CDF from all general turbine trip events $(1.0 \times$ $10^{-6} /$ ry) and the total plant mean CDF of $1.4 \times 10^{-4} /$ ry of the original $W$ plant PRA (internal plus external events).

6.3.3.2 Auxiliary Building T/DHR Seismic Analysis. Key portions of the $W$ plant hydrogen distribution system inside the PAB are seismically qualified (i.e., seismic mounting is used). As discussed previously, the hydrogen piping consists of small-bore type pipe (e.g., 1 to 3 in. diameter). 

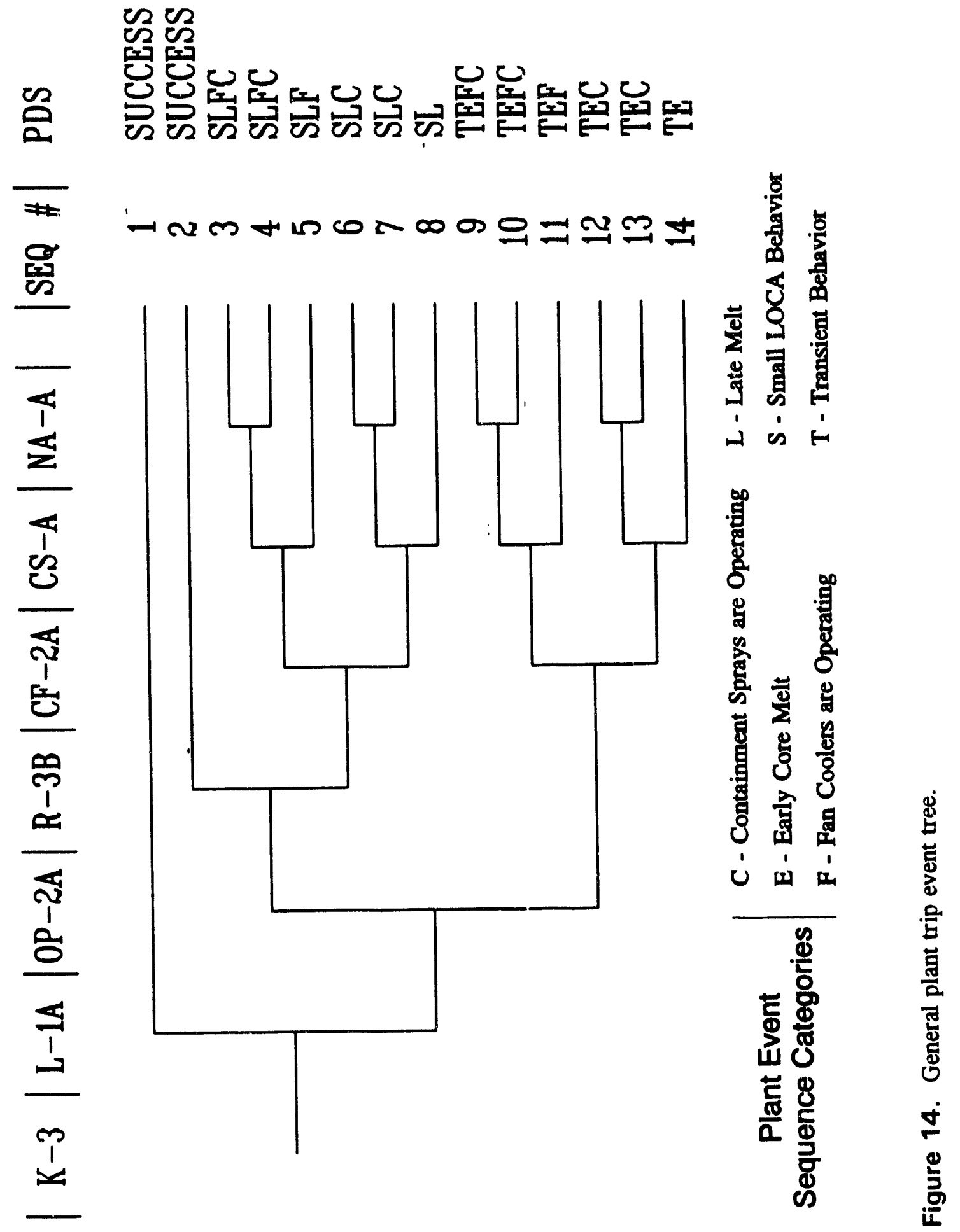
Table 5. General turbine trip event tree top events.

\begin{tabular}{lll}
\hline Name & Probability & Description \\
\hline K-3 & $2.0 \times 10^{-5}$ & Probability of a reactor trip failure \\
L-1A & $1.9 \times 10^{-5}$ & Probability of failure of auxiliary feedwater and secondary cooling \\
OP-2A & $6.1 \times 10^{-3}$ & Probability of failure of primary cooling/feed and bleed \\
R-3B & $5.0 \times 10^{-4}$ & Probability of failure of recirculation cooling \\
CF-2A & $5.0 \times 10^{-6}$ & Probability of failure of containment fan coolers \\
CS-A & $8.1 \times 10^{-5}$ & Probability of failure of containment spray system \\
NA-A & $9.6 \times 10^{-4}$ & Probability of failui of sodium hydroxide addition system
\end{tabular}

Several studies ${ }^{32,37,38}$ sponsored by the NRC have concluded that small diameter piping systems (including valves) typically have a very large seismic capacity (i.e., their failure given low-g earthquakes is unlikely) and are not consider $\mathrm{d}$ to be primary failure initiators. Although this is true for the piping runs themselves, connections to equipment may be vulnerable to seismic failure. This is especially the case if the equipment is not adequately anchored or the design of the connecting pipe does not allow adequate flexibility. Since the plant hydrogen gas system is seismically anchored, no damage is expected in the higher frequency, relatively low g-level earthquakes (e.g., $0.05 \mathrm{~g}$ ). II a severe earthquake (e.g., $0.80 \mathrm{~g}$ ), seismic-induced hydrogen fire/explosion contributions will be relatively small compared to the direct darnage caused by the earthquake itself (already considered by the $W$ plant seismic PRA). For example, a severe earthquake may initiate a transient event, most likely a loss of offsite power (LOSP), due to failure of offsite power transformer ceramic insulators. Loss of primary cooling equipment (needed for the F\&B function) could occur due to failure of either the refueling water storage tank (RWST), power operated relief valves, or piping". For the same level earthquake, the RWST, since it has a lower seismic capacity than the small-bore hydrogen system piping $(0.70 \mathrm{~g}$ vs. $2.29 \mathrm{~g}){ }^{9}{ }^{9}$ will fail before damage to the hydrogen lines can occur. Because the hydrogen system for the VCT is seismically qualified, the core damage contribution resulting directly from hydrogen fires or explosions induced by earthquakes is insignificant.

6.3.4 Transient-Induced Loss-of Coolant Accident-Primary Auxiliary Building. The most critical safety-related components in FZ-7A are CCW heat exchangers. Their loss would lead to core damage due to reactor coolant pump (RCP) seal LOCA (i.e., T/LOCA accident scenario). However, given the large distance (about $100 \mathrm{ft}$ ) separating the hydrogen lines and the $\mathrm{CCW}$ heat

\footnotetext{
${ }^{a}$ It is assumed that piping failure includes the hydrogen system, which may lead to a hydrogen fire or explosion that disables primary cooling system equipment such as the safety injection pumps.
} 
exchangers, the concrete walls (each at least $2 \mathrm{ft}$ thick) that are present between the hydrogen pipe and CCW heat exchangers (see Figure 12), and the relatively small quantity of hydrogen ( $2400 \mathrm{scf}$ ) available online from the hydrogen storage facility, it is concluded (based on engineering judgment) that a hydrogen explosion at the 80-ft elevation of the PAB would not lead to the loss of the CCW heat exchangers. Therefore, T/LOCA accident scenarios are assumed not to be applicable to the base case plant auxiliary uuilding.

\subsection{Hydrogen Storage Facility Analysis}

6.4.1 Hydrogen Storage Facility Description. As discussed in the previous subsections, the hydrogen supply at the $W$ plant consists of two separate systems. One system provides hydrogen for main generator cooling, and a smaller system comprising two separate storage areas supplies the cover gas for the VCT. Each of the three storage areas will be addressed separately below.

6.4.1.1 Generator Hydrogen Storage Facility Configuration. The W plant hydrogen gas supply for the main generator is a 45-bottle hydrogen storage facility located approximately $135 \mathrm{ft}$ west of the turbine building and about $300 \mathrm{ft}$ south of the service water pumps at the $15-\mathrm{ft}$ elevation (ground level). The closest air intake is for the control room at a distance of about $300 \mathrm{ft}$. The 45 bottles are configured with 18 online bottles supplying the active manifold, 18 bottles supplying the reserve manifold, and 9 bottles supplying the emergency reserve manifold. Each bottle contains about $1,150 \mathrm{scf}$ of hydrogen at a pressure of about $1,500 \mathrm{psig}$, for a total of about $52,000 \mathrm{scf}$. A hydrogen fill connection is located at the front of the hydrogen storage facility enclosure.

The hydrogen storage facility is protected by a concrete roof. It is open on three sides and the fourth side is a brick wall separating the facility from a bulk liquid oxygen storage tank. Also located under the concrete roof are a pressure reducing station and associated valves, and portions of the hydrogen piping system. The high-pressure (1500 psig) piping has a diameter of $3 / 4$ in. and only connects the storage bottles to the pressure reducing station at the hydrogen storage facility. The lowpressure (125 psig) piping is 1.5 -in. diameter, and runs from the hydrogen storage facility to the west wall of the turbine building. This line is underground at the 9 - $\mathrm{ft}$ elevation.

6.4.1.2 VCT Hydrogen Storage Facility Configuration. The hydrogen gas system supplying the VCT consists of a 12-bottle hydrogen storage facility located adjacent to the north wall of the PAB at the 80-ft elevation, which is also ground level for that side of the PAB. Between the VCT hydrogen storage facility and the safety-related portions of the PAB (over 30-ft separation distance) is the enclosed $\mathrm{N}_{2}$ storage area for the boron injection system. The safety-related PAB wall is at least $2 \mathrm{ft}$ thick. The air intake for the diesel generators is about $90 \mathrm{ft}$ west. A hydrogen truck skid stationed about $200 \mathrm{ft}$ from the VCT hydrogen storage facility provides refilling capability. Each bottle contains about $200 \mathrm{scf}$ of hydrogen at a pressure of about $2,000 \mathrm{psig}$. 
The VCT hydrogen storage facility is housed in a metal shed open to outside air circulation. The metal shed provides weather protection and could also act as a blowout panel in the event of a hydrogen explosion. Located inside the metal shed are a pressure reducing station (and associated valves), and portions of the hydrogen piping system.

6.4. 1.3 Hydrogen Truck Skid Configuration. A truck skid is used on a semi-permanent basis to refill the VCT hydrogen storage facility bottles. The truck skid station is located about $200 \mathrm{ft}$ east of the VCT hydrogen storage facility, adjacent to the northeast corner of the boric acid evaporator building. A 1-in. field-run pipe attached to the north side of the boric acid evaporator building, the boric acid tank building, and the PAB connects the truck skid to the VCT hydrogen storage facility.

The truck skid contains 32 hydrogen tubes, each with a volume of approximately $1,000 \mathrm{scf}$ of hydrogen at about $2,000 \mathrm{psig}$, for a total of about $32,000 \mathrm{scf}$. Though not safety related from a reactor perspective, the boric acid evaporation building has approximately 2 -ft-thick walls for shielding.

\subsubsection{Hydrogen Storage Facility Vital Area Analysis}

6.4.2.1 Generator Hydrogen Storage Facility Vital Area Analysis. The main generator hydrogen storage facility supply meets the EPRI criteria for safe separation distance ${ }^{12}$ from safety-related structures and air intakes (see Table 6). These criteria consider the hazards from hydrogen detonations (in air), and for transport of uncombusted $\mathrm{H}_{2}$ into the ventilation air intakes of safety-related buildings. EPRI criteria do not address hydrogen detonations in oxygen-rich environments (comparable to that possible at the base case plant between a generator hydrogen bottle and the liquid oxygen tank). The nearest safety-related building is the service water pump building (approximately $300 \mathrm{ft}$ away). Hydrogen explosions experts at INEL have stated that given the significant distance between the generator hydrogen storage facility and the service water pump building, the hydrogen detonation impulse generated is not considered to be a threat to that building. Therefore, no further consideration was required for this hydrogen storage facility.

Table 6. W plant generator hydrogen storage facility comparison with EPRI separation criteria.

\begin{tabular}{cccc}
\hline Event & $\begin{array}{c}\text { Nearest Safety-Related } \\
\text { Building }\end{array}$ & $\begin{array}{c}\text { EPRI } \\
\text { Criteria } \\
(\mathrm{ft})\end{array}$ & $\begin{array}{c}\text { Actual } \\
\text { Separation } \\
(\mathrm{ft})\end{array}$ \\
\hline Explosion & Service Water Pump Building & 22 & 300 \\
Air Intake & Control Room & $>170$ & 300 \\
\hline
\end{tabular}

6.4.2.2 'VCT Hydrogen Storage Facility Vital Area Analysis. The VCT hydrogen storage facility meets the EPRI safe separation distance criterion for hydrogen explosion (see Table 7). In addition, the $W$ plant PAB wall is greater than 24 in. thick while the EPRI criteria are based on an 18-in. wall. The VCT hydrogen storage facility does not meet the distance criterion for safety-related 
building air intakes, however. The guidelines call for a separation distance of $225 \mathrm{ft}$ (based on a 1-in.diameter pipe) to the nearest safety-related air intakes (i.e., distance ensures that uncombusted hydrogen cloud concentration will be less than $4 \%$ by volume when it reaches the air intakes).

Table 7. W plant VCT hydrogen storage facility comparison with EPRI separation criteria.

\begin{tabular}{cccc}
\hline Event & $\begin{array}{c}\text { Nearest Safety-Related } \\
\text { Building }\end{array}$ & $\begin{array}{c}\text { EPRI } \\
\text { Criteria } \\
(\mathrm{ft})\end{array}$ & $\begin{array}{c}\text { Actual } \\
\text { Separation } \\
(\mathrm{ft})\end{array}$ \\
\hline Explosion & Primary Auxiliary Building & 8 & 10 \\
Air Intake & Diesel Generator Building & 225 & 90 \\
\hline
\end{tabular}

The EPRI separation criterion for air intakes is based on the potential to develop a concentration of $4 \%$ hydrogen (lower flammability limit) at the air intake. The separation curves were developed using a jet dispersion model with the jet oriented directly toward the safety-related structure. At the $W$ plant, the VCT hydrogen storage facility is located on the 80-ft elevation of the northwest corner of the PAB. The diesel generator building is south of the PAB, on the 67-ft level. Between the hydrogen storage facility and the diesel generator building is the $98-\mathrm{ft}$ elevation of the PAB (overall building height is $116 \mathrm{ft}$ ). For a hydrogen cloud to reach the diesel generator building air intake, it would require going up $36 \mathrm{ft}$ over the PAB wall, traveling over $70 \mathrm{ft}$ of the PAB in a southerly direction, and dropping down about $50 \mathrm{ft}$ to the diesel generator building. This is judged to border on the impossible. Therefore, it is concluded that a catastrophic VCT hydrogen storage facility release at $W$ plant is unlikely to contribute to the overall CDF.

6.4.2.3 Truck Skid Vital Area Analysis. The truck skid meets the EPRI safe separation distance criterion for hydrogen explosion (see Table 8). In addition, the boric acid evaporator building (nonsafety-related) shields the PAB from the truck skid. The truck skid does not meet the safe distance criterion for safety-related building air intakes, however. EPRI guidelines call for a separation distance of $225 \mathrm{ft}$ (based on a 1-in. diameter pipe) for air intakes.

Table 8. W plant truck skid comparison with EPRI separation criteria.

\begin{tabular}{cccc} 
& Nearest Safety-Related & EPRI & Actual \\
Building & $\begin{array}{c}\text { Criteria } \\
(\mathrm{ft})\end{array}$ & $\begin{array}{c}\text { Separation } \\
(\mathrm{ft})\end{array}$ \\
\hline Explosion & Primary Auxiliary Building & 22 & 40 \\
Air Intake & Diesel Generator & 225 & 90 \\
\hline
\end{tabular}


The EPRI separation criterion for air intakes is based on the potential to develop a concentration of $4 \%$ hydrogen (lower flammability limit) at the air intake. The separation curves were developed using a jet dispersion model with the jet oriented directly toward the safety-related structure. At the $W$ plant, the truck skid is located on the 80-ft elevation of the southeast corner of the PAB. The diesel generator building is south of the PAB on the 67-ft level. Between the hydrogen storage facility and the diesel generator building is the $91-\mathrm{ft}$ elevation of the boric acid evaporator building (overall building height is about $105 \mathrm{ft}$ ). For a hydrogen cloud to reach the diesel generator building air intake, it would require going up $25 \mathrm{ft}$ over the boric acid evaporator building wall, traveling over $40 \mathrm{ft}$ of the boric acid evaporator building, and dropping down about $40 \mathrm{ft}$ to the diesel generator building. As with the VCT hydrogen storage facility, this is judged to border on the impossible. Therefore, it is concluded that a catastrophic hydrogen release from the truck skid at the $W$ plant is unlikely to contribute to the overall CDF.

\subsection{Uncertainty Analysis for the $W$ Plant}

An uncertainty analysis was performed on the scenarios from the previous subsections. Table 9 contains the random variables contained in the $W$ base case analysis. The random variables are presented with their associated distribution and parameters. Appendix B contains a detailed derivation on the hydrogen initiating event (gamma) distributions and the conditional probability beta distributions. The lognormal distributions were assumed for most uncertainty distributions where operating data were not available. The standard deviation values for the delayed ignition and blast propagation probabilities comes from the assumption that the lognormal error factor is equal to 10 . The results for the base case analysis is given in Subsection 6.6

\subsection{W Plant Analysis Results}

The CDF results for $W$ base case are presented in Table 10 . The mean value, along with the percentile parameters (5th, 50th, 'and 95th), are presented for each base case hydrogen scenario analyzed. The total overall CDF contribution from hydrogen fire or explosion events for the $W$ base case plant is $7.1 \times 10^{-7} /$ ry. This CDF contribution is insignificant when compared to the $W$ plant original total CDF of $1.4 \times 10^{-4} /$ ry (internal and external events). ${ }^{9}$

\subsection{Hydrogen Events During Operating Modes Other Than Full Power}

Appendix $C$ discusses the differences between the full-power case and the cases where the reactor is in any other operating mode.

During some low power operations (e.g., those associated with ascending and decreasing power to and from full power) the generator cooling system remains charged with hydrogen and the hydrogen supply is sustained as it is during power operation. The hydrogen is generally purged from the generator during maintenance activities and from the VCT if the reactor will be in a shutdown state for a prolonged time period [e.g., cold shutdown (Mode 5), refueling (Mode 6)]. Since the hydrogen sources are not typically present during generator maintenance activities, the reactor is not considered to be vulnerable from hydrogen-induced events. 
Table 9. Random variables for $W$ base case CDF.

\begin{tabular}{|c|c|c|}
\hline Random Variable & Distribution & Parameters \\
\hline $\begin{array}{l}\mathbf{f}\left(\mathrm{H}_{2} \text { fire or explosion at }\right. \\
\text { generator floor level })\end{array}$ & Gamma & $\begin{array}{c}\alpha=8.5 \\
\beta=7.02 \times 10^{-4} / \mathrm{ry}\end{array}$ \\
\hline $\begin{array}{c}\mathrm{f}\left(\mathrm{H}_{2} \text { large release event at }\right. \\
\text { distribution system level })\end{array}$ & Gamma & $\begin{array}{l}\alpha=1.5 \\
\beta=7.02 \times 10^{-4} / \mathrm{ry}\end{array}$ \\
\hline $\mathrm{P}\left(\mathrm{SLB} \backslash \mathrm{H}_{2}\right.$ fire or explosion $)$ & Beta & $\begin{array}{l}\alpha_{1}=0.5 \\
\alpha_{2}=8.5\end{array}$ \\
\hline $\mathrm{P}($ seismic pipe failure $)$ & Lognormal & $\begin{aligned} \text { mean } & =5.3 \times 10^{-5} \\
\text { std.dev. } & =1.87 \times 10^{-3}\end{aligned}$ \\
\hline $\mathrm{P}$ (core damagelSLB) & Lognormal & $\begin{array}{c}\text { mean }=1.02 \times 10^{-4} \\
\text { std.dev. }=9.44 \times 10^{-5}\end{array}$ \\
\hline P(ASSS nonrecovery) & Lognormal & $\begin{aligned} \text { mean } & =4.6 \times 10^{-2} \\
\text { std.dev. } & =2.65 \times 10^{-2}\end{aligned}$ \\
\hline $\begin{array}{c}\mathrm{P}(\text { delayed ignition at } \\
\text { distribution system level) }\end{array}$ & Lognormal & $\begin{aligned} \text { mean } & =1.0 \times 10^{-1} \\
\text { std.dev. } & =2.47 \times 10^{-1}\end{aligned}$ \\
\hline $\mathrm{P}$ (blast propagation) & Lognormal & $\begin{aligned} \text { mean } & =1.0 \times 10^{-1} \\
\text { std.dev. } & =2.47 \times 10^{-1}\end{aligned}$ \\
\hline $\begin{array}{c}\mathrm{f} \text { (auxiliary building } \mathrm{H}_{2} \text { fire or } \\
\text { explosion }\end{array}$ & Gamma & $\begin{array}{c}\alpha=0.5 \\
\beta=1.09 \times 10^{-3}\end{array}$ \\
\hline $\mathrm{P}$ (core damagelplant trip) & Lognormal & $\begin{array}{c}\text { mean }=1.29 \times 10^{-7} \\
\text { std.dev. }=2.01 \times 10^{-7}\end{array}$ \\
\hline
\end{tabular}


Table 10. Analysis results for $W$ base case CDF.

\begin{tabular}{|c|c|c|}
\hline Accident Scenario & Parameter & $\mathrm{CDF}$ (/ry) \\
\hline \multirow{4}{*}{$\begin{array}{c}\text { Plant trip from } \mathrm{H}_{2} \text { fire or } \\
\text { explosion in auxiliary building }\end{array}$} & mean & $7.4 \times 10^{-11}$ \\
\hline & 5th & $1.0 \times 10^{-13}$ \\
\hline & 50th & $1.6 \times 10^{-11}$ \\
\hline & 95th & $3.1 \times 10^{-10}$ \\
\hline \multirow{4}{*}{$\begin{array}{l}\mathrm{H}_{2} \text { induced SLB in turbine } \\
\text { building }\end{array}$} & mean & $3.4 \times 10^{-8}$ \\
\hline & 5 th & $9.0 \times 10^{-11}$ \\
\hline & 50 th & $1.0 \times 10^{-8}$ \\
\hline & 95th & $1.4 \times 10^{-7}$ \\
\hline \multirow{4}{*}{$\begin{array}{l}\text { CSR damage from } \mathrm{H}_{2} \text { fire or } \\
\text { explosion in turbine building } \\
\text { (nonseismic) }\end{array}$} & mean & $4.3 \times 10^{-7}$ \\
\hline & 5 th & $1.0 \times 10^{-9}$ \\
\hline & 50th & $3.4 \times 10^{-8}$ \\
\hline & 95th & $1.6 \times 10^{-6}$ \\
\hline \multirow{4}{*}{$\begin{array}{l}\text { CSR damage from } \mathrm{H}_{2} \text { fire or } \\
\text { explosion in turbine building } \\
\text { (seismic) }\end{array}$} & mean & $2.5 \times 10^{-7}$ \\
\hline & 5th & $8.0 \times 10^{-12}$ \\
\hline & 50th & $2.0 \times 10^{-9}$ \\
\hline & 95th & $5.0 \times 10^{-7}$ \\
\hline
\end{tabular}




\section{GENERIC ANALYSES}

\subsection{Introduction}

The previous chapter documented the GSI-106-related risk of a specific W PWR with a plant specific risk analysis. The purpose of the generic analysis documented in this chapter is to address the risks associated with other types of PWRs and other physical arrangements of vital equipment (AFW, diesels, electrical switchgear, essential service water (SW), component cooling water, etc.) relative to hydrogen supply and distribution systems.

\subsection{Methodology for Generic Plant Analysis}

The following two subsections respectively describe the methods used to quantify GSI-106-related risks from in-plant hydrogen sources and external hydrogen storage facilities.

\subsubsection{Methodology Utilized for Evaluating In-Plant Hydrogen Supply and Distribution}

System Risk. Recognizing that it was not practical to evaluate in detail the risks associated with each and every PWR in the United States, a simplified approach is warranted that considers the risks associated with the different PWR design characteristics and different hydrogen system configurations.

Large quantities of hydrogen are not present near primary coolant system piping, hence pipe break loss-of-coolant and steam generator tube rupture scenarios due to hydrogen release events need not be considered in evaluating the risks associated with GSI-106. Given that large quantities of hydrogen are not present near the primary coolant system piping or the control rod drive motors on top of the reactor vessel, transient events with failure to scram the reactor (ATWS type events) due to hydrogen release events need not be considered in evaluating GSI-106 risks. This leaves only transient-induced core melt scenarios.

The remaining transient-induced core melt scenarios are of two types: transients with failure of decay heat removal systems and transient-induced LOCAs. Transients with failure of decay heat removal systems are a broad class including everything from simple turbine trips to steam line breaks. A basic feature of such scenarios is that all forms of core cooling are lost, the reactor coolant system is at elevated pressure, and coolant inventory is released out of the pressurizer PORVs or safety valves.

Conversely, transient-induced LOCAs involve failure of RCS makeup or recirculation following a consequential RCP seal LOCA (caused by inadequate RCP seal cooling) or PORV LOCA (caused by stuck open PORVs or safety valves). This category includes events such as station blackout and loss of component cooling water.

To quantify the GSI-106 associated risks for various plants, core melt frequency expressions were developed, including the initiating event frequency (typically the hydrogen release scenario frequency for random and seismic-induced releases) and the probabilities of various mitigating systems failing. 
The standard event tree quantification approach was not utilized because of a lack of the necessary plant specific information needed to quantify all event tree paths. Due to considerations of equipment location in a given plant, a coupling can exist between the initiator frequency and one or more of the system failure probabilities. This was handled by modifying the CDF expression as follows:

$$
\begin{aligned}
C D F= & f(\text { initiator }) P(\text { system } A) P(\text { system } B) \\
= & f\left(\mathrm{H}_{2} \text { release }\right) P\left(H_{2}\right. \text { fire or explosion disabling } \\
& \text { system } A \text { and system } B)
\end{aligned}
$$

$A_{1}$ key facet to this type of analysis is the vital area analysis in which hydrogen release and burn scenarios are equated with specific system failure scenarios. Because the intent was to screen a broad cross section of the PWRs in the United States, the level of detail is not what would be employed in a plant specific vital area analysis as discussed in Section 6. Instead, the analysis focused on the key systems involved in the mitigation of the two transient categories. In particular, for transients with loss of decay heat removal, attention is focused on AFW and systems needed for feed-and-bleed (F\&B) cooling. For transient-induced LOCAs, attention is focused on normal and emergency ac power, essential $\mathrm{SW}$, and component cooling water. It is acknowledged there may be some unique plant design feature posing a special vulnerability not considered in the above, but this would properly be a plant-specific versus generic issue concern. In any case, it is beyond the scope of this program to attempt to identify each and every plant-specific safety issue.

Considaring first the transient with loss of decay heat removal scenarios, it is noted that plants can be grouped into several categories. A number of plants have AFW and F\&B systems located in separate buildings away from the hydrogen supplies and distribution systems. In these plants there would be no expected couplings between the initiator event and AFW failure. The complement to this category would be plants that have AFW systems located in the same buildings as a hydrogen system. In this category two levels of AFW dependency can be identified. Many plants are designed in such a way that if all AFW is lost, F\&B cooling can be employed. In general this category embodies almost all $W$ and Babcock and Wilcox (B\&W) PWRs.

ABB Combustion Engineering (CE) PWRs in general do not have the same capability. Newer CE PWRs such as the System 80 design do not have PORVs. Older CE PWRs were not originally designed for F\&B cooling and typically have smaller PORVs, low capacity positive displacement charging pumps, and lower head HPI pumps resulting in only marginal F\&B capability. Attempts have been made to credit F\&B capability in PRAs on some CE PWRs. The problem is that Generic CE Owners Group emergency procedures direct operators to first attempt AFW recovery, then attempt main feedwater recovery, and then depressurize the steam generators and attempt feeding the steam generators with the condensate systems. Should all of these fail, operators are then instructed to attempi an augmented F\&B cooling procedure that utilizes steam generator PORVs, pressurizer PORVs, pressurizer sprays, and charging and HPI pumps. Analyses carried out by Los Alamos National Laboratory using TRAC and INEL using RELAP5 indicate these older CE plants have at most about 20 minutes from the time of losing feedwater to successfully entering the augmented F\&B cooling mode. ${ }^{39,40}$ Given that a relatively short time window exists and that three other recovery actions are given higher priority, it is unlikely that operators will get to the F\&B cooling mode in time. Because of these sonsiderations F\&B cooling is not credited as a viable decay heat removal mechanism (for CE plants) in this generic PRA evaluation. 
Because of the inability to credit F\&B on CE PWRs, there is a higher dependency on AFW which needs special consideration. On some CE plants the AFW system is located in the lowest levels of the turbine building and on others it is located in a portion of the auxiliary building. We now have the following categories (or PWR configurations) to examine:

- $\quad$ PWRs with no AFW in buildings containing hydrogen systems

- $\quad W$ and B\&W PWRs with AFW in the turbine building

- $\quad$ CE PWRs with AFW in the turbine building

- $\quad W$ and B\&W PWRs with AFW in the auxiliary building

- CE PWRs with AFW in the auxiliary building.

These categories exhaustively cover the possible configurations of interest for transients with loss of decay heat removal. Considering now the transient-induced LOCA scenarios, plants can be again grouped into two major categories. The majority of PWRs do not have systems such as emergency diesels, essential SW, or component cooling in buildings where large hydrogen systems are located. Hydrogen release and burn scenarios at these plants would not result in a loss of RCP seal cooling and subsequent RCP seal LOCA or station blackout-induced PORV LOCA. The complement of this group includes PWRs with vital systems located either in the turbine or auxiliary buildings.

Summarizing the specific categories, Table 11 shows the specific PWR configurations to be evaluated and the specific accident scenarios considered in these evaluations.

7.2.2 Methodology Utilized for Evaluating Hydrogen Storage Facility Risks. The separation criteria for the hydrogen storage facility (tank farm) are based on EPRI Report NP-5283SR-A. ${ }^{12}$ In that report, guidelines for the installation and separation of the hydrogen water chemistry (HWC) system at BWRs are specified. These guidelines have been reviewed and accepted by the NRC. The non-HWC storage installations (such as the hydrogen storage facility) are similar to installations addressed in the EPRI guidelines, therefore, these guidelines are considered applicable.

It was not unexpected that numerous plants were found not meeting the EPRI separation distance guidelines (approximately two dozen). However, not meeting the EPRI guidelines does not directly imply high risk since credit for certain existing mitigating site-specific features could also be judged to result in low overall risk. An informal telephone survey of the two dozen plants verified that in some cases licensees could take credit for such mitigating features. For example, an intervening permanent structure between the hydrogen storage facility and the safety-related structure of concern could be justified as sufficient to prevent hydrogen from entering building intakes. However, even so, not all plants examined during the informal telephone survey were in this category. 
Table 11. Generic plant configurations.

\begin{tabular}{|c|c|c|}
\hline Configuration & Plant Applicability & $\begin{array}{l}\text { Important Accident Scenarios } \\
\text { Applicable to Configuration }\end{array}$ \\
\hline I & $\begin{array}{l}\text { All PWRs with AFW and vital } \\
\text { equipment outside of turbine and } \\
\text { auxiliary buildings }\end{array}$ & $\begin{array}{l}\text { T/DHR } \\
\text { T/LOCA }\end{array}$ \\
\hline II & $\begin{array}{l}\text { Babcock \& Wilcox and Westinghouse } \\
\text { with AFW in turbine building } \\
\text { distribution system level }\end{array}$ & $\begin{array}{l}\text { T/DHR } \\
\text { (Feed and bleed credited) }\end{array}$ \\
\hline III & $\begin{array}{l}\text { Combustion Engineering with AFW in } \\
\text { turbine building distribution system } \\
\text { level }\end{array}$ & $\begin{array}{l}\text { T/DHR } \\
\text { (Feed and bleed not credited) }\end{array}$ \\
\hline IV & $\begin{array}{l}\text { All PWRs with vital equipment in } \\
\text { turbine building distribution system } \\
\text { level }\end{array}$ & $\begin{array}{l}\text { T/LOCA } \\
\text { (Station ac blackout, or loss of } \\
\text { CCW, SW) }\end{array}$ \\
\hline V & $\begin{array}{l}\text { All PWRs with vital equipment in } \\
\text { turbine building generator floor level }\end{array}$ & $\begin{array}{l}\text { T/LOCA } \\
\text { (Station ac blackout, or loss of } \\
\text { CCW, SW) }\end{array}$ \\
\hline VI & $\begin{array}{l}\text { Babcock \& Wilcox and Westinghouse } \\
\text { with AFW in auxiliary building }\end{array}$ & $\begin{array}{l}\text { T/DHR } \\
\text { (Feed and bleed credited) }\end{array}$ \\
\hline VII & $\begin{array}{l}\text { Combustion Engineering with AFW in } \\
\text { auxiliary building }\end{array}$ & $\begin{array}{l}\text { T/DHR } \\
\text { (Feed and bleed not credited) }\end{array}$ \\
\hline VIII & $\begin{array}{l}\text { All PWRs with vital equipment in } \\
\text { auxiliary building }\end{array}$ & $\begin{array}{l}\text { T/LOCA } \\
\text { (Loss of CCW, sW) }\end{array}$ \\
\hline
\end{tabular}

Although the assumption is made at this point that most plants can confirm credit for their mitigating features, that still leaves a smaller group of plants deserving closer scrutiny. Three plants presented in Subsection 7.5 as Plants A, B, and C were identified during this survey as requiring a more detailed risk analysis.

Analysis for the hydrogen storage facility was broken into two separate accident scenarios: damage due to the facility exploding locally and damage due to the facility leaking hydrogen that exploded away from the storage facility (such as leakage into building air intakes). For plants that had physical barriers between the storage facility and other vital buildings, credit was given for elimination of explosion risk but not the risk due to hydrogen leakage. 


\subsection{Transients with Loss of Decay Heat Removal}

7.3.1 Turbine Building Nonseismic Analysis. In nuclear power plants designed with no safetyrelated systems in the turbine building, the issue of combustible gas fires or explosions becomes one of economic loss versus a nuclear safety concern. In these plants, a combustible gas fire or explosion in the turbine building is likely to cause a turbine trip or plant shutdown, but no direct damage to any safetyrelated systems. However, a review of a number of U.S. nuclear power plant designs reveals that in many older plants, AFW systems were located in the lower levels of the turbine buildings.

The location of the AFW in the turbine building in a number of earlier designed nuclear power plants was a reflection of the classification of AFW as an auxiliary system not explicitly credited in licensing safety analysis at the time. In these older plants, AFW was typically actuated by operators from the control room when the main feedwater (MFW) was not available after a plant trip. Following the accident at Three Mile Island (TMI)-2 and subsequent investigations by the NRC and industry, AFW systems were recognized to be critical safety features for assuring long-term decay heat removal. TMI action plan activities required the installation of safety-grade automatic actuation of AFW. ${ }^{41}$ AFW systems are now extensively credited for decay heat removal (DHR) in transients, small LOCAs, and various 10 CFR 50 Appendix R safe shutdown scenarios following fires.

In the event of AFW failure, $W$ and $B \& W$ nuclear power plants typically have charging systems and PORVs that are capable of' removing core decay heat via F\&B cooling. Most CE nuclear power plants, on the other hand, do not have high-capacity PORVs and typically utilize piston-driven charging pumps that have at best marginal F\&B cooling capability within 20 minutes of plant trip. ${ }^{39,40}$ The CE System 80 plants do not have PORVs and hence have no F\&B capability. Thus, CE plants are more dependent on the reliability and availability of AFW for transients, including those initiated by combustible gas release fires in the turbine building. A reasonable, limiting type of fire scenario would thus be for a CE plant with its AFW located in the turbine building.

For plants with the AFW system located in the turbine building, the physical separation between the main generator (with its large volume of hydrogen) and the AFW system is on the order of hundreds of feet with many barriers along the way. The main generator is located on the top elevation in the turbine building, while the AFW system is necessarily very low in the building for net positive suction head considerations. Implementation of 10 CFR 50 Appendix R requirements have resulted in the AFW trains being separated in different fire zones. Thus, there are a number of substantial barriers in the horizontal as well as vertical direction. Therefore, it is judged that only an extremely large fire or explosion could disable the AFW system. It is assumed that such an event would also destroy the MFW system, causing a plant trip.

Large fires in the turbine building have always been considered in the plant fire protection and fire-fighting procedures due to the large quantities of turbine lube oil available as fuel. The amount of lube oil on hand can fuel a fire large enough to totally destroy the turbine building. The quantity of hydrogen available to initiate or exacerbate a large fire varies greatly from plant to plant and can be in the $100,000 \mathrm{scf}$ range. However, the capability to deal with large turbine building fires would exist even if there was no hydrogen to consider. The design of fire barriers, while not able to stop a large fire, would slow the spread sufficiently to give the plant operators and firefighters an opportunity to place the plant in a safe condition. 
Several foreign turbine building fires have been extremely large and damaging. The fire at Varidellos-1 in Spain in October of 1989 did damage comparable to that postulated here. Unfortunately, not enough information is available on foreign hydrogen systems and the number of years of system operating experience to make an evaluation of the frequency of large hydrogen releases and large fires. The applicability of foreign data in light of differing regulation and design requirements for safety equipment train separation and fire protection systems must be considered before using the data to investigate U.S. commercial reactor systems.

In order to estimate the frequency of major hydrogen releases which could cause physical damage, the frequency of hydrogen releases is multiplied by the probability of major fire or explosion. The frequency of hydrogen releases may be obtained from the hydrogen event data base. To determine the probability of a sufficiently large hydrogen fire or explosion damaging multiple trains of safety-related equipment via mechanistic analysis (on a plant-specific basis) is beyond the scope of the present analysis. One can develop a value based on engineering judgment by considering the scenario required to yield a hydrogen fire or explosion of sufficient magnitude to damage the safety system. This would involve two items:

- Assuming a major release of the generator hydrogen, the early ignition of the leaking hydrogen would not occur

- Given the continued accumulation and eventual delayed ignition of the released hydrogen, the propagation of a blast wave or fire front throughout the turbine building would proceed in such a manner that equipment enclosed in the various turbine buildings fire zones is heavily damaged and rendered inoperable.

The probability of the first item, $\mathrm{P}$ (delayed ignition), is assessed to be less than $1 \times 10^{-1}$ for the turbine building environment at the hydrogen distribution system level. The la se amount of operating electrical equipment (e.g., pump motors, fan motors, etc.) in the turbine building provides an ignition source necessary for early ignition of the released hydrogen. At the generator floor level, $\mathrm{P}$ (delayed ignition) was assessed to be less than $1 \times 10^{-2}$. Based on discussions with INEL hydrogen combustion experts, the leakage of high-temperature hydrogen into the ionized air surrounding the generator would almost certainly cause immediate ignition, which results in a lower probability of delayed ignition than at the distribution system level. Note that: $\mathrm{P}$ (delayed ignition) $=1-\mathrm{P}$ (ignition).

The probability of the second item, $\mathrm{P}$ (blast propagation), is assessed to be less than $1 \times 10^{-1}$. This takes into consideration spatial interactions (i.e., location of hydrogen sources in the turbine building with respect to safety-related equipment) and the likelihood of the blast wave damaging redundant safetyrelated equipment following zone boundary breach.

While modeling uncertainties exist between building designs, physical separation of redundant safety equipment trains, and explosive potential, a mean estimate of $1 \times 10^{-2}$ may be assumed to be reasonable for the conditional probability of disabling multiple trains of safety-related equipment at the hydrogen distribution system level. For hydrogen-initiated accident sequences at the generator floor level in the turbine building, a mean estimate of $1 \times 10^{-3}$ was assumed to be reasonable for the conditional probability stated above. 
For this analysis it is postulated that the AFW system is damaged by the hydrogen fire or explosion. The frequency of this event is the frequency of turbine building hydrogen fires and explosions that are large enough to cause damage to the AFW system. To date there have been no hydrogen-related fires or explosions in the United States that have impacted the AFW system. It was assumed that only those hydrogen events that were reported as fire and/or explosions in the data base would have the potential to have released large amounts of hydrogen (assuming early ignition did not occur). Thus, these values were used in the calculation of the large release event frequency.

The frequencies for large hydrogen release events at the two different levels in the turbine building are calculated from the Bayesian analysis of a noninformative prior distribution [see Equations (1) and (2), respectively] and are:

$$
\begin{aligned}
& f\left(\mathrm{H}_{2} \text { large release event at distribution system level }\right)_{T B}=\frac{2(1)+1}{2(1424 r y)}=1.1 \times 10^{-3} / r y \\
& f\left(\mathrm{H}_{2} \text { large release event at generator floor level }\right)_{T B}=\frac{2(8)+1}{2(1424 r y)}=6.0 \times 10^{-3} / r y
\end{aligned}
$$

The probability of F\&B failure is assumed to be $4.5^{1} \times 10^{-2}$. This F\&B probability is the average of four different F\&B failure rates from different plant PRAs and is dependent almost exclusively on the human error probabilities and not on design configurations. Table 12 lists the plants ised and the source of the F\&B failure number.

Table 12. Various feed and bleed failure rates from PRAs.

\begin{tabular}{ccc}
\hline Plant & Failure Rate for F\&B & Source \\
\hline Surry & $7.1 \times 10^{-2}$ & NUREG-1150 \\
Sequoyah & $2.2 \times 10^{-2}$ & NUREG-1150 \\
Millstone 3 & $7.7 \times 10^{-2}$ & Plant PRA \\
Oconee 3 & $1.0 \times 10^{-2}$ & NSAC-60 \\
\hline Average & $4.5 \times 10^{-2}$ & \\
\hline
\end{tabular}


Given the fact that the AFW system is disabled by the delayed-ignition of the accumulated hydrogen, the CDF (Configuration II) for this scenario is:

$$
\begin{aligned}
C D F_{A F W} w / F \& B \text { (nonseismic) }= & f\left(H_{2} \text { large release event at distribution system level }\right) P(\text { delayed ignition } \\
& \text { at distribution system level }) P(\text { blast propagation }) P(\text { failure to } F \& B) \\
= & \left(1.1 \times 10^{-3} / r y\right)\left(1 \times 10^{-1}\right)\left(1 \times 10^{-1}\right)\left(4.5 \times 10^{-2}\right) \\
= & 5.0 \times 10^{-7} / r y
\end{aligned}
$$

For the PWR case where F\&B is not possible (CE plants), the F\&B failure rate is set equal to 1.0. Therefore, the CDF (Configuration III) is:

$$
\begin{aligned}
C D F_{A F W \text { wlo } F \& B \text { (nonseismic) }=} & f\left(H_{2} \text { large release event at distribution system level) } P(\text { delayed ignition }\right. \\
& \text { at distribution system level }) P(\text { blast propagation }) P(\text { failure to } F \& B) \\
= & \left(1.1 \times 10^{-3} / r y\right)\left(1 \times 10^{-1}\right)\left(1 \times 10^{-1}\right)(1.0) \\
= & 1.1 \times 10^{-5} / r y
\end{aligned}
$$

Since a hydrogen fire or explosion could damage the steam line, a steam line break (SLB) scenario is investigated. As calculated earlier (Subsection 6.2.3), the frequency for all fires and explosions in the turbine building at the generator level is $6.0 \times 10^{-3} / \mathrm{ry}$. The conditional probability of a fire or explosion causing a SLB is calculated from the data to be:

$$
P\left(S L B \backslash H_{2} \text { fire or explosion }\right)=\frac{0+0.5}{8+1}=0.06
$$

Thus, the SLB initiating event frequency is $3.6 \times 10^{-4} / \mathrm{ry}$. The CDF from the hydrogen-induced SLB initiating event is salculated using the $W$ plant origina! PRA SLB analysis.

The hydrogen initiating event frequency is multiplied by the $W$ base case conditional core damage probability to get a hydrogen-induced CDF. The original mean conditional core damage probability from SL.B is $1.02 \times 10^{-4}$. The CDF (which appiies to all configurations) from hydrogen initiated steam line breaks is calculated by:

$$
\begin{aligned}
C D F_{S L B \text { (nonseismic) }} & =f(\text { steam line break })(\text { core melt/SLB }) \\
& =\left(3.6 \times 10^{-4} / r y\right)\left(1.02 \times 10^{-4}\right)=3.7 \times 10^{-8} / r y
\end{aligned}
$$


7.3.2 Turbine Building Seismic Analysis. Another means of initiating a large fire or explosion in the turbine building is a seismic-induced failure of the hydrogen distribution system. It is judged that only a large fire or explosion could disable the AFW. It is assumed that a seismic event would lead to a LOSP (due to low seismic capacity ceramic insulator failure) and that the large hydrogen event would incapacitate the main feedwater system. ${ }^{a}$ The seismic hydrogen piping fragility frequency is assumed to be the same as that analyzed for the $W$ base case plant in Section 6 (i.e., $5.3 \times 10^{-5} / \mathrm{ry}$ ).

The conditional probability of damaging multiple safety-related core cooling systems in the turbine building due to seismic induced hydrogen system releases is assumed to be $1 \times 10^{-3}$ (see related discussion in Subsection 7.3.1). The F\&B failure rate is also assumed to be $4.5 \times 10^{-2}$, which as noted previously is dominated by human error and not equipment failure. Therefore, the resulting CDF (Configuration II) for this scenario (for a PWR with F\&B capability) is:

$$
\begin{aligned}
C D F_{A F W w / F \& B(\text { seismic })=} & f(\text { seismic pipe failure in turbine building) } P(\text { delayed ignition at } \\
& \text { distribution system level }) P(\text { blast propagation }) P(\text { failure to } F \& B) \\
= & \left(5.3 \times 10^{-5} / r y\right)\left(1 \times 10^{-1}\right)\left(1 \times 10^{-1}\right)\left(4.5 \times 10^{-2}\right) \\
= & 2.4 \times 10^{-8} / r y
\end{aligned}
$$

For the case where F\&B is not possible (CE plant), the F\&B failure rate is equal to 1 . Thus, the CDF (Configuration III) is:

$$
\begin{aligned}
C D F_{A F W \text { wlo F\&B (seismic) }}= & f(\text { seismic pipe failure in turbine building) } P(\text { delayed ignition at } \\
& \text { distribution system level) } P(\text { blast propagation }) P(\text { failure to } F \& B) \\
= & \left(5.3 \times 10^{-5} / r y\right)\left(1 \times 10^{-1}\right)\left(1 \times 10^{-1}\right)(1.0) \\
= & 5.3 \times 10^{-7} / r y
\end{aligned}
$$

7.3.3 Uncertainty Analysis for Turbine Building T/DHR Scenarios. An uncertainty analysis was performed using the Monte Carlo sampling capability of the computer code @RISK. Table 13 lists the random variables, their distributions, and the associated parameters that were used. Appendix B contains a detailed derivation on the hydrogen initiating event (gamma) distributions and the conditional probability (beta) distributions. A lognormal distribution was assumed for the uncertainty distributions where operating data was not available. The standard deviation values for the delayed ignition and blast

a The analysis of seismic initiated hydrogen system failures focuses primarily on seismic/hydrogen system interactions. Seismic interactions with the offsite electrical grid are considered because virtually all U.S. plants are perceived to have the same vulnerability. Additionally, the proper definition of the initiating event requires postulation of LOSP. Direct seismic interactions with other decay heat removal systems, while an important consideration to overall risk, are not considered in this analysis because this is beyond the scope of GSI-106 related concerns. 
Table 13. Random variables for turbine building T/DHR CDF analysis.

\begin{tabular}{|c|c|c|}
\hline Random Variable & Distribution & Parameters \\
\hline $\begin{array}{l}\mathrm{f}\left(\mathrm{H}_{2} \text { large release event at }\right. \\
\text { distribution system level })\end{array}$ & Gamma & $\begin{array}{c}\alpha=1.5 \\
\beta=7.02 \times 10^{-4} / \mathrm{ry}\end{array}$ \\
\hline f(seismic pipe failure) & Lognormal & $\begin{aligned} \text { mean } & =5.3 \times 10^{-5} / \mathrm{ry} \\
\text { std.dev. } & =1.87 \times 10^{-3} / \mathrm{ry}\end{aligned}$ \\
\hline $\begin{array}{c}\mathrm{P} \text { (delayed ignition, at } \\
\text { distribution system level) }\end{array}$ & Lognormal & $\begin{aligned} \text { mean } & =1 \times 10^{-1} \\
\text { std.dev. } & =2.47 \times 10^{-1}\end{aligned}$ \\
\hline P(blast propagation) & Lognormal & $\begin{aligned} \text { mean } & =1 \times 10^{-1} \\
\text { std.dev. } & =2.47 \times 10^{-1}\end{aligned}$ \\
\hline$P(F \& B$ failure $)$ & Lognormal & $\begin{aligned} \text { mean } & =4.5 \times 10^{-2} \\
\text { std.dev. } & =1.11 \times 10^{-1}\end{aligned}$ \\
\hline $\begin{array}{l}\mathrm{f}\left(\mathrm{H}_{2} \text { large release event at }\right. \\
\text { generator level })\end{array}$ & Gamma & $\begin{array}{c}\alpha=8.5 \\
\beta=7.02 \times 10^{-4} / \text { ry }\end{array}$ \\
\hline $\mathrm{P}\left(\mathrm{SLB} \backslash \mathrm{H}_{2}\right.$ fire or explosion) & Beta & $\begin{array}{l}\alpha_{1}=0.5 \\
\alpha_{2}=8.5\end{array}$ \\
\hline $\mathrm{P}($ core melt $I S L B)$ & Lognormal & $\begin{array}{c}\text { mean }=1.02 \times 10^{-4} \\
\text { std.dev. }=9.44 \times 10^{-5}\end{array}$ \\
\hline
\end{tabular}

propagation probabilities comes from the assumption that the lognormal error factor is equal to 10 . The results from the T/DHR analysis are given in Subsection 7.3.7. The uncertainty analysis results are:

- $\quad$ Feed and Bleed available (Configuration II)

Turbine Building ( $A F W$, nonseismic)

$$
\begin{aligned}
& C D F_{5 \text { th }}=2.0 \times 10^{-10} / r y \quad C D F_{50 \text { th }}=2.0 \times 10^{-8} / r y \\
& C D F_{95 \text { th }}=1.1 \times 10^{-6} / r y \quad C D F_{\text {mean }}=6.9 \times 10^{-7} / r y
\end{aligned}
$$

Turbine Building (AFW, seismic)

$$
\begin{aligned}
& C D F_{\text {sth }}=9.0 \times 10^{-14} / r y \quad C D F_{50 \text { th }}=3.0 \times 10^{-11} / r y \\
& C D F_{95_{\text {th }}}=1.3 \times 10^{-8} / r y \quad C D F_{\text {mean }}=8.3 \times 10^{-9} / r y
\end{aligned}
$$

- Steam Line Break (All configurations)

Turbine Building (SLB, nonseismic)

$$
\begin{array}{ll}
C D F_{5 \iota h}=9.0 \times 10^{-11} / r y & C D F_{50 \text { th }}=1.1 \times 10^{-8} / r y \\
C D F_{9 s_{\text {th }}}=1.3 \times 10^{-7} / r y & C D F_{\text {mean }}=3.3 \times 10^{-8} / r y
\end{array}
$$


Turbine Building (AFW, nonseismic)

$$
\begin{array}{ll}
C D F_{5 \text { sh }}=2.0 \times 10^{-8} / r y & C D F_{50 \text { sh }}=2.0 \times 10^{-6} / r y \\
C D F_{95 \text { ch }}=3.3 \times 10^{-5} / r y & C D F_{\text {mean }}=9.5 \times 10^{-6} / r y
\end{array}
$$

Turbine Building (AFW, seismic)

$$
\begin{aligned}
& C D F_{5 \text { ch }}=1.0 \times 10^{-11} / r y \quad C D F_{\text {sath }}=2.1 \times 10^{-9} / r y \\
& C D F_{95 \text { th }}=4.4 \times 10^{-7} / r y \quad C D F_{\text {mean }}=2.4 \times 10^{-7} / r y
\end{aligned}
$$

7.3.4 Auxiliary Building Nonseismic Analysis. If a large hydrogen fire or explosion event is postulated to have occurred inside the auxiliary building, it will lead to a reactor trip either automatically or manually [induced by the plant operators in the control room (out of tolerance condition)]. The turbine should trip immediately as a result of the reactor trip signal, and the AFW should start when the level in the steam generators falls. As long as AFW is being supplied to the steam generators, secondary cooling is ensured (there are numerous pathways for the steam to escape from the steam generators). Core cooling will be achieved either through natural or forced circulation.

As noted previously, for $W$ and $B \& W$ reactors, if AFW cooling should fail, the operators can start a high pressure safety injection pump and manually open the PORVs to provide F\&B cooling to the primary system. Some CE reactors (notably the CE System 80 reactors) do not have PORVs, and thus have no possibility of cooling the core by F\&B function. Older CE reactors have at best marginal F\&B cooling capability provided it is initiated within 20 minutes of plant trip.

For this analysis it is postulated that the AFW system is damaged by a large hydrogen fire or explosion. The frequency of this event is the frequency of auxiliary building hydrogen fires and explosions that are large enough to cause damage to the AFW system. To date there have been no hydrogen-related fires or explosions in the United States that have impacted the AFW system. The frequency of hydrogen fires or explosions in the auxiliary building is $5.5 \times 10^{-4} / \mathrm{ry}$. It was assumed that only the reported fires and explosions in the data base would have the potential to have released large amounts of hydrogen (assuming early ignition did not occur). Thus, the frequency of large hydrogen release in the PAB is assumed to be equal to the frequency of hydrogen fires or explosions in the PAB. Again, the mean conditional probability of damaging multiple safety-related systems in the auxiliary building is assumed to be $1 \times 10^{-2}$ (see Subsection 7.3.1). The F\&B failure rate is assumed to be the same $\left(4.5 \times 10^{-2}\right)$ as calculated in Subsection 7.3.1. Therefore, the resulting CDF (Configuration VI) for this scenario is:

$$
\begin{aligned}
C D F_{A F W} w / F \& B \text { (nonseismic) }= & f\left(H_{2} \text { large release event in } P A B\right) P(\text { delayed ignition in } P A B) \\
& P(\text { blast propagation }) P(\text { failure to } F \& B) \\
= & \left(5.5 \times 10^{-4} / r y\right)\left(1 \times 10^{-1}\right)\left(1 \times 10^{-1}\right)\left(4.5 \times 10^{-2}\right) \\
= & 2.5 \times 10^{-7} / r y
\end{aligned}
$$


For the PWR case where F\&B is not possible, the F\&B failure rate is set equal to 1.0. Thus, the CDF (Configuration VII) is:

$$
\begin{aligned}
C D F_{A F W w / o F \& B \text { (nonseismic) }}= & f\left(H_{2} \text { large release event in } P A B\right) P(\text { delayed ignition in } P A B) \\
& P(\text { blast propagation }) P(\text { failure to } F \& B) \\
= & \left(5.5 \times 10^{-4} / r y\right)\left(1 \times 10^{-1}\right)\left(1 \times 10^{-1}\right)(1.0) \\
= & 5.5 \times 10^{-6} / r y
\end{aligned}
$$

7.3.5 Auxiliary Building Seismic Analysis. A large seismic-induced hydrogen fire or explosion in the auxiliary building may disable the AFW system if a plant has the AFW system in the auxiliary building. As with the turbine building seismic analysis, a LOSP is postulated to occur due to the fragile nature of the ceramic insulators. Similar to the turbine building analysis, seismic induced failures of decay heat removal systems and vital auxiliaries are not postulated because these issues are not associated with GSI-106.

Again, the conditional probability of damaging multiple safety-related systems in the auxiliary building is assumed to be $1 \times 10^{-2}$. The F\&B failure rate is assumed to be the same $\left(4.5 \times 10^{-2}\right)$ as calculated in Subsection 7.3.1 and is dominated by human error and not equipment failure. Thus, the CDF (Configuration VI) for this scenario is:

$$
\begin{aligned}
C D F_{A F W w / F \& B \text { (seismic) }}= & f\left(\text { seismic } H_{2} \text { pipe failure in } P A B\right) P(\text { delayed ignition in } P A B) \\
& P(\text { blast propagation }) P(\text { failure to } F \& B) \\
= & \left(5.3 \times 10^{-5} / r y\right)\left(1 \times 10^{-1}\right)\left(1 \times 10^{-1}\right)\left(4.5 \times 10^{-2}\right) \\
= & 2.4 \times 10^{-8} / r y
\end{aligned}
$$

For the PWR case where F\&B is not possible, the F\&B failure rate is set to 1 . The CDF (Configuration VII) is:

$$
\begin{aligned}
C D F_{A F W \text { w/o F\&B (seismic) }}= & f\left(\text { seismic } H_{2} \text { pipe failure in } P A B\right) P(\text { delayed ignition in } P A B) \\
& P(\text { blast propagation }) P(\text { failure to } F \& B) \\
= & \left(5.3 \times 10^{-5} / r y\right)\left(1 \times 10^{-1}\right)\left(1 \times 10^{-1}\right)(1.0) \\
= & 5.3 \times 10^{-7} / r y
\end{aligned}
$$

7.3.6 Uncertainty Analysis for Auxiliary Building T/DHR Scenarios. An uncertainty analysis was performed using the Monte Carlo sampling capability of the computer code @RISK. Table 14 lists the random variables, their distributions, and the associated parameters that were used. The standard deviation values for the delayed ignition and blast propagation probabilities comes from the 
Table 14. Random variables for auxiliary building T/DHR CDF analysis.

\begin{tabular}{|c|c|c|}
\hline Random Variable & Distribution & Parameters \\
\hline $\begin{array}{c}f\left(\mathrm{H}_{2} \text { large release event in }\right. \\
\text { PAB })\end{array}$ & Gamma & $\begin{array}{c}\alpha=0.5 \\
\beta=1.09 \times 10^{-3} / \mathrm{ry}\end{array}$ \\
\hline f(seismic piping failure) & Lognormal & $\begin{aligned} \text { mean } & =5.3 \times 10^{-5} / \mathrm{ry} \\
\text { std.dev. } & =1.87 \times 10^{-3} / \mathrm{ry}\end{aligned}$ \\
\hline $\mathrm{P}$ (delayed ignition in $\mathrm{PAB}$ ) & Lognormal & $\begin{aligned} \text { mean } & =1 \times 10^{-1} \\
\text { std.dev. } & =2.47 \times 10^{-1}\end{aligned}$ \\
\hline $\mathrm{P}$ (blast propagation) & Lognormal & $\begin{aligned} \text { mean } & =1 \times 10^{-1} \\
\text { std.dev. } & =2.47 \times 10^{-1}\end{aligned}$ \\
\hline$P($ failure to $F \& B)$ & Lognormal & $\begin{aligned} \text { mean } & =4.5 \times 10^{-2} \\
\text { std.dev. } & =1.11 \times 10^{-1}\end{aligned}$ \\
\hline
\end{tabular}

assumption that the lognormal error factor is equal to 10 . The results of the T/DHR analysis are given in Subsection 7.3.7.

The uncertainty analysis results for the auxiliary building T/DHR are:

- $\quad$ Feed and Bleed available (Configuration VI)

Auxiliary Building ( $A F W$, nonseismic)

$$
\begin{array}{ll}
C D F_{5 t h}=1.0 \times 10^{-11} / r y & C D F_{50 t h}=4.0 \times 10^{-9} / r y \\
C D F_{95 t h}=4.8 \times 10^{-7} / r y & C D F_{\text {mean }}=1.8 \times 10^{-7} / r y
\end{array}
$$

Auxiliary Building (AFW, seismic)

$$
\begin{array}{ll}
C D F_{5 t h}=9.0 \times 10^{-14} / r y & C D F_{50 t h}=3.0 \times 10^{-11} / r y \\
C D F_{95 t h}=1.3 \times 10^{-8} / r y & C D F_{\text {mean }}=8.3 \times 10^{-9} / r y
\end{array}
$$

- $\quad$ Feed and Bleed not available (Configuration VII) Auxiliary Building (AFW, nonseismic)

$$
\begin{array}{ll}
C D F_{5 \text { th }}=1.0 \times 10^{-9} / r y & C D F_{50 \text { lt }}=2.0 \times 10^{-7} / r y \\
C D F_{95 t h}=1.8 \times 10^{-5} / r y & C D F_{\text {mean }}=4.4 \times 10^{-6} / r y
\end{array}
$$

Auxiliary Building (AFW, seismic)

$$
\begin{array}{ll}
C D F_{5 t h}=8.0 \times 10^{-12} / r y & C D F_{50 \text { th }}=2.0 \times 10^{-9} / r y \\
C D F_{95 t h}=5.4 \times 10^{-7} / r y & C D F_{\text {mean }}=3.4 \times 10^{-7} / r y
\end{array}
$$


7.3.7 Summary of Transients with Loss of Decay Heat Removal. For the T/DHR analysis, two plant areas were evaluated: the turbine building and the auxiliary building. A seismic and a nonseismic analysis were performed for both plant areas. The resulting mean values from the Monte Carlo analysis are:

- $\quad$ For turbine buildings with steam line (all configurations), the mean for the CDF analysis is:

$$
\mathrm{CDF}_{\text {nonseismic }}=3.3 \times 10^{-8} / \mathrm{ry}
$$

- If AFW equipment is located in the turbine building on the distribution system level, the mean values for the CDF analysis are:

(with F\&B)

(with F\&B)

(Configuration II)

(without F\&B)

(without F\&B)

(Configuration III)

$$
\begin{array}{ll}
\mathrm{CDF}_{\text {nonseismic }} & =6.9 \times 10^{-7} / \mathrm{ry} \\
\mathrm{CDF}_{\text {seismic }} & =8.3 \times 10^{-9} / \mathrm{ry} \\
\mathrm{CDF}_{\text {total }} & =7.0 \times 10^{-7} / \mathrm{ry}
\end{array}
$$

$\mathrm{CDF}_{\text {nonseismic }}=9.5 \times 10^{-6} / \mathrm{ry}$

$\mathrm{CDF}_{\text {seismic }}=\frac{2.4 \times 10^{-7} / \mathrm{ry}}{9.7 \times 10^{-6} / \mathrm{ry}}$

$\mathrm{CDF}_{\text {total }}$$$
=\frac{2.4 \times 10^{-7} / \mathrm{ry}}{9.7 \times 10^{-6} \mathrm{r}}
$$

- If AFW equipment is located in the auxiliary building, the mean values for the CDF analysis are:

(with $F \& B$ )

(with F\&B)

(Configuration VI)

(without F\&B)

(without F\&B)

(Configuration VII)

$$
\begin{array}{ll}
\mathrm{CDF}_{\text {nonseismic }} & =1.8 \times 10^{-7} / \mathrm{ry} \\
\mathrm{CDF}_{\text {seismic }} & =\frac{8.3 \times 10^{-9} / \mathrm{ry}}{\mathrm{CDF}_{\text {total }}}
\end{array}
$$

$$
\begin{array}{ll}
\mathrm{CDF}_{\text {nonseismic }} & =4.4 \times 10^{-6} / \mathrm{ry} \\
\mathrm{CDF}_{\text {seismic }} & =\frac{3.4 \times 10^{-7} / \mathrm{ry}}{\mathrm{CDF}_{\text {total }}}
\end{array}
$$

\subsection{Transient-Induced Loss-of-Coolant Accident}

7.4.1 Turbine Building Nonseismic Analysis. At one W PWR, a key portion of the component cooling water (CCW) system (e.g., CCW heat exchangers) is located in the turbine building. At many PWR plants (including the base case plant), loss of CCW (caused by a large hydrogen explosion failing CCW heat exchangers) would have serious consequences on the plant's ability to rool the reactor coolant pump (RCP) seals. Cooling to the RCP seals is performed redundantly by $C(W$ flow to the thermal barrier heat exchangers, and by RCP seal injection (which is provided by the charging pumps). But loss of CCW leads to loss of the charging pumps, so both means of cooling the RCP seals are lost if CCW is lost. Loss of cooling to the RCP seals leads (with high probability) to failure of the RCP seals, with a resultant small LOCA. Since the oil coolers of the HPSI pumps and the charging pumps are cooled by CCW, loss of CCW also leads to loss of the ability to mitigate the LOCA, unless a recovery action can be performed. Using the conditional probabilities developed in Subsection 7.3.1, The CDFs due to hydrogen-caused seal LOCA at the two levels in the turbine building (by applicable PWR plant configuration) are: 
- Distribution system level (Configuration IV)

$C D F_{C C W}$ (nonseismic) $=f\left(H_{2}\right.$ large release event in turbine building at distribution system level) $P($ delayed ignition at distribution system level) $P$ (blast propagation)

$=\left(1.1 \times 10^{-3} / r y\right)\left(1 \times 10^{-1}\right)\left(1 \times 10^{-1}\right)$

$=1.1 \times 10^{-5} / r y$

- Generatorifloor level (Configuration $V$ )

$C D F_{C C W}$ (nonseismic) $=f\left(H_{2}\right.$ large release event in turbine building at generator floor level)

$P($ delayed ignition at generator floor level) $P$ (blast propagation)

$=\left(6.0 \times 10^{-3} / r y\right)\left(1 \times 10^{-2}\right)\left(1 \times 10^{-1}\right)$

$=6.0 \times 10^{-6} / r y$

7.4.2 Turbine Building Seismic Analysis. If the hydrogen system is not seismic category 1, another means of initiating a large fire or explosion in the turbine building capable of disabling CCW is a seismic-induced failure of the hydrogen distribution system. Once again, it is judged that only an large fire or explosion could disable the CCW. It is assumed that such an event would also cause a LOSP (due to the low fragility of ceramic insulators). The seismic hydrogen piping fragility frequency is assumed to be the same as that analyzed for the $W$ base case plant in Section 6 (i.e., $5.3 \times 10^{-5} / \mathrm{ry}$ ). The conditional probability of damaging multiple safety related systems in the turbine building is assessed similar to that in Subsection 7.3.1 (i.e., by a hydrogen event in the turbine building). The resulting CDFs for these scenarios are:

- $\quad$ Distribution system level (Configuration IV)

$$
\begin{aligned}
C D F_{C C W} \text { (seismic) }= & f(\text { seismic pipe failure in turbine building }) P(\text { delayed ignition at } \\
& \text { distribution system level }) P(\text { blast propagation }) \\
= & \left(5.3 \times 10^{-5} / r y\right)\left(1 \times 10^{-1}\right)\left(1 \times 10^{-1}\right) \\
= & 5.3 \times 10^{-7} / r y
\end{aligned}
$$

- Generator floor level (Configuration V)

$$
\begin{aligned}
C D F_{C C W} \text { (seismic) }= & f(\text { seismic pipe failure in turbine building }) P(\text { delayed ignition at } \\
& \quad \text { generator floor level }) P(\text { blast propagation }) \\
= & \left(5.3 \times 10^{-5} / r y\right)\left(1 \times 10^{-2}\right)\left(1 \times 10^{-1}\right) \\
= & 5.3 \times 10^{-8} / r y
\end{aligned}
$$


If plant emergency diesel generators are contained within the turbine building (such as the case for one PWR), a station blackout condition could result if an earthquake (which is assumed to also cause a LOSP) ruptures the hydrogen piping system, and the resulting hydrogen explosion damages the diesel generators. Damage of the core due to a transient-induced seal LOCA would result unless offsite power was restored. Assuming no immediate restoration of power (consistent with NUREG-1150 seismic analyses $^{29}$ ), the CDF for this scenario is:

$$
\begin{aligned}
C D F_{\text {diesels (seismic) }}= & f(\text { seismic pipe failure in turbine building }) P(\text { delayed ignition } \\
& \text { at distribution system level }) P(\text { blast propagation }) \\
= & \left(5.3 \times 10^{-5} / r y\right)\left(1 \times 10^{-1}\right)\left(1 \times 10^{-1}\right) \\
= & 5.3 \times 10^{-7} / r y
\end{aligned}
$$

The above accident scenario (e.g., diesels damaged by hydrogen explosion) is assumed to have risk significance only if the initiator is a seismic event.

7.4.3 Uncertainty Analysis for Turbine Building T/LOCA Scenarios. An uncertainty analysis was performed using the Monte Carlo sampling capability of the computer code @RISK. The uncertainty distributions for the initiating event frequencies were developed from the LER data base as described in Section 3 and Appendix B. Table 15 lists the random variables, their distributions, and the associated parameters that were used. The standard deviation values for the delayed ignition and blast propagation probabilities comes from the assumption that the lognormal error factor is equal to 10 . This

\begin{tabular}{|c|c|c|}
\hline Random Variable & Distribution & Parameters \\
\hline $\begin{array}{l}\mathrm{f}\left(\mathrm{H}_{2} \text { large release event at }\right. \\
\text { distribution system level })\end{array}$ & Gamma & $\begin{array}{c}\alpha=1.5 \\
\beta=7.02 \times 10^{-4} / \mathrm{ry}\end{array}$ \\
\hline $\begin{array}{l}\mathrm{f}\left(\mathrm{H}_{2} \text { large release event at }\right. \\
\text { generator floor level })\end{array}$ & Gamma & $\begin{array}{c}\alpha=8.5 \\
\beta=7.02 \times 10^{-4} / \mathrm{ry}\end{array}$ \\
\hline f(seismic pipe failures) & Lognormal & $\begin{aligned} \text { mean } & =5.3 \times 10^{-5} / \mathrm{ry} \\
\text { std.dev. } & =1.87 \times 10^{-3} / \mathrm{ry}\end{aligned}$ \\
\hline $\begin{array}{l}\mathrm{P}(\text { delayed ignition at } \\
\text { distribution floor level })\end{array}$ & Lognormal & $\begin{aligned} \text { mean } & =1 \times 10^{-1} \\
\text { std.dev. } & =2.47 \times 10^{1}\end{aligned}$ \\
\hline $\begin{array}{c}\mathrm{P}(\text { delayed ignition at generator } \\
\text { floor level })\end{array}$ & Lognormal & $\begin{aligned} \text { mean } & =1 \times 10^{-2} \\
\text { std.dev. } & =2.47 \times 10^{-2}\end{aligned}$ \\
\hline $\mathrm{P}$ (blast propagation) & Lognormal & $\begin{aligned} \text { mean } & =1 \times 10^{-1} \\
\text { std.dev. } & =2.47 \times 10^{-1}\end{aligned}$ \\
\hline
\end{tabular}
large error factor is used to model the uncertainty inherent within the parameter. The results of the T/LOCA analysis are given in Subsection 7.4.7.

Table 15. Random variables for turbine building T/LOCA CDF analysis. 
The uncertainty analysis results for the turbine building T/LOCA scenarios are:

- $\quad$ Turbine building distribution system level (CCW, nonseismic) (Configuration IV)

$$
\begin{array}{ll}
C D F_{5 t h}=2.0 \times 10^{-8} / r y & C D F_{50 t h}=2.0 \times 10^{-6} / r y \\
C D F_{95 t h}=3.3 \times 10^{-5} / r y & C D F_{\text {mean }}=9.5 \times 10^{-6} / r y
\end{array}
$$

- $\quad$ Turbine building distribution system level (CCW, seismic) (Configuration IV)

$$
\begin{array}{ll}
C D F_{5 \text { th }}=8.0 \times 10^{-12} / r y & C D F_{50 \text { th }}=2.0 \times 10^{-9} / r y \\
C D F_{95 \text { th }}=5.4 \times 10^{-7} / r y & C D F_{\text {mean }}=3.4 \times 10^{-7} / r y
\end{array}
$$

- $\quad$ Turbine building generator floor level (CCW, nonseismic) (Configuration V)

$$
\begin{array}{ll}
C D F_{5 \text { th }}=3.0 \times 10^{-8} / r y & C D F_{50 \text { th }}=8.0 \times 10^{-7} / r y \\
C D F_{95 \text { th }}=2.0 \times 10^{-5} / r y & C D F_{\text {mean }}=5.3 \times 10^{-6} / r y
\end{array}
$$

- $\quad$ Turbine building generator floor level (CCW, seismic) (Configuration V)

$$
\begin{aligned}
& C D F_{5 t h}=1.0 \times 10^{-12} / r y \quad C D F_{50 t h}=1.0 \times 10^{-10} / r y \\
& C D F_{95 \text { th }}=4.8 \times 10^{-8} / r y \quad C D F_{\text {mear }}=2.0 \times 10^{-8} / r y
\end{aligned}
$$

- $\quad$ Turbine building (diesels, seismic)

$$
\begin{array}{ll}
C D F_{\text {sth }}=8.0 \times 10^{-12} / r y & C D F_{50 \text { th }}=2.0 \times 10^{-9} / r y \\
C D F_{95 \text { th }}=5.4 \times 10^{-7} / r y & C D F_{\text {mean }}=3.4 \times 10^{-7} / r y
\end{array}
$$

7.4.4 Auxiliary Building Nonseismic Analysis. Plant visits were conducted at 15 PWRs to gather information on the configuration and characteristics of the hydrogen gas system supplving the VCT. After a thorough review of plant information, it was determined that a large variability "xists among VCT hydrogen gas systems. For example, at some plants, portions of the hydrogen supply system piping inside the auxiliary building are seismically anchored and welded while at other plants this pipe is of a nonseismic carbon steel threaded type. Some plants have excess flow check valves installed in the hydrogen pipe supply to the VCT in order to limit the amount of hydrogen that could be introduced inside the auxiliary building during a guillotine-type pipe break. At some plants the ventilation flow rates and direction are designed to dilute hydrogen to less than its lower flammability limit of $4.1 \%$ by volume. Only very few plants ( 3 of the 15 plants visited) employ sleeved piping for the hydrogen system inside 
the auxiliary building. However, the largest variability associated with the VCT hydrogen supply system is the actual routing and length of the pipe inside the auxiliary building. The pipe length can be as low as $15 \mathrm{ft}$ or as high as $300 \mathrm{ft}$, while the routing can be' (and is) in plant areas containing vital (safetyrelated) components.

Considering the large PWR population of 78 plants, a similar number of hydrogen system piping configurations and hydrogen event scenarios can be envisioned. However, these scenarios could be grouped (as appropriate) to reflect the changes to plant safety functions [i.e., reduced system(s) availability] caused by the hydrogen fires or explosions.

If a large hydrogen fire or explosion event is postulated to have occurred inside the auxiliary building [e.g., plant without excess flow check valves and large (over $1200 \mathrm{scf}$ ) hydrogen storage facility], it will lead to a reactor trip either automatically or be manually induced by the plant operators in the control room (out of tolerance condition). The turbine should trip immediately as a result of the reactor trip signal, and the AFW should start when the levels in the steam generators fall. As long as AFW is being supplied to the steam generators, secondary cooling is ensured (there are numerous pathways for the steam to escape from the steam generators). Core cooling will be achieved either through natural or forced circulation.

If the CCW system is located in the auxiliary building (as is the case for most PWRs), the possibility of a reactor coolant pump seal LOCA is present given that a large hydrogen fire or explosion damages the $\mathrm{CCW}$ system. If the $\mathrm{CCW}$ system is disabled, the reactor coolant pumps are expected to operate for approximately 30 minutes before their seals begin to degrade. Once the pump seals fail, a seal LOCA will occur and core damage will eventually result.

As discussed in Subsection 7.3.1, determining the probability of a large hydrogen fire or explosion damaging multiple trains of safety-related equipment via mechanistic analysis (on a plant specific basis) is beyond the scope of the analysis. One can develop a value based on engineering judgment by considering the scenario required to yield a hydrogen fire or explosion of sufficient magnitude to damage the safety system. The determination of this value would involve two things:

- Assuming a major hydrogen release, the early ignition of the hydrogen would not occur

- Given the continued accumulation and eventual delayed ignition of the leaking hydrogen, the propagation of a blast wave or fire front throughout the auxiliary building would proceed in such a manner that $\mathrm{CCW}$ fire zone boundaries are breached, damaging the enclosed equipment.

The probability of the first item, $\mathrm{P}$ (delayed ignition), is assessed to be less than $1 \times 10^{-1}$ for the auxiliary building environment (similar to that of the turbine building distribution level). The large number of operating electrical equipment (e.g., pump motors, fan motors, etc.) in the auxiliary building provides an ignition source necessary for early ignition of the released hydrogen.

The probability of the second item, $\mathrm{P}$ (blast propagation), is assessed to be less than $1 \times 10^{-1}$. This takes into consideration spatial interactions (i.e., location of hydrogen source in the auxiliary building with respect to safety-related equipment) and the likelihood of the blast wave damaging safety- 
related equipment following zone boundary breach. Therefore, while uncertainties clearly exist in building designs and explosive potential, a mean value of $1 \times 10^{-2}$ may be assumed to be reasonable for the conditional probability of disabling multiple trains of safety-related equipment in the auxiliary building.

The frequency for large hydrogen release events (assumed to equal the frequency of reported hydrogen fire or explosion) in the auxiliary building is calculated from the Bayesian analysis of a noninformative prior distribution [see Equation (1)]:

$$
f\left(H_{2} \text { large release event in } P A B\right)=\frac{2(0)+1}{2(917 r y)}=5.5 \times 10^{-4} / r y
$$

Thus, the CDF (Configuration VIII) is (with no credit given for F\&B due to the unavailability of the high pressure safety injection pumps):

$$
\begin{aligned}
C D F_{C C W} \text { (nonseismic) }= & f\left(H_{2} \text { large release event in } P A B\right) P(\text { delayed ignition in } P A B) \\
& P(\text { blast propagation) } \\
= & \left(5.5 \times 10^{-4} / r y\right)\left(1 \times 10^{-1}\right)\left(1 \times 10^{-1}\right) \\
= & 5.5 \times 10^{-6} / r y
\end{aligned}
$$

7.4.5 Auxiliary Building Seismic Analysis. Another means of initiating a large fire or explosion in the auxiliary building is a seismic-induced failure of the hydrogen distribution system. Once again, it is judged that only an large fire or explosion could disable the CCW. Also, it is assumed that a seismic event would cause a LOSP.

As discussed in Subsection 7.4.4, the mean conditional probability of damaging multiple safety related systems in the auxiliary building is assumed to be $1 \times 10^{-2}$. Therefore, the resulting CDF (Configuration VIII) for this scenario is:

$$
\begin{aligned}
C D F_{C C W} \text { (seismic) }= & f(\text { seismic pipe failure in } P A B) P(\text { delayed ignition in } P A B) \\
& P(\text { blast propagation }) \\
= & \left(5.3 \times 10^{-5} / r y\right)\left(1 \times 10^{-1}\right)\left(1 \times 10^{-1}\right) \\
= & 5.3 \times 10^{-7} / r y
\end{aligned}
$$

7.4.6 Uncertainty Analysis for Auxiliary Building T/LOCA Scenarios. An uncertainty analysis was performed using the Monte Carlo sampling capability of the computer code @RISK. Table 16 lists the random variables, their distributions, and the associated parameters that were used. 
The uncertainty distributions for the initiating event frequencies were developed from the LER data base as described in Section 3 and Appendix B. The standard deviation values for the delayed ignition and blast propagation probabilities comes from the assumption that the lognormal error factor is equal to 10 . The results of the T/LOCA analysis are given in Subsection 7.4.7.

Table 16. Random variables for auxiliary building T/LOCA CDF analysis.

\begin{tabular}{ccc}
\hline Random Variable & Distribution & Parameters \\
\hline $\mathrm{f}\left(\mathrm{H}_{2}\right.$ large release event in & Gamma & $\alpha=0.5$ \\
$\mathrm{PAB})$ & & $\beta=1.09 \times 10^{-3} / \mathrm{ry}$ \\
$\mathrm{f}($ seismic pipe failure) & Lognormal & mean $=5.3 \times 10^{-5} / \mathrm{ry}$ \\
& & std.dev. $=1.87 \times 10^{-3} / \mathrm{ry}$ \\
$\mathrm{P}($ delayed ignition at & Lognormal & mean $=1 \times 10^{-2}$ \\
generator level) & std.dev. $=2.47 \times 10^{-2}$ \\
P(delayed ignition at & mean $=1 \times 10^{-1}$ \\
distribution system level) & & std.dev. $=2.47 \times 10^{-1}$ \\
P(blast propagation) & mean $=1 \times 10^{-1}$ \\
& Lognormal & std.dev. $=2.47 \times 10^{-1}$ \\
\hline
\end{tabular}

The uncertainty analysis results are:

- Auxiliary building (CCW, nonseismic) (Configuration VIII)

$$
\begin{array}{ll}
C D F_{\text {sth }}=1.0 \times 10^{-9} / r y & C D F_{50 \text { ch }}=2.0 \times 10^{-7} / r y \\
C D F_{95 \text { th }}=1.8 \times 10^{-5} / r y & C D F_{\text {mean }}=4.4 \times 10^{-6} / r y
\end{array}
$$

- $\quad$ Auxiliary building (CCW, seismic) (Configuration VIII)

$$
\begin{aligned}
& C D F_{\text {sih }}=8.0 \times 10^{-12} / r y \quad C D F_{50 \text { ch }}=2.0 \times 10^{-9} / r y \\
& C D F_{95 \text { th }}=5.4 \times 10^{-7} / r y \quad C D F_{\text {mean }}=3.4 \times 10^{-7} i r y
\end{aligned}
$$

7.4.7 Summary of Transient-Induced Loss-of-Coolant Accidents. For the T/LOCA analysis, two plant areas were evaluated: the turbine building and the auxiliary building. A seismic and nonseismic analysis was performed for both plant areas. The resulting mean values from the Monte Carlo analysis are: 
- If vital equipment (such as the $C C W$ ) is located in the turbine building on the distribution system level, the mean values for the CDF analysis are:

$$
\begin{array}{ll}
\mathrm{CDF}_{\text {nonseismic }} & =9.5 \times 10^{-6} / \mathrm{ry} \\
\mathrm{CDF}_{\text {seismic }} & =3.4 \times 10^{-7} / \mathrm{ry} \\
\mathrm{CDF}_{\text {total }} & =9.8 \times 10^{-6} / \mathrm{ry} \text { (Configuration IV) }
\end{array}
$$

- If vital equipment (such as the $\mathrm{CCW}$ ) is located in the turbine building on the generator level, the mean values for the $C D F$ analysis are:

$$
\begin{array}{ll}
\mathrm{CDF}_{\text {nonseismic }} & =5.3 \times 10^{-6} / \mathrm{ry} \\
\mathrm{CDF}_{\text {seismic }} & =2.0 \times 10^{-8} / \mathrm{ry} \\
\mathrm{CDF}_{\text {total }} & =\frac{5.3 \times 10^{-6} / \mathrm{ry}}{\text { (Configuration V) }}
\end{array}
$$

- If vital equipment (such as the $\mathrm{CCW}$ ) is located in the primary auxiliary building, the mean values for the $C D F$ analysis are:

$$
\begin{array}{ll}
\mathrm{CDF}_{\text {nonseismic }} & =4.4 \times 10^{-6} / \mathrm{ry} \\
\mathrm{CDF}_{\text {seismic }} & =3.4 \times 10^{-7} / \mathrm{ry} \\
\mathrm{CDF}_{\text {total }} & =4.7 \times 10^{-6} / \mathrm{ry} \text { (Configuration VIII) }
\end{array}
$$

- If the diesel generators are located in the turbine building on the distribution system level, the mean value for the $C D F$ analysis is:

$$
\mathrm{CDF}_{\text {seismic }} \quad=3.4 \times 10^{-7} / \mathrm{ry}
$$

\subsection{Plant-Specific Hydrogen Storage Facility Analysis}

The plants presented in this section were identified during the informal survey (see Subsection 7.2.2) as three examples (Plants A, B, and C) which invoked a need for more detailed risk calculation. The following sections provides this more detailed risk assessment.

\subsubsection{Hydrogen Storage Facility Explosion Analysis.}

7.5.1.1 Plant A. This plant has a hydrogen supply for the VCT of $14,400 \mathrm{scf}$ contained in two tanks. Using the EPRI guidelines, the allowable separation distance is about $25-28 \mathrm{ft}$ (assuming a wall static pressure value of $3 \mathrm{psi}$ ). The main steam enclosure, the closest safety-related structure, contains the main steam stop valves, main steam safety valves, MFW piping, and AFW motor-operated valves. The actual distance to the main steam enclosure is approximately $30 \mathrm{ft}$. Destruction of the main steam enclosure would cause a loss of both MFW and AFW. The top of the main steam enclosure is constructed of sheet-metal blow-out panels to minimize damage in the event of a steam explosion from within the enclosure. The lower portion of the enclosure is made of reinforced concrete. 
Plant $\mathrm{A}$ is similar in design to the $W$ base case plant in that most of the safety-related, nonsupport systems have similar capacities and capabilities. Thus, upon complete loss of secondary cooling, Plant A still has the ability to perform F\&B cooling using the high pressure injection system and the PORVs.

The frequency of all hydrogen fires or explosions is calculated from the LER database using the Bayesian analysis of a noninformative prior distribution (see Appendix B). The frequency of events at hydrogen storage facilities (HSF) is:

$$
f\left(H_{2} \text { fires or explosions in } H S F\right)=\frac{2(3)+1}{2(1424 r y)}=2.5 \times 10^{-3} / r y
$$

The probability of loss of secondary core cooling is 0.1 . This probability is based on engineering judgment and the fact that the separation distance is right at the outer limits set by the EPRI guidelines and the main steam enclosure is made of reinforced concrete greater than 18-in. thick. If it is assumed that there is zero probability that the wall will be breached if the distance was greater than $30 \mathrm{ft}$, then it is reasonable to assume that the probability of breaching the main steam enclosure and destroying both the MFW and AFW equipment within should be very low at $30 \mathrm{ft}$. The failure of $\mathrm{F} \& \mathrm{~B}$ cooling probability is taken from Subsection 7.3.1. The CDF under these conditions becomes:

$$
\begin{aligned}
C D F_{\text {Plant } A}= & f\left(H_{2} \text { fire or explosion in } H S F\right) P(\text { loss of secondary } \\
& \quad \text { cooling }) P(\text { failure to } F \& B) \\
= & \left(2.5 \times 10^{-3} / r y\right)(0.1)\left(4.5 \times 10^{-2}\right) \\
= & 1.1 \times 10^{-5} / r y
\end{aligned}
$$

The uncertainty parameters (calculated using the Monte Carlo analysis in the @RISK program) for the above calculation are: mean $=1.0 \times 10^{-5}, 5$ th $=4 \times 10^{-8}, 50$ th $=1.4 \times 10^{-6}$, and 95 th $=3.9$ $\times 10^{-5}$.

7.5. 1.2 Plant B. At Plant B, one of the hydrogen storage locations contains 85 standard hydrogen bottles (about $200 \mathrm{scf}$ each). At least four bottles are online. These bottles are stored in a metal shed within close proximity of the two emergency diesel generators. In between is the turbine oil storage bay, where large quantities of turbine lube oil are stored. An explosion here has the potential to cause extremely large fires in the area of the turbine building and diesel generator spaces. The hydrogen storage facility, not being seismically qualified, could be ruptured by a seismic event. In addition, the earthquake could cause a LOSP (due to the low seismic fragility of the station transformer's ceramic insulators). The LOSP, coupled with complete damage to the emergency diesel generators, would lead to a station blackout condition for the plant with a low probability of recovery. An estimate of the CDF contribution for this sequence would be: 


$$
\begin{aligned}
C D F_{\text {Plant } B}= & f(\text { seismic pipe failure }) P(\text { loss of offsite power }) \\
& P(\text { fire or explosion } \backslash S S E) P(D G \text { damage }) \\
= & \left(5.3 \times 10^{-5} / r y\right) \text { (1) (1) (1) } \\
= & 5.3 \times 10^{-5} / r y
\end{aligned}
$$

This assumes that the damage from the explosion would always fail both diesel generators. This is reasonable due to the large amount of fuel for a major fire supplied by the turbine lube oil storage bay next to the hydrogen storage facility.

The uncertainty parameters (hand-calculated since the CDF equation has only one lognormal variable) for the above calculation are: mean $=5.3 \times 10^{-5}, 5$ th $=1.9 \times 10^{-8}, 50$ th $=1.5 \times 10^{-6}$, and 95 th $=1.2 \times 10^{-4}$.

\subsubsection{Hydrogen Storage Facility Leakage into Air Intakes Analysis.}

7.5.2. 1 Plant A. The main generator hydrogen supply is $90 \mathrm{ft}$ away from the pump house containing the essential SW pumps (closest safety-related air intakes). The pump house is constructed of sheet metal with no forced ventilation. The essential SW pumps are deep-well pumps with the pumps down in the sump and the motors at ground level. The loss of SW would mean a loss of the ultimate heat sink for most of the safety-related systems, including the motor-driven AFW pump trains and the safety injection systems.

For a catastrophic leak from the hydrogen storage facility to be a risk concern, the uncombusted hydrogen cloud would have to drift over to the essential SW pump house and enter the pump house in sufficient concentration to be exploded by an ignition source,such as a pump motor. The eyplosion would have to render enough essential SW pumps inoperable to cause insufficient cooling water flow to necessary safety-related equipment. This transient is typically addressed in the plant's off-normal operating procedures. Actions in these procedures to restore cooling water flow or reduce the impact of the loss of flow usually include isolation of nonessential loads, staggering the operation of running equipment, or cross-connecting to other sources of cooling water such as the fire protection system. In many configurations, the turbine-driven AFW pump does not depend on any support systems for cooling and, therefore, is available.

The frequency of having a catastrophic hydrogen leak (with no fire or explosion) is based on no reported occurrences of leaks in over 1424 hydrogen storage facility years of oper ation. The probability of an explosion in the pump house is given a value of 0.5 . This implies that half the time that a leak occurs that the wind conditions, leak rate from the hydrogen storage facility, and hydrogen gas dispersion rate are such that the hydrogen cloud is ignited and explodes in the pump house. It was assumed that if such an explosion did occur, then all pumps would be made inoperable (with a failure probability of 1.0). The failure of the turbine-driven AFW train was that used in the $W$ base case PWR plant analysis for the failure of the turbine-driven pump train. The probability of failing to recover from the loss of $\mathrm{SW}$ is assumed to be dominated by failure of the plant operators to take the appropriate actions, since 
other water sources, electrical power, and all other needed support should be available. With the operators focused on getting cooling water back and the time available due to the operating AFW train, a human failure probability of $1 \times 10^{-2}$ was deemed appropriate.

An expression of the CDF for this sequence is:

$$
\begin{aligned}
C D F_{\text {Plant A }}= & f\left(H_{2} \text { leak }\right) P(\text { explosion Veak }) P(\text { damage to all } \\
& \text { pumps }) P(\text { turbine } A F W \text { failure }) P(\text { non-recovery }) \\
= & \left(3.5 \times 10^{-4} / r y\right)(0.5)(1)(0.014)\left(1.0 \times 10^{-2}\right) \\
= & 2.5 \times 10^{-8} / r y
\end{aligned}
$$

The uncertainty parameters (calculated using the Monte Carlo analysis in the @RISK program) for the above CDF are: mean $=6.1 \times 10^{-8}, 5$ th $=6 \times 10^{-11}, 50$ th $=1.1 \times 10^{-8}$, and 95 th $=2.9 \times$ $10^{-7}$.

7.5.2.2 Plant $B$. The close proximity of the hydrogen storage facility to the diesel generators poses a potential for hydrogen leakage into the diesel generator spaces. The resultant explosion would have the same impacts as described for explosion of the hydrogen storage facility itself.

A leak from the hydrogen storage facility would generate a hydrogen cloud that could escape from the metal shed around the storage facility. This cloud could then travel along the front or over the top of the diesel generator spaces. Most likely this cloud would continue on until it dissipated to very low hydrogen concentrations because there is no forced ventilation into the diesel generator spaces unless the diesel generators are running. The only time that the loss of the diesel generators would be important is during a LOSP.

The frequency of having a catastrophic hydrogen leak (with no fire or explosion) is based on no incidents in over 1424, hydrogen storage facility years. The frequency for the LOSP came from the NUREG-1150 analysis for Zion. The mean rate for the LOSP was found to be 0.078 per year (from NUREG-1150). This frequency was then used in the Poisson distribution to obtain the probability of having a LOSP during a one-year mission time. From the Poisson distribution, this probability of LOSP was found to be 0.075 .

The probability of an explosion assumes that the hydrogen cloud is equally likely to go toward the diesel generator spaces as away from them (a 50-50 chance). If the cloud goes toward the diesel generators it is assumed that an explosion will occur and both diesel generators will be destroyed. Thus, the only way to keep the core from damage is to recover offsite power before the station batteries deplete or the turbine-driven AFW pump train fails. The NUREG-1150 offsite power curve for Zion shows a six-hour value of 0.05 for failure to recover offsite power. The six-hour value assumes that the LOSP and the hydrogen explosion would occur simultaneously. Any time between the LOSP and the hydrogen explosion gives that much more time for the recovery of offsite power. 
An estimate for the CDF from this sequence is:

$$
\begin{aligned}
C D F_{\text {Plant B }}= & f\left(H_{2} \text { leak }\right) P(L O S P) P(\text { fire or explosion } \backslash \text { leak }) \\
& P(\text { no offsite power recovery }) \\
= & \left(3.5 \times 10^{-4} / r y\right)(0.075)(0.5)(0.05) \\
= & 6.6 \times 10^{-7} / r y
\end{aligned}
$$

The uncertainty parameters (calculated using the Monte Carlo analysis in the @RISK program) for the above CDF are: mean $=6.9 \times 10^{7}, 5$ th $=4 \times 10^{-9}, 50$ th $=7.5 \times 10^{-7}$, and 95th $=2.9 \times$ $10^{-5}$.

7.5.2.3 Plant $C$. The hydrogen storage facility at Plant $C$ consists of a tube trailer with $110,000 \mathrm{scf}$ of hydrogen in 10 tubes at $2500 \mathrm{psig}$. It is located about $140-180 \mathrm{ft}$ away from the $4160-\mathrm{V}$ switchgear area ventilation intake, which is partially protected by the startup transformer. Loss of the 4160-V switchgear room will cause a loss of most safety-related equipment. Important exceptions are the diesel generators and the turbine-driven AFW pump. A point estimate of the CDF for this sequence is:

$$
\begin{aligned}
C D F_{\text {Plant } C}= & f\left(H_{2} \text { leak }\right) P(\text { explosion } \backslash \text { leak }) P(\text { damage to all } \\
& \text { electrical equipment }) P(\text { turbine driven } A F W \text { failure }) \\
= & \left(3.5 \times 10^{-4} / r y\right)(0.5)(1.0)(0.014) \\
= & 2.5 \times 10^{-6} / r y
\end{aligned}
$$

The frequency of having a catastrophic hydrogen leak (with no fire or explosion) is based on no reported occurrences of leaks in over 1424 hydrogen storage facility years of operation. The probability of an explosion in the pump house is given a value of 0.5 . This implies that half the time that a leak occurs that the wind conditions, leak rate from the storage facility, and hydrogen gas dispersion rate are such that the hydrogen cloud is ignited and explodes in the switchgear room. It was assumed that if such an explosion did occur, then all safety-related equipment except the diesel generators and turbine-driven AFW pump would be made inoperable (with a failure probability of 1.0 ). The failure of the turbinedriven AFW train was that used in the Zion PRA for a turbine-driven pump train with dc power available.

The uncertainty parameters (calculated using the Monte Carlo analysis in the @RISK program) for the above CDF are: mean $=2.6 \times 10^{-6}, 5$ th $=3 \times 10^{-9}, 50$ th $=5.8 \times 10^{-7}$, and 95th $=1.2 \times$ $10^{-5}$. 


\subsection{Summary of Plant Generic Analyses}

The possible hydrogen accident scenarios have been grouped into 11 different PWR configurations (including three different hydrogen storage facility configurations). Table 17 lists the different configurations (excluding the hydrogen storage facility configurations), the plant applicabilities, the important hydrogen accident scenarios corresponding to each configuration, and the calculated CDF for each configuration.

Table 17. Generic plant configurations.

\begin{tabular}{|c|c|c|c|}
\hline Configuration & Plant Applicability & $\begin{array}{l}\text { Important Accident Scenarios } \\
\text { Applicable to Configuration }\end{array}$ & $\begin{array}{c}\text { CDF } \\
\text { (per ry) }\end{array}$ \\
\hline I & $\begin{array}{l}\text { All PWRs with AFW and vital } \\
\text { equipment outside of turbine and } \\
\text { auxiliary buildings }\end{array}$ & $\begin{array}{l}\text { T/DHR } \\
\text { T/LOCA }\end{array}$ & $3.4 \times 10^{-8}$ \\
\hline II & $\begin{array}{l}\text { Babcock \& Wilcox and Westinghouse } \\
\text { with AFW in turbine building } \\
\text { distribution system level }\end{array}$ & $\begin{array}{l}\text { T/DHR } \\
\text { (Feed and bleed credited) }\end{array}$ & $7.3 \times 10^{-7}$ \\
\hline III & $\begin{array}{l}\text { Combustion Engineering with AFW in } \\
\text { turbine building distribution system } \\
\text { level }\end{array}$ & $\begin{array}{l}\text { T/DHR } \\
\text { (Feed \& bleed not credited) }\end{array}$ & $9.4 \times 10^{-6}$ \\
\hline IV & $\begin{array}{l}\text { All PWRs with vital equipment in } \\
\text { turbine building distribution system } \\
\text { level }\end{array}$ & $\begin{array}{l}\text { T/LOCA } \\
\text { (Station ac blackout, or loss of } \\
\text { CCW, SW) }\end{array}$ & $9.4 \times 10^{-6}$ \\
\hline V & $\begin{array}{l}\text { All PWRs with vital equipment in } \\
\text { turbine building generator floor level }\end{array}$ & $\begin{array}{l}\text { T/LOCA } \\
\text { (Station ac blackout, or loss of } \\
\text { CCW, SW) }\end{array}$ & $5.2 \times 10^{-6}$ \\
\hline VI & $\begin{array}{l}\text { Babcock \& Wilcox and Westinghouse } \\
\text { with AFW in auxiliary building }\end{array}$ & $\begin{array}{l}\text { T/DHR } \\
\text { (Feed and bleed credited) }\end{array}$ & $2.0 \times 10^{-7}$ \\
\hline VII & $\begin{array}{l}\text { Combustion Engineering with AFW in } \\
\text { auxiliary building }\end{array}$ & $\begin{array}{l}\text { T/DHR } \\
\text { (Feed and bleed not credited) }\end{array}$ & $4.7 \times 10^{-6}$ \\
\hline VIII & $\begin{array}{l}\text { All PWRs with vital equipment in } \\
\text { auxiliary building }\end{array}$ & $\begin{array}{l}\text { T/LOCA } \\
\text { (Loss of CCW, SW) }\end{array}$ & $4.7 \times 10^{-6}$ \\
\hline
\end{tabular}




\section{COST/BENEFIT ANALYSIS}

To assess the cost effectiveness of a particular plant alternative, a dollar-to-person-rem averted ratio (DPR) is generated. A value of $\$ 1000$ per person-rem is used by the NRC as an upper bound in deciding whether corrective measures may be appropriate. The DPR is calculated as cost of alternative divided by the offsite person-rem averted:

$$
D P R=\frac{\text { cost of altermative }}{\text { offsite person-rem averted }}
$$

When onsite averted costs (OSAC) (i.e., potential reduction of onsite accident costs) are included as a cost offset in the expression for the DPR, the ratio becomes:

$$
D P R=\frac{\text { cost of alternative }- \text { onsite averted cost }}{\text { offsite person-rem averted }}
$$

The cost/benefit analysis is comprehensive and follows the guidelines of NUREG/CR-3568, ${ }^{41} \mathrm{~A}$ Handbook for Value-Impact Assessment, and NUREG/CR-4627, Revision 2, Generic Cosi Estimates. ${ }^{42}$

\subsection{Alternatives Considered}

Alternatives are considered for the turbine building, auxiliary building, and hydrogen storage facility. For each of these plant areas, three alternatives were considered.

8.1.1 Alternatives Considered for the Turbine Building. Three alternatives for the turbine building hydrogen distribution system were identified in Subsection 5.9. They include:

Alternative 1: Install an excess flow check valve on the hydrogen line header and a check valve on the hydrogen supply line at the generator. This hydrogen system alternative would require the placement of one excess flow check valve just downstream of the pressure regulator, and one check valve on the hydrogen supply line at the generator. If properly sized, an excess flow check valve would limit the amount of hydrogen released due to a pipe break to a concentration level easily dissipated, either by outside air or by building ventilation. The check valve on the hydrogen line at the generator will prevent backflow out of the generator given a hydrogen supply line pipe break.

Alternative 2: Periodic hydrogen makeup to the generator. This hydrogen system alternative would require changing plant procedures to allow periodic hydrogen makeup to the generator. This procedure was estimated to be an approximately $1 / 2$-hour task for two people each day. This alternative would allow the isolation of the hydrogen supply from the turbine building to the generator for the remaining 23-1/2 hours of the day. 
Alternative 3: Enclose the safety-related equipment in a blast-proof structure. This hydrogen system alternative is for those plants whose turbine building configuration is considered at higher risk from hydrogen-initiated events. It includes the cost of the engineering evaluation and the cost of performance of a alternative identified by the evaluation.

8.1.2 Alternatives Considered for the Auxiliary Building. Three alternatives for the auxiliary building hydrogen distribution system were identified in Subsection 5.9. They include:

Alternative 1: Install an excess flow check valve in the hydrogen supply line leading to the VCT. This hydrogen system alternative would require the placement of one excess flow check valve (sized for $150 \%$ of the maximum daily hydrogen flow) downstream of the pressure regulator in the hydrogen distribucion line for the VCT. The excess flow check valve (if properly sized) would restrict hydrogen flow out of a broken line to a level that could be easily dissipated by the building ventilation.

Alternative 2: Limit the hydrogen supply to a three 250-scf hydrogen storage facility for the VCT. This hydrogen system alternative would require the removal of three of the six existing 250 -scf hydrogen tanks present in the auxiliary building and the removal of the supply piping connection to the main hydrogen storage facility. The three remaining 250 -scf tank would be reconnected to form a limited supply day tank for the VCT. Limiting the amount of hydrogen in the auxiliary building would reduce the potential of a hydrogen storage facility emptying a large volume of hydrogen inside safety-related structures.

Alternative 3: Periodic hydrogen makeup to VCT. This hydrogen system alternative would require changing plant procedures to allow periodic hydrogen makeup to the VCT. This procedure was estimated to be an approximately 1/2-hour task for two people each day. This alternative would allow the isolation of the hydrogen supply from the auxiliary building to the VCT for the remaining 23-1/2 hours of the day.

8.1.3 Alternatives Considered for the Hydrogen Storage Facility. Three alternatives for the hydrogen storage facility distribution system were identified in Subsection 5.9. They include:

Alternative 1: Relocate the hydrogen storage facility to a distance within EPRI NP-5283-SR-A guidelines. ${ }^{12}$ This hydrogen system alternative would relocate the hydrogen storage facility to a distance meeting EPRI NP-5283-SR-A safe separation criteria. This would eliminate any potential of damage to safety-related equipment presently located near the hydrogen storage facility.

Alternative 2: Install a hydrogen blast wave deflection shield. This hydrogen system alternative would install a blast wave deflection shield. By deflecting the blast wave from a hydrogen detonation, a blast shield can greatly lessen the blast impact.

Alternative 3: Install hydrogen analyzer-actuated air intake louvers. This hydrogen system alternative would require the installation of automatic shutters controlled by hydrogen analyzers. This alternative would eliminate the ingress of a flammable (or detonable) hydrogen mixture into safety-related struciures via air intake pathways. 


\subsection{Core Damage Frequency Results}

In Sections 6 and 7 of this report, the hydrogen-initiated CDF contributions for the base case plant and other generic PWR plant configurations were calculated. These represent the CDF contribution before any plant alternatives (e.g., hardware and procedural changes) are implemented.

Configuration I accident scenarios are characterized by a hydrogen event (at the generator floor level) leading to a general plant transient or a steam line break. As discussed in Subsection 7.1, hydrogen-caused plant transients cannot be prevented (unless the hydrogen is eliminated from being used in plant operations) and main steam lines cannot be shielded from potential hydrogen detonations. Therefore, it was assumed that the risk associated with the Configuration I accident scenarios constitutes the base-line risk $\left(3.4 \times 10^{-8} /\right.$ ry $)$ and cannot be eliminated by any of the considered alternatives.

Each alternative implemented results in a reduction in the total accident sequence CDF. The change in CDF (or delta CDF) is the original accident sequence CDF (before CDF) minus the CDF after (CDF after) the alternative is implemented. The resultant delta CDF is multiplied by the consequences (or offsite release) to get the total offsite dose. Subsection 8.3 discusses how total offsite dose values were subsequently utilized in the cost/benefit analysis. Table 18 presents the CDFs for the various configurations and the delta CDFs for each configuration, which result after implementation of an applicable alternative. The numbers in this table are the calculated mean values from the uncertainty analyses performed in Sections 6 and 7.

\subsubsection{Delta CDF for Turbine Building Alternatives}

Alternative 1: Installing an excess flow check valve on the hydrogen line header would limit the amount of hydrogen released due to a pipe break to a concentration level easily dissipated, and check valve on the hydrogen supply line at the generator would prevent backflow out of the generator given a hydrogen supply line pipe break. Therefore, this alternative would reduce the contribution to risk from Configurations II, III, and IV, and from the base case plant configuration. The hydrogen risk due to general transient and SLB would remain for all four configurations $\left(3.4 \times 10^{-8} / \mathrm{ry}\right)$. The delta CDF after implementation of this alternative represents the removal of the potential for damage to the AFW system in Configurations II and III, and of the potential for T/LOCA in Configuration IV. It would not reduce the risk due to Configuration $\mathrm{V}$.

Alternative 2: Periodic hydrogen makeup to the generator would allow the isolation of the hydrogen supply from the turbine building to the generator for the remaining 23-1/2 hours of the day. Therefore this alternative would reduce the contribution to risk from Configurations II, III, and IV, and from the base case plant configuration. The hydrogen risk due to general transient and SLB would remain for all four configurations $\left(3.4 \times 10^{-8} / \mathrm{ry}\right)$. The delta CDF after implementation of this alternative represents the removal of the potential for damage to the AFW system in Configurations II and III, and of the potential for T/LOCA in Configuration IV. It would not reduce the risk due to Configuration $V$.

Alternative 3: Enclose the safety-related equipment in a blast-proof structure. This hydrogen system alternative is for those plants whose turbine building configuration is considered at higher risk from hydrogen-initiated events. This alternative could potential reduce the contribution to risk from

Configurations II, III, IV, and V, and from the base case plant configuration. The hydrogen risk due 


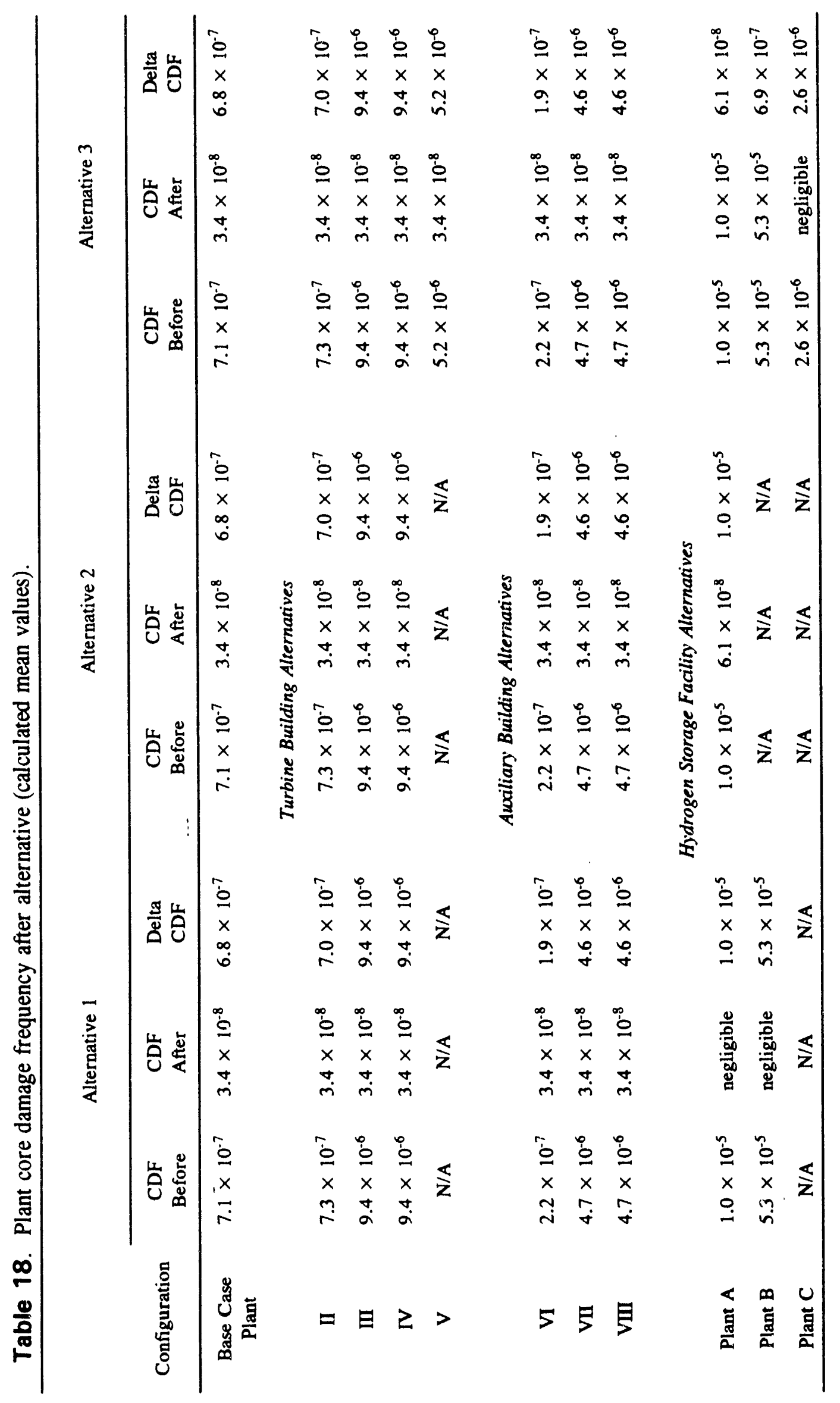


to general transient and SLB would remain for all five configurations $\left(3.4 \times 10^{-8} / \mathrm{ry}\right)$. The delta CDF after implementation of this alternative should represent the removal of the potential for damage to the AFW system in Configurations Il and III, and of the potential for T/LOCA in Configurations IV and V.

\subsubsection{Delta CDF for Auxiliary Building Alternatives}

Alternative 1: Installing an excess flow check valve in the hydrogen supply line leading to the VCT would restrict hydrogen flow out of a broken line to a level easily dissipated by the building ventilation. Therefore, this alternative would reduce the contribution to risk from Configurations VI, VII, and VIII. The hydrogen risk due to general transient and SLB would remain for all three configurations $\left(3.4 \times 10^{-8} / \mathrm{ry}\right)$. The delta CDF after implementation of this alternative represents the removal of the potential for damage to the AFW system in Configurations VI and VII, and of the potential for T/LOCA in Configuration VIII.

Alternative 2: Limiting the hydrogen supply to a three 250-scf hydrogen storage facility for the VCT would reduce the potential of a hydrogen storage facility emptying its hydrogen volume inside safety-related structures. Therefore, this alternative would reduce the contribution to risk from Configurations VI, VII, and VIII. The hydrogen risk due to general transient and SLB would remain for all three configurations $\left(3.4 \times 10^{-8} / \mathrm{ry}\right)$. The delta CDF after implementation of this alternative represents the removal of the potential for damage to the AFW system in Configurations VI and VII, and of the potential for T/LOCA in Configuration VIII.

Alternative 3: Periodic hydrogen makeup to VCT would allow the isolation of the hydrogen supply from the auxiliary building to the VCT for the remaining 23-1/2 hours of the day. Therefore this alternative would reduce the contribution to risk from Configurations VI, VII, and VIII. The hydrogen risk due to general transient and SLB would remain for all three configurations $\left(3.4 \times 10^{-8} / \mathrm{ry}\right)$. The delta CDF after implementation of this alternative represents the removal of the potential for damage to the AFW system in Configurations VI and VII, and of the potential for T/LOCA in Configuration VIII.

\subsubsection{Delta CDF for the Hydrogen Storage Facility Alternatives}

Alternative 1: This hydrogen system alternative would relocate the hydrogen storage facility to a distance meeting EPRI NP-5283-SR-A safe separation criteria. This alternative should eliminate the risk of a hydrogen explosion damage to nearby safety-related equipment and damage resulting from hydrogen leakage into air intakes for both Plants A and B. The CDF after Alternative 1 is negligible. Plant C's hydrogen storage facility was located at a safe distance from safety-related equipment (for explosion effects), and therefore Alternative 1 was not considered.

Alternative 2: This hydrogen system alternative would install a blast wave deflection shield. By deflecting the blast wave from a hydrogen detonation, a blast shield would reduce the risk of damaging safety-related equipment presently located near the hydrogen storage facility for Plant A. However, this will not eliminate the risk associated with hydrogen leakage into air intakes $\left(6.1 \times 10^{-8} / \mathrm{ry}\right)$. The physical configuration of the hydrogen storage facility of Plant B does not allow for Alternative 2 to be implemented (i.e., hydrogen gas cylinders located adjacent to building wall). Plant C's hydrogen storage facility was located at a safe distance from safety-related equipment (for explosion effects) and therefore Alternative 2 was not considered. 
Alternative 3: This hydrogen system alternative would require the installation of automatic shutters controlled by hydrogen analyzers. This would eliminate the risk due to leakage of a flammable (or detonable) hydrogen mixture into safety-related structures via air intake pathways for Plants A, B, and $C$. However, for Plants A and B this will not eliminate the risk associated with hydrogen explosion damage to nearby safety-related equipment $\left(1.0 \times 10^{-5} / \mathrm{ry}\right.$ and $5.3 \times 10^{-5} / \mathrm{ry}$, respectively). Since Plant $C$ 's hydrogen storage facility was located at a safe distance from safety-related equipment (for explosion effects) the CDF after Alternative 3 for this plant is negligible.

\subsection{Consequence Analysis}

The methodology employed in this consequence analysis is similar to that used in the NRCsponsored Adequacy of Decay Heat Removal Studies for Unresolved Safety Issue A-45. ${ }^{43}$ To convert the calculated delta CDF to an offsite dose, a simple functional containment event tree was used. The generic PWR containment event tree (CET) from that study is shown in Figure 15 . The three containment functions (shown on the CET as top events) are:

$$
\begin{aligned}
& \mathrm{Z}=\text { overpressure prevention function } \\
& \mathrm{C}_{2}=\text { radiation removal function using sprays } \\
& \mathrm{F}^{\prime}=\text { radiation removal function using spray recirculation. }
\end{aligned}
$$

The event tree has six end states depending on the success or failure of the three functions (i.e., top events). Success or failure of the overpressure protection is plant specific, but is a function of the status of the fan coolers, the containment spray pumps, and the containment spray recirculation pumps.

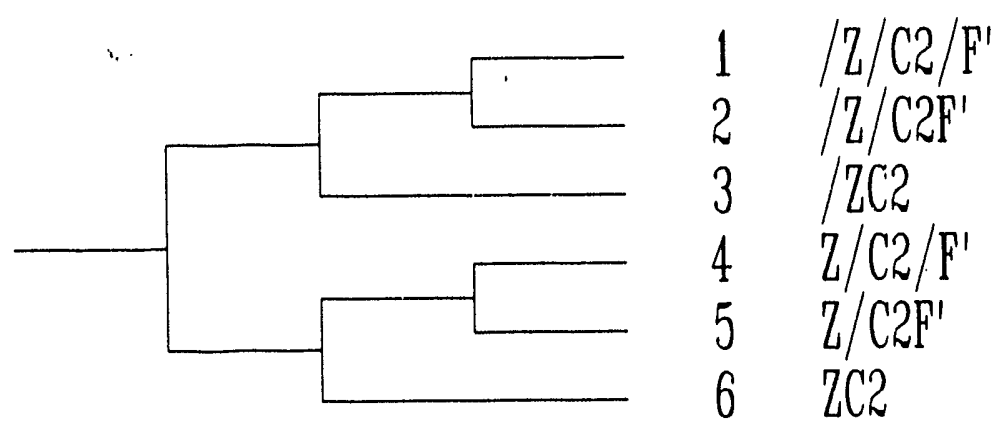

Figure 15. Generic PWR containme t event tree. 
The CET is used as follows. First, each accident sequence contributing to the CDF is mapped to one or more of the end-state branches (containment systems sequences) of the CET (e.g., $\mathrm{Z} / \mathrm{C}_{2} \mathrm{~F}^{\prime}$, $\mathrm{ZC}_{2}$ ). Each $\mathrm{CET}$ containment systems sequence is then assigned to a specific release category corresponding to a specific containment failure mode (with its own timing and mode of release of fission products). This assignment of CET sequences is performed using values presented in Table 19. Each containment failure mode (e.g., $\alpha, \beta)$ has a probability associated with a particular containment systems sequence. Under each probability, a release category (numbered 1 to 7 ) is found. For each sequence, the containment failure mode probability associated with the release category is multiplied by the appropriate source term factor presented in Table 20. This yields an individual offsite dose per event value. Summing all the offsite dose per event values calculated will then yield a total offsite dose per event. To calculate the total offsite dose (person-rem per year), the CDF mapped to that containment systems sequence must be multiplied by the total offsite dose per event.

Table 19. PWR accident sequence to release category mapping.

\begin{tabular}{|c|c|c|c|c|c|c|}
\hline \multirow{2}{*}{$\begin{array}{l}\text { Containment } \\
\text { Systems } \\
\text { Sequence }\end{array}$} & \multirow{2}{*}{$\begin{array}{c}\text { Special } \\
\text { Conditions } \\
\text { (core melt) }\end{array}$} & \multicolumn{5}{|c|}{$\begin{array}{l}\text { Containment Failure Mode with } \\
\text { Probability and Release Category }\end{array}$} \\
\hline & & $\alpha$ & $\beta$ & $\gamma \delta_{e}$ & $\delta_{e}$ & $\epsilon$ \\
\hline$/ \mathrm{Z} / \mathrm{C}_{2} / \mathrm{F}^{\prime}$ & & $1 \times 10^{-4}$ & $2 \times 10^{-3}$ & $\frac{1.4 \times 10^{-2}}{3}$ & $\frac{1.8 \times 10^{-1}}{5}$ & $\begin{array}{c}2.5 \times 10^{-1} \\
7\end{array}$ \\
\hline \multirow[t]{2}{*}{$/ \mathrm{Z} / \mathrm{C}_{2} \mathrm{~F}^{\prime}$} & $\mathrm{EM}^{\mathrm{a}}$ & $1 \times 10^{-4}$ & $\begin{array}{c}2 \times 10^{-3} \\
5\end{array}$ & $\begin{array}{c}1.4 \times 10^{-2} \\
3\end{array}$ & $\frac{1.8 \times 10^{-1}}{4}$ & $\frac{2.5 \times 10^{-1}}{6}$ \\
\hline & $\mathrm{LM}^{\mathrm{b}}$ & $1 \times 10^{-4}$ & $\begin{array}{c}2 \times 10^{-3} \\
4\end{array}$ & $\begin{array}{c}1.4 \times 10^{-2} \\
2\end{array}$ & $\underbrace{1.8}_{3} \times 10^{-1}$ & $\begin{array}{c}2.5 \times 10^{-1} \\
6\end{array}$ \\
\hline$/ \mathrm{ZC}_{2}$ & & $1 \times 10^{-4}$ & $2 \times 10^{-3}$ & $\frac{1.4 \times 10^{-2}}{2}$ & $\frac{1.8 \times 10^{-1}}{3}$ & $2.5 \times 10^{-1}$ \\
\hline $\mathrm{Z} / \mathrm{C}_{2} / \mathrm{F}^{\prime}$ & & $1 \times 10^{-4}$ & $2 \times 10^{-3}$ & $\begin{array}{c}1.4 \times 10^{-2} \\
3\end{array}$ & $\frac{1.8 \times 10^{-1}}{5}$ & $\begin{array}{c}2.5 \times 10^{-1} \\
7\end{array}$ \\
\hline \multirow[t]{2}{*}{$\mathrm{Z} / \mathrm{C}_{2} \mathrm{~F}^{\prime}$} & $\mathrm{EM}^{\mathrm{a}}$ & $1 \times 10^{-4}$ & $\begin{array}{c}2 \times 10^{-3} \\
.5\end{array}$ & $\frac{1.4 \times 10^{-2}}{3}$ & ${ }_{4}^{1.8 \times 10^{-1}}$ & $\frac{2.5 \times 10^{-1}}{6}$ \\
\hline & $\mathrm{LM}^{\mathrm{b}}$ & $1 \times 10^{-4}$ & $2 \times 10^{-3}$ & $\begin{array}{c}1.4 \times 10^{-2} \\
2\end{array}$ & $\mathbb{3}_{3}^{1.8} \times 10^{-1}$ & $\frac{2.5 \times 10^{-1}}{6}$ \\
\hline $\mathrm{ZC}_{2}$ & & $1 \times 10^{-4}$ & $2 \times 10^{-3}$ & $\begin{array}{c}1.4 \times 10^{-2} \\
2\end{array}$ & $\underbrace{1.8 \times 10^{-1}}_{3}$ & $2.5 \times 10^{-1}$ \\
\hline $\begin{array}{l}\text { a. } E M=\text { ear } \\
\text { b. } L M=\text { lat } \\
\text { Italicized num }\end{array}$ & $\begin{array}{l}\text { damage } \\
\text { damage } \\
\text { are the rele }\end{array}$ & 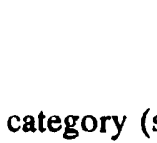 & e 20). & & & \\
\hline
\end{tabular}


Table 20. Conditional consequences values.

\begin{tabular}{cccc}
\hline $\begin{array}{c}\text { Release } \\
\text { Category }\end{array}$ & $\begin{array}{c}\text { Lower Bound Source } \\
\text { Term Population Dose } \\
\text { within 50 miles } \\
\text { (person-rem) }\end{array}$ & $\begin{array}{c}\text { Best Estimate Source } \\
\text { Term Population Dose } \\
\text { within 50 miles } \\
\text { (person-rem) }\end{array}$ & $\begin{array}{c}\text { Upper Bound Source } \\
\text { Term Population Dose } \\
\text { within 50 miles } \\
\text { (person-rem) }\end{array}$ \\
\hline 1 & $1.2 \times 10^{6}$ & $2.2 \times 10^{6}$ & $2.6 \times 10^{6}$ \\
2 & $1.6 \times 10^{6}$ & $2.4 \times 10^{6}$ & $3.5 \times 10^{6}$ \\
3 & $1.0 \times 10^{6}$ & $1.8 \times 10^{6}$ & $3.1 \times 10^{6}$ \\
4 & $3.7 \times 10^{5}$ & $7.5 \times 10^{5}$ & $1.5 \times 10^{6}$ \\
5 & $1.3 \times 10^{5}$ & $2.8 \times 10^{5}$ & $6.4 \times 10^{5}$ \\
6 & $2.2 \times 10^{4}$ & $4.1 \times 10^{4}$ & $9.6 \times 10^{4}$ \\
7 & $1.2 \times 10^{4}$ & $1.3 \times 10^{4}$ & $1.4 \times 10^{4}$ \\
\hline
\end{tabular}

The lower bound, baseline, and upper bound source term factors were derived from more detailed studies of containment failure and release and are used as generic estimates for a "typical" PWR as described in NUREG/CR-4762. ${ }^{43}$ In NUREG/CR-4762, the estimates of the fission product releases were used to calculate the potential consequences. The NUREG/CR-4762 supplied three sets of Calculations of Reactor Accident Consequences Version 2 computer code (CRAC) results for the source term as shown in Table 19. These are the integrated doses (in person-rem) received by the population around the plant after an accident, integrated out to a distance of 50 miles.

Using the methodology presented above, the $\mathrm{ZC}_{2}$ containment systems sequence of the CET total best estimate dose over 20 years was calculated to be $7.39 \times 10^{6}$ person-rem. The best estimate of the total ofisite dose reduction due to implementation of an alternative is obtained by multiplying the best estimate dose over 20 years by the delta CDF for that alternative from Table 18 . The calculated dose reductions for the alternatives considered are presented in Table 21.

For the uncertainty analysis, the yearly population dose parameters were found to be 209,000 person-rem, 370,000 person-rem, and 635,000 person-rem, for lower bound, best estimate, and upper bound, respectively. The yearly dose numbers are multiplied by the calculated mean of the delta CDF. Tha resulting person-rem per year, modeled with a triangular distribution (see Subsection 8.8), are then multiplied by the remaining lifetime of the reactor, which for this study is assumed to be 20 years.

\subsection{Onsite Averted Costs}

In addition to the costs associated with the alternative, the potential reduction of onsite accident costs as a cost offset was evaluated. A Handbook for Value-Impact Assessment ${ }^{41}$ was used as the reference for this evaluation. This reference calculates the OSAC using the following equation:

$$
\mathrm{V}_{\mathrm{op}}=\mathrm{NU}\left(\mathrm{F}_{\mathrm{O}}-\mathrm{F}_{\mathrm{N}}\right)
$$


where

$$
\begin{aligned}
& \mathrm{V}_{\mathrm{op}}=\text { cost of avoided onsite property damage (OSAC) } \\
& \mathbf{N}=\text { number of affected facilities } \\
& \mathrm{U}=\text { present worth of onsite property damage given a release } \\
& \mathrm{F}_{\mathrm{O}}=\text { original CDF (base case) } \\
& \mathrm{F}_{\mathrm{N}}=\text { CDF after implementing an option. }
\end{aligned}
$$

\begin{tabular}{|c|c|c|c|}
\hline Configuration & $\begin{array}{l}\text { Alternative } 1 \\
\text { Offsite Dose } \\
\text { (person-rem) }\end{array}$ & $\begin{array}{l}\text { Alternative } 2 \\
\text { Offsite Dose } \\
\text { (person-rem) }\end{array}$ & $\begin{array}{l}\text { Alternative } 3 \\
\text { Offsite Dose } \\
\text { (person-rem) }\end{array}$ \\
\hline Base Case Plant & 5.0 & 5.0 & 5.0 \\
\hline \multicolumn{4}{|c|}{ Turbine Building Alternatives } \\
\hline II & 5.2 & 5.2 & 5.2 \\
\hline III & 69 & 69 & 69 \\
\hline IV & 69 & 69 & 69 \\
\hline V & $\mathbf{N} / \mathbf{A}$ & N/A & 38 \\
\hline \multicolumn{4}{|c|}{ Auxiliary Building Alternatives } \\
\hline VI & 1.4 & 1.4 & 1.4 \\
\hline VII & 34 & 34 & 34 \\
\hline VIII & 34 & 34 & 34 \\
\hline \multicolumn{4}{|c|}{ Hydrogen Storage Facility Alternatives } \\
\hline Plant A & 74 & 74 & 0.45 \\
\hline Plant B & 390 & N/A & 5.1 \\
\hline Plant C & N/A & N/A & 19 \\
\hline
\end{tabular}

Table 21. Total offsite dose by PWR configuration (person-rem for 20-year PWR plant lifetime). 
The present worth of onsite property damage given a release, $\mathrm{U}$, is calculated by:

$$
U=\frac{C}{m}\left[\left(e^{-r t}\right) / r^{2}\right]\left[1-e^{-r\left(t_{f}-t_{1}\right)}\right]\left(1-e^{-r m}\right)
$$

where

$$
\begin{array}{lll}
\mathrm{C} & = & \text { cleanup, repair, and replacement power costs } \\
\mathrm{t}_{\mathrm{f}} & = & \begin{array}{l}
1 \\
\mathrm{t}_{\mathrm{i}}
\end{array} \quad=\quad \text { years remaining until end of plant life } \\
\mathrm{m} & =\text { period of time over which damage costs are paid out } \\
r & =\text { discount rate (for } 10 \%, r=0.10) .
\end{array}
$$

When an uncertainty in the calculation $r$. $\mathrm{V}_{\text {op }}$ is considered, it is appropriate to calculate a low, best, and high estimate for the worth of $U$. 'I hese values can then be multiplied by the delta CDF to yield a low, best, and high cost for $\mathrm{V}_{\mathrm{op}}$. The cost handbook ${ }^{41}$ recommends low, best, and high estimate values for input to calculating $U$ (percent value of onsite property damage given a release) as follows:

$$
\begin{array}{ll}
\mathrm{C}= & \text { Low- } \$ 1,035 \times 10^{6} \\
& \text { Best-- } \$ 1,650 \times 10^{6} \\
& \text { High-- } \$ 4,950 \times 10^{6} \\
\mathrm{~m}= & \text { Low--7.5 years } \\
& \text { Best--10 years } \\
\mathrm{r}= & \text { High--10 years } \\
\mathrm{t}_{\mathrm{f}}= & 0.10 \\
\mathrm{t}_{\mathrm{i}}= & 20 \text { ry }
\end{array}
$$

A Handbook for Value-Impact Assessment ${ }^{41}$ states that "the quantity, U, must be interpreted carefully to avoid misunderstandings. It does not represent the expected onsite property damage due to a single accident. Rather, it is the present value of a stream of potential losses extending over the remaining lifetime of the reactor. Thus, it reflects the expected loss due to a single accident; the possibility that such an accident could occur, with some small probability, at any time over the remaining 
reactor life; and the effects of discounting these potential future losses to present value. When the quantity, $\mathrm{U}$, is multiplied by the accident frequency, the result is the expected loss over the reactor life, discounted to present value."

The low, best, and high present onsite property damage costs (including cleanup cost, repair/refurbishment cost, and replacement energy cost) given a release were calculated and are presented below:

$$
\begin{aligned}
& \text { Low estimate of } U=\$ 6.3 \times 10^{9} / \text { severe accident event } \\
& \text { Best estimate of } U=\$ 9.0 \times 10^{9} / \text { severe accident event } \\
& \text { High estimate of } U=\$ 2.7 \times 10^{1 \%} / \text { severe accident event. }
\end{aligned}
$$

For this study, the OSAC was calculated using the delta CDF (from Table 17) for each plant configuration for each applicable alternative considered. The calculated mean delta CDFs were multiplied by the low, best, and high estimates of $U$ values shown above to yield the low, best, and high OSAC as shown in Table 22.

\subsection{Cost Estimating Methodology}

This subsection presents the general methodology used in performing the cost analysis for the hydrogen system alternatives considered. This involved an initial design evaluation of the alternative considered, identification of equipment and materials necessary for each alternative, and an assessment of the work area within the plant in which each alternative would take place. All plant cost estimates are presented in 1991 dollars and represent implementation costs for the specific improvement and any recurring costs associated with each plant alternative.

8.5.1 Assumptions. The following general assumptions were made in developing cost estimates for the alternatives considered:

- $\quad$ Alternatives will be made during normal plant operations or during scheduled shutdowns such that no replacement energy costs will be incurred by the utility

- Socioeconomic impacts will be considered minimal (since the changes only entail relatively simple hardware changes) and will not be included as an increment of cost

- Although equipment/component locations for an alternative are specific to the reference plant, the environmental factors chosen to estimate worker productivity reductions are appropriate for the entire PWR plant population. 


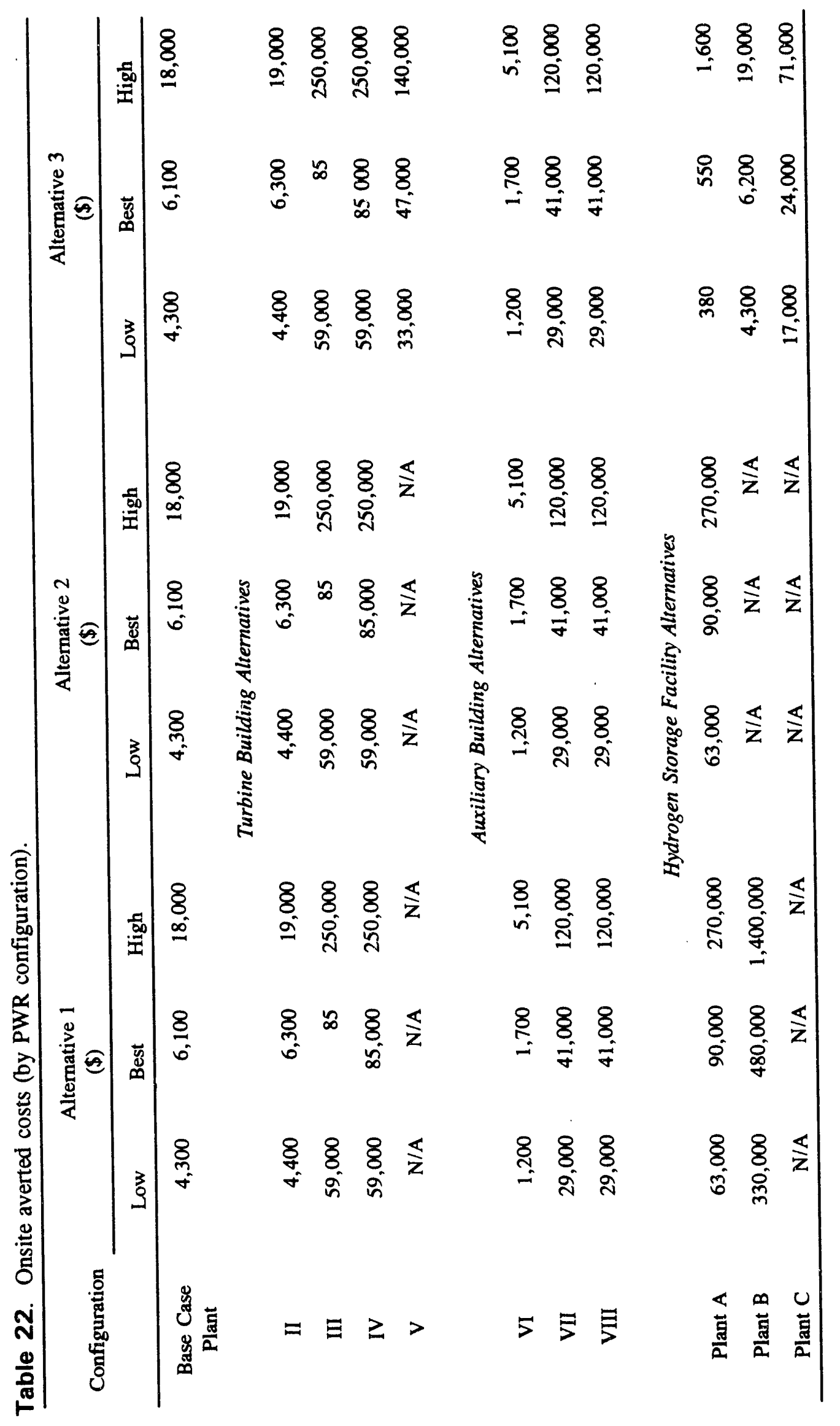


8.5.2 Cost Categories Considered. All costs were computed using FORECAST $2.1^{44}$ and were based on the input provided by the cost analyst. The cost analyses were limited to the following:

- $\quad$ Cost of equipment, materials, and structures

- Installation and removal costs (where applicable) and associated overhead

- Engineering and quality assurance costs

- $\quad$ Radiation exposure costs

- Health physics support costs

- Licensee costs for rewriting procedures, staff training, and other technical subtasks

- Licensee recurring costs

- $\quad$ NRC implementation costs associated with the review of the plant alternatives

- $\quad$ NRC recurring costs

- Onsite averted costs that represent the averted onsite property damages, including allowances for cleanup, repair, and replacement energy costs.

The following subsection explains the overall methodology and parameters used by FORECAST 2.1 in the cost derivation.

\subsubsection{Key Cost Parameters.}

8.5.3.1 Labor and Equipment/Materials Costs. The Energy Economic Data Base $(E E D B)^{44-46}$ built into the FORECAST 2.1 code provided the basis for the equipment/material cost and labor estimate. The EEDB incorporates "as-built" cost information (both material unit cost and installation labor hours) for nuclear plant construction activities. Additionally, for operating nuclear power plants there are a number of workplace characteristics that significantly reduce the level of productivity and thus increase the number of labor hours required to accomplished a task. These characteristics, discussed in detail in FORECAST $2.1,{ }^{44}$ include access, congestion and interference, radiation, task management, etc. Since EEDB reflects only new (or "as-built") plant conditions, the installation and/or removal labor hours were adjusted to properly consider actual conditions existing at operating nuclear plants.

The total labor costs associated with the alternatives considered include overhead charges to account for contractor management, administrative support, rent, insurance, etc. 
8.5.3.2 Engineering and Quality Assurance/Control Costs. Engineering and quality assurance costs reflect the cost of engineering and design, as well as quality assurance/control (QA/QC) activities associated with implementing the requirements. For requirements affecting structures/systems already in place (operating plants) the guidelines of Abstract 6.4 of Generic Cost Estimates, ${ }^{42}$ recommend a $25 \%$ engineering and $\mathrm{QA} / \mathrm{QC}$ factor be applied to the direct cost (i.e., labor and materials cost but without any overhead charges). All cost estimates developed in this study include this engineering and QA/QC cost component when applicable.

8.5.3.3 Radiation Exposure. Worker radiation exposure estimates were derived based on guidelines presented in Abstract 4.3 of Generic Cost Estimates. ${ }^{42}$ The collective radiation exposure associated with the implementation of a alternative considered is estimated by taking the product of the in-field labor hours necessary to perform the task and the work area dose rate associated with that particular task.

8.5.3.4 Health Physics Support Costs. Health physics requirements for the alternative considered were developed based on information and guidelines presented in Abstract 2.1.6 of Generic Cost Estimates. 4? Two factors were considered: the size of the work crew and the magnitude of the radiation field. 'The plant health physics personnel perform radiological surveys that are conducted throughout the tìne required to perform the alternative, staff radiological checkpoints, set up anticontamination clothing removal areas, as well as determine badging requirements.

8.5.3.5 Other Licensee Costs. Other costs incurred by the utility as a result of implementing the alternatives considered included the costs of re-writing procedures, training the staff (both maintenance and operations), and changing recordkeeping or reporting requirements. For each of the above-stated cost categories, the costs were derived following the guidelines presented in Abstracts $2.2 .2,2.2 .3$, and 2.2 .4 , respectively, of Reference 42 .

8.5.4 NRC Costs. NRC implementation costs account for such one-time NRC activities as developing inspection guidelines and procedures, ensuring compliance with the regulatory action, and other technical tasks. Cost for NRC recurring operation includes periodic inspections of nuclear facilities to ensure compliance with regulations and standards.

8.5.5 Cost Estimating Uncertainty. The areas of uncertainty associated with the cost estimating model for this study included the following:

- Labor rate variations due to plant site location

- Contingency allowance

- Variability of in-plant work environment conditions

- Licensee procedural/administrative/analytical cost

- NRC procedural/administrative/analytical cost

- Discount rate variation in the recurring cost module. 
Each cost estimate was evaluated to determine all areas of uncertainty applicable. Specific numerical values were used for each indiviáual cost analysis. However, the following general assumptions were made:

- Labor rate variations due to plant sice location are a consideration when calculating labor costs. The assumed labor rate variation was as follows: best estimate is $100 \%$ of the labor cost, the high cost estimate is $112 \%$, and the low cost estimate is $88 \%$. This accounts for the geographic variability in labor rates.

- The contingency factor provides the user with a means for including an allowance for uncertainty and cost variations at the summary cost level. A contingency perceritage can be applied to some or all of the applicable licensee cost categories (i.e., physical alternative costs, replacement energy costs, recurring costs and procedural/analytical costs) and for NRC recurring and procedural/analytical costs. A $10 \%$ contingency factor was assumed applicable to cost categories for the high cost estimate. For the best estimate and low estimate, no contingency factor was applied.

- The working environment characteristics are reflected in the labor productivity factor. Radiation, congestion, and access and handling conditions in the area where the alternative is being performed increase the amount of time spent for that task. For the best estimate cost calculation, the labor productivity factor for typical work conditions (as derived by the FORECAST 2.1 code) was used. A labor productivity factor for an environment reflecting less radiation and congestion was used for the low cost estimate calculation. Conversely, a higher value for the labor productivity factor, (an environment reflecting more radiation and congestion) was used for the high cost estimate calculation.

- The licensee procedural/administrative/analytical cost module in FORECAST 2.1 allows alternatives to reflect uncertainty in the following cost categories: technical specification change, writing procedures, staff training, recordkeeping and other technical costs. In the case of the technical specification change, writing procedures and recordkeeping the FORECAST 2.1 package allows a change from "simple" to "complex" depending on the plant specific situation. The value developed for the simple change is used for the low cost estimate and the value developed for the complex change is used for the high cost estimate. For both, the staff training and other technical costs, uncertainty is reflected by varying the number of students and/or hours required for the training/evaluation. For example, training costs will be greater in those plants with additional operators needing training (e.g., five operator teams versus six teams in other plants).

- The NRC procedural/administrative/analytical cost module in FORECAST 2.1 allows alternatives to reflect uncertainty in the following cost categories: implementation and other technical costs. For the low, best, and high cost estimate calculations, implementation and other technical costs were modified by varying the staff hours and/or hourly rate. 
- In the recurring cost modules for the licensee and the NRC, all future costs considered (e.g., maintenance and testing costs) are discounted to reflect the present value using the high and low discount rates chosen. The defaults used are a $10 \%$ rate, appropriate for the low cost estimate, and a $5 \%$ rate, appropriate for the best cost estimate. No present value discounting rate was used for the high cost estimate.

\subsection{Plant Alternative Cost Estimate}

In Subsection 8.1, several alternatives considered for the hydrogen distribution systems were identified. The alternatives are relisted below to aid in following the cost analysis.

8.6.1 Alternatives Considered for the Turbine Building. Three alternatives for the turbine building hydrogen distribution system were identified in Subsection 8.1. They are:

- Install an excess flow check valve on the hydrogen line header and a check valve on the hydrogen supply line at the generator (Alternative 1)

- Periodic hydrogen makeup to the generator (Alternative 2)

- $\quad$ Enclose the safety-related equipment in a blast-proof structure (Alternative 3).

8.6.1.1 Alternative 1 - Installation of Valves. The hydrogen system alternative would require the placement of one excess flow check valve just downstream of the pressure regulator, and one check valve on the hydrogen supply line at the generator. The excess flow check valve will be sized to allow only that amount of hydrogen for normal daily operation (between 600 and $1000 \mathrm{scf} /$ day). For the initial generator purge and fill process, a supply line containing a removable spool piece, bypassing the excess flow check valve (downstream of the pressure regulator), will be installed. If properly sized, an excess flow check valve would limit the amount of hydrogen released due to a pipe break to a concentration level easily dissipated, either by outside air or by building ventilation. The check valve on the hydrogen line at the generator will prevent backflow out of the generator given a hydrogen supply line pipe break.

The cost of flow check valve is approximately $\$ 870$ each, and the average cost of the removal spool piece and associated piping, is approximately $\$ 1000$. It was estimated to require 2 persondays/valve or spool for installation (1 person-day/valve or spool for a welder and 1 person-day/valve or spool for a fitter). The hourly labor rate from the EEDB data base in FORECAST 2.1 was used. Licensee recurring costs include $\$ 500 /$ year for test and maintenance. All cost were adjusted according to the workplace characteristics and included overhead charges.

In this study, the cost estimates associated with the NRC were primarily derived from guidelines and input provided in NUREG/CR-3568 $8^{41}$ and NUREG/CR-4627, Rev. 2.42 For NRC one-time activities, the best cost estimate assumed that the NRC implementation costs per plant would include 5 person-hours to develop guidelines, and 2 person-days for initial plant inspection. For NRC recurring 
costs, it was assumed that 1 person-day per year was necessary per plant for review and inspection of plant operation and maintenance activities.

A low, best, and high range of cost estimates were developed following the guidelines described in Subsection 8.5. Table 23 shows the cost breakdown for this alternative. The total cost values are $\$ 14,600$ for the low estimate, $\$ 19,900$ for the best estimate, and $\$ 32,100$ for the high estimate. This is a range difference from the low to the high cost estimate of $\$ 17,500$. A main contributor to this difference is the contingency factor (10\% included in the high cost estimate), and the discount rate included in the recurring costs (see Subsection 8.5.5).

Table 23. Turbine building Alternative 1 cost breakdown.

\begin{tabular}{lrrr} 
& \multicolumn{3}{c}{ Cost Estimate } \\
\cline { 2 - 4 } \multicolumn{1}{c}{ Category } & $\begin{array}{r}\text { Low } \\
(\$)\end{array}$ & $\begin{array}{r}\text { Best } \\
(\$)\end{array}$ & $\begin{array}{r}\text { High } \\
(\$)\end{array}$ \\
\hline Material and hardware cost & 2,000 & 2,000 & 2,000 \\
Installation labor & 2,900 & 3,100 & 3,700 \\
Engineering/QA costs & 900 & 900 & 1,000 \\
Licensee procedural/analytical & 1,000 & 1,500 & 2,000 \\
Licensee contingency & $\mathrm{N} / \mathrm{A}$ & $\mathrm{N} / \mathrm{A}$ & 900 \\
& & & \\
Total licensee one-time cost & 6,800 & 7,500 & 9,600 \\
Total licensee recurring cost & 4,500 & 7,000 & 12,900 \\
Total NRC one-time cost & 500 & 1,000 & 1,800 \\
Total NRC recurring cost & 2,800 & 4,400 & 7,800 \\
Total (without onsite averted cost) & 14,600 & 19,900 & 32,100 \\
\hline
\end{tabular}

8.6. 1.2 Alternative 2 - Periodic Hydrogen Makeup to the Generator. Alternative 2 would require changing plant procedures to allow periodic hydrogen makeup to the generator. This procedure was estimated to be an approximately $1 / 2$-hour task for two people each day. This alternative would allow the isolation of the hydrogen supply from the turbine building to the generator for the remaining 23-1/2 hours of the day.

For licensee procedural and analytical activities, the best cost estimate included the costs of a routine operating procedure write-up, $\$ 1000$ for routine recordkeeping, and staff training (10 students with two hours classroom and two hours on the job training). For NRC one-time activities, the best cost estimated that the NRC technical cost per plant would include 40 person-hours. 
The licensee recurring cost, due to the change in operating procedures, is the largest contributor to the total cost analysis. This alternative would require a yearly licensee recurring cost of 256 hours ( 1 person-hour per day $\times 365$ days per year $\times 0.70$ plant availability factor) for the remaining plant life (20 years). The best estimate for this cost are calculated in FORECAST 2.1 to reflect the labor productivity factors inherent in this area of the PAB.

A low, best, and high range of cost estimates was developed for Alternative 2 following the guidelines described in Subsection 8.5. Table 24 shows the cost breakdown for this alternative. The total cost values are: $\$ 65,800$ for the low estimate, $\$ 106,100$ for the best estimate, and $\$ 220,000$ for the high estimate. This is a range difference from the low to the high cost estimate of $\$ 154,200$. A main contributor to this differences is the contingency factor (10\% included in the high cost estimate), the discount rate applied to recurring costs, and the change from a simple to complex operation procedure rewrite (see Subsection 8.5.5).

Table 24. Turbine building Alternative 2 cost breakdown.

\begin{tabular}{lrrr} 
& \multicolumn{3}{c}{ Cost Estimate } \\
\cline { 2 - 4 } \multicolumn{1}{c}{ Category } & Low & Best & High \\
& $(\$)$ & $(\$)$ & 22,500 \\
\hline Licensee procedural/analytical & 2,900 & 3,800 & 2,300 \\
Licensee contingency & 0 & 0 & \\
& & & 24,800 \\
Total licensee one-time cost & 2,900 & 3,800 & 191,900 \\
Total licensee recurring cost & 62,000 & 100,500 & 3,300 \\
Total NRC one-time cost & 900 & 1,800 & N/A \\
Total NRC recurring cost & N/A & N/A & 220,000 \\
Total (without onsite averted cost)
\end{tabular}

8.6.1.3 Alternative 3 - Enclose Safety-Re/ated Equipment. This alternative is for those plants whose turbine building configuration is considered at higher risk from hydrogen-initiated events. The turbine building plant configurations were identified in Section 7 of this report. The contribution to CDF varies from $9.4 \times 10^{-6} / \mathrm{ry}$ to less than $3.4 \times 10^{-8} / \mathrm{ry}$, depending on the turbine building accident scenario. This alternative includes the cost of a plant specific $\$ 100,000$ engineering evaluation of the risk inherent to safety-related equipment and the cost of the implementation of an alternative to reduce risk. To reduce CDF $10^{-5} / \mathrm{yr}$, it is justifiable to spend a maximum cost of $\$ 200,000$. To reduce CDF $10^{-4} / r y$, it is justifiable to spend a maximum of $\$ 2$ million. It is anicipated that for those plant configurations considered at the higher risk (in the range of $10^{-4} /$ ry), that the alternative would have a best cost estimate of 1 million dollars. 
The low, best, and high cost estimate breakdown for this alternative is done on an order of magnitude scale, due to the potential differences in plant configurations and contribution to risk. This resulted in a low estimate of $\$ 100,000$ and a high estimate of $\$ 10$ million as shown in Table 25 .

Table 25. Turbine building Alternative 3 cost breakdown.

\begin{tabular}{|c|c|c|c|}
\hline \multirow[b]{2}{*}{ Category } & \multicolumn{3}{|c|}{ Cost Estimate } \\
\hline & $\begin{array}{r}\text { Low } \\
(\$)\end{array}$ & $\begin{array}{r}\text { Best } \\
(\$)\end{array}$ & $\begin{array}{r}\text { High } \\
(\$)\end{array}$ \\
\hline Engineering costs & 10,000 & 100,030 & $1,000,000$ \\
\hline Alternative costs & 100,000 & $1,000,000$ & $10,000,000$ \\
\hline Total (without onsite averted cost) & 110,000 & $1,100,000$ & $11,000,000$ \\
\hline
\end{tabular}

8.6.2 Alternatives Considered for the Auxiliary Building. Three alternatives for the auxiliary building hydrogen distribution system were identified. They are:

- Install an excess flow check valve in the hydrogen supply line leading to the VCT (Alternative 1)

- Limit the hydrogen supply to a three 250 -scf hydrogen storage facility for the VCT (Alternative 2)

- $\quad$ Periodic hydrogen makeup to VCT (Alternative 3).

8.6.2.1 Alternative 1 - Excess Flow Check Valve. The hydrogen system alternative would require the placement of one excess flow check valve (sized for $150 \%$ of the maximum daily hydrogen flow) downstream of the pressure regulator in the hydrogen distribution line for the VCT. The excess flow check valve (if properly sized) would restrict hydrogen flow out of a broken line to a level easily dissipated by the building ventilation.

The average cost of one excess flow check valve is approximately $\$ 870$ and was estimated to require 2 person-day/valve for installation (1 person-day/valve for a welder and 1 person-day/valve for a fitter). The hourly labor rate from the EEDB data base in FORECAST 2.1 was used. Recurring licensee costs include 10 person-hours/year for test and maintenance. All cost were adjusted according to the workplace characteristics and included overhead charges.

For the best cost estimate, a minimum health physics cost increment ( $\$ 100$ per plant) is included, since area radiological surveys and other health physics activities still have to be performed even though this alternative will be performed in an area of minimal exposure. 
In this study, the cost estimates associated with the NRC were primarily derived from guidelines and input provided in NUREG/CR-3568 ${ }^{41}$ and NUREG/CR-4627, Rev. $2 .^{42}$ For NRC one-time activities, the best cost estimate assumed that the NRC implementation costs per plant would include 5 person-hours to develop guidelines, and 1 person-day for initial plant inspection. For NRC recurring costs, it was assumed that 1 person-day per year was necessary per plant; for review and inspection of plant operation and maintenance activities.

A low, best, and high range of cost estimates were developed for Alternative 1 following the guidelines described in Subsection 8.5. Table 26 shows the cost breakdown for this alternative. The total cost values are: $\$ 9,000$ for the low estimate, $\$ 12,300$ for the best estimate and $\$ 20,700$ for the high estimate. This is a range difference from the low to the high cost estimate of $\$ 11,700$. A main contributor to these differences is the contingency factor $(10 \%$ included in the high cost estimate: see Subsection 8.5.5).

Table 26. Auxiliary building Alternative 1 cost breakdown.

\begin{tabular}{lrrr} 
& \multicolumn{3}{c}{ Cost Estimate } \\
\cline { 2 - 4 } \multicolumn{1}{c}{ Category } & $\begin{array}{r}\text { Low } \\
(\$)\end{array}$ & $\begin{array}{r}\text { Best } \\
(\$)\end{array}$ & $\begin{array}{r}\text { High } \\
(\$)\end{array}$ \\
\hline Material and hardware cost & 900 & 900 & 900 \\
Installation labor & 1,300 & 1,400 & 1,600 \\
Engineering/QA costs & 400 & 400 & 400 \\
Health physics costs & 0 & 100 & 300 \\
Licensee procedural/analytical & 800 & 1,000 & 1,300 \\
Licensee contingency & $\mathrm{N} / \mathrm{A}$ & $\mathrm{N} / \mathrm{A}$ & 500 \\
& & & \\
Total licensee one-time cost & 3,400 & 3,800 & 5,000 \\
Total licensee recurring cost & 2,400 & 3,600 & 6,700 \\
Total NRC one-time cost & 400 & 600 & 1,100 \\
Total NRC recurring cost & 2,800 & 4,300 & 7,900 \\
Total (without onsite averted cost) & 9,000 & 12,300 & 20,700 \\
\hline
\end{tabular}

8.6.2.2 Alternative 2 - Limiting Hydrogen Tank Supply. Alternative 2 would require the removal of three of the six existing 250 -scf hydrogen tanks present in the auxiliary building and the removal of the supply piping connection to the main hydrogen storage facility. The three remaining 250 scf tank would be reconnected to form a limited supply day tank for the VCT. Limiting the amount of 
hydrogen in the auxiliary building would reduce the potential of a hydrogen storage facility emptying its hydrogen volume inside safety-related structures.

The removal of three tanks offline and the removal of the connection with the main hydrogen storage facility were estimated to require 8 and 4 person-hours of labor, respectively. The reconfiguration of the remaining three tanks online, including hookup to the existing pressure reducing station and pressure regulator, was estimated to require 48 person-hours. The hourly labor rate from the EEDB data base in FORECAST 2.1 was used. All cost were adjusted according to the workplace characteristics and included overhead charges. Recurring costs were not included, since existing hookup already requires test and maintenance.

For the best cost estimate, a minimum health physics cost increment ( $\$ 600$ per plant) is included, since area radiological surveys and other health physics activities still have to be performed even though this alternative will be performed in an area of minimal exposure.

For licensee procedural and analytical activities, the best cost estimate assumed that it would require one routine operating procedure to be written, and a $\$ 1000$ for routine recordkeeping procedures. For NRC one-time activities, the best cost estimate assumed that the NRC technical costs per plant would include $\mathbf{4 0}$ person-hours. No NRC recurring costs were applied.

A low, best, and high range of cost estimates was developed for Alternative 2 following the guidelines described in Subsection 8.5. Table 27 shows the cost breakdown for this alternative. The total cost values are: $\$ 6,400$ for the low estimate, $\$ 8,800$ for the best estimate and $\$ 30,600$ for the high estimate. This is a range difference from the low to the high cost estimate of $\$ 24,200$. A main contributor to this differences is the contingency factor (10\% included in the high cost estimate), and the change from a simple to complex operation procedure rewrite (see Subsection 8.5.5).

8.6.2.3 Alternative 3 - Periodic Hydrogen Makeup to the VCT. Alternative 3 would require changing plant procedures to allow periodic hydrogen makeup to the VCT. This procedure was estimated to be an approximately $1 / 2$-hour task for two people each day. This alternative would allow the isolation of the hydrogen supply from the auxiliary building to the VCT for the remaining 23$1 / 2$ hours of the day.

For licensee procedural and analytical activities, the best cost estimate included the costs of a routine operating procedure write-up, $\$ 1000$ for routine recordkeeping, and staff training (10 students with two hours classroom and two hours on the job training). For NRC one-time activities, the best cost estimated that the NRC technical cost per plant would include 40 person-hours.

The licensee recurring cost, due to the change in operating procedures, is the largest contributor to the total cost analysis. This alternative would require a yearly licensee recurring cost of 256 hours ( 1 person-hour per day $\times 365$ days per year $\times 0.70$ plant availability factor) for the remaining plant life (20 years). The best estimate for this cost is calculated in FORECAST 2.1 to reflect the labor productivity factors inherent in this area of the PAB. 
Table 27. Auxiliary building Alternative 2 cost breakdown.

\begin{tabular}{|c|c|c|c|}
\hline \multirow[b]{2}{*}{ Category } & \multicolumn{3}{|c|}{ Cost Estimate } \\
\hline & $\begin{array}{r}\text { Low } \\
(\$)\end{array}$ & $\begin{array}{r}\text { Best } \\
(\$)\end{array}$ & $\begin{array}{r}\text { High } \\
(\$)\end{array}$ \\
\hline Installation labor & 2,900 & 3,600 & 3,600 \\
\hline Removal labor & 200 & 300 & 300 \\
\hline Engineering/QA costs & 400 & 500 & 500 \\
\hline Health-physics costs & 0 & 600 & 600 \\
\hline Licensee procedural/analytical & 2,000 & 2,000 & 19,800 \\
\hline Licensee contingency & N/A & N/A & 2,500 \\
\hline Total !icensee sne-time sost & 5,500 & 7,000 & 27,300 \\
\hline Total licensee recurring cost & N/A & N/A & N/A \\
\hline Total NRC one-time cost & 900 & 1,800 & 3,300 \\
\hline Total NRC recurring cost & N/A & N/A & N/A \\
\hline Total (without onsite averted cost) & 6,400 & 8,800 & 30,600 \\
\hline
\end{tabular}

A. low, best, and high range of cost estimates was developed for Alternative 3 following the guidelines described in Subsection 8.5. Table 28 shows the cost bre:kdown for this alternative. The total cost values are: $\$ 65,800$ for the low estimate, $\$ 106,100$ for the best estimate, and $\$ 220,000$ for the high estimate. Th:s is a range difference from the low to the high cost estimate of $\$ 154,200$. A main contributor to this differences is the contingency factor $(10 \%$ included in the high cost estimate), the discount rate applied to recurring costs, and the change from a simple to complex operation procedure rewrite (see Subsection 8.5.5).

8.6.3 Alternatives Considered for the Hydrogen Storage Facility. Three alternatives for the hydrogen storage facility distribution system were identified in Subsection 8.1. They are:

- Relocate the hydrogen storage facility to a distance within EPRI NP-5283-SR-A guidelines (Alternative 1)

- Install a hydrogen blast wave deflection shield (Alternative 2)

- Install hydrogen analyzer-actuated air int:ke louvers (Alternative 3). 
Table 28. Auxiliary building Alternative 3 cost breakdown.

\begin{tabular}{lrrr}
\hline \multicolumn{1}{c}{ Category } & \multicolumn{3}{c}{ Cost Estimate } \\
\cline { 2 - 4 } & $\begin{array}{r}\text { Low } \\
(\$)\end{array}$ & $\begin{array}{r}\text { Best } \\
(\$)\end{array}$ & $\begin{array}{r}\text { High } \\
(\$)\end{array}$ \\
\hline Licr-see procedural/analytical & 2,900 & 3,800 & 22,500 \\
Licensee contingency & 0 & 0 & 2,300 \\
& & & \\
Total licensee one-time cost & 2,900 & 3,800 & 24,800 \\
Total licensee recurring cost & 62,000 & 100,500 & 191,900 \\
Total NRC one-time cost & 900 & 1,800 & 3,300 \\
Total NRC recurring cost & $\mathrm{N} / \mathrm{A}$ & $\mathrm{N} / \mathrm{A}$ & $\mathrm{N} / \mathrm{A}$ \\
Total (without onsite averted cost) & 65,800 & 106,100 & 220,000 \\
\hline
\end{tabular}

8.6.3.1 Alternative 1-Relocation of Hydrogen Storage Facility. Alternative 1 would relocate the hydrogen storage facility. Moving the hydrogen storage facility to a distance meeting EPRI NP-5283-SR-A safe separation criteria would eliminate any potential of damage to safety-related equipment presently located near the hydrogen storage facility. The low and best cost estimates for this alternative are the actual cost of the completed alternative, as incurred recently at two PWRs. The low and best costs do not include a cost breakdown. The breakdown for high cost estimate was developed from the EEDB data base in FORECAST 2.1. The high cost was estimated to include $\$ 25,000$ for site hardware and equipment cost (it is assumed that the old hydrogen storage facility hydrogen vessels, associated manifolds, and pressure reducing stations are reutilized), and $\$ 727,700$ for installation labor. No removal labor was considered. The engineering and QA/QC costs were added at $25 \%$ of the direct costs as described in Subsection 8.5. No health physics or radioactive waste disposal costs were included. The licensee procedural/analytical costs included 80 person-hours for other technical assistance. NRC one-time costs were estimated to be $\$ 2,000$. A contingency factor of $10 \%$ was added to the analysis and no recurring costs were considered. The summary of this cost analysis is shown in Table 29.

\subsubsection{Alternative 2 - Installation of Blast Wave Deflection Shields.} Alternative 2 describes the installation of a blast wave deflection shield. By deflecting the blast wave from a hydrogen detonation, a blast shield can greatly lessen the blast impact. The major cost of this alternative is the engineering evaluation which will be required to maximize placement of the shield. The deflection shield itself will be a 10 -ft-high by 20 -ft-long brick wall on a concrete pad.

For the purpose of this study it was determined that it would require 86 person-hours of labor to build the shield wall and 14 person-hours to construct the concrete pad. No removal or waste disposal activity is necessary. A cost of $\$ 1200$ was designated for the barrier material consisting of 225 blocks 
Table 29. Hydrogen storage facility Alternative 1 cost breakdown.

\begin{tabular}{|c|c|c|c|}
\hline \multirow[b]{2}{*}{ Category } & \multicolumn{3}{|c|}{ Cost Estimate } \\
\hline & $\begin{array}{c}\text { Low } \\
\mathbf{( \$ )}\end{array}$ & $\begin{array}{c}\text { Best } \\
(\$)\end{array}$ & $\begin{array}{c}\text { High } \\
(\$)\end{array}$ \\
\hline Material and hardware cost & $N / A$ & N/A & 24,800 \\
\hline Installation Labor & N/A & N/A & 727,700 \\
\hline Engineering/QA costs & N/A & N/A & 97,100 \\
\hline Licensee procedural/analytical & N/A & N/A & 5,000 \\
\hline Licensee contingency & N/A & N/A & 85,500 \\
\hline Total licensee one-time cost & 400,000 & 500,000 & 940,100 \\
\hline Total licensee recurring cost & N/A & N/A & N/A \\
\hline Total NRC one-time cost & N/A & N/A & 2,000 \\
\hline Total NRC recurring cost & N/A & N/A & N/A \\
\hline Total (without onsite averted cost) & 400,000 & 500,000 & 942,100 \\
\hline
\end{tabular}

$(8 \times 16 \times 12$ in.). A $25 \%$ engineering/quality assurance cost was calculated. It was determined that the alternative would require 16 person-hours for technical costs. The NRC cost included 8 technical staff person-hours.

The low and high cost estimates were developed using the methodology described in Subsection 8.5. Table 30 shows the cost breakdown for this alternative. The total cost values are: $\$ 12,600$ for the low estimate, $\$ 14,000$ for the best estimate, and $\$ 17,500$ for the high estimate. This is a range difference from the low to the high cost estimate of $\$ 4,900$. A main contributor to these differences is the contingency factor (10\% included in the high cost estimate: see Subsection 8.5.5).

8.6.3.3 Alternative 3 - Installation of Automatic Shutters. Alternative 3 proposes the installation of automatic shutters controlled by hydrogen analyzers. This alternative would not allow the ingress of a flammable hydrogen mixture into safety-related structures via air intake pathways.

As described in Section 7, some hydrogen storage facility accident scenarios are significant CDF contributors. The contribution to CDF can be as high as $1.5 \times 10^{-3} /$ ry depending on the hydrogen storage facility location related to safety-related equipment. To reduce the CDF $10^{-5} / \mathrm{yr}$, it is justifiable to spend a maximum cost of $\$ 200,000$. To reduce to CDF $10^{-4} / r y$, it is justifiable to spend a maximum of $\$ 2$ million. 
Table 30. Hydrogen storage facility Alternative 2 cost breakdown.

\begin{tabular}{lrrr}
\hline & \multicolumn{3}{c}{ Cost Estimate } \\
\cline { 2 - 4 } \multicolumn{1}{c}{ Category } & $\begin{array}{r}\text { Low } \\
(\$)\end{array}$ & $\begin{array}{r}\text { Best } \\
(\$)\end{array}$ & $\begin{array}{r}\text { High } \\
(\$)\end{array}$ \\
\hline Material and härdware cost & 2,700 & 2,700 & 2,700 \\
Installation labor & 6,000 & 6,800 & 7,600 \\
Engineering/QA costs & 2,900 & 3,100 & 3,300 \\
Licensee procedural/analytical & 800 & 1,000 & 1,500 \\
Licensee contingency & $\mathrm{N} / \mathrm{A}$ & $\mathrm{N} / \mathrm{A}$ & 1,500 \\
& & & \\
Total licensee one-time cost & 12,400 & 13,600 & 16,600 \\
Total licensee recurring cost & $\mathrm{N} / \mathrm{A}$ & $\mathrm{N} / \mathrm{A}$ & $\mathrm{N} / \mathrm{A}$ \\
Total NRC one-time cost & 200 & 400 & 900 \\
Total NRC recurring cost & $\mathrm{N} / \mathrm{A}$ & $\mathrm{N} / \mathrm{A}$ & $\mathrm{N} / \mathrm{A}$ \\
Total (without onsite averted cost) & 12,600 & 14,000 & 17,500 \\
\hline
\end{tabular}

This cost analysis uses an order of magnitude cost estimate technique due to the great range of difference in hydrogen storage facility location and subsequent contribution to CDF from plant to plant. The low, best, and high cost breakdown for this alternative are done on an order of magnitude scale. As shown in Table 31 , these resulted in a low cost estimate of $\$ 10,000$, a best cost estimate of $\$ 100,000$, and a high cost estimate of $\$ 1$ million.

Table 31. Hydrogen storage facility Alternative 3 cost breakdown.

\begin{tabular}{|c|c|c|c|}
\hline \multirow[b]{2}{*}{ Category } & \multicolumn{3}{|c|}{ Cost Estimate } \\
\hline & $\begin{array}{r}\text { Low } \\
(\$)\end{array}$ & $\begin{array}{r}\text { Best } \\
(\$)\end{array}$ & $\begin{array}{r}\text { High } \\
(\$)\end{array}$ \\
\hline Licensee costs & 10,000 & 100,000 & $1,000,000$ \\
\hline Total (without onsite averted cost) & 10,000 & 100,000 & $1,000,000$ \\
\hline
\end{tabular}




\subsection{Total Cost Results}

NRC policy recommends inclusion of the onsite averted cost. As stated in the introduction to Subsection 8.4, the OSAC is a cost offset in the cost/benefit equation. The best estimate costs, with the best OSAC included, are shown in Table 32. Some of the OSACs are larger than the cost estimates for the alternative, and thus, the resulting cost estimates are negative numbers (i.e., a cost savings).

Table 32. Cost of modifications minus OSACs (point estimates).

\begin{tabular}{cccc}
\hline Configuration & $\begin{array}{c}\text { Alternative } 1 \\
(\$)\end{array}$ & $\begin{array}{c}\text { Alternative } \\
(\$)\end{array}$ & $\begin{array}{c}\text { Alternative } 3 \\
(\$)\end{array}$ \\
\hline Base Case Plant ' & 13,800 & 100,000 & $1,100,000$ \\
& Turbine Building Alternatives & \\
II & 14,000 & 100,000 & $1,100,000$ \\
III & $-65,000$ & 22,000 & $1,000,000$ \\
IV & $-65,000$ & 22,000 & $1,000,000$ \\
V & N/A & N/A & $1,000,000$ \\
& Auxiliary Building Alternatives & & \\
VI & 11,000 & 7,100 & 100,000 \\
VII & $-29,000$ & $-33,000$ & 65,000 \\
VIII & $-29,000$ & $-33,000$ & 65,000 \\
& Hydrogen Storage Facility Alternatives & \\
Plant A & 410,000 & $-76,000$ & 99,000 \\
Plant B & 23,000 & N/A & 94,000 \\
Plant C & N/A & N/A & 76,000 \\
\hline
\end{tabular}

\subsection{Cost/Benefit Uncertainty Discussion}

The Handbook for Value-Impact Assessment ${ }^{41}$ states that the estimation and presentation of uncertainties are vital parts of a value-impact assessment. The PRA Procedures Guide ${ }^{21}$ and NUREG/CR-5197 ${ }^{47}$ discuss the two contributors to uncertainty: the model uncertainty and the data uncertainty. The model uncertainty is related to the model's accuracy and completeness for core damage sequence, containment failure, and consequence. Only the data uncertainty was addressed in this analysis.

Data uncertainty is important to any analysis of this type. If only the point estimate results are given, much information about the data is lost and an unjustified opinion about the precision of the result may occur. The larger the standard error or the statistical confidence intervals, the less reliable the point estimate becomes. The distribution of the data also communicates a greater amount of information for 
the decision-making process than the point estimates alone. For the cost/benefit uncertainty analysis, both the uncertainty in the cost estimate calculations and the uncertainty in the benefit calculations were addressed.

In earlier sections of this report, a distribution for each parameter value was reported. The distribution of a value in an analysis illustrates the fact that variables are not precisely known and have an associated uncertainty. Sustaining the uncertainty throughout the analysis allows the analyst to adequately present the uncertainty inherent to the final cost/benefit model.

The cost/benefit ratio uncertainty is calculated using the DPR equations shown in the introduction to Section 8. A DPR ratio was calculated for both equations, including and excluding the OSAC. The @RISK computer program was used for evaluation of the uncertainty in the cost/benefit analysis. Each of the random variables in a relationship is represented by a specific distribution function. The @RISK program uses a Monte Carlo sampling method to determine a resultant cost/benefit distribution by random sampling, over many iterations, of the contribution risk and cost data distribution functions. Input to the @RISK program included: the cost (the cost of the alternative), the benefit (offsite person-rem averted) and the OSAC.

The cost variable was modeled using a triangular distribution with the low, best, and high value (see Subsection 8.6) as input. The cost value is represented in @RISK by a triangular distribution function. The triangular distribution is used in cost applications where only three points, a low, best, and high cost estimate are known. When sampled, all the cost values will lie in a range from the low cost estimate to the high cost estimate.

As discussed in,Subsection 8.3 , the benefit values are calculated by multiplying the delta CDF by its associated consequence. The delta CDF is the original CDF minus the core damage after the alternative and is represented by a lognormal distribution. The delta CDF distributions are presented in the uncertainty analysis in Section 7. As discussed in Subsection 8.3, the yearly population dose parameters are: low) 209,000 person-rem, best) 370,000 person-rem, and high) 634,000 person-rem. The uncertainty for the yearly dose number is modeled with a triangular distribution and is then multiplied by the remaining plant lifetime ( 20 years) and by the delta CDF distribution to obtain the benefit (offsite person-rem averted).

The OSAC is calculated by multiplying the point estimate delta CDF by the low, best, and high estimates of $U$ values to develop a triangular distribution as discussed in Subsection 8.4 and presented in Table 22. This triangular distribution is maintained in the final DPR ratio analysis.

\subsection{Uncertainty Analysis Results}

The cost, benefit, and OSAC uncertainty distribution are entered in the final DPR ratio calculations (with and without OSAC) as shown in the introduction to Section 8. The results of the DPR ratio (with and without OSAC) uncertainty analyses are shown in Table 33 and 34. The resulting DPR ratio distribution graphs are presented in Appendix F. 
Table 35 presents a summary of the cumulative distribution results, which can be interpreted as follow's: Configuration III, Alternative 1 (without OSAC), has a 44\% chance that its DPR will be less than $1000 \$ /$ person-rem, and a $56 \%$ chance that its DPR will be greater than 1000 \$/person-rem, and Configuration III, Alternative 1 (with OSAC), has a 100\% chance that its DPR ratio is less than 1000 $\$ /$ person-rem, and a $0 \%$ chance that its DPR will be greater than $1000 \$ /$ person-rem. In this case including the OSAC in the DPR makes the ratio a negative number. In such situations the DPR will always less than 1000 . 


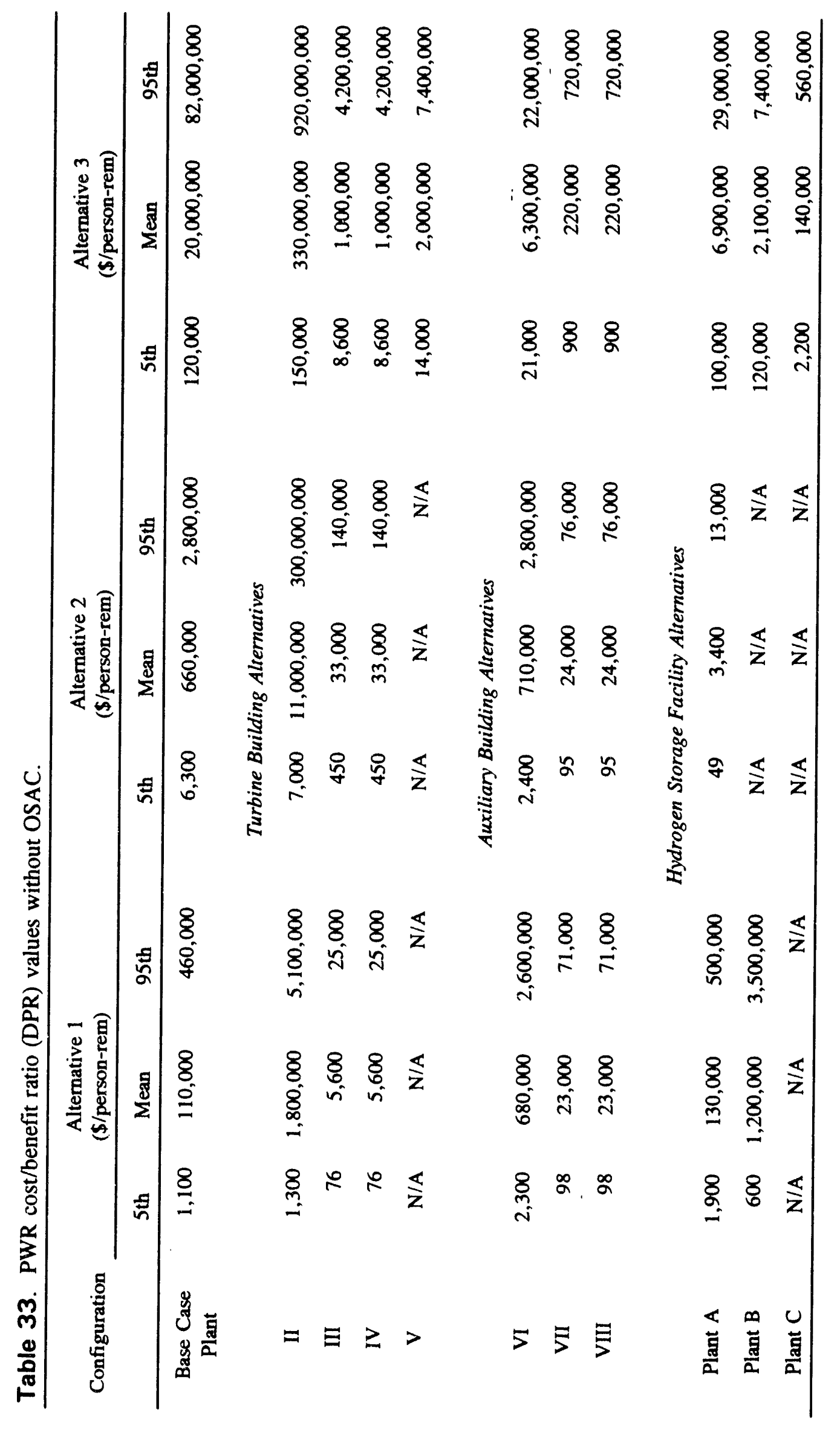




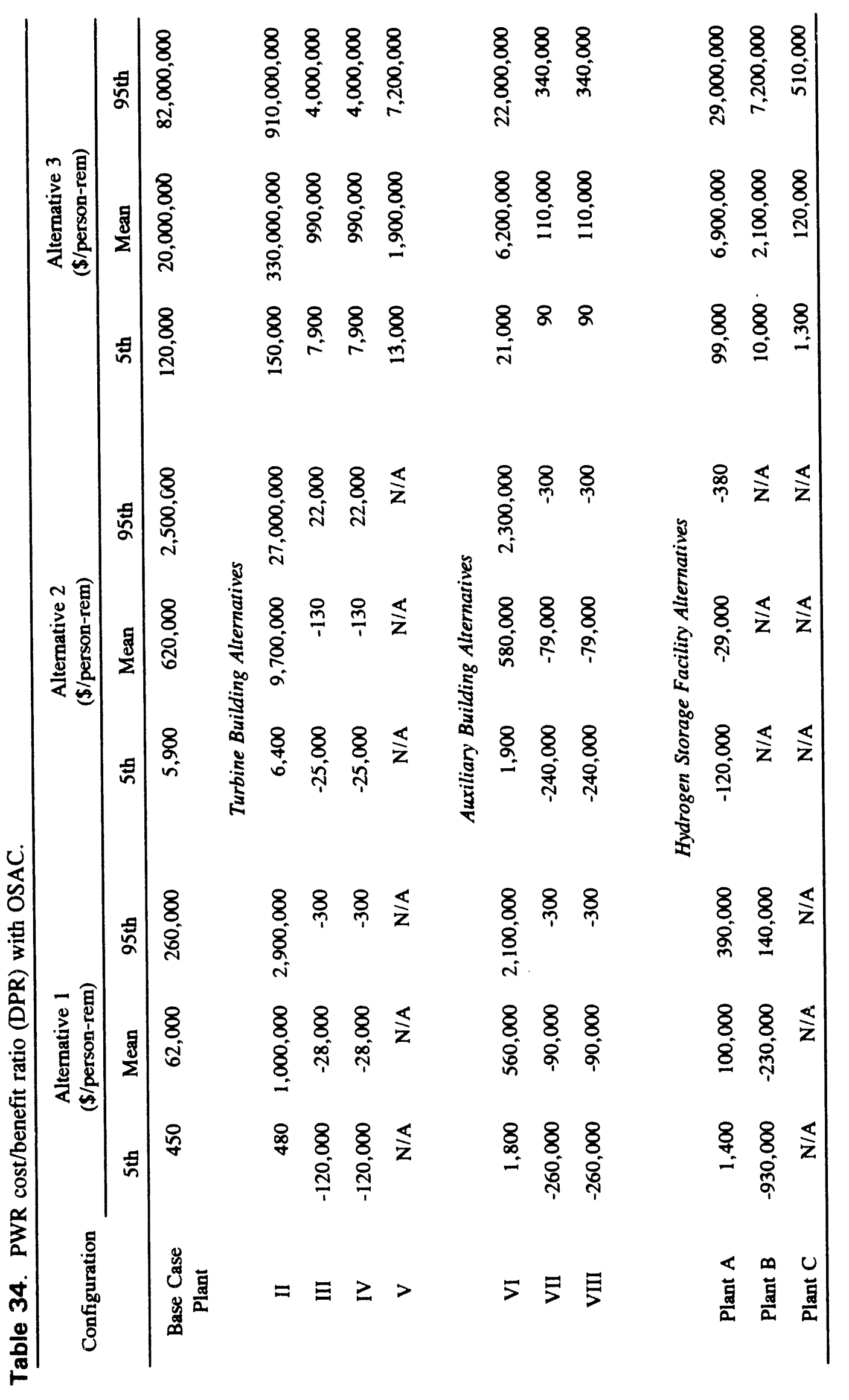


Table 35. Cost/benefit uncertainty results.

\begin{tabular}{|c|c|c|c|c|c|}
\hline \multirow[b]{2}{*}{ Configuration } & \multirow[b]{2}{*}{ Alternative } & \multicolumn{2}{|c|}{ With OSAC } & \multicolumn{2}{|c|}{ Without OSAC } \\
\hline & & $\begin{array}{c}\text { Percent } \\
\text { Probability } \\
<1000 \\
(\$ / \text { person-rem) }\end{array}$ & $\begin{array}{c}\text { Percent } \\
\text { Probability } \\
>1,000 \\
(\$ / \text { person-rem) }\end{array}$ & $\begin{array}{c}\text { Percent } \\
\text { Probability } \\
<1,000 \\
(\$ / \text { person-rem) }\end{array}$ & $\begin{array}{c}\text { Percent } \\
\text { Probability } \\
>1,000 \\
(\$ / \text { person-rem) }\end{array}$ \\
\hline \multirow[t]{3}{*}{ Base Case } & $T$ & 10 & 90 & 5 & 95 \\
\hline & 2 & $<1$ & $>99$ & $<1$ & $>99$ \\
\hline & 3 & 0 & 100 & 0 & 100 \\
\hline \multirow[t]{3}{*}{ II } & 1 & 8 & 92 & 4 & 96 \\
\hline & 2 & 1 & 99 & $<1$ & $>99$ \\
\hline & 3 & 0 & 100 & 0 & 100 \\
\hline \multirow[t]{3}{*}{ III } & 1 & 100 & 0 & 44 & 56 \\
\hline & 2 & 69 & 31 & 12 & 88 \\
\hline & 3 & $<1$ & $>99$ & $<1$ & $>99$ \\
\hline \multirow[t]{3}{*}{ IV } & 1 & 100 & 0 & 44 & 56 \\
\hline & 2 & 69 & 31 & 12 & 88 \\
\hline & 3 & $<1$ & $>99$ & $<1$ & $>99$ \\
\hline \multirow[t]{3}{*}{ v } & 1 & N/A & N/A & N/A & N/A \\
\hline & 2 & N/A & N/A & N/A & N/A \\
\hline & 3 & $<1$ & $>99$ & $<1$ & $>99$ \\
\hline \multirow[t]{3}{*}{ VI } & 1 & 3 & 97 & 2 & 98 \\
\hline & 2 & 3 & 97 & 2 & 98 \\
\hline & 3 & $<1$ & $>99$ & $<1$ & $>99$ \\
\hline \multirow[t]{3}{*}{ VII } & 1 & 100 & 0 & 33 & 67 \\
\hline & 2 & 100 & 0 & 33 & 67 \\
\hline & 3 & 17 & 83 & 6 & 94 \\
\hline \multirow[t]{3}{*}{ VIII } & 1 & 100 & 0 & 33 & 67 \\
\hline & 2 & 100 & 0 & 33 & 67 \\
\hline & 3 & 17 & 83 & 6 & 94 \\
\hline \multirow[t]{3}{*}{ Plant A } & 1 & 3 & 97 & 2 & 98 \\
\hline & 2 & 100 & 0 & 54 & 46 \\
\hline & 3 & 0 & 100 & 0 & 100 \\
\hline \multirow[t]{3}{*}{ Plant B } & 1 & 74 & 26 & 7 & 93 \\
\hline & 2 & N/A & N/A & N/A & N/A \\
\hline & 3 & $<1$ & $>99$ & $<1$ & $>99$ \\
\hline \multirow[t]{3}{*}{ Plant C } & 1 & N/A & N/A & N/A & N/A \\
\hline & 2 & N/A & N/A & N/A & N/A \\
\hline & 3 & 4 & 96 & 2 & 98 \\
\hline
\end{tabular}




\section{SUMMARY AND CONCLUSIONS}

This report documents the risk analysis of highly combustible gases (predominantly hydrogen) in PWRs. To conduct the base case risk assessment, a prototypical plant configuration was analyzed. The plant chosen for this study was a $W$ four-loop PWR that went into commercial operation in 1974. This choice was based on the availability of a completed Level III PRA with a fire analysis, and an NSSS design that represented a large fraction of the PWR population.

To address different reactor vendor designs and balance of plant arrangements, the base case PRA analysis was supplemented with a series of sensitivity analyses.

The technical findings of this evaluation are summarized for both the qualitative and quantitative aspects of this generic issue:

- Based on a screening analysis and other considerations, station batteries, portable gas bottle storage areas, and gaseous waste systems pose a negligible level of risk when compared to other sources.

- $\quad$ Based on the base case $W$ plant analysis, the effects of hydrogen releases and subsequent burns are relatively small contributors to the overall core melt risk. Table 36 summarizes the full power (Mode 1) base case core melt frequencies (mean values) due to internal events, seismic events, fires, etc., and the additional core melt frequency due to various hydrogen release scenarios. As discussed in Appendix $\mathrm{C}$, the consideration of hydrogen release during reactor shutdown (Modes 2-5) are not expected to be significant to risk because of a number of operational considerations.

- The relatively low base case CDF risk is attributed to the following features:

- The location of the AFW system away from possible hydrogen sources.

- The feasibility of F\&B core cooling in the event AFW became unavailable.

- The location of vital support systems or auxiliaries (diesels, component cooling water, service water) in different locations away from possible hydrogen sources.

- The quantity of hydrogen that can empty inside the auxiliary building is limited.

- $\quad$ Recognizing the specific issues that caused the low risk for the base case analysis, it was possible to identify different reactor vendor design features and balance of plant equipment arrangements that would pose significantly larger risks. These include:

PWR plants with the AFW system physically located in the turbine building or auxiliary building. 
Table 36. Comparison of base case analysis results.

\begin{tabular}{ccc}
\hline Document & Scenarios & CDF (/ry) \\
\hline & Internal events & $7.9 \times 10^{-5}$ \\
& Seismic events & $7.7 \times 10^{-6}$ \\
Licensee's PRA & Fire events & $1.4 \times 10^{-5}$ \\
& High winds & $3.6 \times 10^{-5}$ \\
& Total & $1.4 \times 10^{-4}$ \\
\hline This base case study & $\mathrm{H}_{2}$ fire/explosions & $7.1 \times 10^{-7}$ \\
\hline
\end{tabular}

- CE PWRs that have either marginal or no capabilities of using F\&B core cooling in the event AFW becomes unavailable.

- $\quad$ PWR plants with either diesels, component cooling water, or other vital support systems located near major potential hydrogen sources.

- The generic contiguration (revised based case) CDF risk associated with hydrogen release scenarios for the above design features are summarized in Table 37. These risks are clearly larger than found in the $W$ base case analysis.

- To address the hydrogen-related risks, a number of possible alternatives were considered. These included:

\section{Turbine Building Alternatives}

Alternative 1: Install an excess flow check valve on the hydrogen line header and a check valve on the hydrogen supply line at the generator. This hydrogen system alternative would require the placement of one excess flow check valve just downstream of the pressure regulator, and one check valve on the hydrogen supply line at the generator. If properly sized, an excess flow check valve would limit the amount of hydrogen released due to a pipe break to a concentration level easily dissipated, either by outside air or by building ventilation. The check valve on the hydrogen line at the generator will prevent backflow out of the generator given a hydrogen supply line pipe break.

Alternative 2: Periodic hydrogen makeup to the generator, This hydrogen system alternative would require changing plant procedures to allow periodic hydrogen makeup to the generator. This procedure was estimated to be an approximately $1 / 2$-hour task for two people each day. This alternative would allow the isolation of the hydrogen supply from the turbine building to the generator for the remaining 23-1/2 hours of the day. 
Table 37. Generic plant configurations.

\begin{tabular}{|c|c|c|c|}
\hline Configuration & Plant Applicability & $\begin{array}{c}\text { Important Accident } \\
\text { Scenarios } \\
\text { Applicable to Configuration }\end{array}$ & $\begin{array}{l}\text { CDF } \\
\text { (per ry) }\end{array}$ \\
\hline 1 & $\begin{array}{l}\text { All PWRs with AFW and vital } \\
\text { equipment outside of turbine and } \\
\text { auxiliary buildings }\end{array}$ & $\begin{array}{l}\text { T/DHR } \\
\text { T/LOCA }\end{array}$ & $3.4 \times 10^{-8}$ \\
\hline II & $\begin{array}{l}\text { Babcock \& Wilcox and Westinghouse } \\
\text { with AFW in turbine building } \\
\text { distribution system level }\end{array}$ & $\begin{array}{l}\text { T/DHR } \\
\text { (Feed and bleed credited) }\end{array}$ & $7.3 \times 10^{-7}$ \\
\hline III & $\begin{array}{l}\text { Combustion Engineering with AFW in } \\
\text { turbine building distribution system } \\
\text { level }\end{array}$ & $\begin{array}{l}\text { T/DHR } \\
\text { (Feed and bleed not credited) }\end{array}$ & $9.4 \times 10^{-6}$ \\
\hline IV & $\begin{array}{l}\text { All PWRs with vital equipment in } \\
\text { turbine building distribution system } \\
\text { level }\end{array}$ & $\begin{array}{l}\text { T/LOCA } \\
\text { (Station ac blackout, or loss } \\
\text { of CCW, SW) }\end{array}$ & $9.4 \times 10^{-6}$ \\
\hline $\mathrm{V}$ & $\begin{array}{l}\text { All PWRs with vital equipment in } \\
\text { turbine building generator floor level }\end{array}$ & $\begin{array}{l}\text { T/LOCA } \\
\text { (Station ac blackout, or loss } \\
\text { of CCW, SW) }\end{array}$ & $5.2 \times 10^{-6}$ \\
\hline VI & $\begin{array}{l}\text { Babcock \& Wilcox and Westinghouse } \\
\text { with AFW in auxiliary building }\end{array}$ & $\begin{array}{l}\text { T/DHR } \\
\text { (Feed and bleed credited) }\end{array}$ & $2.0 \times 10^{-7}$ \\
\hline VII & $\begin{array}{l}\text { Combustion Engineering with AFW in } \\
\text { auxiliary building }\end{array}$ & $\begin{array}{l}\text { T/DHR } \\
\text { (Feed and bleed not credited) }\end{array}$ & $4.7 \times 10^{-6}$ \\
\hline VIII & $\begin{array}{l}\text { All PWRs with vital equipment in } \\
\text { auxiliary building }\end{array}$ & $\begin{array}{l}\text { T/LOCA } \\
\text { (Loss of CCW, SW) }\end{array}$ & $4.7 \times 10^{-6}$ \\
\hline
\end{tabular}

Alternative 3: Enclose the safety-related equipment in a blast-proof structure. This hydrogen system alternative is for those plants whose turbine building configuration is considered at higher risk from hydrogen-initiated events. It includes the cost of the engineering evaluation and the cost of performance of a alternative identified by the evaluation.

\section{Auxiliary Building Alternatives}

Alternative 1: Install an excess flow check valve in the hydrogen supply line leading to the VCT. This hydrogen system alternative would require the placement of one excess flow check valve (sized for $150 \%$ of the maximum daily hydrogen flow) downstream of 
the pressure regulator in the hydrogen distribution line for the VCT. The excess flow check valve (if properly sized) would restrict hydrogen flow out of a broken line to a level that could be easily dissipated by the building ventilation.

Alternative 2: Limit the hydrogen supply to a three 250-scf hydrogen storage facility for the VCT. This hydrogen system alternative would require the removal of three of the six existing 250 -scf hydrogen tanks present in the auxiliary building and the removal of the supply piping connection to the main hydrogen storage facility. The three remaining 250-scf tank would be reconnected to form a limited supply day tank for the VCT. Limiting the amount of hydrogen in the auxiliary building would reduce the potential of a hydrogen storage facility emptying a large volume of hydrogen inside safety-related structures.

Alternative 3: Periodic hydrogen makeup to VCT. This hydrogen system alternative would require changing plant procedures to allow periodic hydrogen makeup to the VCT. This procedure was estimated to be an approximately 1/2-hour task for two people each day. This alternative would allow the isolation of the hydrogen supply from the auxiliary building to the VCT for the remaining 23-1/2 hours of the day.

\section{Hydrogen Storage Facility Alternatives}

Alternative 1: Relocate the ogen storage facility to a distance within EPRI NP-5283-SRA guidelines. ${ }^{12}$ This hydrogen system alternative would relocate the hydrogen storage facility to a distance meeting EPRI NP-5283-SR-A safe separation criteria. This would eliminate any potential of damage to safety-related equipment presently located near the hydrogen storage facility.

Alternative 2: Install a hydrogen blast wave deflection shield. This hydrogen system alternative would install a blast wave deflection shield. By deflecting the blast wave from a hydrogen detonation, a blast shield can greatly lessen the blast impact.

Alternative 3: Install hydrogen analyzer-actuated air intake louvers. This hydrogen system alternative would require the installation of automatic shutters controlled by hydrogen analyzers. This alternative would eliminate the ingress of a flammable (or detonable) hydrogen mixture into safety-related strictures via air intake pathways.

- When averted onsite costs were factored into the cost/benefit analysis, DPR results were obtained. Table 38 presents these DPR values. A negative DPR value for an alternative considered indicates an overall cost saving. Table 39 presents the DPR values for the case where the averted onsite costs were not factored into the cost/benefit analysis. 


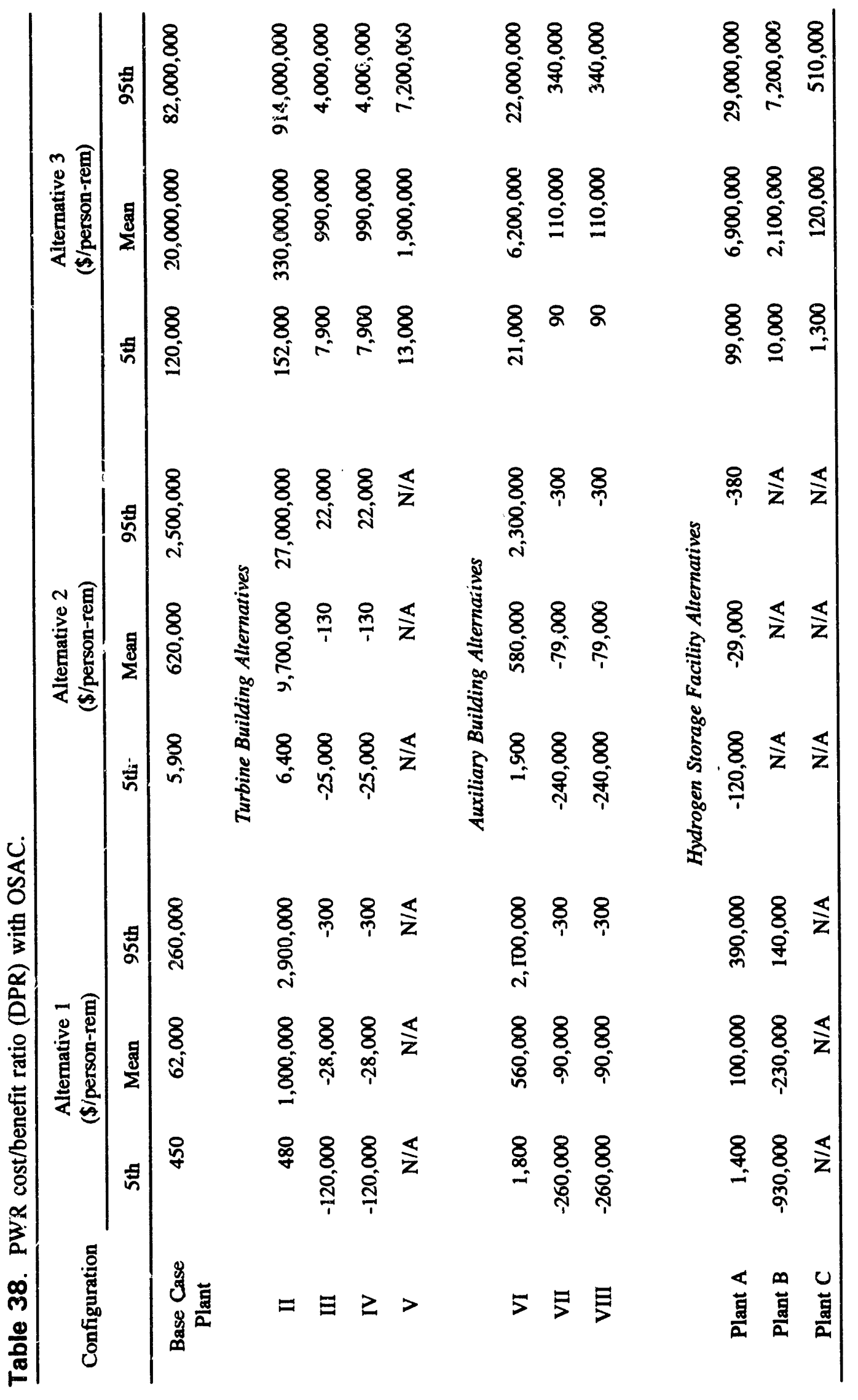




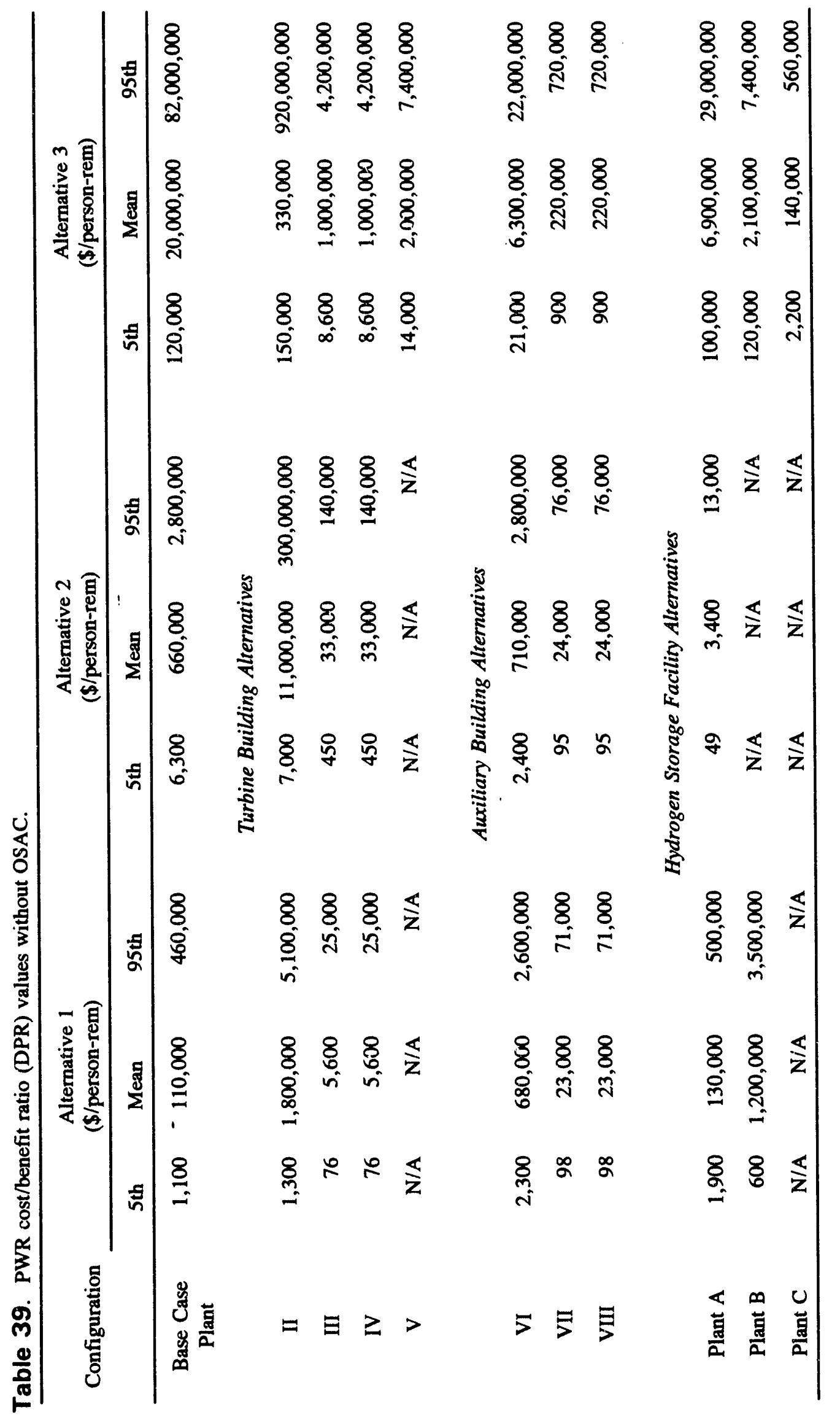




\section{REFERENCES}

1. U.S. Nuclear Regulatory Commission, Identification of New Unresolved Safety Issues Relating to Nuclear Power Plant Stations, NUREG-0705, February 1981.

2. U.S. Nuclear Regulatory Commission, Hydrogen Leak in Auxiliary Building, NRC Information Notice No. 87-20, April 20, 1987.

3. U.S. Nuclear Regulatory Commission, Hydrogen Storage on the Roof of the Control Room, NRC Information Notice No. 89-44, April 27, 1989.

4. J. L. Ballif, K. D. Bulmahn, and R. G. Neve, Draft Technical Evaluation Report on U.S. Commercidl Power Reactor Hydrogen Tank Farms and Their Compliance with Separation Distance Safety Criteria, SCIE-EGG-103-89, March 1990.

5. Code of Federal Regulations, Title 10 Part 50, Appendix R-Fire Protection Program For Nuclear Power Facilities Operating Prior To January 1, 1979.

6. U.S. Nuclear Regulatory Commission, Office of Nuclear Reactor Regulation, Standard Review Plan for the Review of Safety Analysis Reports for Nuclear Power Plants, Section 9.5.1, NUREG0800, July 1981 .

7. Yankee Atomic Electric Company, Yankee Nuclear Power Station Severe Accident Closure Submittal, December 1989.

8. J. C. Stachew, PWR Plant Hydrogen Gas Supply and Distribution System Information for Risk Analysis to Assess Plant Damage from Fotential Hydrogen Gas Explosions/Burns, EGG-NTA8260, March 1989.

9. Power Authority of the State of New York and Consolidated Edison Company of New York, Inc., Indian Point Probabilistic Safety Study, 1982.

10. A. L. Camp et al., Light Water Reactor Hydrogen Manual, NUREG/CR-2726, August 1983.

11. C. Kido et al., Technical Evaluation Report on Recommendations for Hydrogen Safety Features for the Hydrogen Distribution System in PWR Plants, EGG-NTA-8466, March 1989.

12. Electric Power Research Institute, Guidelines for Permanent BWR Hydrogen Water Chemistry Installations, EPRI-NP-5283-SR-A, September 1987.

13. Oak Ridge National Laboratory, Safety Implications Associated with In-Plant Pressurized Gas Storage and Distribution Systems in Nuclear Power Plants, NUREG/CR-3551, ORNL/NOAC214, May 1985.

14. U.S. Nuclear Regulatory Commission, Nuclear Documents System-Advanced Design (NUDOCS/AD), September 1989. 
15. S. M. Stoller Corporation, Nuclear Power Experience, 1919 14th Street, Suite 500, Boulder, Colorado 80302-5386.

16. L. A. Lambright and V. F. Nicolette, Fire Risk Scoping Study: Investigation of Nuclear Power Plant Fire Risk, Including Previously Unaddressed Issues, NUREG/CR-5088, SAND88-0177RP, January 1989.

17. Nuclear Safety Council, The October 19, 1989, Accident at Vandellos I Nuclear Power PlantFinal Report, Nuclear Safety Council, Madrid, Spain, April 1990.

18. B. Wamsley (ed), Commercial Nuclear Power Plants, 17th Edition, NUS Corporation, 910 Clopper Road, Gaitherburg, Maryland 20878.

19. D. G. Eisenhut, NRR, "Implementation of Fire Protection Requirements (Generic Letter 86-10)," April 24, 1986.

20. EXIDE, "Stationary Lead-Acid Battery Systems (Flooded Type)," Section 50.00, EXIDE, 645 Penn Street, Reading, PA. 19601-3509.

21. U.S. Nuclear Regulatory Commission, PRA Procedures Guide-A Guide to the Performance of Probabilistic Risk Assessments for Nuclear Power Plants, NUREG/CR-2300, January 1983, Section 5.

22. R. C. Bertucio and S. R. Brown, Analysis of Core Damage Frequency: Sequoyah, Unit 1 Internal Events Appendices, NUREG/CR-4550, Vol. 5, Rev.1, Part 1, April 1990.

23. R. C. Bertucio and J. A. Julius, Analysis of Core Damage Frequency: Surry, Unit 1 Internal Events, NUREG/CR-4550, Vol. 3, Rev. 1, Part 1, April 1990.

24. R. E. Hall, A Risk Assessment of a Pressurized Water Reactor for Class 3-8 Accidents, NUREG/CR-0603, October 1979, p.134.

25. U.S. Nuclear Regulatory Commission, An Assessment of Risks at Commercial Nuclear Power Plants, WASH-1400, 1973.

26. P. D. Randolph et al., Control of Explosive Mixtures in PWR Waste Gas Systems, NUREG/CR3237, January 1985.

27. S. A. Varga, NRR, "Implementation of Programmatic Controls for Radiological Effluent Technical Specifications in the Administrative Controls Section of the Technical Specifications and the Relocation of Procedural Details of RETS to the Offsite Dose Calculation Manual or to the Process Control Program (Generic Letter 89-01)," January 31, 1989.

28. Palisades Corporation, @RISK, Version 1.5, "Risk Analysis and Modeling for the PC," March $1,1988$. 
29. U.S. Nuclear Regulatory Commission, Severe Accident Risks: An Assessment for Five U.S. Nuclear Power Plants, NUREG-1150, June 1989.

30. G. J. Kolb et al., Review and Evaluation of the Indian Point Probabilistic Safety Study, NUREG/CR-2934, December 1982.

31. Maine Yankee, "Plant Trip on Main Transformer Failure," LER 309-91-005, April 29, 1991.

32. R. J. Budnitz et al., An Approach to the Quantification of Seismic Margins in Nuclear Power Plants, NUREG/CR-4334, August 1985, pp. C-13 to C-17.

33. R. D. Campbell, Probability of Seismic Induced Actuation of Three Indian Point Unit 2 Fire Protection Systems, EQE Engineering Consultants, Costa Mesa, California, November 1990.

34. K. D. Russell et al., Integrated Reliability and Risk Analysis System, Version 2.5, Reference Manual, NUREG/CR-5300, EGG-2613, EG\&G Idaho, Inc., March 1991.

35. W. W. Madsen, "Brief Documentation of Conversations with Mr. Simion about certain Hydrogen Blast Wave Effects," EG\&G Interoffice Correspondence WWM-03-91, July 25, 1991.

36. Consolidated Edjson Company of New York and Power Authority of the State of New York, Review of the Indian Point Station Fire Protection Program, April 1977.

37. D. L. Bernreuter et al., Seismic Hazard Characterization of 69 Nuclear Plant Sites East of the Rocky Mountains, NUREG/CR-5250, October 1988.

38. A Methodology for Assessment of Nuclear Power Plant Seismic Margin, EPRI NP-6041, October 1988, pp. 5-15 and 5-16.

39. G. G. Loomis and J. M. Cozzuol, Decay Heat Removal Using Feed and Bleed for U.S. Pressurized Water Reactors, NUREG/CR-5072, June 1988.

40. B. E. Boyak et al., Los Alamos PWR Decay-Heat-Removal Studies Summary Results and Conclusions, NUREG/CR-4471, March 1986.

41. S. Heaberlin et al., A.Handbook for Value/Impact Assessment, NUREG/CR-3568, December 1983.

42. E. Claiborne et al., Generic Cost Estimates, NUREG/CR-4627, Revision 1, February 1989.

43. G. A. Sanders et al., Shutdown Decay Heat Removal Analysis of a Westinghouse Three-Loop Pressurized Water Reactor: Case Study, NUREG/CR-4762, March 1987.

44. B. Lopez and F.W. Sciacca, FORECAST 2.1 User Manual, SEA Report No. 89-461-04-A:1, April 1990. 
45. United Engineers and Constructors, Phase VIII Update (1986) Report for the Energy Economic Data Base Program, DOE/NE-OO51/1, August 1986.

46. United Engineers and Constructors, Phase VIII Update (1986) BWR supplement for the Energy Economic Data Base Program, NUREG/CR-5764, December 1986.

47. D. A. Reny et al., Evaluation of Generic Issue 115, Enhancement of the Reliability of Westinghouse Solid State Protection System, NUREG/CR-5197, EGG-2456, January 1989. 


\section{APPENDIX A}

\section{REPORTS OF HYDROGEN EXPERIENCE \\ AT COMMERCIAL REACTORS}


Table A-1. PWR/BWR hydrogen event data--offgas system

\begin{tabular}{|c|c|c|c|c|c|}
\hline Plant Name & $\begin{array}{c}\text { Event } \\
\text { Occurrence }\end{array}$ & $\begin{array}{l}\text { Plant } \\
\text { Status }\end{array}$ & $\begin{array}{l}\text { Event } \\
\text { Type }^{\mathrm{a}}\end{array}$ & $\begin{array}{l}\text { Effected } \\
\text { System }\end{array}$ & Comments \\
\hline Oyster Creek & $08 / 01 / 77$ & & $\mathrm{E}$ & Offgas & $\begin{array}{l}\text { Augmented offgas system } \\
\text { explosion }\end{array}$ \\
\hline Millstone 1 & $12 / 13 / 77$ & $89 \%$ & $\mathrm{E}$ & Offgas & $\begin{array}{l}\text { Blown stack loop seals, frozen } \\
\text { fill line-welding equipment and } \\
\text { level switch op cause explosion }\end{array}$ \\
\hline Brunswick 2 & $04 / 01 / 76$ & & $\mathrm{C}$ & Offgas & $\begin{array}{l}\text { Catalyst migrated out of } \mathrm{H}_{2} \\
\text { recombiner }\end{array}$ \\
\hline Vermont Yankee & $09 / 01 / 73$ & $68 \%$ & $\mathrm{E}$ & Offgas & Detonation in IOG \\
\hline Dresden 1 & $08 / 01 / 71$ & & $\mathrm{E}$ & Offgas & $\begin{array}{l}\text { Detonation in offgas } \\
\text { system--ground level release }\end{array}$ \\
\hline Vermont Yankee & $09 / 08 / 73$ & $65 \%$ & $\mathrm{E}$ & Offgas & Detonation in the offgas system \\
\hline Oyster Creek & $03 / 17 / 78$ & & $\mathrm{E}$ & Offgas & $\begin{array}{l}\text { Detonation in the augmented } \\
\text { offgas system }\end{array}$ \\
\hline Brunswick 2 & $01 / 01 / 76$ & & $\mathrm{E}$ & Offgas & $\begin{array}{l}\text { Explosion and fire in the filter } \\
\text { house }\end{array}$ \\
\hline Monticello & $11 / 01 / 71$ & & $\mathrm{E}$ & Offgas & Explosion in offgas system \\
\hline Dresden 3 & $04 / 01 / 76$ & $57 \%$ & $\mathrm{E}$ & Offgas & $\begin{array}{l}\text { Explosion in offgas } \\
\text { system--gaseous release }\end{array}$ \\
\hline Dresden 3 & $11 / 01 / 74$ & & $\mathrm{E}$ & Offgas & $\begin{array}{l}\text { Explosion in offgas } \\
\text { system--release }\end{array}$ \\
\hline Cooper & $04 / 01 / 76$ & $79 \%$ & $\mathrm{E}$ & Offgas & $\begin{array}{l}\text { Failed } \mathrm{H}_{2} \text { analyzer and } \\
\text { personnel error caused offgas } \\
\text { explosion }\end{array}$ \\
\hline Cooper & $01 / 07 / 76$ & $83 \%$ & $E$ & Offgas & $\begin{array}{l}\text { Faulty flow indicator, ice } \\
\text { blockage resulted in } \mathrm{H}_{2} \\
\text { buildup and explosion }\end{array}$ \\
\hline
\end{tabular}


Table A-1. (continued)

\begin{tabular}{|c|c|c|c|c|c|}
\hline Plant Name & $\begin{array}{c}\text { Event } \\
\text { Occurrence }\end{array}$ & $\begin{array}{l}\text { Plant } \\
\text { Status }\end{array}$ & $\begin{array}{l}\text { Event } \\
\text { Type }^{\mathrm{a}}\end{array}$ & $\begin{array}{r}\text { Effected } \\
\text { System }\end{array}$ & Comments \\
\hline Browns Ferry 3 & $07 / 17 / 77$ & & $F$ & Offgas & $\begin{array}{l}\text { Fire in offgas system charcoal } \\
\text { absorber bed }\end{array}$ \\
\hline FitzPatrick & $12 / 01 / 77$ & & $\mathrm{~F}$ & Offgas & $\begin{array}{l}\mathrm{H}_{2} \text { combustion in air ejector } \\
\text { after condenser }\end{array}$ \\
\hline FitzPatrick & $01 / 03 / 78$ & & $\mathbf{F}$ & Offgas & $\begin{array}{l}\mathrm{H}_{2} \text { combustion in air ejector } \\
\text { after condenser }\end{array}$ \\
\hline FitzPatrick & $01 / 05 / 78$ & & $\mathbf{F}$ & Offgas & $\begin{array}{l}\mathrm{H}_{2} \text { combustion in air ejector } \\
\text { after condenser }\end{array}$ \\
\hline Vermont Yankee & $05 / 16 / 80$ & $100 \%$ & $\dot{\mathrm{E}}$ & Offgas & $\begin{array}{l}\mathrm{H}_{2} \text { detonation in SJAE sample } \\
\text { system initiated } \mathrm{H}_{2} \text { recomber } \\
\text { upstream of } \mathrm{AOG} \text { recombiner }\end{array}$ \\
\hline Vermont Yankee & $03 / 01 / 78$ & $60 \%$ & $\mathrm{E}$ & Offgas & $\begin{array}{l}\mathrm{H}_{2} \text { explosion in isolated } \\
\text { portion of offgas system }\end{array}$ \\
\hline Oyster Creek & $12 / 01 / 87$ & $100 \%$ & $\mathrm{C}$ & Offgas & $\begin{array}{l}\text { High hydrogen concentration } \\
\text { area under plant vent stack }\end{array}$ \\
\hline Hatch 1 & $06 / 01 / 79$ & $1 \%$ & $\mathrm{C}$ & Offgas & High offgas $\mathrm{H}_{2}$ concentrations \\
\hline Hatch 1 & $07 / 01 / 79$ & & $\mathrm{C}$ & Offgas & High offgas $\mathrm{H}_{2}$ concentrations \\
\hline Hatch 1 & $07 / 02 / 79$ & & $\mathrm{C}$ & Offgas & High offgas $\mathrm{H}_{2}$ concentrations \\
\hline La Crosse & $03 / 06 / 86$ & $39 \%$ & $\mathrm{E}$ & Offgas & $\begin{array}{l}\text { Hydrogen explosion during } \\
\text { offgas sampling }\end{array}$ \\
\hline Dresden 2 & $05 / 02 / 85$ & $40 \%$ & $\mathbf{F}$ & Offgas & $\begin{array}{l}\text { Hydrogen/oxygen fire } \\
\text { upstream of recombiner }\end{array}$ \\
\hline Vermont Yankee & $08 / 30 / 73$ & $50 \%$ & $\mathrm{E}$ & Offgas & $\begin{array}{l}\text { Lightning and possible } \\
\text { smoldering material caused two } \\
\text { offgas system explosions }\end{array}$ \\
\hline Vermont Yankee & $06 / 01 / 73$ & $78 \%$ & $\mathbf{E}$ & Offgas & $\begin{array}{l}\text { Lightning caused explosion in } \\
\text { offgas system }\end{array}$ \\
\hline
\end{tabular}


Table A-1. (continued)

\begin{tabular}{|c|c|c|c|c|c|}
\hline Plant Name & $\begin{array}{c}\text { Event } \\
\text { Occurrence } \\
\end{array}$ & $\begin{array}{r}\text { Plant } \\
\text { Status } \\
\end{array}$ & $\begin{array}{l}\text { Event } \\
\text { Type }^{a}\end{array}$ & $\begin{array}{r}\text { Effected } \\
\text { System }\end{array}$ & Comments \\
\hline Dresden 2 & $03 / 01 / 73$ & & $\mathrm{E}$ & Offgas & $\begin{array}{l}\text { Offgas explosion caused by } \\
\text { welding--inadvertent release }\end{array}$ \\
\hline Peach Bottom & $02 / 01 / 80$ & $100 \%$ & $\mathrm{~L}$ & Offgas & $\begin{array}{l}\text { Offgas recombiner } \mathrm{H}_{2} \text { analyzer } \\
\text { leaked--release }\end{array}$ \\
\hline Quad-Cities 1 & $03 / 01 / 74$ & & E & Offgas & Offgas system explosion \\
\hline Dresden 2 & $06 / 01 / 76$ & $92 \%$ & $\mathbf{E}$ & Offgas & $\begin{array}{l}\text { Offgas system } \\
\text { explosion--gaseous release }\end{array}$ \\
\hline Dresden 2 & $05 / 01 / 75$ & & $\mathrm{E}$ & Offgas & $\begin{array}{l}\text { Offgas system } \\
\text { explosion--release }\end{array}$ \\
\hline Dresden 3 & $02 / 01 / 74$ & & $\mathrm{E}$ & Offgas & $\begin{array}{l}\text { Offgas explosion--filters not } \\
\text { completely grounded }\end{array}$ \\
\hline Monticello & $06 / 01 / 74$ & & $\mathrm{E}$ & Offgas & Offgas ignition \\
\hline Monticello & $08 / 01 / 77$ & $95 \%$ & $\mathrm{~F}$ & Offgas & $\begin{array}{l}\text { Offgas recombined at air } \\
\text { ejector }\end{array}$ \\
\hline Grand Gulf 1 & $02 / 27 / 88$ & $100 \%$ & $\mathrm{E}$ & Offgas & $\begin{array}{l}\text { Offgas system channel } \\
\text { absorber beds ignited }\end{array}$ \\
\hline Dresden 1 & $09 / 01 / 77$ & $48 \%$ & $\mathrm{E}$ & Offgas & Offgas system explosion \\
\hline Brunswick 2 & $06 / 01 / 77$ & & $\mathrm{~F}$ & Offgas & $\begin{array}{l}\text { Offgas system over } \\
\text { pressurization and energy } \\
\text { release }\end{array}$ \\
\hline Monticello & $07 / 01 / 74$ & $25 \%$ & $\mathrm{E}$ & Offgas & $\begin{array}{l}\text { Recombiner catalyst } \\
\text { transported--offgas ignition }\end{array}$ \\
\hline Browns Ferry 3 & $07 / 01 / 79$ & $40 \%$ & $\mathrm{E}$ & Offgas & $\begin{array}{l}\text { Steam valve failures--offgas } \\
\text { explosion }\end{array}$ \\
\hline Hatch 1 & $05 / 01 / 78$ & $96 \%$ & $\mathrm{~L}$ & Offgas & Underground offgas line leaked \\
\hline Monticello & $05 / 01 / 74$ & & $\mathrm{E}$ & Offgas & $\begin{array}{l}\text { Valve closure ignited off gas } \\
\text { explosion }\end{array}$ \\
\hline
\end{tabular}


Table A-1. (continued)

\begin{tabular}{|c|c|c|c|c|c|}
\hline Plant Name & $\begin{array}{l}\text { Event } \\
\text { Occurrence }\end{array}$ & $\begin{array}{l}\text { Plant } \\
\text { Status }\end{array}$ & $\begin{array}{l}\text { Event } \\
\text { Type }\end{array}$ & $\begin{array}{r}\text { Effected } \\
\text { System }\end{array}$ & Comments \\
\hline San Onofre 1 & $07 / 17 / 81$ & & $E$ & Offgas & $\begin{array}{l}\text { Air leakage into } \mathrm{N}_{2} \text { system } \\
\text { caused buildup of } \mathrm{O}_{2} \text { and } \mathrm{H}_{2} \text { in } \\
\text { waste gas--ignited }\end{array}$ \\
\hline McGuire 1 & $05 / 31 / 81$ & & $\mathrm{C}$ & Offgas & $\begin{array}{l}\text { Concentration of } \mathrm{O}_{2} \text { and } \mathrm{H}_{2} \text { in } \\
\text { the waste gas shutdown tank } \\
\text { exceeded limits }\end{array}$ \\
\hline Zion 1 & $01 / 12 / 87$ & & $\mathrm{C}$ & Offgas & $\begin{array}{l}\text { Explosive mixture of } \mathrm{H}_{2} / \mathrm{O}_{2} \text { in } \\
\text { holdup tank } 1\end{array}$ \\
\hline Three Mile Island & $08 / 27 / 83$ & & $\mathrm{C}$ & Offgas & $\begin{array}{l}\text { High } \mathrm{H}_{2} \text { concentration in a } \\
\text { Island } 1 \text { waste storage tank }\end{array}$ \\
\hline St. Lucie 2 & $06 / 02 / 83$ & & $\mathrm{C}$ & Offgas & $\begin{array}{l}\mathrm{O}_{2} \text { and } \mathrm{H}_{2} \text { concentration above } \\
\text { specifications in waste gas } \\
\text { decay tanks }\end{array}$ \\
\hline Sequoyah 1 & $12 / 21 / 82$ & & $\mathrm{C}$ & Offgas & $\begin{array}{l}\mathrm{O}_{2} \text { and } \mathrm{H}_{2} \text { concentration in } \\
\text { waste gas tank incorrect }\end{array}$ \\
\hline Byron 1 & $07 / 11 / 85$ & $98 \%$ & $\mathrm{C}$ & Offgas & $\begin{array}{l}\mathrm{O}_{2} / \mathrm{H}_{2} \text { explosive mixture } \\
\text { present in the OD waste gas } \\
\text { decay tank }\end{array}$ \\
\hline Crystal River 3 & $09 / 01 / 77$ & $99 \%$ & $\mathrm{~L}$ & Offgas & $\begin{array}{l}\mathrm{R} / \mathrm{A} \text { gas released during } \mathrm{PM} \\
\text { on } \mathrm{H}_{2} \text { system--valves } \\
\text { leaked--procedure changed }\end{array}$ \\
\hline Cook 1 & $11 / 18 / 83$ & & $\mathrm{C}$ & Offigas & $\begin{array}{l}\mathrm{H}_{2} \text { concentration in the waste } \\
\text { storage tank exceeded } \\
\text { specifications }\end{array}$ \\
\hline Sequoyah 1 & $07 / 30 / 82$ & & $\mathrm{C}$ & Offgas & $\begin{array}{l}\mathrm{O}_{2} \text { and } \mathrm{H}_{2} \text { concentration in the } \\
\text { waste gas decay tank greater } \\
\text { than specifications }\end{array}$ \\
\hline
\end{tabular}


Table A-2. PWR/BWR hydrogen event data--generator system

\begin{tabular}{|c|c|c|c|c|c|}
\hline Plant Name & $\begin{array}{c}\text { Event } \\
\text { Occurrence }\end{array}$ & $\begin{array}{l}\text { Plant } \\
\text { Status }\end{array}$ & $\begin{array}{l}\text { Event } \\
\text { Type }^{\mathrm{a}}\end{array}$ & $\begin{array}{l}\text { Effected } \\
\text { System }\end{array}$ & Comments \\
\hline Harris & $10 / 09 / 89$ & $100 \%$ & $\mathrm{~F}$ & Generator & $\begin{array}{l}\text { Electrical fault on main } \\
\text { generator output bus causes } \\
\text { plant trip and fire }\end{array}$ \\
\hline Cook 2 & $11 / 13 / 78$ & & F & Generator & $\begin{array}{l}\text { Fire during removal of bushing } \\
\text { covers }\end{array}$ \\
\hline H.B. Robinson & $01 / 07 / 89$ & & $\mathrm{~F}$ & Generator & $\begin{array}{l}\text { Fires and explosive mixtures } \\
\text { resulted from introduction of } \\
\mathrm{H}_{2} \text { into plant air system }\end{array}$ \\
\hline Prairie Is. 2 & $03 / 01 / 76$ & $100 \%$ & $\mathrm{~L}$ & Generator & $\begin{array}{l}\text { Hydrogen cooler leak found, } \\
\text { generator ground }\end{array}$ \\
\hline San Onofre 3 & $04 / 08 / 85$ & $100 \%$ & $\mathrm{~F}$ & Generator & $\begin{array}{l}\text { Hydrogen fire in generator } \\
\text { rotor bearing housing }\end{array}$ \\
\hline Indian Point 2 & $12 / 19 / 84$ & $100 \%$ & $\mathrm{E}$ & Generator & $\begin{array}{l}\text { Hydrogen leakage caused two } \\
\text { fires and an explosion }\end{array}$ \\
\hline Unknown PWR & $02 / 04 / 82$ & & F & Generator & $\begin{array}{l}\text { Hydrogen leaked from bad seal } \\
\text { into generator }\end{array}$ \\
\hline Sequoyah & $04 / 13 / 85$ & $18 \%$ & $\mathrm{~L}$ & Generator & $\begin{array}{l}\text { Manual shutdown due to } \mathrm{H}_{2} \\
\text { leak at generator }\end{array}$ \\
\hline South Texas 1 & $01 / 20 / 89$ & $100 \%$ & $\mathrm{~F}$ & Generator & $\begin{array}{l}\text { Reactor trip due to main } \\
\text { generator fire }\end{array}$ \\
\hline Haddam Neck & $01 / 01 / 69$ & & L & Generator & $\begin{array}{l}\text { Serious hydrogen leakage from } \\
\text { the generator existed for } 18 \\
\text { months (1968 to June } 1969 \text { ) }\end{array}$ \\
\hline North Anna 1 & $05 / 09 / 83$ & $100 \%$ & L & Generator & $\begin{array}{l}\text { Severe } \mathrm{H}_{2} \text { leak from inner } \\
\text { cooled turbine generator }\end{array}$ \\
\hline Rancho Seco & $03 / 19 / 84$ & $92 \%$ & $\mathrm{E}$ & Generator & Explosion and fire \\
\hline Indian Point 2 & $02 / 02 / 85$ & $100 \%$ & $\mathrm{~L}$ & Generator & $\begin{array}{l}\text { Main generator } \mathrm{H}_{2} \text { seal oil unit } \\
\text { failed, filter clogged and } \\
\text { allowed a } \mathrm{H}_{2} \text { leak }\end{array}$ \\
\hline
\end{tabular}


Table A-2. (continued)

\begin{tabular}{|c|c|c|c|c|c|}
\hline Plant Name & $\begin{array}{c}\text { Event } \\
\text { Occurrence } \\
\end{array}$ & $\begin{array}{r}\text { Plant } \\
\text { Status } \\
\end{array}$ & $\begin{array}{l}\text { Event } \\
\text { Type }^{\mathrm{a}} \\
\end{array}$ & $\begin{array}{r}\text { Effected } \\
\text { System } \\
\end{array}$ & Comments \\
\hline St. Lucie 1 & $04 / 03 / 77$ & $100 \%$ & $\mathbf{F}$ & Generator & $\begin{array}{l}\text { Main generator lead box leaked } \\
\text { hydrogen }\end{array}$ \\
\hline Monticello & $05 / 01 / 71$ & & L & Generator & $\begin{array}{l}\text { A generator } \mathrm{H}_{2} \text { leak was } \\
\text { experienced in May }\end{array}$ \\
\hline Perry 1 & $06 / 30 / 87$ & $28 \%$ & L & Generator & $\begin{array}{l}\text { High hydrogen concentration } \\
\text { leak }\end{array}$ \\
\hline
\end{tabular}


Table A-3. PWR/BWR hydrogen event data--VCT system

\begin{tabular}{|c|c|c|c|c|c|}
\hline Plant Name & $\begin{array}{c}\text { Event } \\
\text { Occurrence }\end{array}$ & $\begin{array}{l}\text { Plant } \\
\text { Status }\end{array}$ & $\begin{array}{l}\text { Event } \\
\text { Type }\end{array}$ & $\begin{array}{r}\text { Effected } \\
\text { System }\end{array}$ & Comments \\
\hline Ft. Calhoun & $05 / 01 / 86$ & $100 \%$ & L. & VCT & $\begin{array}{l}\text { Auxiliary building ventilation } \\
\text { isolation radgas released; } \\
\text { valve selector switch left } \\
\text { aligned to VCT }\end{array}$ \\
\hline Ft. Calhoun 1 & $09 / 01 / 78$ & $98 \%$ & $\mathbf{L}$ & VCT & $\begin{array}{l}\text { Back leakage from relief valve } \\
\text { HG-105 and isolation valve } \\
\text { HG-101 }\end{array}$ \\
\hline Ft. Calhoun 1 & $04 / 01 / 77$ & $93 \%$ & $\mathbf{L}$ & VCT & $\begin{array}{l}\text { Back leakage through check } \\
\text { valves CH-284 and HG-100 } \\
\text { and relief valve HG-105 }\end{array}$ \\
\hline Vogtle 1 and 2 & $02 / 20 / 87$ & PreO & $\mathrm{L}$ & VCT & $\begin{array}{l}\text { Hydrogen leakage in auxiliary } \\
\text { building }\end{array}$ \\
\hline Conn. Yankee & $04 / 01 / 74$ & & $\mathrm{~L}$ & VCT & $\begin{array}{l}\text { Regulator diaphragm was } \\
\text { source of gas release }\end{array}$ \\
\hline Calvert Cliffs 2 & $11 / 09 / 81$ & & $\mathbf{L}$ & VCT & VCT gas supply valve leaked \\
\hline Cook 2 & $10 / 31 / 81$ & $100 \%$ & $\mathbf{L}$ & VCT & $\begin{array}{l}\text { VCT sampling valve leaked } \\
\text { radiogas, which also contains } \\
\mathrm{H}_{2} \text { at this point }\end{array}$ \\
\hline Salem 1 & $09 / 03 / 82$ & $99 \%$ & $\mathrm{~L}$ & VCT & $\begin{array}{l}\text { VCT vent line drain valve } \\
\text { leaked }\end{array}$ \\
\hline Ft. Calhoun 1 & $11 / 18 / 84$ & & $\mathbf{L}$ & VCT & Vent header leaking gas \\
\hline Cook 2 & $10 / 31 / 81$ & $100 \%$ & $\mathrm{~L}$ & VCT & $\begin{array}{l}\text { Gas from the VCT had leaked } \\
\text { pass valve NS-186 and entered } \\
\text { the WDS }\end{array}$ \\
\hline Cook 1 & $12 / 04 / 81$ & $100 \%$ & $\mathrm{~L}$ & VCT & $\begin{array}{l}\text { Waste gas vent header } \\
\text { overpressurized during VCT } \\
\text { venting }\end{array}$ \\
\hline eak & & & & & \\
\hline
\end{tabular}


Table A-4. PWR/BWR hydrogen event data--storage tank system

\begin{tabular}{|c|c|c|c|c|c|}
\hline Plant Nams & $\begin{array}{c}\text { Event } \\
\text { Occurrence }\end{array}$ & $\begin{array}{r}\text { Plant } \\
\text { Status } \\
\end{array}$ & $\begin{array}{l}\text { Event } \\
\text { Type }\end{array}$ & $\begin{array}{r}\text { Effected } \\
\text { System }\end{array}$ & Comments \\
\hline Three Mile Island 1 & $03 / 01 / 74$ & & E & Storage Tank & $\begin{array}{l}\text { Explosion and large fireball at } \\
\text { tank farm caused by ice plug } \\
\text { on rupture disc }\end{array}$ \\
\hline Waterford 3 & $03 / 03 / 87$ & & E & Storage Tank & Deflagration and one hour fire \\
\hline La Salle $1 \& 2$ & $07 / 20 / 84$ & & $\mathbf{F}$ & Storage Tank & $\begin{array}{l}\text { During recharge of } \mathrm{H}_{2} \text { bank, a } \\
\text { tank ruptured disc blew out } \\
\text { and escaping } \mathrm{H}_{2} \text { ignited }\end{array}$ \\
\hline
\end{tabular}

Table A-5. FWR/BW/K hydrogen event data--battery system

\begin{tabular}{llllll}
\hline Plant Name & $\begin{array}{c}\text { Event } \\
\text { Occurrence }\end{array}$ & $\begin{array}{r}\text { Plant } \\
\text { Status }\end{array}$ & $\begin{array}{l}\text { Event } \\
\text { Type }\end{array}$ & $\begin{array}{c}\text { Effected } \\
\text { System }\end{array}$ & Comments \\
\hline Palisades & $04 / 04 / 79$ & $100 \%$ & E & Battery & $\begin{array}{l}\text { Battery burst due to explosion } \\
\text { of } \mathrm{H}_{2}\end{array}$ \\
\hline & & & & & \\
\hline${ }^{\mathrm{a}} \mathrm{E}=$ explosion & & & & & \\
\hline
\end{tabular}


APPENDIX B

UNCERTAINTY ESTIMATE CALCULATIONS

B-1 


\section{APPENDIX B \\ UNCERTAINTY ESTIMATE CALCULATIONS}

\section{Introduction}

The hydrogen explosion, fire, and uncombusted release experience for the U.S. commercial reactor industry was described in Section 2 and Subsection 3.1 of the body of this report. These data will be used as the basis for the hydrogen event frequency estimates. A hydrogen event is identified as a hydrogen leak, fire, or explosion, and in the case of the waste gas systems, an event includes hydrogen concentrations above technical specifications.

An alternate method of frequency estimation (i.e., development of system models comprised of multiple components and use of component failure rate data) was also used in an earlier study. ${ }^{\text {B-1 }}$ This modeling approach is not used here because it is considered to have greater uncertainty. There is not sufficient data available for components in hydrogen applications to support this methodology.

The objective in this appendix is to calculate a value for the initiating event frequency and probability of causing a hydrogen fire or explosion given that a hydrogen event has occurred based upon the operating experience data in the United States involving all actual hydrogen releases. Table B-1 summarizes the events reported in Subsection 3.1.

Table B-1. Summary of the hydrogen events in each plant location

\begin{tabular}{|c|c|c|c|c|c|}
\hline $\begin{array}{c}\text { Event Location } \\
\text { (applicable reactor years) }\end{array}$ & $\begin{array}{l}\text { Explosion } \\
\text { Events }\end{array}$ & $\begin{array}{l}\text { Fire } \\
\text { Events }\end{array}$ & $\begin{array}{l}\text { Uncombusted } \\
\text { Leak }\end{array}$ & $\begin{array}{l}\text { Other } \\
\text { Events }\end{array}$ & $\begin{array}{l}\text { Total } \\
\text { Events }\end{array}$ \\
\hline $\begin{array}{l}\text { Turbine Building } \\
\text { (1424 BWR/PWR) }\end{array}$ & 2 & 7 & 7 & 0 & 16 \\
\hline $\begin{array}{l}\text { VCT in PAB } \\
\text { (917 PWR) }\end{array}$ & 0 & 0 & 11 & 0 & 11 \\
\hline $\begin{array}{l}\text { Waste Gas System in PAB } \\
\text { (917 PWR) }\end{array}$ & 1 & 0 & 1 & $8^{a}$ & 10 \\
\hline $\begin{array}{l}\mathrm{H}_{2} \text { Tank Farm } \\
(1424 \text { BWR/PWR) }\end{array}$ & 2 & 1 & 0 & 0 & 3 \\
\hline $\begin{array}{l}\text { Batteries } \\
\text { (1424 BWR/PWR) }\end{array}$ & 1 & 0 & 0 & 0 & 1 \\
\hline Total $\mathrm{H}_{2}$ Events & 6 & 8 & 19 & 8 & 41 \\
\hline
\end{tabular}

a Hydrogen concentrations above technical specifications. 


\section{Description of Methodology}

The PRA Procedures Guide $\mathrm{B}^{\mathrm{B}-2}$ outlines two basic methods for analyzing data to estimate constant failure rates (based on an underlying Poisson distribution of the failures)--the classical method and the Bayesian method. Initiating event frequency and conditional probability calculations were performed using the noninformative prior Bayesian method for impact assessment since the Bayesian method provides slightly higher' frequencies than the classical method.

2.1 Constant Failure Rate Derivation. For the initiating events, a constant failure rate is assumed. The Bayesian 5th percentile, mean, 95th percentile, and variance (the standard deviation equals the square-root of the variance) for a noninformative prior distribution are defined (see Reference B-2, pp. 5-50) for $n$ events in $T$ years by:

$$
\begin{aligned}
5 \text { th } & =\frac{\chi_{0.05}^{2}(2 n+1)}{2 T} \\
\text { mean } & =\frac{(2 n+1)}{2 T} \\
95 \text { th } & =\frac{\chi_{0.95}^{2}(2 n+1)}{2 T} \\
\text { variance } & =\frac{(2 n+1)}{2 T^{2}}
\end{aligned}
$$

where $\chi^{2}{ }_{0.05,0.95}(2 n+1)$ is from the chi-square distribution.

The posterior probability density function (PDF) from the PRA procedures guide is a form of the gamma distribution. The posterior PDF is:

$$
f=\frac{T^{\alpha_{1}} \lambda^{\alpha_{2}} e^{-\lambda T}}{\Gamma\left(\alpha_{1}\right)} \quad \lambda>0
$$

where $\alpha_{1}=$ (\# failures $)+0.5, \alpha_{2}=(\#$ failures $)-0.5$, and $T=$ total time .

The traditional gamma PDF is:

$$
f=\frac{\lambda^{\alpha-1} e^{-\lambda / \beta}}{\beta^{\alpha} \Gamma(\alpha)} \quad \lambda>0
$$


Comparing Equation (B-2) with Equation (B-3) reveals the following relationships:

$$
\begin{aligned}
& \alpha=(\# \text { failures })+0.5 \\
& \beta=\frac{1}{\mathrm{~T}}
\end{aligned}
$$

These two parameters are used with the gamma function in the @RISK Monte Carlo program to evaluate the uncertainty for constant failure rate variables (such as frequency of hydrogen fires or explosions).

2.2 Demand Failure Rate Derivation. For demand driven failure rates, such as the probability of hydrogen explosion given that there is a leak, the PRA Procedures Guide gives the following Bayesian equations for a noninformative prior distribution, given $\mathbf{n}$ events in $\mathrm{D}$ demands.

$$
\begin{aligned}
5 \text { th } & =\frac{n+0.5}{n+0.5+(D-n+0.5) F_{0.05}(2 D-2 n+1,2 n+1)} \\
\text { mean } & =\frac{(n+0.5)}{(D+1)} \\
95 \text { th } & =\frac{n+0.5}{n+0.5+(D-n+0.5) F_{0.95}(2 D-2 n+1,2 n+1)} \\
\text { variance } & =\frac{(n+0.5)(D-n+0.5)}{\left[(D+1)^{2}(D+2)\right]}
\end{aligned}
$$

where $F_{0.05,0.95}(2 D-2 n+1,2 n+1)$ is from the F-distribution.

The posterior PDF is a form of the beta distribution. The posterior PDF is:

$$
f=\left(\frac{\Gamma(n+1)}{\Gamma(r+0.5) \Gamma(n-r+0.5)}\right) P^{r-0.5}(1-P)^{n-r-0.5}
$$

where $r=(\#$ failures $)$ and $n=(\#$ demands $)$.

The traditional beta PDF is:

$$
f=\left[\frac{\Gamma\left(\alpha_{1}+\alpha_{2}\right)}{\Gamma\left(\alpha_{1}\right) \Gamma\left(\alpha_{2}\right)}\right] P^{\alpha_{1}-1}(1-P)^{\alpha_{2}-1}
$$


Comparing Equation (B-6) with Equation (B-7) reveals the following relationships:

$$
\begin{aligned}
& \alpha_{1}=(\# \text { failures })+0.5 \\
& \alpha_{2}=(\# \text { demands })-(\# \text { failures })+0.5
\end{aligned}
$$

These two parameter are used with the beta function in the @RISK Monte Carlo program to evaluate the uncertainty for demand failure rate variables (such as the probability of fire or explosion given a hydrogen leak).

\section{Uncertainty Derivation Conclusions}

The Bayesian method produces a larger mean value than the classical method, but results in a slightly less conservative distribution since the Bayesian intervals are narrower than the classical intervals. Table B-2 lists the calculated initiating event frequencies and conditional probabilities for the different plant locations. The mean value and standard deviation are presented for each location.

\begin{tabular}{|c|c|c|c|}
\hline Event location & Parameter & $\begin{array}{c}\text { Frequency of Hydrogen } \\
\text { Event (ry) }\end{array}$ & $\begin{array}{c}\text { Probability of Fire/Explosion } \\
\text { Given Hydrogen Event }\end{array}$ \\
\hline \multirow{2}{*}{$\begin{array}{l}\text { Turbine Building } \\
\text { (distribution system level) }\end{array}$} & Mean & $1.1 \times 10^{-3}$ & $8.8 \times 10^{-2}$ \\
\hline & Std. Dev. & $8.6 \times 10^{-4}$ & $4.5 \times 10^{-3}$ \\
\hline \multirow{2}{*}{$\begin{array}{l}\text { Turbine Building } \\
\text { (generator level) }\end{array}$} & Mean & $6.0 \times 10^{-3}$ & $5.0 \times 10^{-1}$ \\
\hline & Std. Dev. & $2.0 \times 10^{-3}$ & $1.4 \times 10^{-2}$ \\
\hline \multirow[t]{2}{*}{ VCT in PAB } & Mean & $1.3 \times 10^{-2}$ & $4.2 \times 10^{-2}$ \\
\hline & Std. Dev. & $3.7 \times 10^{-3}$ & $5.5 \times 10^{-2}$ \\
\hline \multirow[t]{2}{*}{ Waste Gas System } & Mean & $1.1 \times 10^{-2}$ & $1.4 \times 10^{-1}$ \\
\hline & Std. Dev. & $3.5 \times 10^{-3}$ & $9.9 \times 10^{-2}$ \\
\hline \multirow[t]{2}{*}{ Hydrogen Tank Farm } & Mean & $2.5 \times 10^{-3}$ & $8.8 \times 10^{-1}$ \\
\hline & Std. Dev. & $1.3 \times 10^{-3}$ & $1.5 \times 10^{-1}$ \\
\hline \multirow[t]{2}{*}{ Batteries } & Mean & $1.1 \times 10^{-3}$ & $7.5 \times 10^{-1}$ \\
\hline & Std. Dev. & $8.6 \times 10^{-4}$ & $2.5 \times 10^{-1}$ \\
\hline
\end{tabular}

Table B-2. Initiating event frequency and conditional probability results 


\section{References for Appendix B}

B-1. C. Kido, J. C. Stachew, S. A. Eide, and T. Thatcher, Technical Evaluation Report on Recommendations for Hydrogen Safety Features for the Hydrogen Distribution Systems in PWRs, EG\&G Idaho, Inc., EGG-NTA-8466, March 1989.

B-2. U.S. Nuclear Regulatory Commission, PRA Procedures Guide--A Guide to the Performance of Probabilistic Risk Assessments for Nuclear Power Plants, Section 5, NUREG/CR-2300, January 1983. 


\section{APPENDIX C}

\section{OTHER PLANT OPERATING MODES}

C-1 


\section{APPENDIX C}

\section{OTHER PLANT OPERATING MODES}

\section{Hydrogen-Related Operations During Operating Modes}

This appendix addresses the differences between the full-power case and cases where the reactor is in any other operating mode. In the transition from refueling to full power operation, the reactor goes through predefined conditions (operating modes) that limit the temperatures, pressures, heat-up rates, etc. These operating mode definitions are similar for all PWRs, and these general definitions are summarized in Table C-1. Table C-1 lists the different reactor operating modes along with the critical operating parameters, including core reactivity, plant power level, and average coolant temperature.

1.1 Generator Cooling System. During some low power operations (e.g., those associated with ascending and decreasing power to and from full power), the generator cooling system remains charged with hydrogen and the hydrogen supply is sustained as it is during power operation. However, the hydrogen pressure may be allowed to drop relative to its power production pressure, but the pressure will always remain above atmospheric to prevent oxygen contamination. This potential difference in pressure is considered to be a minor difference.

Hydrogen is generally purged from the generator during maintenance activities or if the reactor will be in a shutdown state for a prolonged time period [e.g., cold shutdown (Mode 5), refueling (Mode 6)].

In conclusion, the hydrogen supply to the generator is highly dependent upon the reactor operating mode.

As part of ongoing NRC research work on plant shutdown risk contributions, the shutdown PRA model used excludes low power operations. This is due to the short time periods associated with these modes relative to total shutdown time ( 120 hours versus 2400 hours, or about $5 \%$ of the shutdown time). Hydrogen events may occur during any operating mode and their rate of occurrence is considered here to be independent of operating mode. However, since the hydrogen sources are not typically present during generator maintenance activities (the most time consuming), the reactor is not considered to be vulnerable from hydrogen-induced events.

1.2 VCT. The VCT will rernain in service whenever the reactor coolant pumps (RCPs) are in operation. This means the VCT is necessarily in-service during Power Operation through Hot Standby (Modes 1 through 3), and also for portions of Hot Shutdown (Mode 4). The VCT will be isolated and purged with nitrogen whenever the RCS is to be opened to atmosphere. This purging is generally initiated during cooldown in Hot Standby (Mode 4). The VCT is also purged after open-RCS maintenance activities to remove all oxygen from the RCS. Since the hydrogen supply lines in the PAB are typically isolated for long duration shutdown modes, the hydrogen events related to the VCT are judged not to lead to significant vulnerability of the reactor core. 
Table C-1. Definition of reactor operating modes

\begin{tabular}{|c|c|c|c|c|}
\hline Operating Modę & $\begin{array}{c}\text { Reactivity } \\
\left(\mathbf{K}_{\text {eff }}\right)\end{array}$ & $\begin{array}{l}\text { Power } \\
\text { Level }\end{array}$ & $T_{\text {avg }}$ & Comments \\
\hline 1. Power Operation & $\geq 0.99$ & $>5 \%^{\circ}$ & $\geq 300^{\circ} \mathrm{F}^{\mathrm{a}}$ & \\
\hline 2. Startup & $\geq 0.99$ & $\leq 5 \%^{\circ}$ & $\geq 300^{\circ} \mathrm{F}^{\mathrm{a}}$ & $\begin{array}{l}\text { Differs from power operation } \\
\text { by power level }\end{array}$ \\
\hline 3. Hot Standby & $<0.99$ & $0 \%$ & $\geq 300^{\circ} \mathrm{F}^{a}$ & Reactor is subcritical \\
\hline 4. Hot Shutdown & $<0.99$ & $0 \%$ & $\begin{array}{l}300^{\circ} \mathrm{F}^{\mathrm{a}}>\mathrm{T}_{\text {avg }} \\
>200^{\circ} \mathrm{F}\end{array}$ & $\begin{array}{l}\text { May begin cooling via RHR/- } \\
\text { SCS/DHR as the pressure is } \\
\text { lowered }\end{array}$ \\
\hline 5. Cold Shutdown & $<0.99$ & $0 \%$ & $\leq 200^{\circ} \mathrm{F}$ & $\begin{array}{l}\text { May or may not be water- } \\
\text { solid. May or may not flood } \\
\text { reactor cavity }\end{array}$ \\
\hline $\begin{array}{l}6 . \text { Refueling } \\
\text { head bolts are untorqued }\end{array}$ & $<0.95$ & $0 \%$ & $\leq 140^{\circ} \mathrm{F}$ & RCS is vented and vessel \\
\hline
\end{tabular}

a The exact value is vendor and plant specific. Power levels range from 2 to $5 \%$, and $\mathrm{T}_{\text {avg }}$ values range from 300 to $350^{\circ} \mathrm{F}$.

\section{Safety System Operability Requirements}

The specific requirements for operation/operability of each safety-related system are dependent upon the reactor operating mode. The limiting conditions for operation (LCOs) portion of the plant's technical specifications (TS) prescribe the number of trains of each safety system which must be operable and/or operating for each reactor operating mode. The TS are plant specific, but the standard technical specifications (STS) developed by the NSSS vendors are representative of the minimum requirements for each plant. The following sections summarize the LCO requirements in each NSSS vendor's STSs. The requirements for all three are similar, and the differences between vendors are not considered to be major.

2.1 Babcock \& Wilcox (B\&W) Plants. The system operability requirements for B\&W plants are summarized in Table C-2. The B\&W STS were used as the basis for this summary of LCO requirements. As shown in the table, Modes 1-3 have virtually identical operability requirements. Mode 4 represents a transition mode where all of the same basic functions are required as for Modes 1-3, but the degree of redundancy is reduced and the requirement for the Decay Heat Removal System (DHR) begins. 
Table C-2. B\&W STS system LCO requirements for reactor operating modes

\begin{tabular}{|c|c|c|c|c|c|c|}
\hline System & $\begin{array}{c}\text { Mode } 1 \\
\text { power } \\
\text { operation }\end{array}$ & $\begin{array}{l}\text { Mode } 2 \\
\text { Startup }\end{array}$ & $\begin{array}{c}\text { Mode } 3 \\
\text { Hot } \\
\text { Standby }\end{array}$ & $\begin{array}{c}\text { Mode } 4 \\
\text { Hot } \\
\text { Shutdown }\end{array}$ & $\begin{array}{c}\text { Mode } 5 \\
\text { Cold } \\
\text { Shutdown }\end{array}$ & $\begin{array}{c}\text { Mode } 6 \\
\text { Refueling }\end{array}$ \\
\hline Coolant Loops & \multicolumn{2}{|c|}{ All } & \multicolumn{2}{|c|}{2 operable, 1 operating } & & \\
\hline Steam Generators & \multicolumn{2}{|c|}{ All } & \multicolumn{2}{|c|}{ all operable, 1 operating } & & \\
\hline Auxiliary Feedwater & \multicolumn{3}{|c|}{$\geq 3$} & & & \\
\hline MSIV \& MSSV & \multicolumn{3}{|c|}{ All } & & & \\
\hline Condensate Storage Tank & \multicolumn{3}{|c|}{ available } & & & \\
\hline Core Flooding Tanks & \multicolumn{3}{|c|}{ All } & & & \\
\hline Decay Heat Removal & & & & 1 & $2 / 1^{\circ}$ & 1 \\
\hline Low Pressure Safety Injection & & 2 & & 1 & & \\
\hline High Pressure Safety Injection & & 2 & & 1 & & \\
\hline Makeup Pumps & \multicolumn{4}{|c|}{2} & 1 & 1 (or DHR) \\
\hline Borated Water Storage Tank & \multicolumn{4}{|c|}{ available } & \multicolumn{2}{|c|}{ or concentrated B.A. system } \\
\hline Concentrated Boric Acid System & \multicolumn{4}{|c|}{ available } & \multicolumn{2}{|c|}{ or BWST } \\
\hline Pressurizer Code Safety Valves & \multicolumn{3}{|c|}{ All } & \multicolumn{2}{|c|}{$\geq 1$} & \\
\hline PORV & \multicolumn{3}{|c|}{ All } & \multicolumn{3}{|c|}{$\geq 2$ (or vent $R C S$ ) } \\
\hline Component Cooling Water & \multicolumn{4}{|c|}{22} & & \\
\hline Service Water & \multicolumn{4}{|c|}{$\geq 2$} & & \\
\hline CS, CCF, CTMT Isolation, CTMT & \multicolumn{4}{|c|}{ available } & & \\
\hline Electric Power (EDG, AC, DC) & \multicolumn{4}{|c|}{2} & \multicolumn{2}{|c|}{$\geq 1$} \\
\hline $\begin{array}{l}\text { a. } 2 / 1 \text { denotes a requirement for } 2 \text { t } \\
\text { Note: System operability requiremer } \\
\text { of shading. }\end{array}$ & $\begin{array}{l}\text { ains to be of } \\
\text { s are indica }\end{array}$ & $\begin{array}{l}\text { able, with } \\
\text { by shadi }\end{array}$ & 1 train requi & $\begin{array}{l}\text { to be operat } \\
\text { tce of requir }\end{array}$ & ents is indica & by absence \\
\hline
\end{tabular}


2.2 Combustion Engineering (CE) Plants. The system operability requirements for CE plants are summarized in Table C-3. The CE STS were used as the basis for this summary of LCO requirements. As shown in the table, Modes 1-3 have virtually identical operability requirements. Mode 4 represents a transition mode where all of the same basic functions are required as for Modes 1-3, but the degree of redundancy is reduced in some cases and the requirement for the Shutdown Cooling System begin.

2.3 Westinghouse' Plants. The system operability requirements for Westinghouse plants are summarized in Table C-4. The Westinghouse STS were used as the basis for this summary of LCO requirements. As shown in the table, Modes 1-3 have virtually identical operability requirements. Mode 4 represents a transition mode where all of the same basic functions are required as for Modes 1-3, but the degree of redundancy is reduced and the requirement for the Residual Heat Removal System (RHR) begin.

\section{Crucial Factors for Each Operating Mode}

Not only are the system operability requirements different for each operating mode, but there are other factors which affect the thermal-hydraulic requirements for safety. A generalized discussion of these factors, their variation with operating modes and their potential significance for hydrogen events are presented below. A summary is provided in Table C-5.

\subsection{Decay Heat}

3.1.1 Decay Heat Loads. The decay heat of the core is at a maximum for the case of prolonged full power operation. The reduction in the decay heat generation rate is a function of time after reactor shutdown, and the relationship is well defined. Therefore, Startup through Refueling (Modes 2 through 6) will not have a decay heat load greater than immediately after reactor trip from full power operation at the end of a fuel cycle. For the Cold Shutdown and Refueling modes of operation, the decay heat levels will be significantly lower than for the full power case analyzed previously. In the case where the reactor is being restarted after refueling, the heat loads will be much lower than the case of shutting down to begin refueling (i.e., spent fuel at shutdown has greater decay heat than fresh fuel). Overall, the decay heat loads analyzed for the full power case equal or exceed the heat loads for all other modes of operation, and are therefore bounding.

3.1.2 Decay Heat Removal Options. As presented in Section 2.1, the options for decay heat removal are the same for Power Operation through Hot Standby conditions (Modes 1 through 3). These options include:

- Main feedwater with condenser (no STS requirements)

- $\quad$ Auxiliary feedwater with atmospheric dump valves

- $\quad$ Feed and bleed

- $\quad$ SCS/RHR/DHR (for lower pressures). 
Table C-3. CE STS system LCO requirements for each reactor operating mode

\begin{tabular}{|c|c|c|c|c|c|c|}
\hline System & $\begin{array}{l}\text { Mode } 1 \\
\text { Power } \\
\text { Operation } \\
\end{array}$ & $\begin{array}{l}\text { Mode } 2 \\
\text { Startup }\end{array}$ & $\begin{array}{l}\text { Mode } 3 \\
\text { Hot } \\
\text { Standby }\end{array}$ & $\begin{array}{c}\text { Mode } 4 \\
\text { Hot } \\
\text { Shutdown }\end{array}$ & $\begin{array}{l}\text { Mode } 5 \\
\text { Cold } \\
\text { Shutdown }\end{array}$ & $\begin{array}{c}\text { Mode } 6 \\
\text { Refueling }\end{array}$ \\
\hline Coolant Loops & \multicolumn{2}{|c|}{ All operating } & $2 / 1^{a}$ & $\begin{array}{l}2 / 1 \text { (or } \\
\text { SCS) }\end{array}$ & & \\
\hline Steam Generators & \multicolumn{4}{|c|}{ All } & & \\
\hline Auxiliary Feedwater & \multicolumn{3}{|c|}{$\geq 3$} & & & \\
\hline MSIV and MSSV & \multicolumn{3}{|c|}{ All } & & & \\
\hline Condensate Storage Tank & \multicolumn{3}{|c|}{ available } & & & \\
\hline Accuinulators & \multicolumn{3}{|c|}{ All } & & & \\
\hline Shutdown Cooling System & & & & 1 & $2 / 1$ & $\begin{array}{l}1(2 \text { if } \\
\text { water } \\
\text { level }< \\
\left.23^{\prime}\right)\end{array}$ \\
\hline Low Pressure Injection & & 2 & & 1 & & \\
\hline High Pressure Injertion & $2(1$ & $P<170$ & sia) & 1 & 1 (or chs & ing pump) \\
\hline Charging Pumps & \multicolumn{4}{|c|}{2} & \multicolumn{2}{|c|}{1 (or 1 HPSI pump) } \\
\hline Refueling Water Tank & \multicolumn{4}{|c|}{ available } & \multicolumn{2}{|c|}{ (or BMT) } \\
\hline Boron Makeup Tank & \multicolumn{4}{|c|}{ available } & \multicolumn{2}{|c|}{ (or RWT) } \\
\hline Pressurizer Safety Valves & \multicolumn{3}{|c|}{ All } & \multicolumn{2}{|c|}{$\geq 1$} & \\
\hline PORV & \multicolumn{3}{|c|}{2} & \multicolumn{3}{|c|}{2 (or vented RCS) } \\
\hline Component Cooling Water & \multicolumn{4}{|c|}{$\geq 2$} & & \\
\hline Service Water & \multicolumn{4}{|c|}{$\geq 2$} & & \\
\hline CS, CCF, CTMT Isolation, CTMT & \multicolumn{4}{|c|}{ available } & & \\
\hline Electric Power (EDG, AC, DC) & \multicolumn{4}{|c|}{2} & \multicolumn{2}{|c|}{$\geq 1$} \\
\hline $\begin{array}{l}\text { a. } 2 / 1 \text { denotes a requirement for } 2 \\
\text { Note: System operability requireme } \\
\text { absence of shading. }\end{array}$ & $\begin{array}{l}\text { ins to be ope } \\
\text { are indicate }\end{array}$ & $\begin{array}{l}\text { Able, with } \\
\text { by shadin }\end{array}$ & rain requir & $\begin{array}{l}\text { to be opera } \\
\text { ce of requir }\end{array}$ & ts is indic & d by the \\
\hline
\end{tabular}


Table C-4. Summary of Westinghouse STS system LCO requirements for operating modes

\begin{tabular}{|c|c|c|c|c|c|c|}
\hline System & $\begin{array}{c}\text { Mode } 1 \\
\text { Power } \\
\text { Operation }\end{array}$ & $\begin{array}{c}\text { Mode } 2 \\
\text { Startup }\end{array}$ & $\begin{array}{c}\text { Mode } 3 \\
\text { Hot } \\
\text { Standby }\end{array}$ & $\begin{array}{c}\text { Mode } 4 \\
\text { Hot } \\
\text { Shutdown }\end{array}$ & $\begin{array}{l}\text { Mode } 5 \\
\text { Cold } \\
\text { Shutdown }\end{array}$ & $\begin{array}{c}\text { Mode } 6 \\
\text { Refueling }\end{array}$ \\
\hline Coolant Loops & \multicolumn{2}{|c|}{ All } & \multicolumn{2}{|c|}{$\begin{array}{l}2 \text { operable, } \\
1 \text { operating }\end{array}$} & & \\
\hline Steam Generators & \multicolumn{2}{|c|}{ All } & \multicolumn{2}{|c|}{$\begin{array}{l}\text { All operable, } \\
1 \text { operating }\end{array}$} & $\begin{array}{l}1 \text { (or } \\
2 \text { RHR) }\end{array}$ & \\
\hline Auxiliary Feedwater & \multicolumn{3}{|c|}{$\geq 3$} & & & \\
\hline MSIV \& MSSV & \multicolumn{3}{|c|}{ All } & & & \\
\hline Condensate Storage Tank & \multicolumn{3}{|c|}{ available } & & & \\
\hline Accumulator & \multicolumn{3}{|c|}{ All } & & & \\
\hline Residual Heat Removal & & & & 1 & $\begin{array}{l}2 \text { (or } 1+2 \\
\mathrm{SG})\end{array}$ & $\begin{array}{l}1 \text { (2 if water } \\
\text { level }<23 \text { ') }\end{array}$ \\
\hline Low Pressure Safety Injection & & 2 & & 1 & & \\
\hline High Pressure Safety Injection & & 2 & & 1 & & \\
\hline Charging Pumps & \multicolumn{4}{|c|}{2} & \multicolumn{2}{|c|}{1} \\
\hline Refueling Water Storage Tank & \multicolumn{4}{|c|}{ available } & \multicolumn{2}{|c|}{ (or BIT) } \\
\hline Boron Injection Tank & \multicolumn{3}{|c|}{ available } & \multicolumn{3}{|c|}{ (or RWST) } \\
\hline Pressurizer Safety Valves & \multicolumn{3}{|c|}{ All } & \multicolumn{2}{|c|}{$\geq 1$} & \\
\hline PORV & \multicolumn{3}{|c|}{ All } & \multicolumn{3}{|c|}{$\geq 2$ (or vent $\mathrm{RCS}$ ) } \\
\hline Component Cooling Water & \multicolumn{4}{|c|}{$\geq 2$} & & \\
\hline Service Water & \multicolumn{4}{|c|}{$\geq 2$} & & \\
\hline CS, CCF, CTMT Isolation, CTMT & \multicolumn{4}{|c|}{ available } & & \\
\hline Electric Power (EDG, AC, DC) & \multicolumn{4}{|c|}{2} & \multicolumn{2}{|c|}{$\geq 1$} \\
\hline
\end{tabular}


Table C-5. Comparison of reactor conditions for each operating mode

\begin{tabular}{|c|c|c|c|c|c|c|}
\hline Design Factors & $\begin{array}{c}\text { Mode } 1^{a} \\
\text { Power } \\
\text { Operation }\end{array}$ & $\begin{array}{l}\text { Mode } 2 \\
\text { Startup }\end{array}$ & $\begin{array}{c}\text { Mode } 3 \\
\text { Hot } \\
\text { Standby }\end{array}$ & $\begin{array}{c}\text { Mode } 4 \\
\text { Hot } \\
\text { Shutdown }\end{array}$ & $\begin{array}{l}\text { Mode } 5 \\
\text { Cold } \\
\text { Shutdown }\end{array}$ & $\begin{array}{l}\text { Mode } 6 \\
\text { Refueling }\end{array}$ \\
\hline Decay Heat Load & Addressed & $\leq$ Mode $1^{b}$ & SMode 1 & $\leq$ Mode 1 & $<$ Mode 1 & $<$ Mode 1 \\
\hline Decay Heat Removal & Addressed & $=$ Mode 1 & $=$ Mode 1 & $\leq$ Mode 1 & <Mode 1 & < Mode 1 \\
\hline RCS Coolant Inventory & Addressed & $\approx$ Mode 1 & $\approx$ Mode 1 & $\geq$ Mode 1 & $\geq$ Mode 1 & $\geq$ Mode 1 \\
\hline RCS Coolant Makeup & Addressed & $=$ Mode 1 & $=$ Mode 1 & $\leq$ Mode 1 & $<$ Mode 1 & $<$ Mode 1 \\
\hline Containment Integrity & Addressed & $=$ Mode 1 & $=$ Mode 1 & $=$ Mode 1 & $<$ Mode 1 & <Mode 1 \\
\hline Boration Systems & Addressed & $=$ Mode 1 & $=$ Mode 1 & SMode 1 & <Mode 1 & $<$ Mode 1 \\
\hline Vital Auxiliary Systems & Addressed & $=$ Mode 1 & $=$ Mode 1 & $=$ Mode 1 & $<$ Mode 1 & $<$ Mode 1 \\
\hline Working Environment & Addressed & < Mode 1 & $<$ Mode 1 & $<$ Mode 1 & $<$ Mode 1 & $<$ Mode 1 \\
\hline Accident Procedures & Addressed & $<$ Mode 1 & $<$ Mode 1 & $<$ Mode 1 & $<$ Mode 1 & $<$ Mode 1 \\
\hline Ac ident Training & Addressed & $<$ Mode 1 & <Mode 1 & <Mode 1 & <Mode 1 & < Mode 1 \\
\hline Time in This Mode & Addressed & < Mode 1 & <Mode 1 & <Moje 1 & $<$ Mode 1 & < Mode 1 \\
\hline \multicolumn{7}{|c|}{$\begin{array}{l}\text { a. The risk assessments in the other sections of this document address } 100 \% \text { power operating conditions. The other power } \\
\text { levels less than } 100 \% \text { power are considered in this section. } \\
\text { b. Each parameter is compared for Modes } 2 \text { througn } 6 \text { to its Mode } 1 \text { condition. For example, Decay Heat Load for Mode } 2 \\
\text { is "SMode } 1 . "\end{array}$} \\
\hline
\end{tabular}

The number of trains of each system required to be operable is the same throughout the Power Operation through Hot Standby (Mode 1 through 3) operations, and therefore the decay heat removal options are the same as those assumed for the full power case.

In Hot Shutdown (Mode 4), thi decay heat removal options required to be operable involve the same systems, but generally fewer trains are required to be operable than in Power Operation. In some cases, the same equipment may be required for another function (e.g., LPSI converted to RHR application), and therefore the same equipment is in fact still required to be available. There is some decrease in the redundancy of decay heat removal options available for Hot Shutdown relative to the full power case analyzed earlier. The heat loads are 2 so reduced, however, and at least 2 heat removal options are retained. In Cold Shutdown and Refueling (Modes 5 and 6), the decay heat removal options and trains per system required to be operable are significantly reduced relative to Power Operation (Mode 1).

\subsection{RCS Coolant}

3.2.1 RCS Conlant Inventory. The coolant in the RCS varies depending upon the operating mode and the maintenance activities which are planned. The water level of the reactor is maintained at approximately the same levels for Power Operation through Hot Standby (Modes 1 through 3). The mass of water in the primas, loop will be at least the same or somewhat greater in Startup and Hot Standby 
(Modes 2 and 3) than at Power Operation, however, since $T_{\text {avg }}$ is lower and the water density will be slightly greater. Depending upon the future operating plans, some additional coolant is generally added during reactor cool-down from Power Operation while coolant is removed for reactor heat-ups. If the reactor is returning to Power Operation (Mode 1) and is only temporarily brought to Hot Standby (Mode 3), then there will be a tendency to avoid addition and subsequent withdrawal of coolant. Startup and $\mathrm{H} n$ t Standby (Modes 2 and 3) are therefore enveloped by the assumptions used for the full power case.

In Hot Shutdown (Mode 4), the reactor water level will be lowered if the gas bubble in the pressurizer is to be maintained and will be raised to eliminate the gas bubble if the pressure boundary is going to be opened. The mass of water in the RCS will remain equal to or greater than the full power case because of the increased density at lower temperatures. Therefore, the mass of water in the reactor will remain as great or greater than that assumed for the full-power case, and the Hot Standby (Mode 4) RCS coolant inventory case is enveloped by the full power case.

In Cold Standby (Mode 5), $\mathrm{T}_{\mathrm{avg}}$ is considerably lower than in Power Operation. The mass of water in the RCS in Cold Standby will exceed the mass during Power Operation, and if the system is water-solid, the difference is quite significant. The exception to this generalization is mid-loop operation (also referred to as reduced inventory operation) where the coolant level and mass are reduced to their minimum for any mode of operation to allow specific RCS maintenance activities. Cold Standby conditions are therefore enveloped by the Power Operation case, except for mid-loop operations.

The maximum water volume in the RCS is during Refueling (Mode 6) when the refueling cavity is flooded. There is a large increase in RCS water inventory available to the core at this time. There is the exception of mid-loop operations, which can also occur in Refueling (Mode 6).

In summary, the mass of coolant in the RCS for Startup through Refueling operations will be roughly equal to or greater than the mass of coolant in the RCS for the Power Operations case. Therefore, for the coolant inventory factor, all operating modes are enveloped by the full power case. The only exception to this generality is mid-loop operations during Cold Standby and Refueling (Modes 5 and 6) where the coolant inventory is at its minimum.

3.2.2 RCS Coolant Makeup Capacity. As presented in Section 2.1, the options for RCS coolant makeup are the same for Power Operation through Hot Standby conditions (Modes 1 through 3). These options include:

- Normal charging flow

- $\quad$ ECCS (HPSI/HPI plus RWST/RWT/BWST)

- $\quad$ Boration system (charging or HPSI/HPI, plus BIT/BMT).

The number of trains of each systern required to be operable is the same throughout Power Operation through Hot Standby (Modes 1 through 3) operations, and therefore the options are the same as those assumed for the full power case. 
In Hot Shutdown (Mode 4), the RCS coolant addition options required to be operable involve the same systems, but generally fewer trains are required to be operable than in Power Operation (Mode 1). In some cases, the same equipment may be required for another function (e.g., HPSI pumps are converted to a charging application), and therefore the same equipment is still required to be available. There is, however, some decrease in the coolant inventory options available for Hot Shutdown relative the full power case analyzed earlier.

In Cold Shutdown and Refueling (Modes 5 and 6), the RCS coolant addition options and trains per system required to be operable are significantly reduced relative to Power Operation (Mode 1).

\subsection{Containment Integrity}

The LCO requirements of the containment isolation, spray, fan coolers, etc., are the same for Power Operation though Hot Shutdown (Modes 1 through 4). Therefore, for the containment integrity, these operating modes are the same as the full power case.

For Cold Standby and Refueling (Modes 5 and 6), the containment integrity is considerably degraded relative to the full power case. On the other hand, there would generally be considerably greater time available for recovery of containment integrity before core damage can result from any event (other than fuel handling).

\subsection{Boration Systems}

The reactivity of the core is controlled by the boron concentration as well as the insertion of rods (control rods and safety rods). The boration systems available for core reactivity control include:

- BIT/BMT with charging or HPSI/HPI pumps

- $\quad$ RWST/RWT/BWST with charging or HPSI/HPI pumps.

The number of trains of each system required to be operable is the same throughout Power Operation through Hot Standby (Modes 1 through 3) operations, and therefore the options are the same as those assumed for the full power case. The shutdown margins are also the same (e.g., nominally $1 \%$ $\delta \mathbf{k} / \mathbf{k})$.

In Hot Shutdown (Mode 4), the RCS boration options required to be operable involve the same systems, but generally fewer trains are required to be operable than in Power Operation (Mode 1). In some cases, the same equipment may be required for another function (e.g., HPSI pumps are converted to a charging application), and therefore the same equipment is in fact still required to be available. In the case of Westinghouse reactors, the BIT is not required to be operable for Hot Shutdown (Mode 4) operation if the RWST is available. The shutdown margins are the same for Hot Shutdown as they were for Power Operation (e.g., $1 \% \delta \mathrm{k} / \mathrm{k}$ ). 
In Cold Shutdown and Refueling (Modes 5 and 6), the RCS boration options and the number of trains per system required to be operable are significantly reduced relative to Power Operation (Mode 1). The shutdown margins are the same for Cold Standby and Refueling (Modes 5 and 6), which is nominally $1.0 \% \delta \mathrm{k} / \mathrm{k}$.

\subsection{Vital Auxiliary Systems}

In order for the safety-related systems discussed above to operate properly, they require support from various auxiliary systems. The main auxiliary systems required include:

- Component cooling system

- $\quad$ Service water system

- $\quad$ Off-site power and distribution system

- $\quad$ Emergency diesel generators (EDGs) and distribution system

- DC power and distribution system.

As presented in Section 2.1, the operability requirements for these auxiliary systems remains the same for Power Operation through Hot Shutdown (Modes 1 through 4). The full power case is applicable for this range of operation (Modes 1 through 4).

For Cold Shutdown and Refueling (Modes 5 and 6), the electrical power (ac, dc, and EDG) requirements are reduced to one train of each. There are no CCW or SW requirements explicitly specified, but availability of these and other auxiliary systems is implicitly required in the operability requirements of the safety-related system.

It is therefore concluded that the vital auxiliary systems operability requirements are at least implicitly comparable to the corresponding safety related system requirements.

\subsection{Human Factore Considerations}

3.6.1 Working Environment. The working environment is generally more hectic during nonpower operating modes (Modes 3 through 6). This working environment increases the demands and stresses on the operators, and may increase the chances of operator error in the event of a hydrogen fire/explosion. In this respect, operation in the nonpower modes is not adequately addressed by the full power case.

3.6.2 Accident Procedures. Reactor accident procedures are not generally intended to address the nonpower modes of operation. The lack of procedures reduces the operator's resources and therefore they are more dependent upon their own understanding of the phenomena and appropriate reactions. 
3.6.3 Accident Training. Accident training is generally focused on Power Operation (Mode 1), and does not specifically address the nonpower modes (Modes 3 through 6). The training is generally applicable and appropriate for Power Operation through Hot Standby (Modes 1 through 3).

The appropriateness of the training decreases for Hot Shutdown through Refueling (Modes 4 through 6) because of the differences in system operability and heat removal demands. The allowable time for decision-making and response increases for these modes because of the lower decay heat loads.

\section{Net Impact of Operating Mode on Hydrogen Event Consequences}

It is beyond the scope of this study to quantitatively determine whether the risks associated with hydrogen events during full power operation are greater than the risks associated with hydrogen events during other modes of operation. However, various power-state dependent factors were discussed and a qualitative assessment was performed of the risk associated with off-power conditions. The following conclusions can be made regarding the hydrogen risk associated with shutdown reactor modes:

- Hydrogen events associated with generator cooling, the VCT, or the tank farm can occur during any reactor operating mode, and the rate of these hydrogen events is largely dependent of operating mode.

- $\quad$ Power Operation through Hot Standby (Modes 1 through 3) risks should be bounded by the full power operating cases presented previously. This conclusion is based upon system operability requirements, decay heat loads, RCS coolant inventory, RCS coolant makeup capacity, containment integrity, and operability of vital auxiliaries.

- Hydrogen-induced events during Hot Standby (Mode 4), Cold Shutdown, and Refueling (Modes 5 and 6) are considered to have insignificant impact on the reactor core. This conclusion is based upon the fact that hydrogen is typically absent from in-plant distribution systems, of the considerable reduction in decay heat loads, the increased coolant inventories, and the lower coolant temperatures (all of which allow more time for recovery of damaged systems). 


\section{APPENDIX D}

WESTINGHOUSE PLANT DESCRIPTION

D-1 


\section{APPENDIX D}

\section{WESTINGHOUSE PLANT DESCRIPTION}

\section{Plant, Site, and General Characteristics}

The plant, site, and general information for the Indian Point 2 Station (IP2) is obtained from the final safety analysis report (FSAR) ${ }^{D-1}$ and the Indian Point Probabilistic Safety Study. ${ }^{\text {D-2 }}$ Indian Point Unit 2 is owned and operated by the Consolidated Edison Company of New York, Inc. The unit employs a pressurized water reactor nuclear steam supply system furnished by Westinghouse Electric Corporation. Westinghouse Electric Corporation was the primary contractor and had responsibility for the design, construction, testing, and initial startup of the facility. Westinghouse had contracted with United Engineers and Constructors as architect-engineer to provide engineering assistance in the design and construction of the structural and civil works. The reactor is presently licensed to operate until September 28,2013 , at a thermal power of $3017.4 \mathrm{MW}(\mathrm{t})$ which corresponds to a design turbine-generator output of $971 \mathrm{MW}(\mathrm{e})$ net.

All systems and components of the facility are classified according to their importance. Those items vital to safe shutdown and isolation of the reactor or whose failure might cause or increase the severity of a loss-of-coolant accident (LOCA) or result in an uncontrolled release of excessive amounts of radioactivity are designated Class $\mathrm{I}$. Those items important to reactor operation but not essential to safe shutdown and isolation of the reactor or control of the release of substantial amounts of radioactivity are designated Class II. Those items not related to reactor operation or safety are designated Class III.

Class I buildings and structures include the containment (including all penetrations and airlocks, the concrete shield, the liner, and the interior structures), spent fuel pit, control room, diesel generator room, intake structure, service water screenwell and auxiliary building (except for steel superstructure). All these structures were designed to meet earthquake criteria and protect against high winds, sudden barometric pressure changes, flooding and other natural phenomena.

\section{Description of Plant Systems}

The description of plant systems for the Indian Point 2 Station (IP2) is obtained from the Indian Point Probabilistic Safety Study. ${ }^{\mathrm{D}-2}$ This section discusses the system descriptions and system models of the major frontline and support systems identified as important for this analysis. The discussion of the systems that follow includes:

- A brief functional description of the system with reference to the one-line diagrams that were developed to indicate which components were included in the model.

- Safety-related success criteria that were applied to the system. 
Interfaces and safety actuation provisions between the frontline systems and the support systems.

2.1 Electrical Power System. The electrical power system at ndian Point 2 is shown as a one-line diagram in Figure D-1. The 480-V Essential Power Supply subsystem consists of the station auxiliary transformer, four $6.9-\mathrm{kV}$ buses $(2,3,5$, and 6$)$, four $480-\mathrm{V}$ essential buses $(2 \mathrm{~A}, 3 \mathrm{~A}, 5 \mathrm{~A}$, and $6 \mathrm{~A})$, and three diesel generators $(21,22$, and 23). All ac safeguards equipment is supplied power from these 480-V buses. The dc power subsystem shown in Figure D-2 consists of four independent battery installations $(21,22,23$, and 24$)$, each of which is connected to a dc power panel and maintained under continuous charge by a self-regulating battery charger. Power panels 21 and 22 provide the primary sources of power to the safeguards equipment in Unit 2.

In the event of a turbine trip, power is supplied to $6.9-\mathrm{kV}$ Buses 5 and 6 from the station auxiliary transformer; power is supplied to Buses 2 and 3 through bus tie breakers from Buses 5 and 6 , respectively. All three diesel generators start cutomatically upon either detection of an undervoltage condition on any of the $480-\mathrm{V}$ essential buses or a safety injection signal. The diesel generator output breakers will close automatically, loading the diesel generators onto their respective buses, only on detection of an undervoltage condition on Bus 5A (Buses 2A and 5A are loaded) or 6A (Buses 3A and $6 A$ are loaded). Table D-1 shows the $480-V$ essential buses loading. Table D-2 shows the major dc power system loads.

The availability of ac electrical power is essential to proper operation of most of the systems analyzed. To account for this strong systems interaction, the event trees were constructed with an eightstate electric power branch immediately following the initiating event. Because 480-V Buses $2 \mathrm{~A}$ and $3 \mathrm{~A}$ are both powered by diesel generator 22 , it has been assumed that these two buses always fail simultaneously. The eight electrical power support states are shown in Table D-3.

\subsection{Reactor Protection System}

The reactor protection system (RPS) performs the following four functions:

1. Protects the reactor core against fuel rod cladding damage caused by departure from nucleate boiling or high powier density

2. Protects against reactor coolant system damage caused by high primary system pressure

3. Protects the reactor coolant system from sudden loss of its heat sink through the steam generators

4. In conjunction with engineered safety features systems, detects a failure of the reactor coolant system and initiates actions to contain any radioactive fission products. 


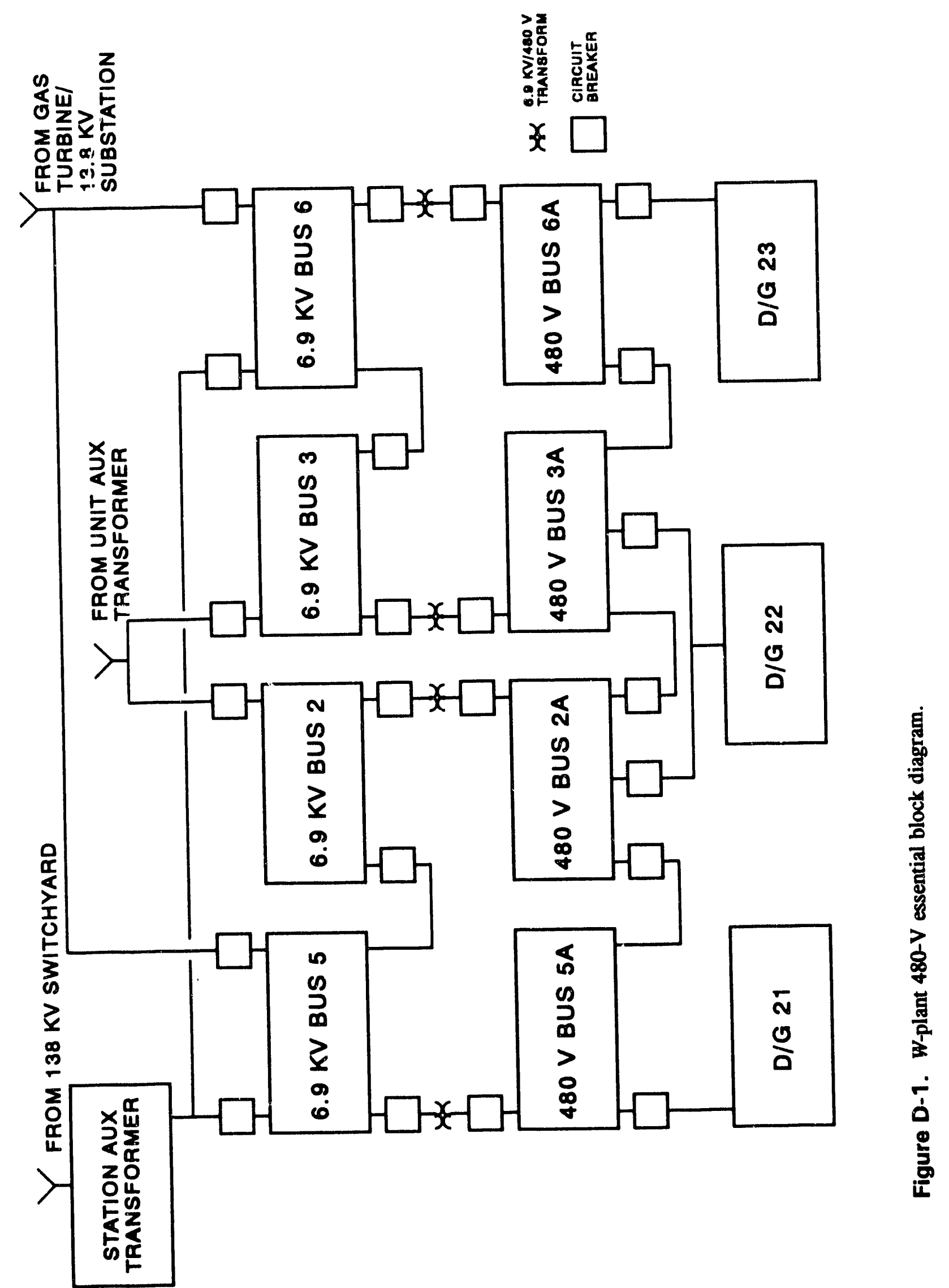

D-5 


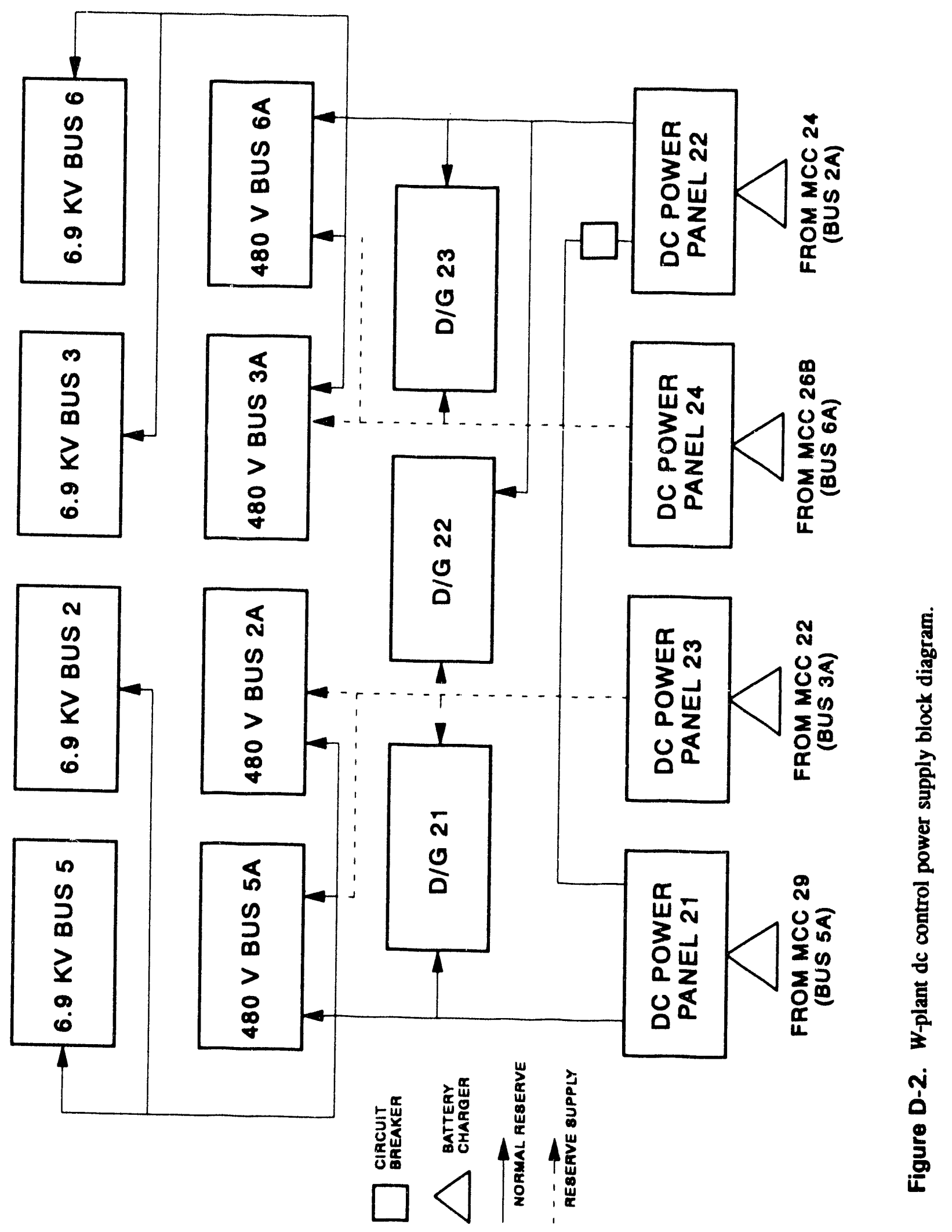


Table D-1. 480-V essential bus loads

\begin{tabular}{|c|c|}
\hline Bus & Load \\
\hline Bus 2A & $\begin{array}{l}\text { Pressurizer Heaters Backup Group } 22 \\
\text { Component Cooling Pump } 22 \\
\text { Service Water Pump } 22 \text { (redundant supply from Bus 3A) } \\
\text { Service Water Pump } 25 \text { (redundant supply from Bus 3A) } \\
\text { Safety Injection Pump } 22 \text { (redundant supply from Bus 3A) } \\
\text { Fan Cooler Unit 23, De-Icing Pump } 21 \\
\text { Rod Power Supply M-G Set } 21 \\
\text { MCC 21, MCC 23, MCC 24, MCC } 210 \\
\text { Lighting Transformer } 21 \text { (normal supply) }\end{array}$ \\
\hline Bus 3A & $\begin{array}{l}\text { Pressurizer Heaters Backup Group } 21 \\
\text { Component Cooling Pump } 23 \\
\text { Service Water Pump } 22 \text { (redundant supply from Bus 2A) } \\
\text { Service Water Pump } 25 \text { (redundant supply from Bus 2A) } \\
\text { Safety Injection Pump } 22 \text { (redundant supply from Bus 2A) } \\
\text { Residual Heat Removal Pump } 21 \\
\text { Auxiliary Feedwater Pump } 21 \\
\text { Fan Cooler Unit 24, Charging Pump 22, De-Icing Pump } 22 \\
\text { MCC 22, MCC 25, Lighting Transformer } 22\end{array}$ \\
\hline Bus 5A & $\begin{array}{l}\text { Pressurizer Heaters Backup Group } 23 \\
\text { Safety Injection Pump 21, Containment Spray Pump } 21 \\
\text { Recirculation Pump 21, Component Cooling Pump } 21 \\
\text { Service Water Pump 21, Service Water Pump } 24 \\
\text { Fan Cooler Unit 21, Fan Cooler Unit 22 } \\
\text { Charging Pump 21, Service Air Compressor } \\
\text { MCC 26A, MCC 28, MCC } 29 \\
\text { Lighting Transformer } 23\end{array}$ \\
\hline Bus 6A & $\begin{array}{l}\text { Pressurizer Heaters Control Group } \\
\text { Safety Injection Pump 23, Containment Spray Pump } 22 \\
\text { Recirculation Pump 22, Residual Heat Removal Pump } 22 \\
\text { Service Water Pump 23, Service Water Pump } 26 \\
\text { Auxiliary Feedwater Pump } 23 \\
\text { Fan Cooler Unit 25, Charging Pump } 23 \\
\text { Rod Power Supply M-G Set } 22 \\
\text { Main Turbine Auxiliary Lube Oil Pump } \\
\text { MCC 26B, MCC 27, MCC } 211 \\
\text { Lighting Transformer } 21 \text { (emergency supply) }\end{array}$ \\
\hline
\end{tabular}


Table D-2. Major de power system loads

\begin{tabular}{|c|c|}
\hline System & Load \\
\hline Power Panel 21 & $\begin{array}{l}\text { Main Turbine Emergency Oil Pump } \\
\text { Instrument Bus } 21 \text { Static Invertor } \\
6.9-k V \text { Buses 1, 2, and } 5 \text { Control Power } \\
\text { 480-V Buses 3A and 5A Control Power (normal supply) } \\
\text { Train A Reactor Trip Breakers Control Power } \\
\text { Control Rod Position Indication Invertor } \\
\text { Conventional Plant Emergency Lighting } \\
\text { Control Room Emergency Lighting } \\
\text { Diesel Generator Building Emergency Lighting } \\
\text { Distribution Panel } 21 \text { and 21A }\end{array}$ \\
\hline Distribution Panel 21 & $\begin{array}{l}\text { Safety Injection System Valves Control Power } \\
\text { Diesel Generator } 21 \text { Control Power (normal supply) } \\
\text { Main Steam Dump Control } \\
\text { Main Generator Trip Relays } \\
\text { Main Turbine Trip Relays } \\
\text { Station Auxiliary Transformer Trip Relays } \\
\text { Safeguards Actuation Train A Relays } \\
\text { Reactor Coolant System Overpressurization Protection Train A }\end{array}$ \\
\hline Distribution Panel 21A & $\begin{array}{l}\text { Reactor Protection Train A Relays } \\
\text { Miscellaneous Plant Fire Protection } \\
\text { System Controls }\end{array}$ \\
\hline Power Panel 22 & $\begin{array}{l}\text { Main Feedwater Pumps Emergency Oil Pump } \\
\text { Air Side Seal Oil Backup Pump } \\
\text { Instrument Bus } 22 \text { Static Invertor } \\
6.9-k V \text { Buses 3, } 4 \text { and } 6 \text { Control Power } \\
480-V \text { Buses 2A and 6A Control Power (normal supply) } \\
\text { Train B Reactor Trip Breakers Control Power } \\
\text { Nuclear Plant Emergency Lighting } \\
\text { Distribution Panel } 22 \text { and 22A }\end{array}$ \\
\hline
\end{tabular}


Table D-2. (continued)

\begin{tabular}{ll}
\hline System & \multicolumn{1}{c}{ Load } \\
\hline Distribution Panel 22 & $\begin{array}{l}\text { Safety Injection System Valves Control Power } \\
\text { Diesel Generators 22 and 23 Control Power (normal supply) } \\
\text { Main Generator Backup Trip Relays } \\
\text { Main Turbine Backup Trip Relays } \\
\text { Station Auxiliary Transformer } \\
\text { Backup Trip Relays } \\
\text { Safeguards Actuation Train B Relays } \\
\text { Reactor Protection Train B Relays }\end{array}$ \\
Distribution Panel 22A & $\begin{array}{l}\text { Reactor Coolant System Overpressurization Protection Train B } \\
\text { Peactor Analog Protection Invertor }\end{array}$ \\
& $\begin{array}{l}\text { Instrument Bus 23 Static Invertor } \\
\text { Power Panel 23 }\end{array}$ \\
& Diesel Generators 21 and 22 Control Power (reserve supply) \\
Power Panel 24 & Instrument Bus 24 Static Invertor \\
& 480-V Buses 2A and 6A Control Power (reserve supply) \\
& Diesel Generators 23 Control Power (reserve supply) \\
\hline
\end{tabular}

Table D-3. Electric power support states

\begin{tabular}{cl}
\hline Support State & \multicolumn{1}{c}{ Power Available At } \\
\hline 1 & Buses 2A, 3A, 5A, and 6A \\
2 & Buses 2A, 3A, and 6A \\
3 & Buses 2A, 3A, and 5A \\
4 & Buses 5A and 6A \\
5 & Buses 2A and 3A \\
6 & Bus 6A \\
7 & Bus 5A \\
8 & Power not available at 480-V essential buses \\
\hline
\end{tabular}


To accomplish these functions, the RPS utilizes trip signals from various process sensors throughout the plant to deenergize undervoltage devices in two series-connected reactor trip breakers. Opening the reactor trip breakers removes power from the magnetic coils, allowing the rod control cluster assemblies to fall into the active fuel region causing the reactor to shut down.

A simplified diagram of the RPS for Indian Point 2 (IP2) is provided in Figure D-3. There are four instrumentation channels that provide trip signals to both logic channels. Each logic channel controls the undervoltage trip device for one normally closed reactor trip breaker. The reactor trip breakers RTA and RTB are arranged in series; therefore, opening either reactor trip breaker will remove power from the rnd control cluster assembles. Bypass breakers BYA and BYB are provided to facilitate testing and maintenance of the RPS. During testing, a single logic channel supplies both the normal reactor trip breaker and the trip bypass breaker. This arrangement allows one logic channel to be tested to the reactor trip breaker without tripping the reactor.

The RPS interfaces with the 120-Vac instrument power supply system for power to the process sensors. The reactor trip breakers and logic channels are energized from separate $125-\mathrm{V} d \mathrm{c}$ buses. Loss of either source results in a trip signal which leads to a reactor scram.

The success criterion is the availability of a signal from the appropriate protective instrumentation to the reactor protection logic trains and the availability of the scram breakers, wiring, and the control rod drive mechanisms themselves.

\subsection{Safeguards Actuation System}

The safeguards actuation system (SAS) serves to limit plant damage in the event of breaks in the reactor coolant system of the secondary systems (main steam, feedwater, or steam generators).

The SAS at IP2 is composed of two subsystems. These subsystems are safety injection (SI) and containment spra (CS). Simplified diagrams for these subsystems are presented in Figures D-4 and D-5. An SI actuation signal initiates feedwater isolation, turbine trip, and reactor trip (via RPS). Components automatically started by the SI signal are the auxiliary feedwater pumps, safety injection pumps, residual heat removal pumps, containment fan coolers, service water pumps, component cooling pumps, and diesel generators. The SI actuation signal also initiates phase A containment isolation, containment ventilation isolation, control room ventilation isolation, and safeguards sequence. The CS actuation signal initiates containment spray injection, phase B containment isolation and containment ventilation isolation.

To accomplish these functions, the SAS uses trip signals from various primary and secondary plant sensors, and processes these signals through various logic matrices. Signals are then sent to the engineered safeguard systems based on the sensed conditions.

Failure of the safety injection actuation subsystem is defined as failure of both channels of safety injection logic or failure in the safety injection instrumentation. Failure of a single channel of safety injection logic includes failure to actuate any single equipment actuation relay. Failure of the containment spray actuation subsystem is defined as failure of both channels of containment spray logic or failure in the containment spray instrumentation. 


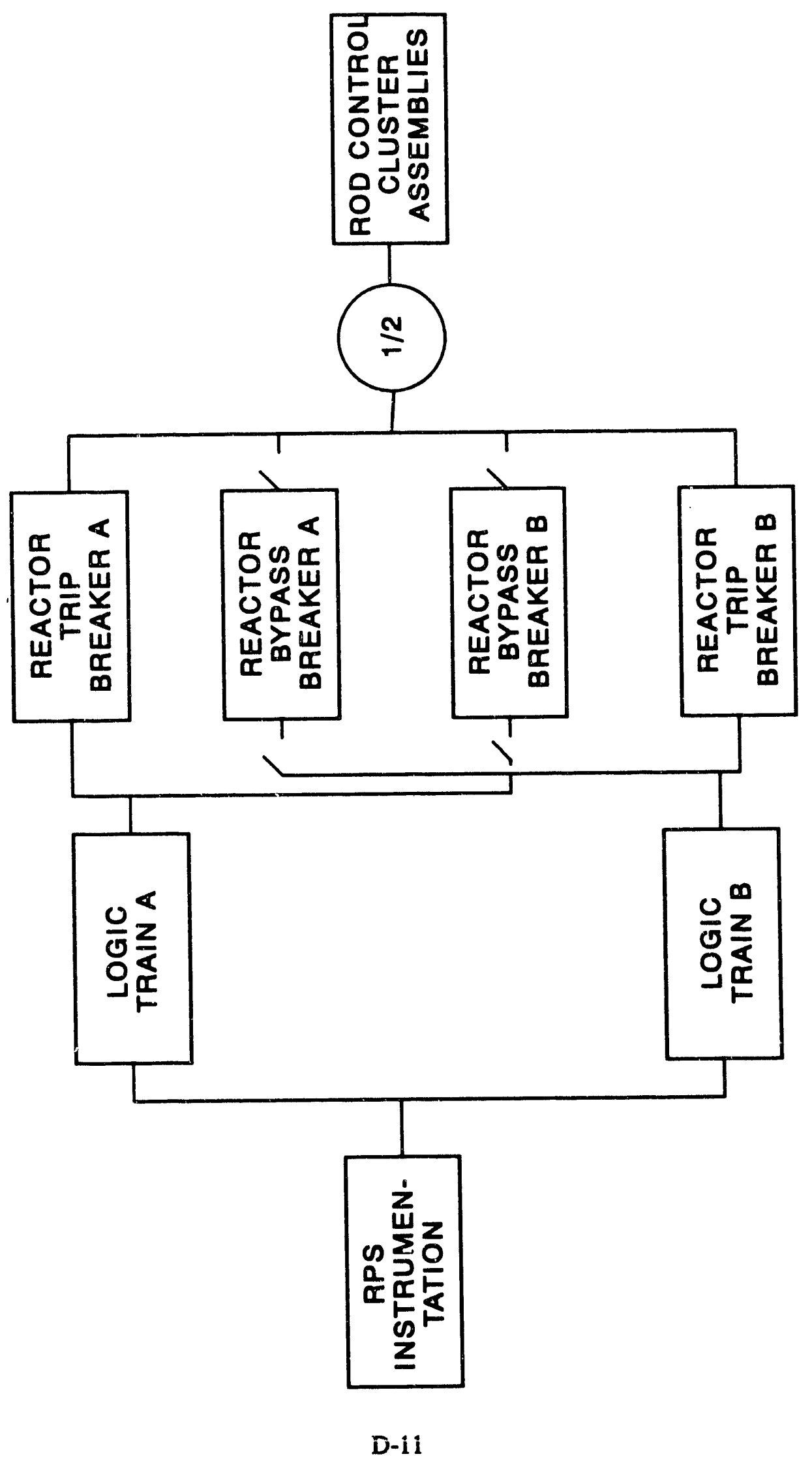




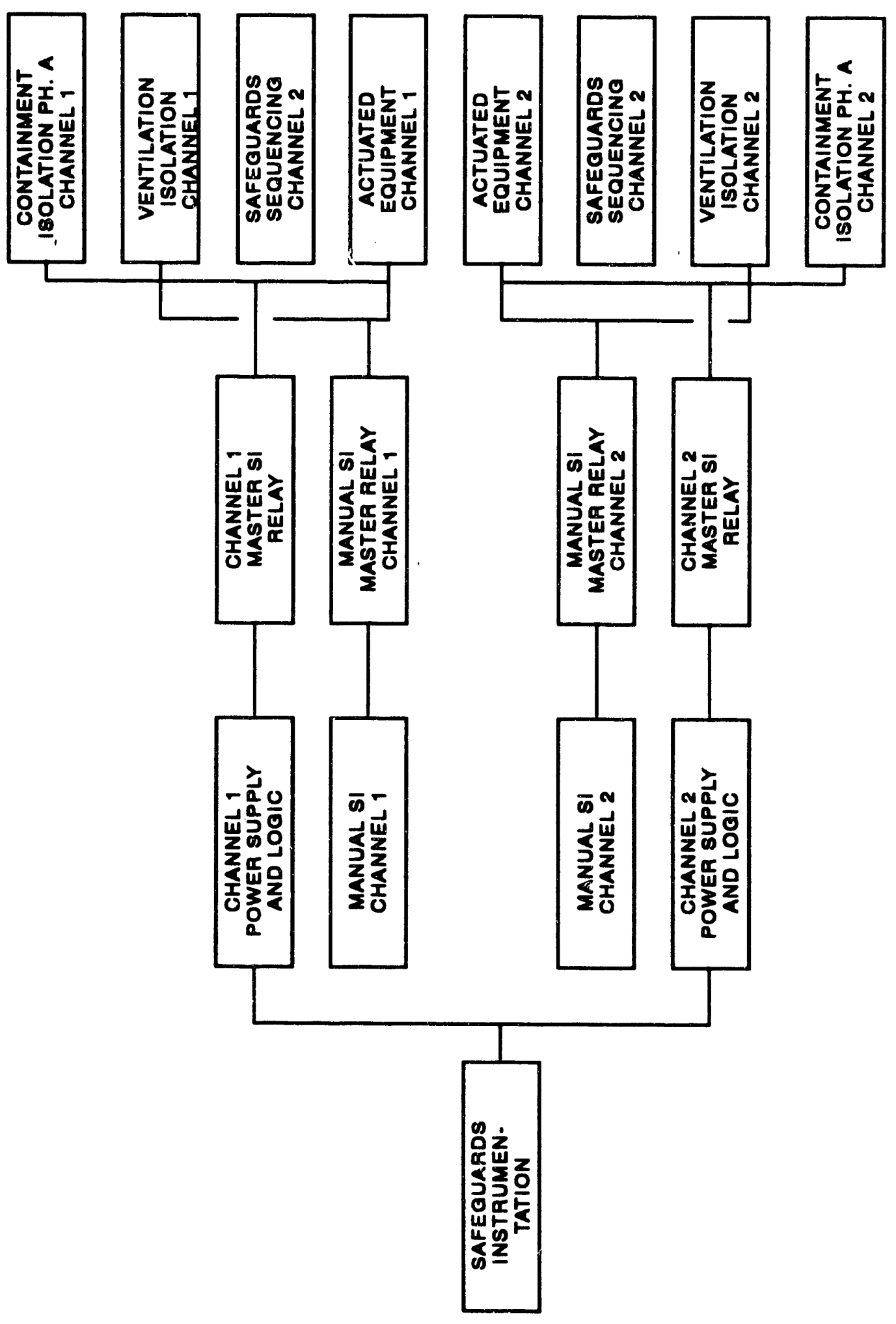

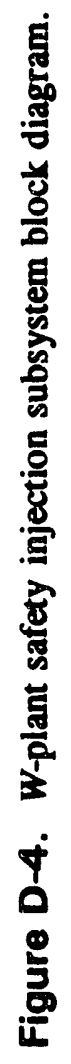




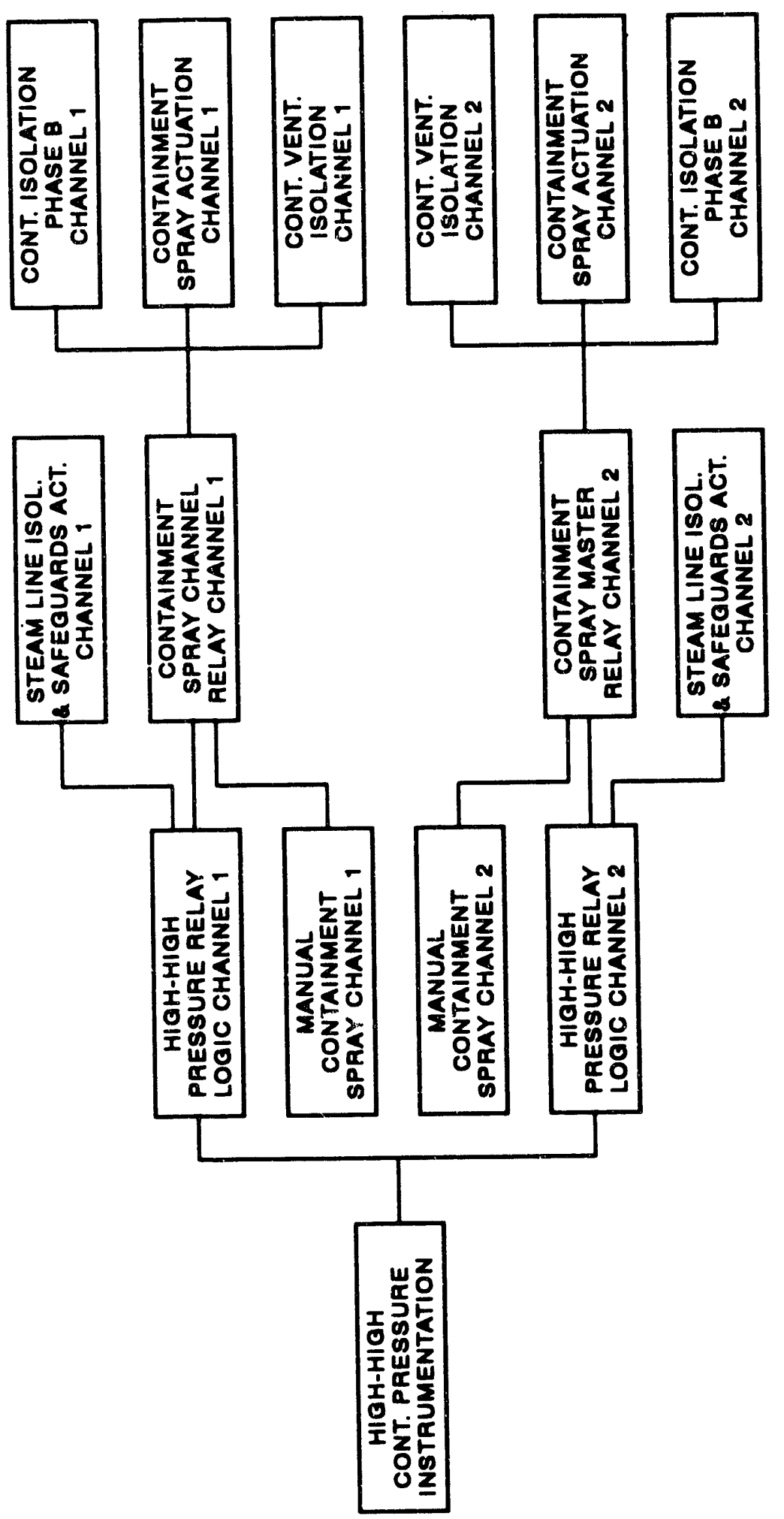

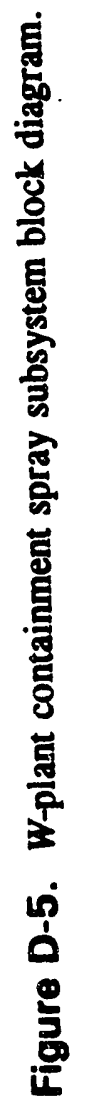

D-13 


\subsection{High Pressure Injection System}

The high pressure injection system (HPIS) provides cooling water to the reactor coolant system in case of a medium ( 2 to 6 in.) pipe break LOCA, a small (less than 2 in.) pipe break LOCA, and a secondary steam break. A simplified diagram of the high pressure injection system for IP2 is presented in Figure D-6. Three pump trains are shown. These trains are commonly connected to the boron injection tank (BIT) and the refueling water storage tank.

Upon indication of a small LOCA, medium LOCA, or a steam break, the system is started by an SI signal. All three pumps start and the motor operated valves align in their correct positions. The pumps first take suction from the BIT (as opposed to the RWST) because of the 90 psig overpressure. When three out of four level detectors indicate a level of $10 \%$ in the BIT, the four valves leading to the BIT will automatically close. Then suction will be taken from the RWST to the two main discharge headers and deliver coolant to the four cold leg reactor coolant system injection lines. The discharge line valves to the reactor coolant system cold legs are normally open.

The HPIS system may also be used in the feed and bleed cooling mode. The only difference in this mode of operation from that discussed above is that a SAS is not necessarily generated, so the HPIS system is manually placed in service.

Success for a medium LOCA is defined as two of three pumps delivering cooling water to one of four injection legs. Success for a small LOCA is defined as one of three pumps delivering cooling water to one of four injection legs.

\subsection{Recirculation System}

The recirculation system provides long-term core cooling and containment spray after a LOCA of any break size. It recirculates the sump water back into the core and/or spray nozzles after passing it through the residual heat removal (RHR) heat exchangers.

A simplified diagram of the recirculation system for IP2 is presented in Figure D-7. The recirculation phase is evaluated in the context of a LOCA. This phase calls for the combined operation of several systems and components: the RHR system, the containment sump, the recirculation sump and pumps, the SI system, and containment spray nozzles. For ease of reference, this group is called the recirculation system.

The system is initiated by the operators when the water level in the RWST is at "low level" alarm point (a one out of two system). For core cooling, the system can be operated in three different modes: high pressure, low pressure, and hot leg recirculation.

The two recirculation pumps are vertical, centrifugal pumps that have air-to-water heat exchangers. The water to these heat exchangers is supplied by the auxiliary component cooling pumps or main component cooling loop. The booster pumps are started by the SI system to protect the motors of the recirculation pumps from possible damage caused by containment high temperature conditions before the switchover to recirculation. 


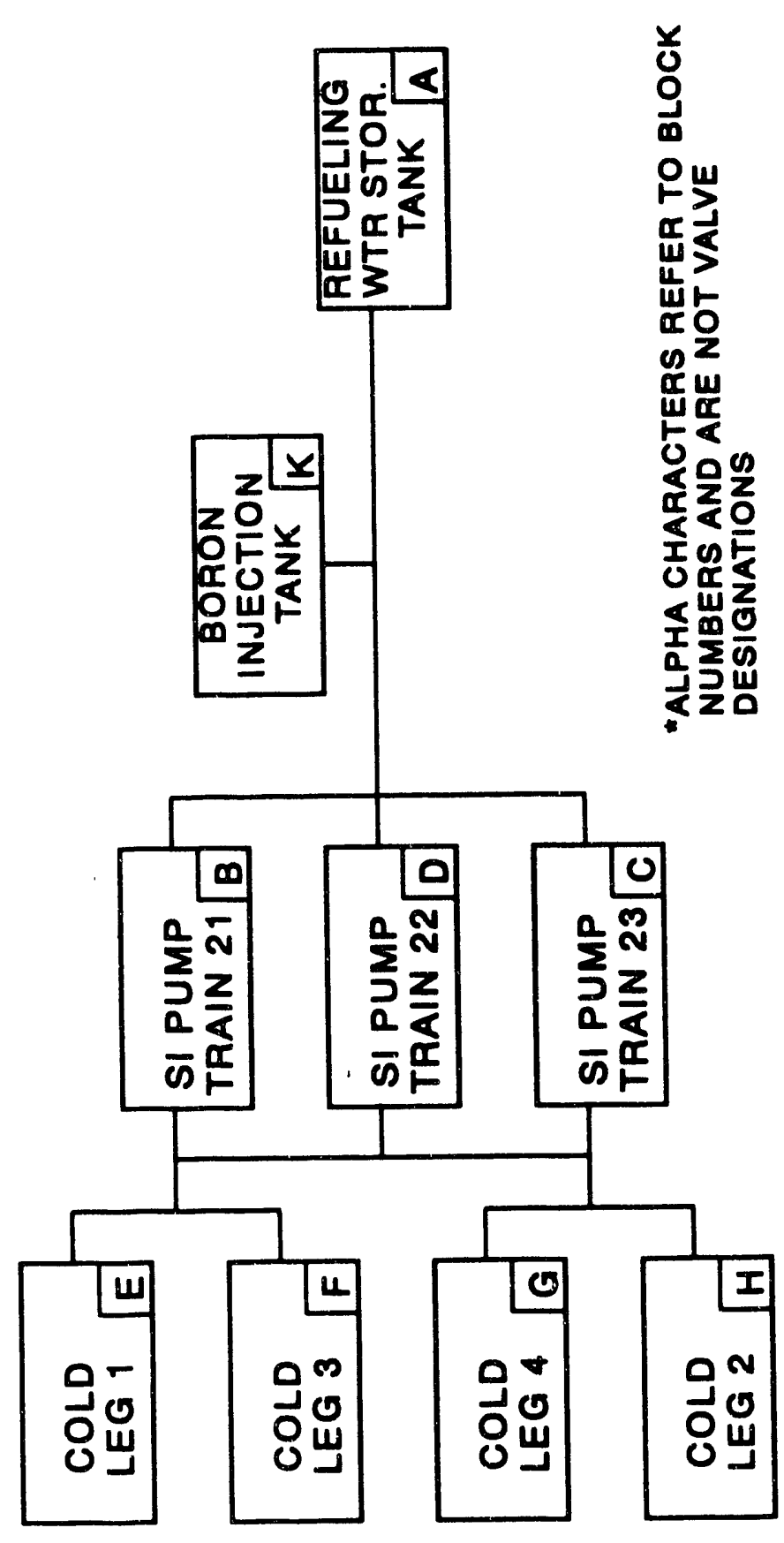

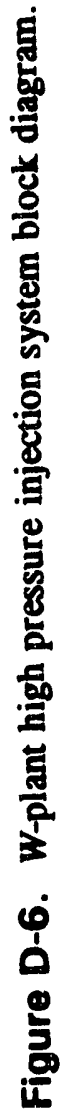

D-15 


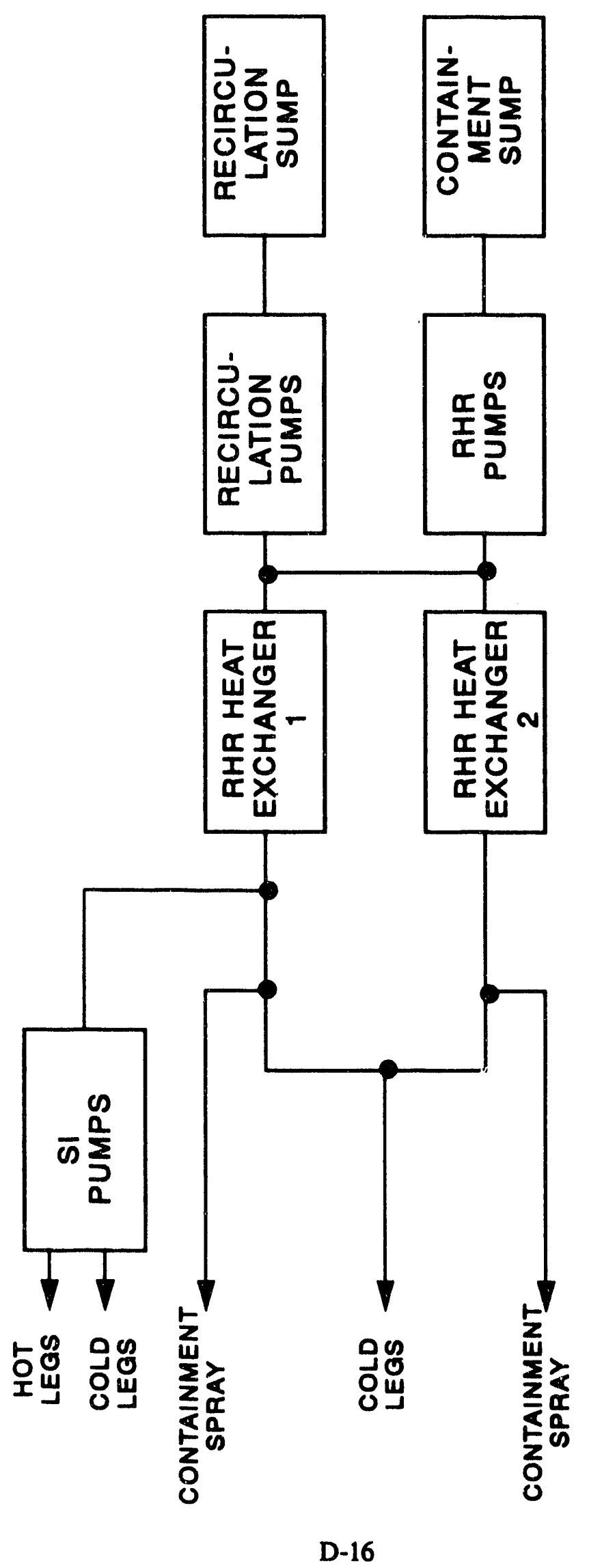

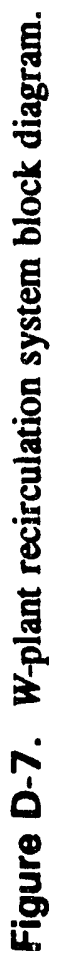


Four pumps can take suction from the sumps. The two recirculation pumps take suction from the recirculation sump, and two RHR pumps take suction from the containment sump. The configuration of components in the recirculation system is such that the low head pumps take suction from a sump and pass the coolant through the RHR heat exchangers. Any one of the four pumps can provide sufficient coolant flow to cool the core and simultaneously spray the containment. Depending on the operator decision and the pressure in the reactor coolant system and in the containment, the flow is routed for core cooling or containment spray, or both. Priority is given to core cooling.

The RHR heat exchangers cool the sump water. Their secondary side is connected to the component cooling system (CCS) which is cooled by the service water system (SWS) drawn from the ultimate heat sink (Hudson River). The component cooling outlet valves (for each heat exchanger) are opened by the safeguards actuation signal. If heat exchanger cooling is not available, the fan coolers can remove the heat from the containment atmosphere by condensing the steam generated in the core. In the recirculation phase, any three of the five fan coolers can remove all the decay heat following a large LOCA.

Flow can be directed in four different directions from the heat exchangers. Core and containment conditions determine which flow path should be chosen. The path for low pressure cold leg recirculation is the same as for low pressure injection and is opened by the safeguards actuation signal. If the reactor coolant system (RCS) pressure is above the shutoff head of the low pressure pumps, the flow is directed toward the suction line of the SI system pumps for high head recirculation. The third path leads to the containment spray headers. Hot leg recirculation is also possible. The isolation valves to the hot legs are normally closed and deenergized. If one heat exchanger train is unavailable, it is possible to align the other train for simultaneous core cooling and containment spray recirculation. Also, if high head injection is needed and the connection pipe between the RHR heat exchangers and the SI system pumps is closed or failed, the RHR pump flow can be realigned toward the suction side of the SI system pumps. The heit exchangers are bypassed in this situation. Therefore, this mode of recirculation will be successful only if the containment fan coolers are available to remove the heat generated in the core.

Success criteria for the small L.OCA response is that the operator recognizes the need to shift to recirculation cooling and continues high pressure recirculation as required.

Success criteria which applies to the transient event tree sequences includes the operator terminating the bleed operation and shifting to RHR cooling, shifting to high pressure recirculation, or depressurizing the RCS below 150 psig and shifting to low pressure recirculation.

\subsection{Containment Spray System}

The primary functions of the containment spray system (CSS) are to reduce the containment pressure following a LOCA or a steam break accident inside containment. Also the CSS removes iodine, (by sodium hydroxide acidition), released to the containment atmosphere in the event of a breach in the fuel cladding following a LOCA. 
A simplified diagram of the containment spray system CSS for IP2 is presented in Figure D-8. The CSS is composed of two 100 percent capacity spray injection trains. Upon the initiation of SI signal, the appropriate valve line up is obtained and the CSS pumps start. Each spray train draws water from the RWST through independent suction lines and discharges the coolant to its associated containment spray header.

The success criterion for the CSS is one of the two CSS trains providing flow to any one containment spray header.

\subsection{Containment Fan Cooling System}

The purpose of the containment fan cooling system (CFCS) is to limit containment pressure following a LOCA or a steam line break inside containment. This is accomplished by cooling fans that cool and circulate the containment atmosphere. This system also removes fission products from the containment building atmosphere following a LOCA.

A simplified diagram for containment fan cooling system (CFCS) is presented in Figure D-9. There are five cooling units. Given a LOCA or steam break followed by a safety injection signal, the fan coolers will automatically transfer to the accident mode. The fan coolers require electric power to run the fan motors and service water to cool the atmosphere and condense the steam. The normally closed service water valves on the common fan cooler discharge are opened by the SI signal to bypass service water flow around the normally throttled temperature control valve. Condensate from the cooling coils is routed to the containment sump.

System success criterion is three or more of the five fan cooler units placed in the accident mode with their charcoal filter beds available.

\subsection{Component Cooling Water System}

The component cooling water system (CCS) loop is one of three subsystems of the auxiliary coolant system (ACS) at IP2. It is a closed loop cooling system that is designed to remove residual and sensible heat from various primary plant components during power, shutdown operations, and under accident and transient conditions. The system also provides a barrier between the primary plant and the environment by preventing radioactive releases from entering the environment.

A simplified diagram of the component cooling water system is presented in Figure D-10. The CCS loop consists of three horizontal, centrifugal pumps, two heat exchangers which are cooled by service water, a single surge tank, and the necessary piping and valves to supply the various cooled equipment.

The success criterion during normal piant operation, is that two out of three pumps are required to supply the necessary flow for plant cooling loads. During accident conditions, one of the three pumps is required at the start of the recirculation phase to supply the necessary flow for the plant emergency cooling loads. A second pump is started when power is available. 


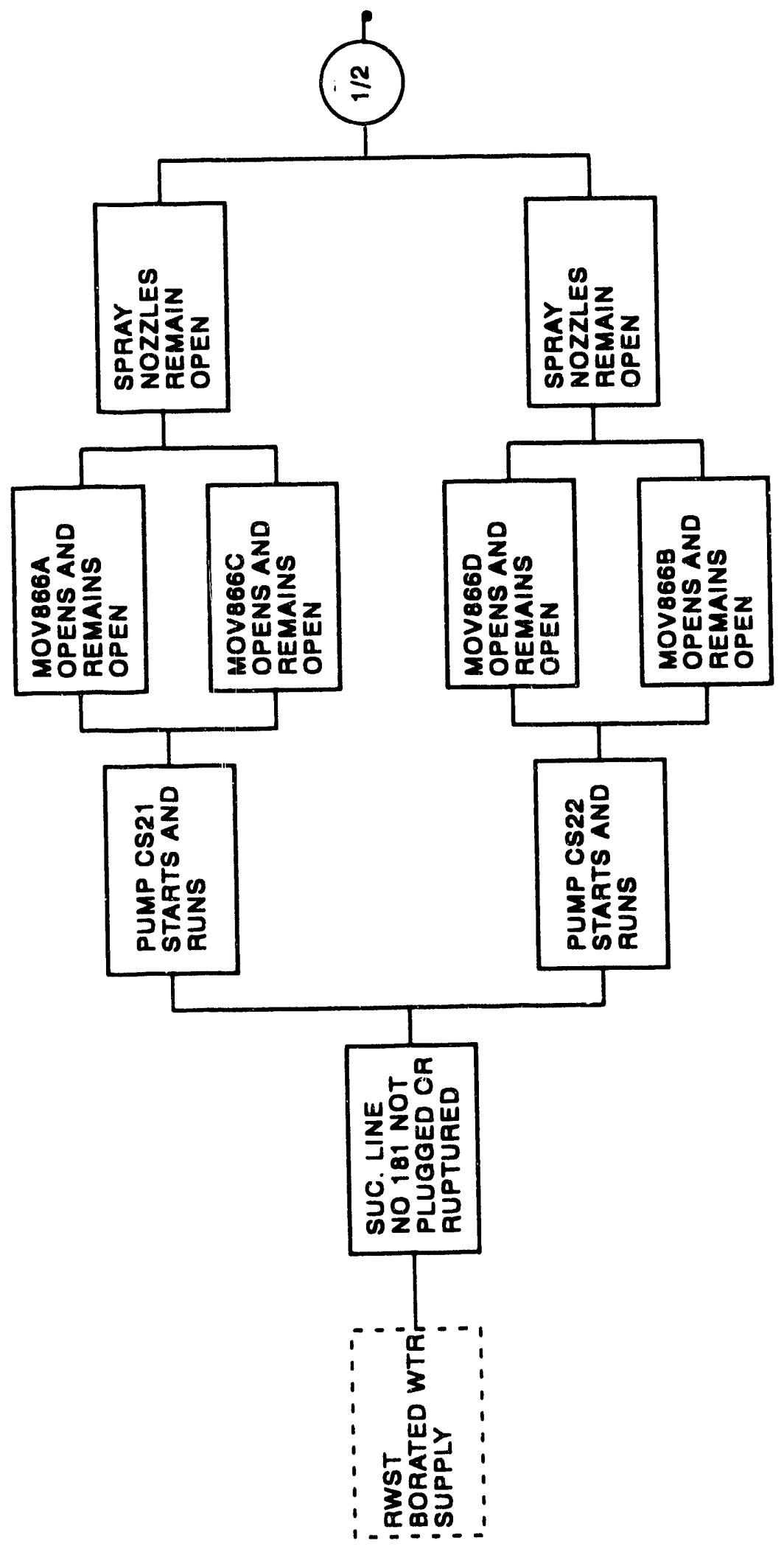

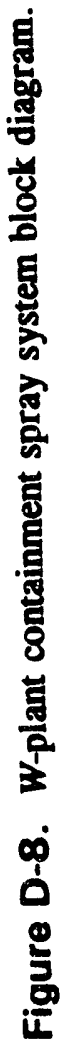

D-19 


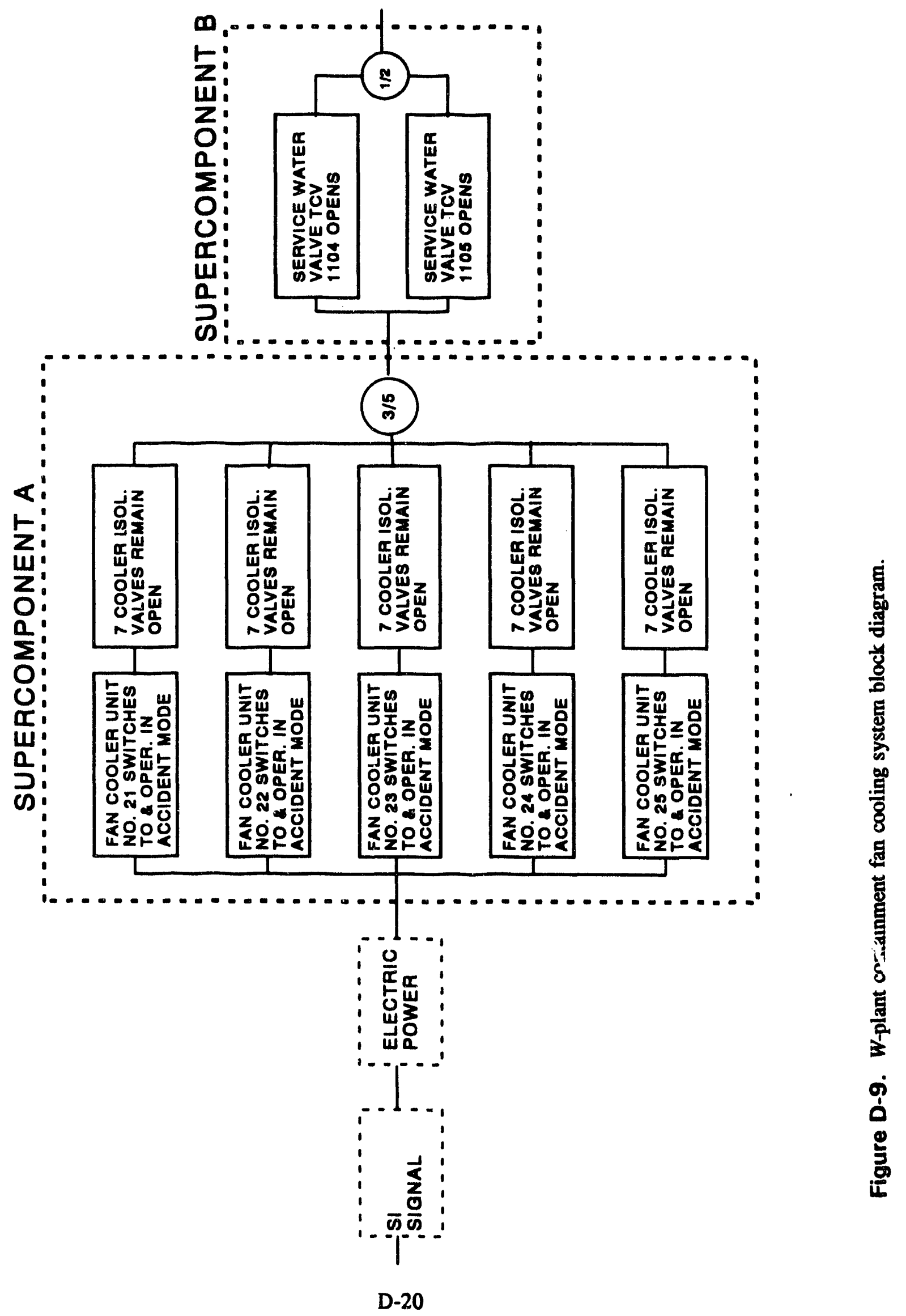




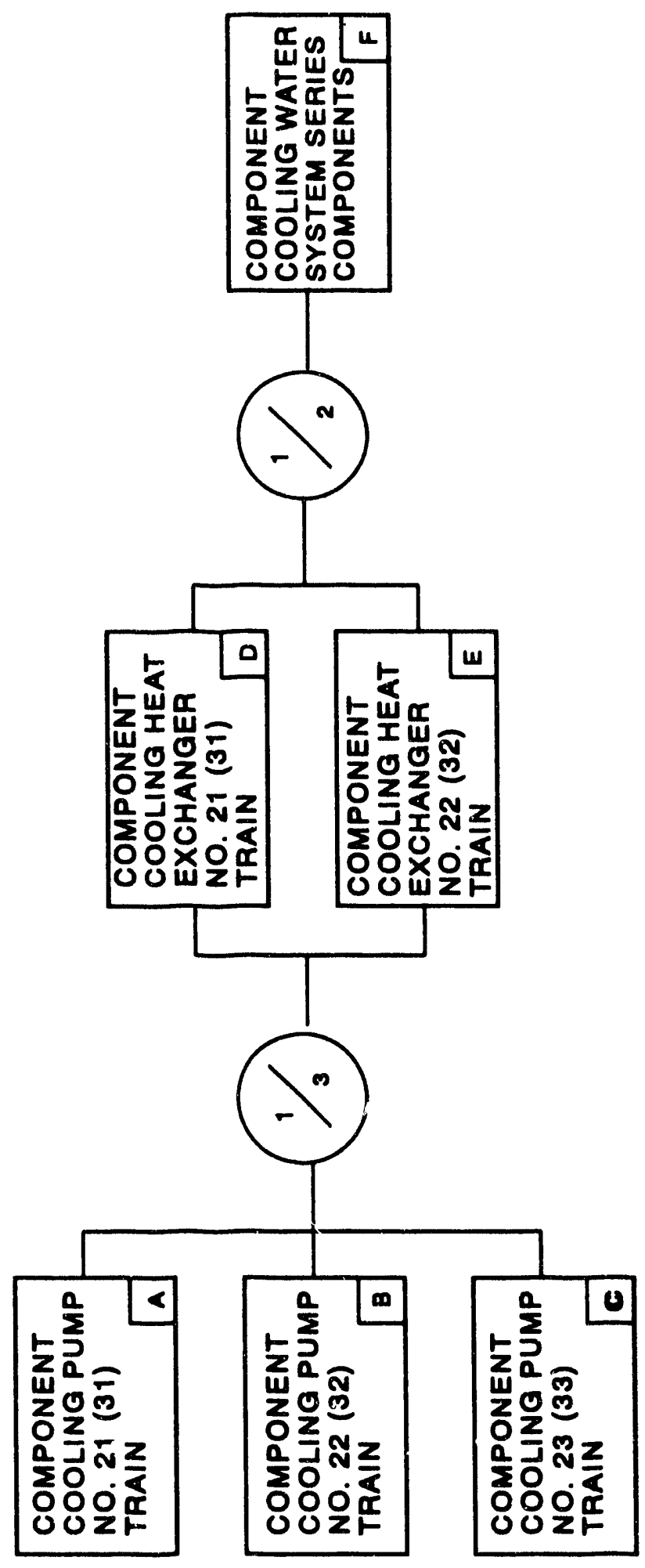

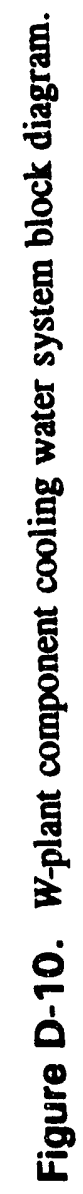

D-21 


\subsection{Service Water System}

The service water system (SWS) provides water to the various plant components that require heat removal for proper operation during normal and abnormal plant conditions. The components requiring service water during abnormal conditions are the three emergency diesel generators (EDG), the five containment building fans cooling units (FCUs), and the two component cooling heat exchangers. A simplified block diagram of the SWS for IP2 is provided in Figure D-11. The SWS consists of two groups of three pumps and two cooling water headers. The first group of pumps supplies cooling water to the essential plant services through the nuclear header. The essential plant services for this analysis consists of the EDGs and the FCUs. The other group of three pumps supplies cooling water to the nonessential plant through the conventional header. Operator action is required to manually realign and change header services.

System failure is defined as "No or Insufficient Flow from the Service Water System." This is defined as the failure of two of three service water pumps selected for supplying water to the nuclear service header, or the failure of one of three pumps selected for supplying water to the conventional service header.

\subsection{Auxiliary Foedwater System}

The auxiliary feedwater (AFW) system provides emergency cooling for the primary system when main feedwater is not available. The AFW system also prevents overpressurization of the primary system by supplying coolant to the steam generator.

A simplified diagram of the AFW for IP2 is provided in Figure D-12. The AFW for IP2 is a three train system, two electric motor driven pumps and one steam turbine driven pump. Each pump can draw suction from a primary or secondary water supply. The primary water supply is the 600,000 gallon condensate storage water tank. From this volume, 360,000 gallons are dedicated for AFW system use. If the primary water supply is not available, there is a secondary water supply for the auxiliary pumps. The secondary water supply is a 1.5 million gallon city water storage tank. There is a sufficient water supply to remove residual heat generated by the reactor for at least 24 hours for hot shutdown conditions. Coolant to the steam generators is supplied by eight parallel lines. Each line contains a check vaive, and two locked open manual isolation valves, that are in series with an air operated control valve. Motor driven pump 21 supplies coolant to steam generators 21 and 22 and motor driven pump 23 supplies coolant to steam generators 23 and 24 . The turbine driven pump 22 supplies coolant to all four steam generators.

The motor driven AFW pumps will automatically start during a loss of either of the two main feedwater pumps, a low steam generator level in any one of the four steam generators, a unit trip initiated by a safety injection system, or a unit trip with a loss of offsite power with no safety injection signal. The turbine driven pump will automatically start on receipt of indication of low steam generator level in any two of the four steam generators, or loss of offsite power concurrent with a main turbine generator trip with no safety injection signal.

The success criterion for the AFW system following all events except an ATWS is flow from any one AFW pump to any of the four steam generators. 


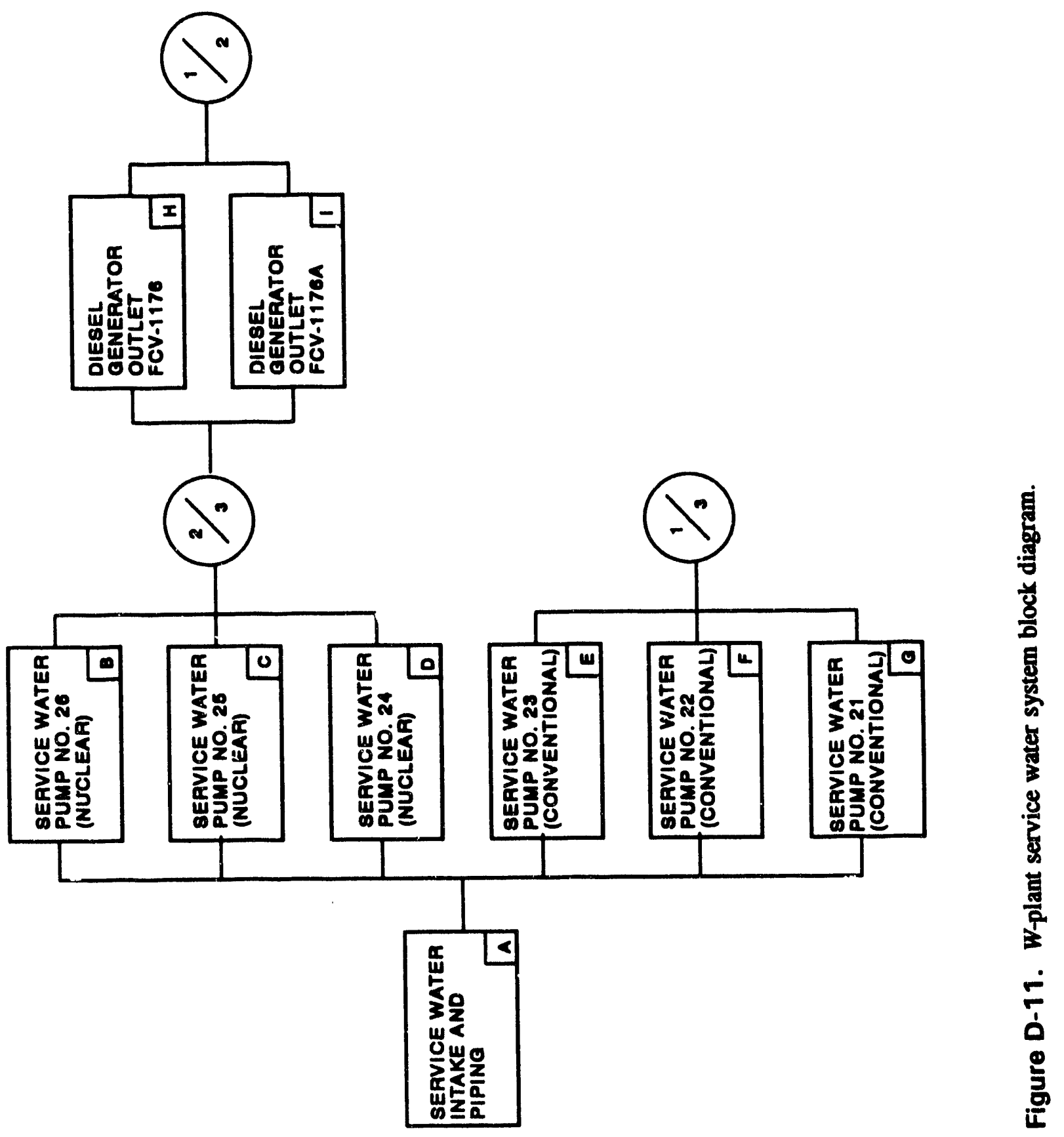

D-23 


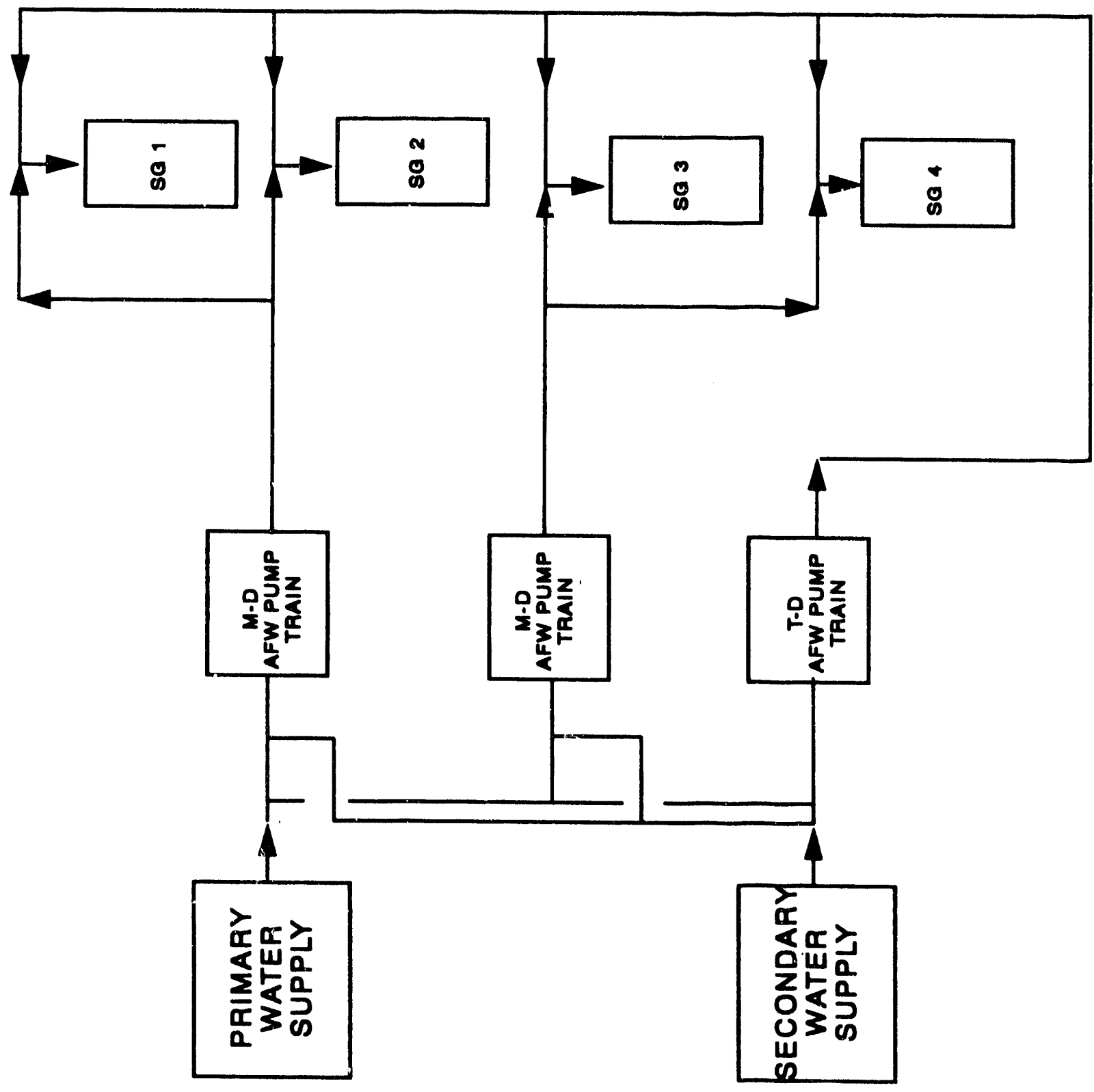

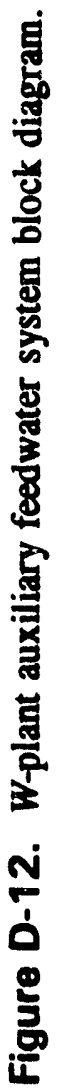




\subsection{Alternate Safe Shutdown System}

Plan..$^{\text {D. } 3}$

This system information was obtained from the Indian Point Unit 2 Fire Protection Program

The functions of the IP2 alternate safe shutdown system (ASSS) are to:

- Provide the necessary shutdown functions for a fire that damages the capability to power and control equipment from IP2 sources

- Provide the capability to perform only selected safe shuidown functions wher: these have been lost due to a fire

- Satisfy the performance requirements of Section III.L of 10 CFR 50, Appendix $R$

- Provide the capability to perform the above shutdown runctions independent of fire zones that, if involved in a fire, would require the use of the ASSS.

The ASSS provides the capability to perform the following critical safety functions: maintenance of reactor subcriticality, core cooling $\{x$ hot shutdown (through natural circulation, and primary system pressure and inventory control), reactor coolant system integrity, secondary heat removal for hot shutdown, long-term decay heat removal, and process monitoring. Following the unlikely loss of normal and preferred alter ate power, additional independent and separate power supplies from the IP1 480-V switchgear are provided through the ASSS for a number of safe shutdown components.

The Unit $1480-\mathrm{V}$ switchgear is supplied from the Buchanan 13.8-kV system through separate transformers. These are powered by one of three gas turbines.

Independent power supplies from IP1 auxiliaries are hardwired to manually operated transfer switches to power one train of the following safe shutdown components to maintain the ASSS safe shutdown functions listed below:

- Component cooling pump 23

- $\quad$ Auxiliary boiler feed pump 21

- Service water pump 23

- $\quad$ Service water pump 24

- Charging pump 23

- $\quad$ MCC 27, RHR pump 21 or SI pump 21 (through use of casualty cables). 
To perform the necessary safe shutdown functions, pneumatic instrumentation for the ASSS has been provided in the fan house to supplement existing local displays for the following functions: pressurizer level, pressurizer pressure, and steam generator level.' Additionally, source range neutron monitoring instrumentation and reactor coolant system hot $\mathrm{lgg}$ and cold leg temperature indication have been provided as part of the ASSS.

The ASSS is designed to function given a loss of offsite power. The system is designed to be independent of IP2 fire zones as much as practical. In certain locations, power is fed from the alternate safe shutdown system as well as the transfer switches located in IP2 fire zones. Exemption requests justify those locations where three-hour fire barriers do not separate the ASSS components from IP2 fire zones, and where ASSS components are located within IP2 fire zones. The ASSS uses separate raceways (generally dedicated conduit) from IP2 raceways. The conceptual design of the ASSS is to provide separate power supplies and switchgear to power IP2 safe shutdown equipment. Transfer switches are located in close proximity to equipment served, and may also be used to select the power source (IP2 or ASSS).

\section{References for Appendix D}

D-1. Consolidated Edison Company of New York, Inc., Indian Point Unit 2 Updated Final Safety Analysis Report, Revision 3, July 1985.

D-2. Power Authority of the State of New York aild Consolidated Edison Company of New York, Inc., Indian Point Probabilistic Safety Study, 1982.

D-3. Power Authority of the State of New York and Coniolidated Edison Company of New York, Inc., Indian Point Unit 2 Fire Protection Plan, Revision 3, October 1987. 


\section{APPENDIX E}

WESTINGHOUSE BASE CASE PLANT PRA MODEL

E-1 


\title{
APPENDIX E
}

\section{WESTINGHOUSE PRA MODEL}

\section{Introduction}

The Indian Point 2 (IP-2) PRA model was used as the basis for the base case and generic studies. This appendix presents the detailed PRA model for the general turbine trip events as described in the Indian Point 2 Probabilistic Safety Study, 1982.

\section{Turbine Trip--Event Tree 11}

The turbine trip event tree applies to three separate causes of turbine trip sequences. The first is turbine trip resulting from the loss of offsite power; that is, a load rejection transient in which no offsite power is available to supply the emergency buses. Next is turbine trip resulting from the loss of service water. The third includes all other turbine trips. The same tree structure applies to all three cases, but because of system interdependencies, they are quantified separately. The event tree uses the following symbols to identify system and operator functions:

$\begin{array}{ll}\text { ET-11 } & 1.0 \\ \text { K-3 } & 2.0 \times 10^{-5} \\ \text { L-1 } & 1.9 \times 10^{-5} \\ \text { OP-2 } & 6.1 \times 10^{-3} \\ \text { R-3 } & 5.0 \times 10^{-4} \\ \text { CF-2 } & 5.0 \times 10^{-6} \\ \text { CS } & 8.1 \times 10^{-5} \\ \text { NA } & 9.6 \times 10^{-4}\end{array}$

\author{
Initiating Event Turbine Trip \\ Reactor Trip \\ AFWS Actuation and Secondary Cooling \\ Primary Cooling Bleed and Feed \\ Recirculation Cooling \\ Fan Coolers \\ Containment Spray \\ Sodium Hydroxide Addition
}

Turbine trips are relatively mild transients that plants experience several times each year. In general, no problems should occur following turbine trip. The reactor should trip immediately as a result of the turbine trip signal, and the auxiliary feedwater should start when the levels in the steam generators fall. As long as auxiliary feedwater is being supplied to the steam generators, the multitude of pathways for the steam to escape from the steam generators ensures secondary cooling. Cooling of the core will follow by natural circulation or forced circulation. The turbine driven auxiliary feedwater system is designed to operate without service water and without offsite electric power. Therefore, successful termination of the turbine trip transient requires only a reactor trip and actuation of auxiliary feedwater.

\subsection{Initiators}

While any of the accidents or transients already discussed should eventually lead to turbine trip, the events considered here are those that essentially begin with the turbine trip. These trips are direct or are caused by load rejection or loss of service water. In these cases, the turbine trip is the first event shown in the sequence. 


\section{Basic Turbine Trip Event Tree (ET-11)}

\subsection{Systems and Plant Functions}

The top events of the turbine trip event tree (ET-11), K-3 through NA, are described in detail to provide an understanding of the systems and operator functions involved.

1. K-3, Reactor Trip. The success of K-3 depends on the actual trip of control rods. This is based on automatic signals generated by the logic based on occurrence of turbine trip, or by the logic based on low-low level in any single steam generator. On turbine trip resulting from loss of offsite power, electric power to the control rods is lost. Therefore, the only cause for failure of reactor trip is the mechanical failure of the rods to insert.

2. L-1, AFWS Actuation and Secondary Cooling. The success of the auxiliary feedwater system depends on the start of one motor-driven pump or the turbine-driven pump in response to an automatic actuation signal or operator action. The automatic signals to start the auxiliary feedwater pumps for this event tree come from low-low steam generator level.

Secondary coling is achieved by removing heat from the steam generator. This is done by automatically or manually opening a relief valve(s) associated with a steam generator(s) receiving auxiliary feedwater. Heat is also removed by safety valves, steam dumps to the main condenser, or blowdown. Only the steam reliefs and safeties are modeled for secondary cooling since they are adequate.

Heat removal from the primary system can be provided by one steam generator. Given these conditions, the reactor core will be cooled by forced flow or by single or two-phase naturai circulation to the steam generator.

3. OP-2, Primary Cooling Feed and Bleed. If auxiliary feedwater csoling should fail, the operator can start a high head safety injection pump and manually open the PORV block valves and PORVs to provide feed and bleed (F\&B) cooling to the primary system. For success of this branch, the operator must determine that such action is necessary and then take the proper action. In addition, the appropriate valves must be open and the appropriate pump must start. Water from the refueling water storage tank is also required.

4. R-3, Recirculation Cooling. When L-1 is failed and short-term cooling is provided by F\&B, long-term cooling must be accomplished using at least one RHR or recirculation pump. The success of R-3 depends on service water and component cooling and fan cooler operation. It can be accomplished in three ways. If the plant is completely depressurized to less than 150 psig, low pressure recirculation is possible using an RHR or recirculation pump. If the plant is depressurized to less than $600 \mathrm{psig}$, either high pressure recirculation or preferred normal RHR cooling is possible. At pressures greater than 600 psig, only high pressure recirculation can be used. Success depends on the operator recognizing what action to take and the successful operation of RHR pumps and other equipment. 
5. CF-2, Fan Coolers. Containment fan coolers provide long-term cooling for the containment atmosphere. They prevent overpressure and can effectively supply cool recirculation water to the containment sumps. Fan coolers are only shown on the event tree for core melt sequences in which the fan coolers are useful in protecting the containment from overpressure failure. For CF-2, the probability that CF fails (less than three out of five operate properly and service water cooling is available) is calculated conditional on the failure of $\mathbf{R}-3$.

The reasons for R-3 failure include service water failure (this also fails the fan coolers) and failure of both component cooling to the RHR heat exchangers and failure of the fan coolers. This complicated calculation could be avoided by restructuring the tree as SW-CF-R-3 rather than R-3-CF. However, the second structure describes the transient sequence progression more clearly.

6. CS, Containment Spray. Containment spray protects the containment from overpressure failure and scrubs the containment atmosphere of radionuclides. These functions are important because they reduce the chance and severity of releases should core melt occur. Event CS includes the successful generation of an automatic actuation signal. Automatic actuation occurs on high-high containment pressure. One of two pumps must operate for this analysis to be successful. Intermittent manual operation can be effective as long as water is available in the RWST. In this event tree, it is very unlikely that sprays will provide any useful function. They are required if F\&B cooling is required and R-3 fails. In such a case, the operator will probably use the remaining RWST water to continue F\&B to save the core rather than use it for sprays after melt. Another possibility is that the RWST is refilled after melt but before containment overpressure.

\subsection{Tree Structure}

1. Displayed Dependencies

a. When K-3 reactor trip fails, no other branches are taken from the event tree. The sequences branch to the ATWS tree (ET-13) for further analysis. The reason for this is that the definitions of functional success in the original tree may change during an ATWS.

b. When K-3 reactor trip and L-1 are successful, no other branches are taken since cooling is successful.

c. When L-1 fails, but OP-2 and R-3 succeed, the core is protected. No further branches are needed, and the transient is ended.

d. All remaining cases lead to core melt, and containment protection is examined. When CS fails, NA cannot succeed.

2. Systems Interaction. Most dependencies caused by systems interaction have been discussed in the previous section. Others are as follows: 
a. All active systems depend on electric power. This is handled in the quantification of the event tree by making separate quantification runs of the tree for each state of electric power. The results from each run are then combined based on the likelihood of the plant being in a specific electric power configuration following the initiating event.

b. Diesel generators require service water for cooling.

c. Successful recirculation cooling (R-3) requires service water and component cooling. Service water provides a heat sink for component cooling and for the fan coolers, if required. Component cooling removes heat from the recirculation or RHR pumps, and from the RHR heat exchangers, if required. Closed loop RHR cooling requires an RHR pump and heat exchanger. Open loop recirculation cooling requires a recirculation or RHR pump and an RHR heat exchanger or the fan coolers.

3. Degraded Core States. All degraded core states branch to the ATWS tree (ET-13) or are assigned to the accident sequence types TE and SL (for early and late failures). All are transient sequences. Depending on the success or failure of fan coolers and containment spray, the assignments are as follows:

\begin{tabular}{llcc}
$\begin{array}{l}\text { Plant Event } \\
\text { Sequence } \\
\text { Category }\end{array}$ & $\begin{array}{l}\text { System Failure } \\
\text { Responsible for } \\
\text { Core Melt }\end{array}$ & CF-2 & CS \\
\cline { 2 - 3 } TEFC & L-1 and OP-2 & 1 & 1 \\
TEF & & 1 & 0 \\
TEC & & 0 & 1 \\
TE & R-3 & 0 & 0 \\
SLFC & & & \\
SLF & & 1 & 1 \\
SLC & & 1 & 0 \\
SL & & 0 & 1 \\
& & 0 & 0 \\
- $\quad 1=$ Success & & & \\
& $0=$ Failure
\end{tabular}

\section{Steam Break Outside Containment--Event Tree 6}

The steam line break outside containment event tree 6 applies to those transients that begin with a steam line break outside containment. The normal progress of this transient is high head safety 
injection, reactor trip, MSIV trip, and auxiliary feedwater system actuation resulting from the safety injection signal. This is followed by the operator's taking control of the AFWS and secondary cooling. The steam line break outside containment event tree used the following symbols to identify systems and operator functions:

$\begin{array}{lll}\text { SA-2 } & 1.3 \times 10^{-4} & \text { SI Signal and High Head Pumps } \\ \text { K-3 } & 2.0 \times 10^{-5} & \text { Reactor Trip } \\ \text { MS-1 } & 1.5 \times 10^{-2} & \text { MSIV Trip } \\ \text { L-1 } & 1.9 \times 10^{-5} & \text { AFWS Actuation and Secondary Cooling } \\ \text { OP-1 } & 6.1 \times 10^{-3} & \text { Feed and Bleed Cooling } \\ \text { R-3 } & 5.0 \times 10^{-4} & \text { Recirculation Cooling } \\ \text { CF-2 } & 5.0 \times 10^{-6} & \text { Fan Coolers } \\ \text { CS } & 8.1 \times 10^{-5} & \text { Containment Spray } \\ \text { NA } & 9.6 \times 10^{-4} & \text { Sodium Hydroxide Addition }\end{array}$

The event tree is used to quantify the frequency of degraded core states. Such conditions can occur only when the functions previously described are unsuccessful. Cooling can be provided by AFWS and steam generator cooling or by direct primary F\&B.

\subsection{Initiators}

The steam break outside containment event tree (ET-6) is initiated by random events. Similar events may also be caused by external event influences.

\subsection{Systems and Operator Functions}

The top events of the steam line break outside containment event tree (ET-6), SA-2 through NA, are described in detail to provide an understanding of the systems and operator functions involved.

1. SA-2, Safety Injection Signal and High Head Pumps. The actuation signals generated for ET-6 are:

a. Low pressurizer pressure

b. High steam flow with low $\mathrm{T}_{\mathrm{avg}}$ or low steam pressure.

The success of SA-2 requires the generation of a safety injection signal and the start of one of the three high head injection pumps.

2. $\quad K-3$, Reactor Trip. The success of $\mathrm{K}-3$ depends on control rod insertion in response to an automatic reactor trip signal. Automatic trip signals may be generated from the following:
a. Low pressurizer pressure
b. Safety injection actuation
c. Low-low steam generator level. 
3. MS-1, MSIV Trip. The success of MS-1 depends on the automatic manual closure of all the MSIVs. The automatic isolation signal is generated from the high steam flow safety injection signal. The emergency operating procedures direct the operator to manually close the MSIV for the faulted steam generator.

4. L-1, AFWS Actuation and Secondary Cooling. AFWS success requires the start of one motor-driven or turbine-driven pump in response to an automatic signal or operator action. The automatic signal is derived from safety injection actuation or low-low steam generator level. The success of secondary cooling requires the automatic or manual opening of a relief or safety valve. The steam dump to the condenser is not available since the MSIVs are presumed closed. The emergency operating procedures direct the operator to secure feed to the depressurized (faulted) steam generator.

5. OP-1, Feed and Bleed Cooling. If auxiliary feedwater cooling should fail, the operator can manually open the PORV block valves and PORVs to provide F\&B cooling to the primary system. For success for this branch, the operator must determine that such action is necessary and then take the proper action. In addition, the appropriate valves must open.

6. R-3, Recirculation Cooling. When L-1 is failed arid short-term cooling is provided by F\&B, long-term cooling must be accomplished using at least one RHR or recirculation pump. The success of R-3 depends on service water and component cooling and fan cooler operation. It can be accomplished in three ways. If the plant is completely depressurized to less than $150 \mathrm{psig}$, low pressure recirculation is possible using an RHR or recirculation pump. If the plant is depressurized to less than $600 \mathrm{psig}$, either high pressure recirculation or preferred normal RHR cooling is possible. At pressures greater than 600 psig, only high pressure recirculation can be used. Success depends upon the operator recognizing what action to take and the successful operation of RHR pumps and other equipment.

7. CF-2, Fan Coolers. Containment fan coolers provide long-term cooling for the containment atmosphere. They prevent overpressure and can effectively supply cool recirculation water to the containment sumps. Fan coolers are only shown on the event tree for core melt sequences in which the fan coolers are useful in protecting the containment from overpressure failure. For CF-2, the probability that CF fails (less than three out of five operate properly and service water cooling is available) is calculated conditional on the failure of R-3. The reasons for R-3 failure include service water failure (this also fails the fan coolers) and failure of both component cooling to the RHR heat exchangers and failure of the fan coolers. This complicated calculation could be avoided by restructuring the tree as SW-CF-R rather than R-CF. However, the second structure describes the transient sequence progression more clearly.

8. CS, Containment Spray. Containment spray protects the containment from overpressure failure and scrubs the containment atmosphere of radionuclides. These functions are important because they reduce the chance and severity of releases should core melt occur. Event includes the successful generation of an automatic actuation signal. Automatic actuation occurs on high-high containment pressure. One of two pumps must operate for this analysis to be successful. Intermittent manual operation can be effective as long as 
water is available in the RWST. In this event tree, it is very unlikely that sprays will provide any useful function. They are needed if F\&B cooling is required and R-3 fails. In such a case, the operator will probably use the remaining RWST water to continue F\&B to save the core rather than use it for sprays after melt. Another possibility is that the RWST is refilled after melt, prior to containment overpressure.

9. NA, Sodium Hydroxide Addition. The success of this system depends on the proper lineup of the sodium hydroxide tank with the containment spray system to provide a high $\mathrm{pH}$ containment spray for additional scrubbing of radioactive iodine from the containment atmosphere.

\subsection{Tree Structure}

\section{Displayed Dependencies}

a. If steam generator isolation (MS-1) fails, the steam generators rapidly boil dry and, although the auxiliary feedwater system could supply water to the steam generators for cooling, current operating procedures may cause the operators to secure flow in the auxiliary feedwater system. Thus, when MS-1 fails, L-1 (auxiliary feedwater system) is modeled as failed. The operating procedures are written to maintain water level in the steam generator and to stop feeding a steam generator if that level cannot be maintained. This prevents excessive cooldown in faulted steam generators.

b. If reactor trip $(\mathrm{K}-3)$ fails, then no further branches are on the tree.

c. If safety injection actuation (SA-2) and MS-1 fail, then core damage is modeled and the tree branches directly to the containment pressure control events.

d. If SA-2 and L-1 fail, core damaged is modeled and the tree branches directly to the containment pressure control events. If $L-1$ is successful, the transient is completed.

e. If L-1 and primary F\&B (OP-1) fail, core damage is modeled and the tree branches directly to containment pressure control events.

f. If containment spray fails, then sodium hydroxide (NA) fails.

2. Systems Interaction. Most dependencies caused by systerns interaction were discussed in the previous section. Others are as follows:

a. When OP-1 requires that the operator begin F\&B cooling, the only action to be taken is to open the PORV block valves and the PORVs since safety injection, the high head pumps, has already actuated. 
b. R-3, recirculation cooling, depends on starting a recirculation or RHR pump. Hence, success of R-3 must includes successful pump operation in addition to valve realignment.

c. Successful recirculation cooling (R-3) requires service water and component cooling. Service water provides a heat sink for component cooling and for the fan coolers, if required. Component cooling removes heat from either the recirculation or the RHR pumps and from the RHR heat exchangers, if required. Closed loop RHR cooling requires an RHR pump and heat exchanger. Open loop recircuiation cooling requires a recirculation or RHR pump and an RHR heat exchanger or the fan coolers.

d. All active systems require electric power.

e. Service water is required for diesel generator operation.

3. Degraded Core States. All degraded core states branch to the ATWS tree (ET-13) or are assigned to the accident sequence types TE and SL (for early and late failures). All are transient sequences. Depending on success or failure of fan coolers and containment spray, the assignments are as follows:

\begin{tabular}{lcccc}
$\begin{array}{c}\text { Plant Event } \\
\text { Sequence } \\
\text { Category }\end{array}$ & $\begin{array}{c}\text { System Failure } \\
\text { Responsible for } \\
\text { Core Melt }\end{array}$ & CF-2 & CS \\
\cline { 2 - 3 } TEFC & L-1 and OP-1 & 1 & 1 \\
TEF & & 1 & 0 \\
TEC & & 0 & 1 \\
TE & & 0 & 0 \\
SLFC & R-3 & 1 & 1 \\
SLF & & 1 & 0 \\
SLC & & 0 & 1 \\
SL & & 0 & 0
\end{tabular}




\section{APPENDIX F COST/BENEFIT UNCERTAINTY ANALYSIS}




\section{APPENDIX F}

\section{COST/BENEFIT UNCERTAINTY ANALYSIS}

The uncertainty analysis for each cost/benefit calculation is performed via propagating separate distributions (represented by probability density functions) representing the uncertainties in costs and in benefits through the expression for DPR. The results of the calculation are a probability density function for the DPR which when integrated yields the cumulative distribution function, mean value, and upper and lower bounds on DPR.

It should be noted that the predicted cost/benefit ratio mean value is larger than the point estimate values. This is because of the fact that in the expectation of a nonlinear function such as the DPR, the effects of uncertainties in the cost and benefit add to the mean. This is because for any general function of $n$ random variables $Z=f\left(X_{1}, X_{2}, \ldots X_{n}\right)$, the mean or expected value of $Z$ may be obtained by a Taylor series expansion in terms of the various moments of each of the random variable ${ }^{a}$. Thus:

$$
\begin{aligned}
E(Z)= & f\left(E\left(X_{1}\right), E\left(X_{2}\right), \ldots, E\left(X_{n}\right)\right)+\frac{1}{2} \sum_{i=1}^{n} \frac{\partial^{2} f}{\partial x_{1}^{2}} \operatorname{Var}\left(X_{i}\right)+\frac{1}{2} \sum_{\substack{i=1 \\
i \neq j}}^{n} \sum_{j=1}^{n} \frac{\partial^{2} f}{\partial x_{1} \partial x_{j}} \operatorname{Covar}\left(x_{i}, x_{j}\right) \\
& + \text { higher order terms. }
\end{aligned}
$$

Computation of the expected value of the cost/benefit ratio, considering uncertainties, would yield the iollowing expression:

$$
E(D P R) \approx \frac{E(\text { Cost })}{E(\text { Benefit })}+\frac{E(\text { Cost })}{E(\text { Benefit })^{3}} \operatorname{Var}(\text { Benefit) }
$$

The implication of this is that uncertainties in the benefits (namely risk reduction) predominately contributed to the overall mean or expected value of the cost/benefit ratio.

Twenty-eight case models were investigated and the results are presented in this appendix. Figures F-1 through F-28 show the cumulative probability distributions (CDF) for the different cases. The distributions are presented only for the cases where the onsite avgrted cost is included. The vertical dashed line contained on each CDF signifies the value of the mean.

a. G.J. Hahn and S. S. Shapiro, Statistical Models in Engineering, New York: Wiley, 1967. 


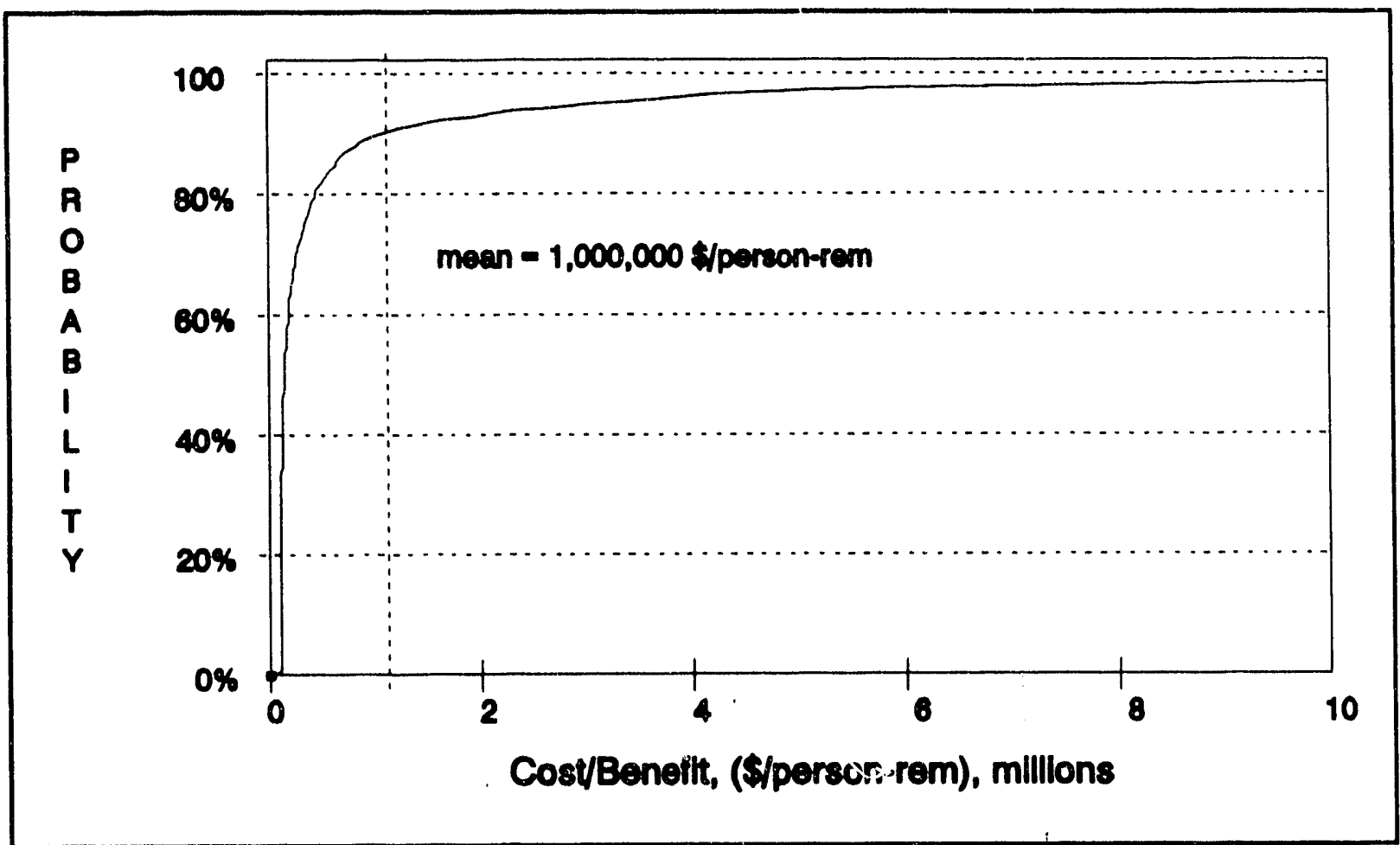

Figure F-1. Configuration II (modification 1) cost/benefit CDF.

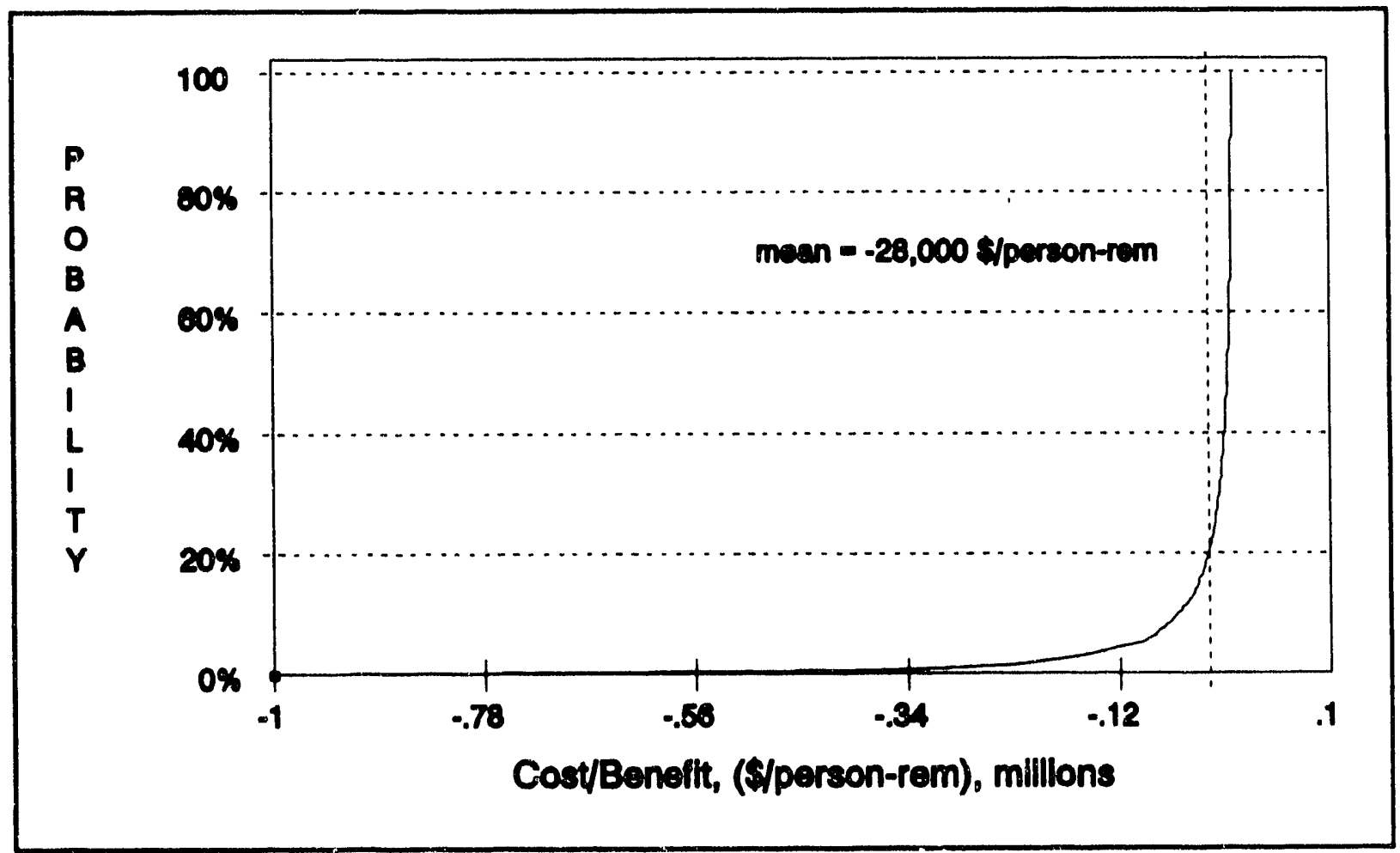

Fgure F-2. Configuration III (modification 1) cost/benefit CDF. 


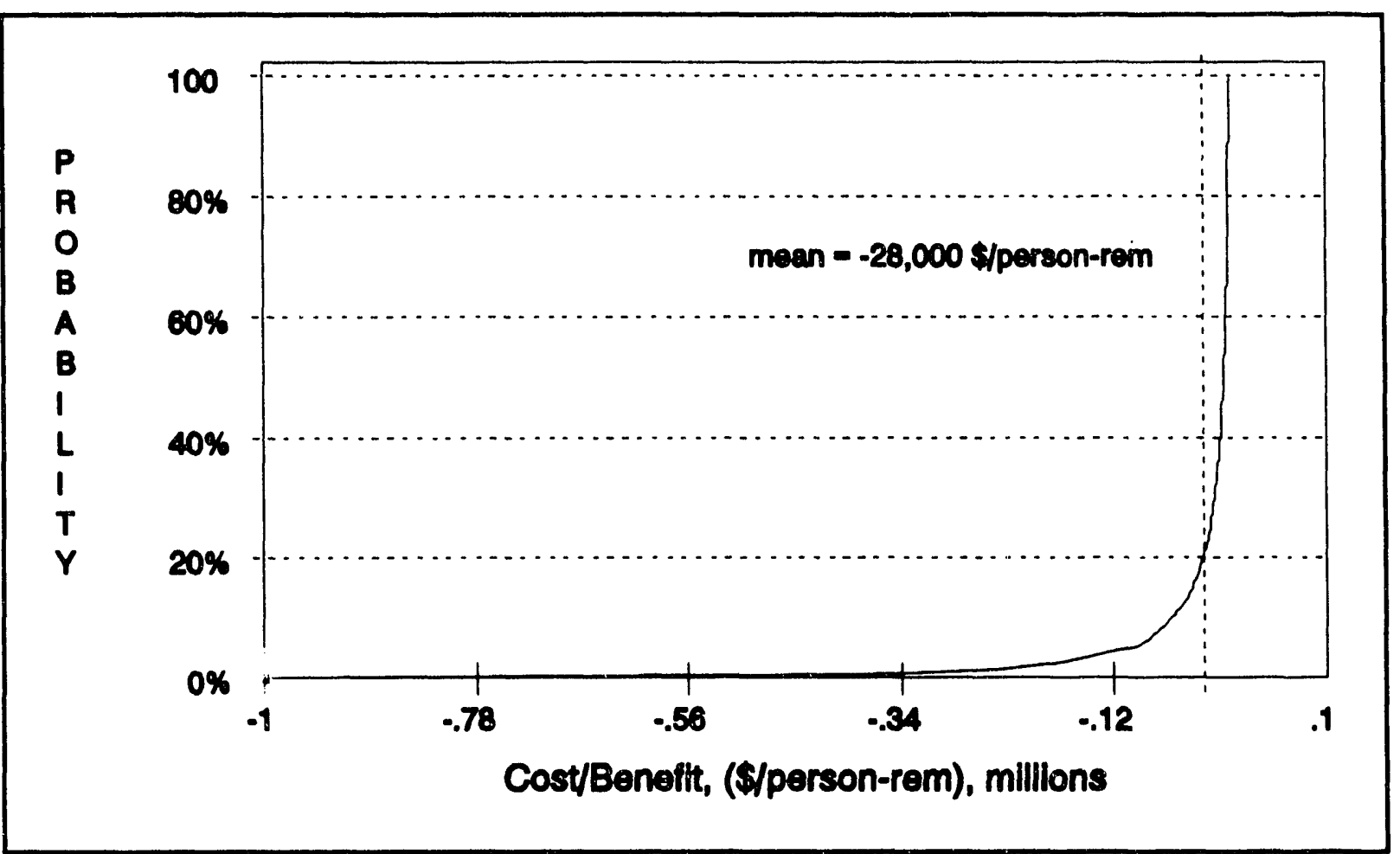

Figure F-3. . Configuration IV (modification 1) cost/benefit CDF.

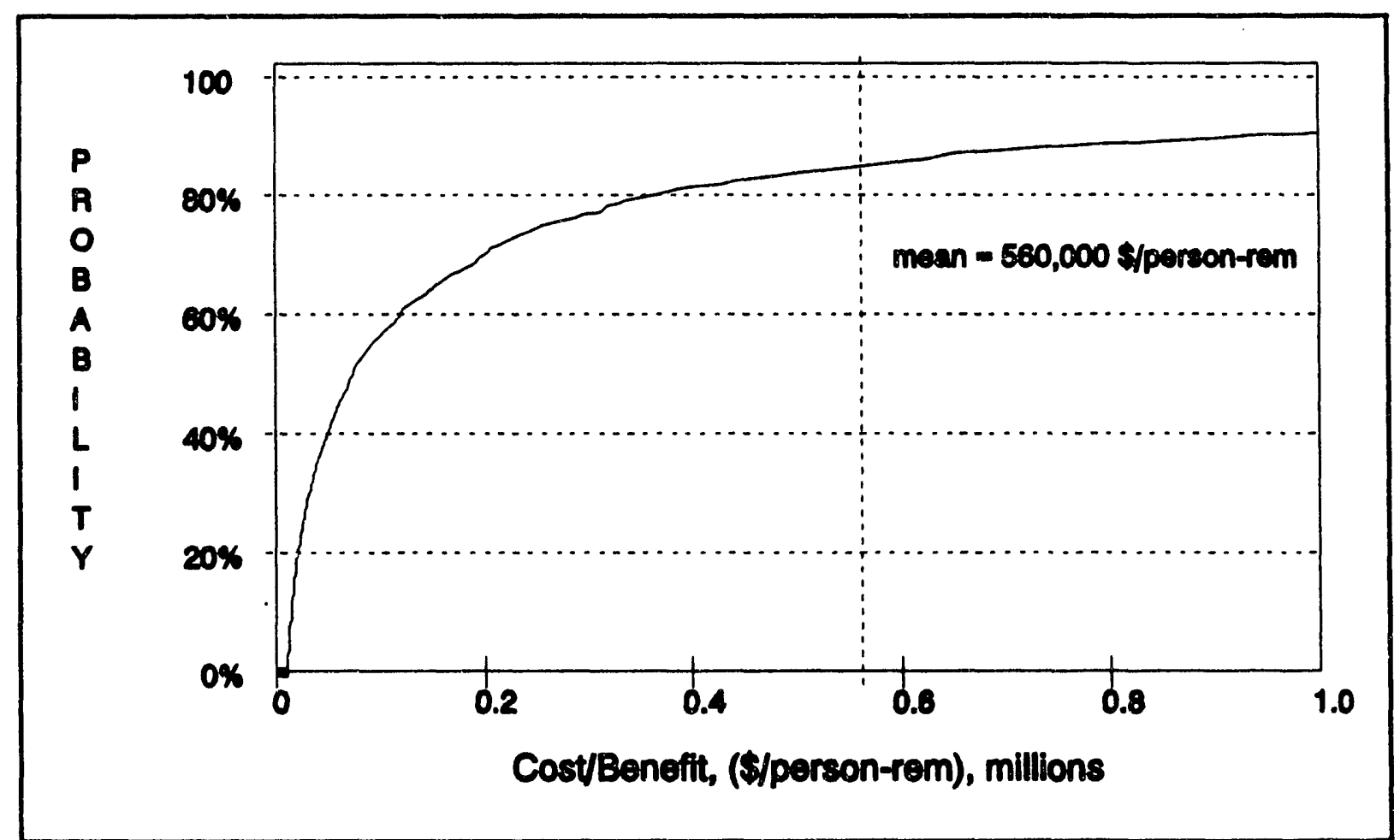

Figure F-4. Configuration VI (modification 1) cost/benefit CDF. 


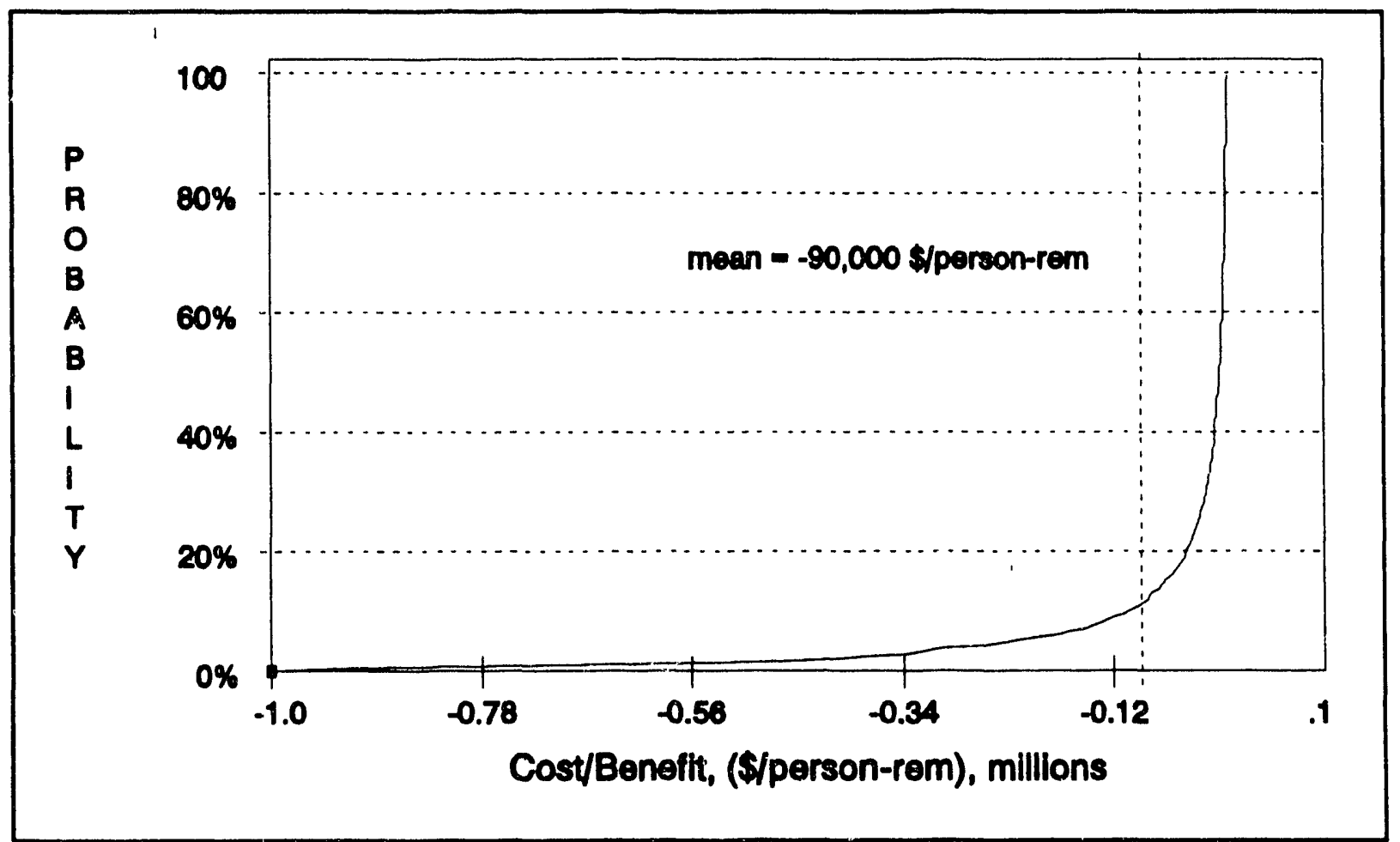

Figure F-5. Configuration VII (modification 1) cost/benefit CDF.

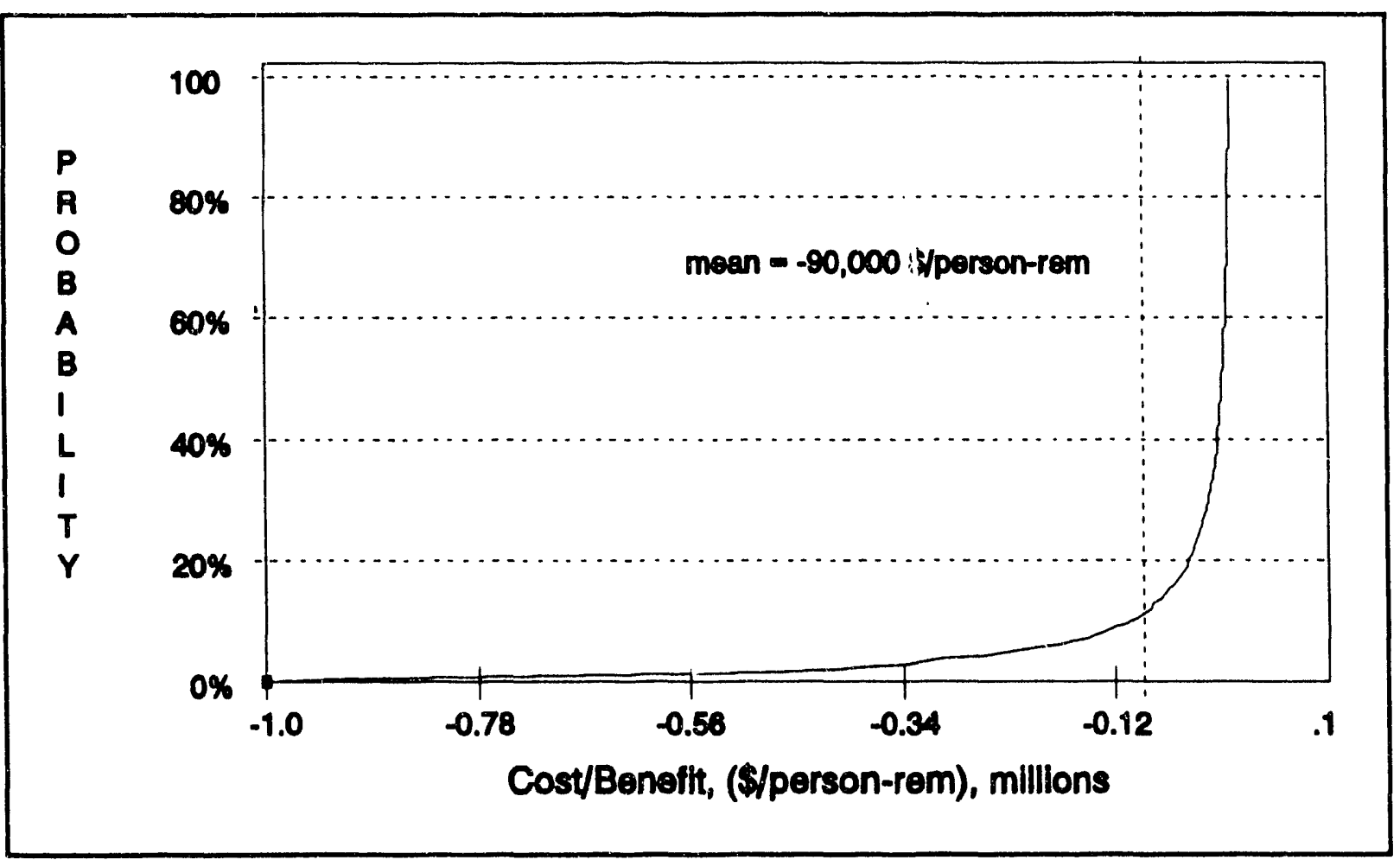

Figure F-6. Configuration VIII (modification 1) cost/benefit CDF. 


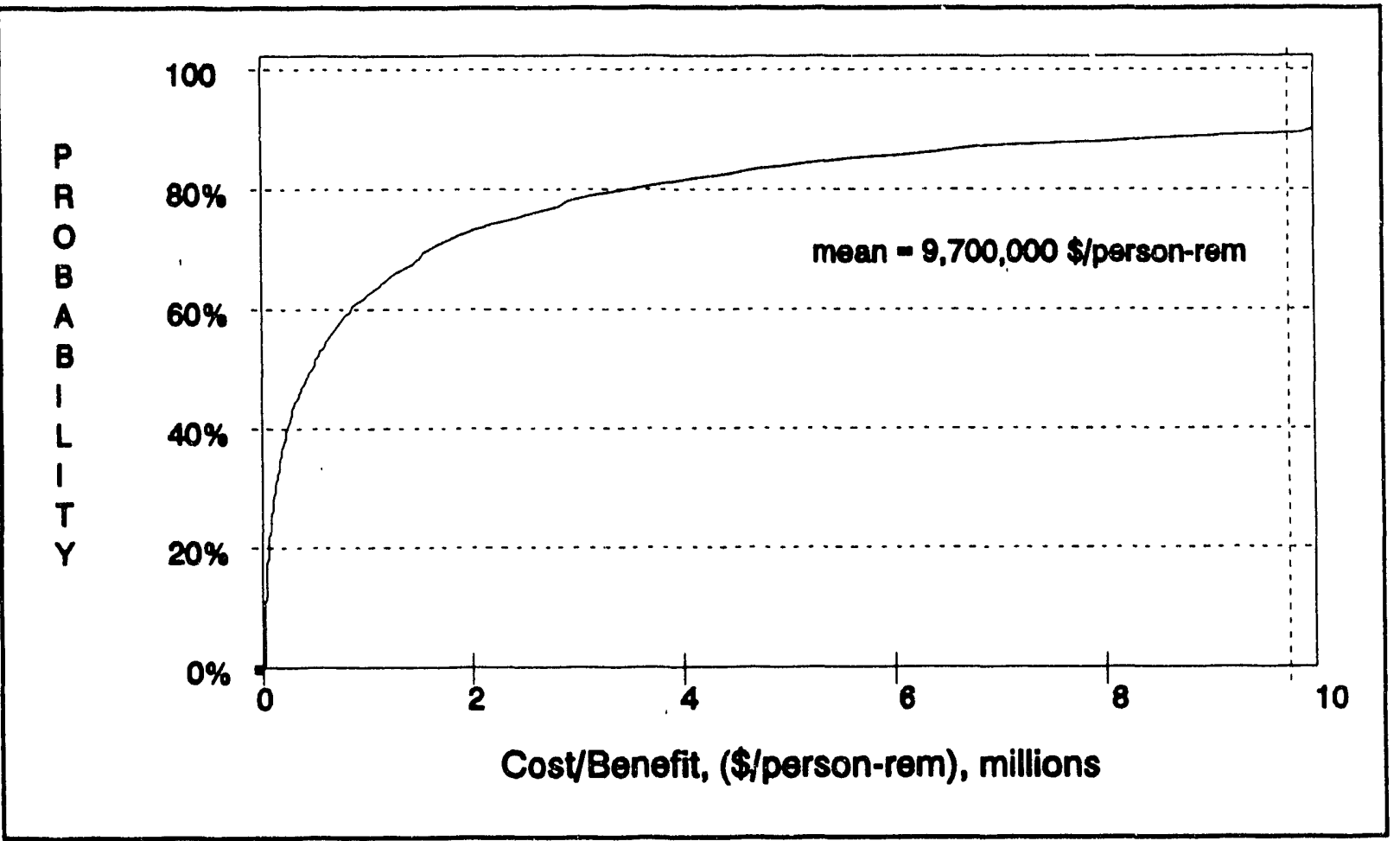

Figure F-7. Configuration II (modification 2) cost/benefit CDF.

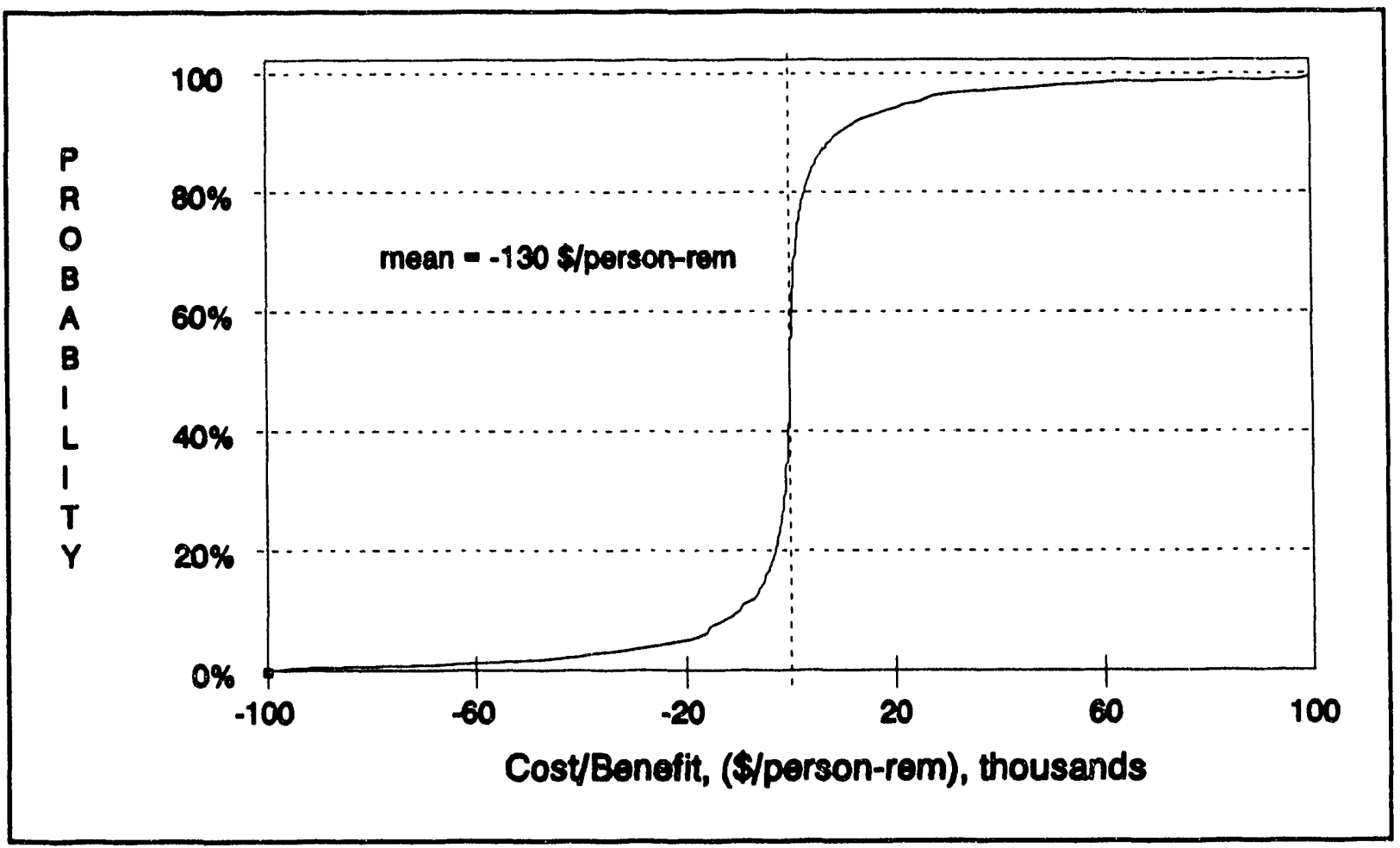

Figure F-8. Configuration III (modification 2) cost/benefit CDF. 


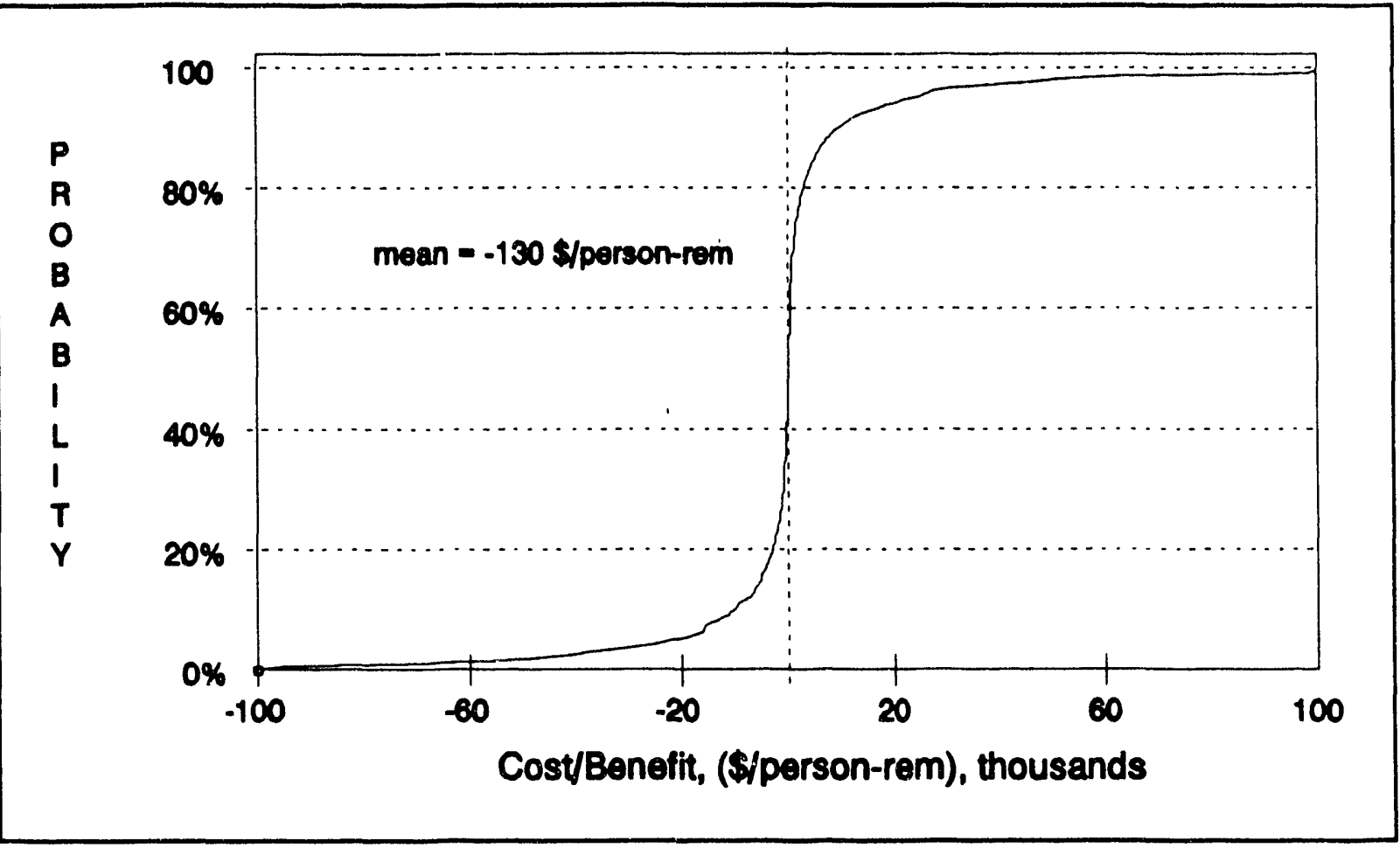

Figure F-9. Configuration IV (modification 2) cost/benefit CDF.

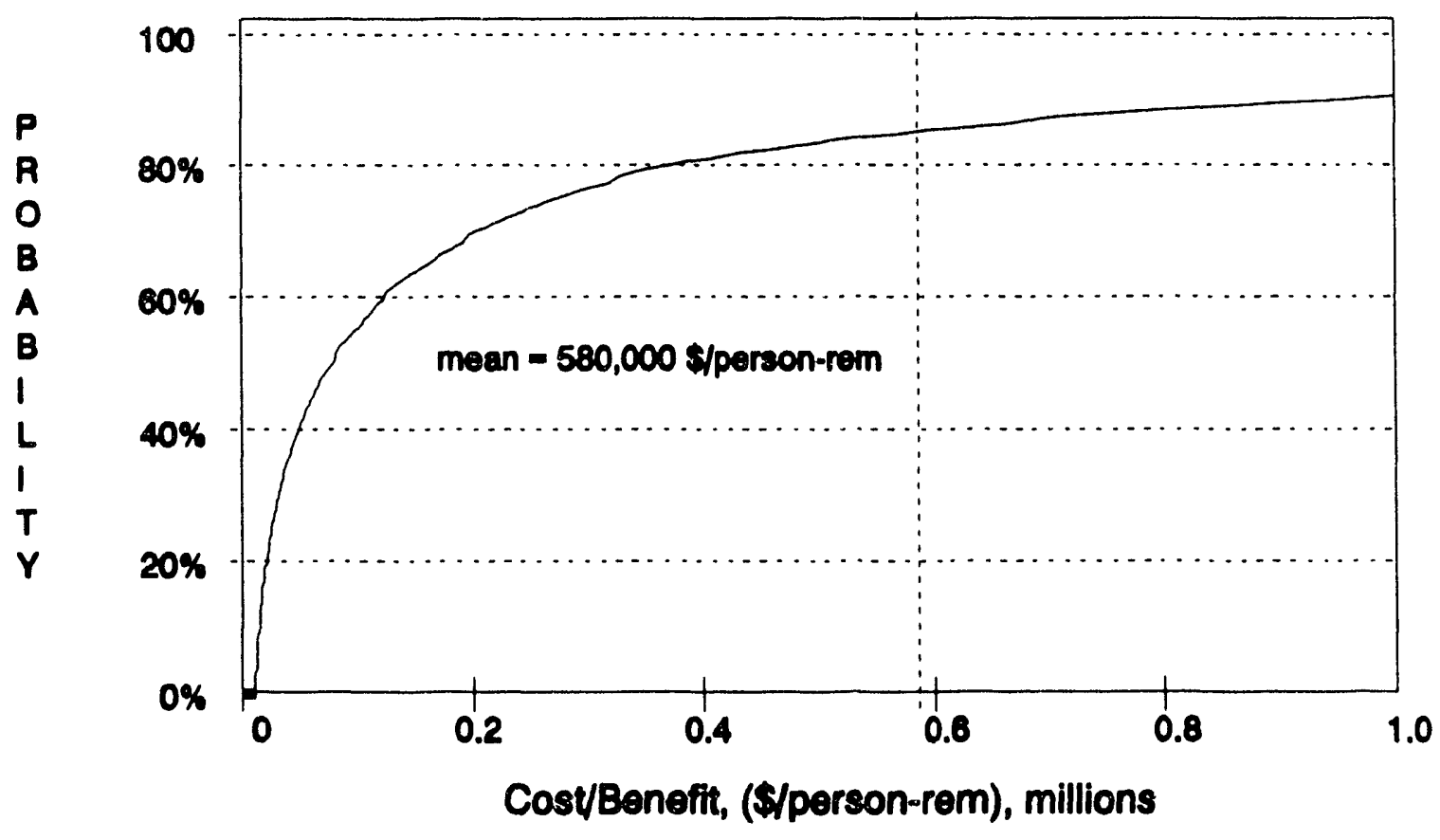

Figure F-10. Configuration VI (modification 2) cost/benefit CDF. 


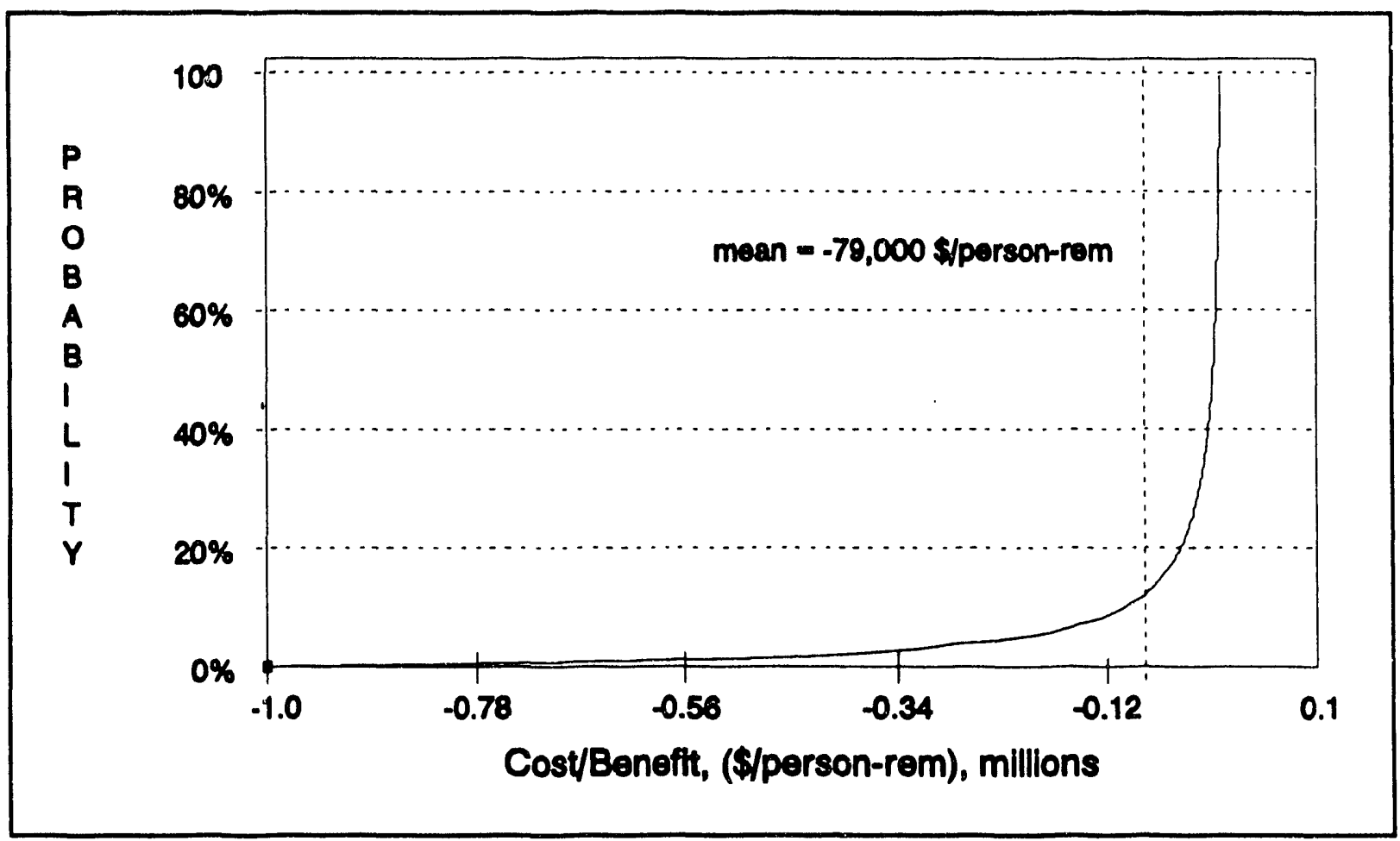

Figure F-11. Configuration VII (modification 2) cost/benefit CDF.

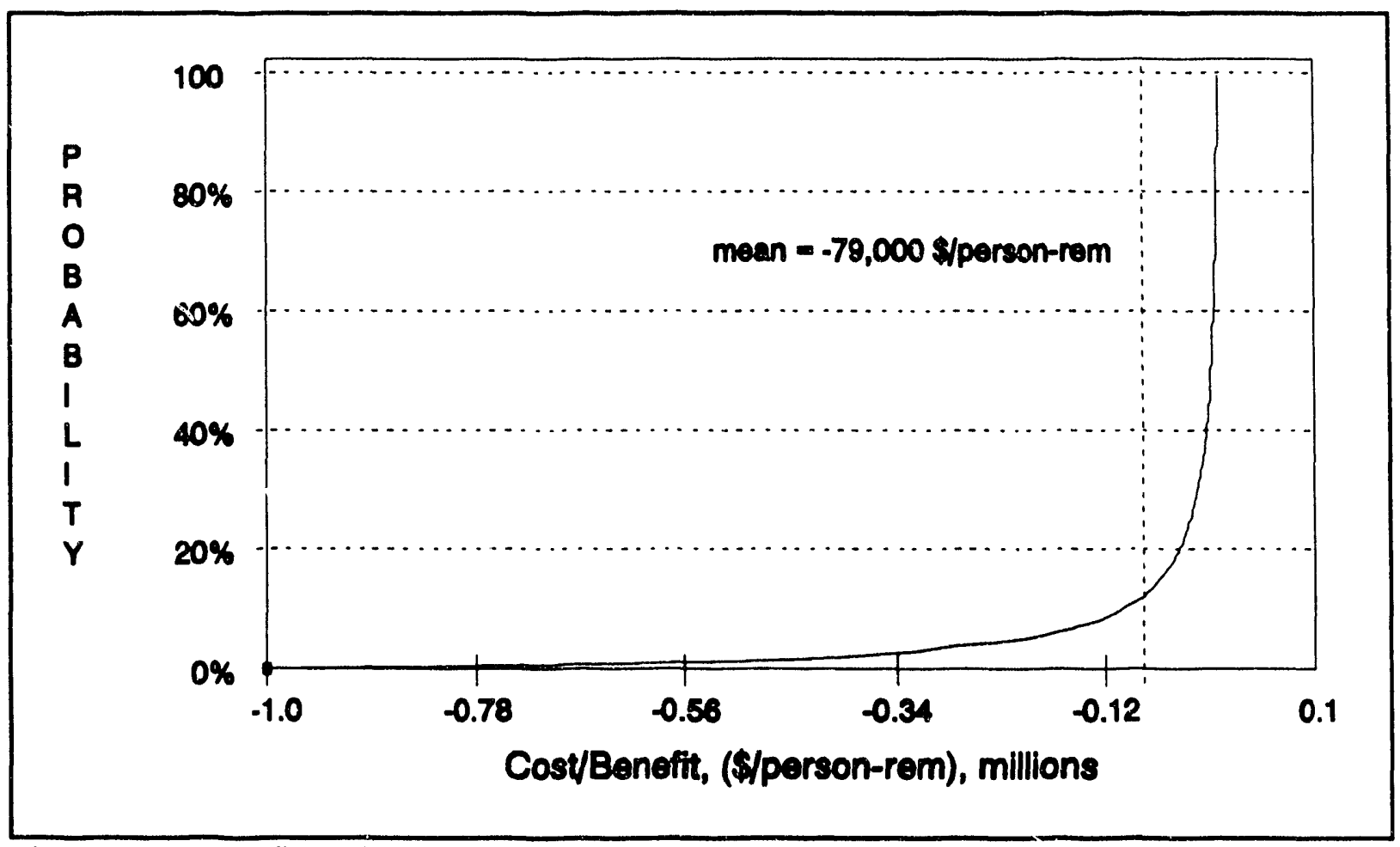

Figure F-12. Configuration VIII (modification 2) cost/benefit CDF. 


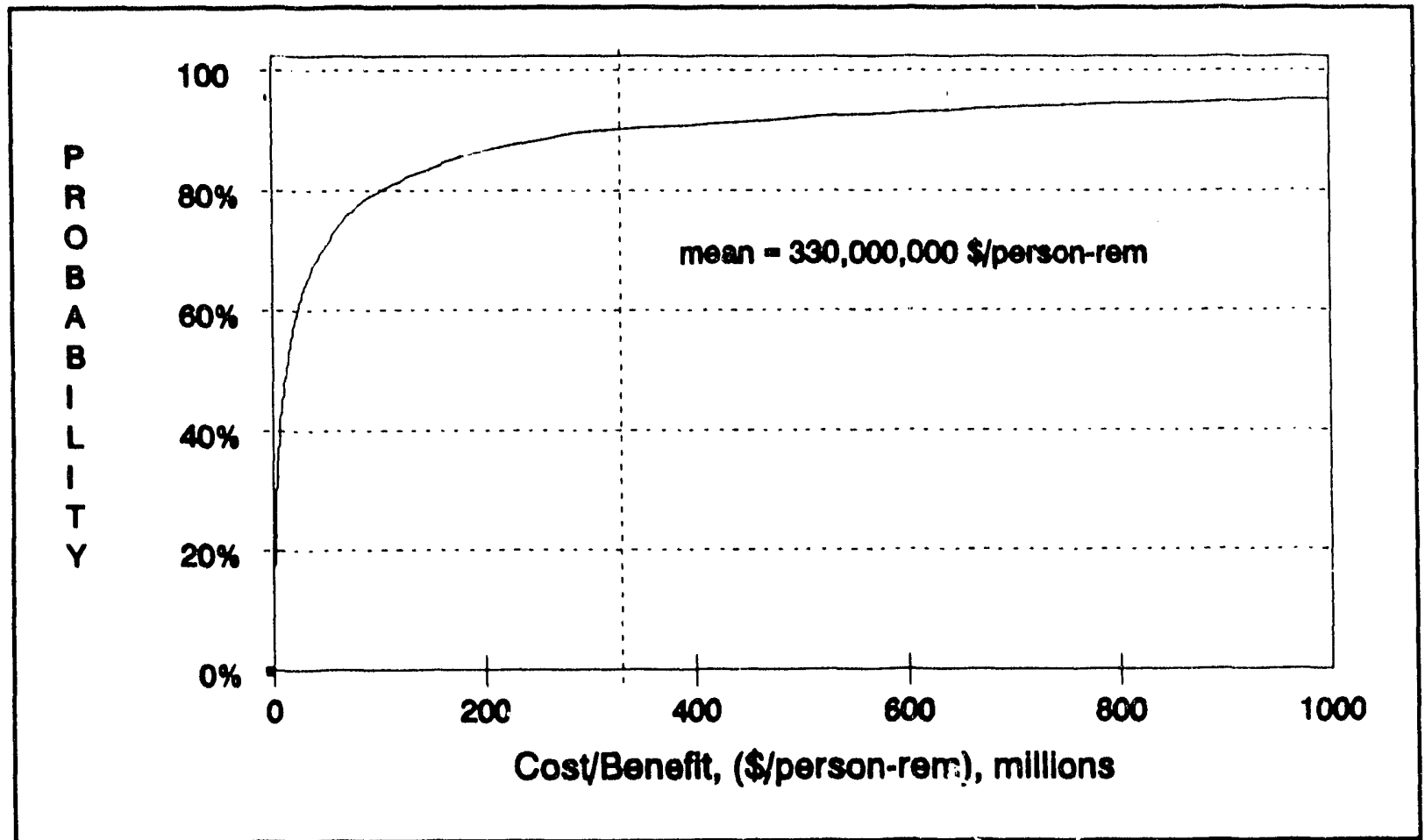

Figure F-13. Configuration II (modification 3) cost/benefit CDF.

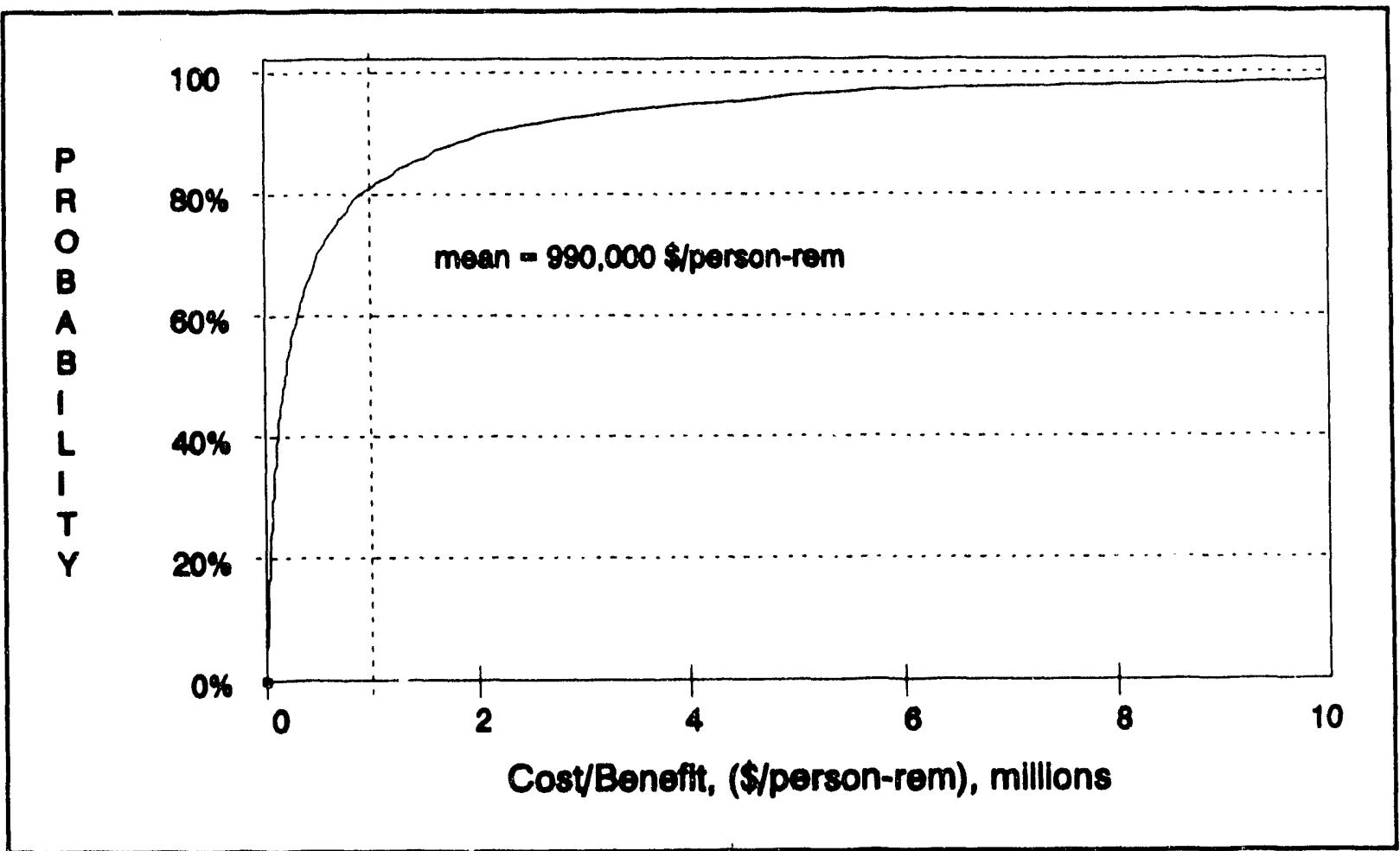

Figure F-14. Configuration III (modification 3) cost/benefit CDF.

F-10 


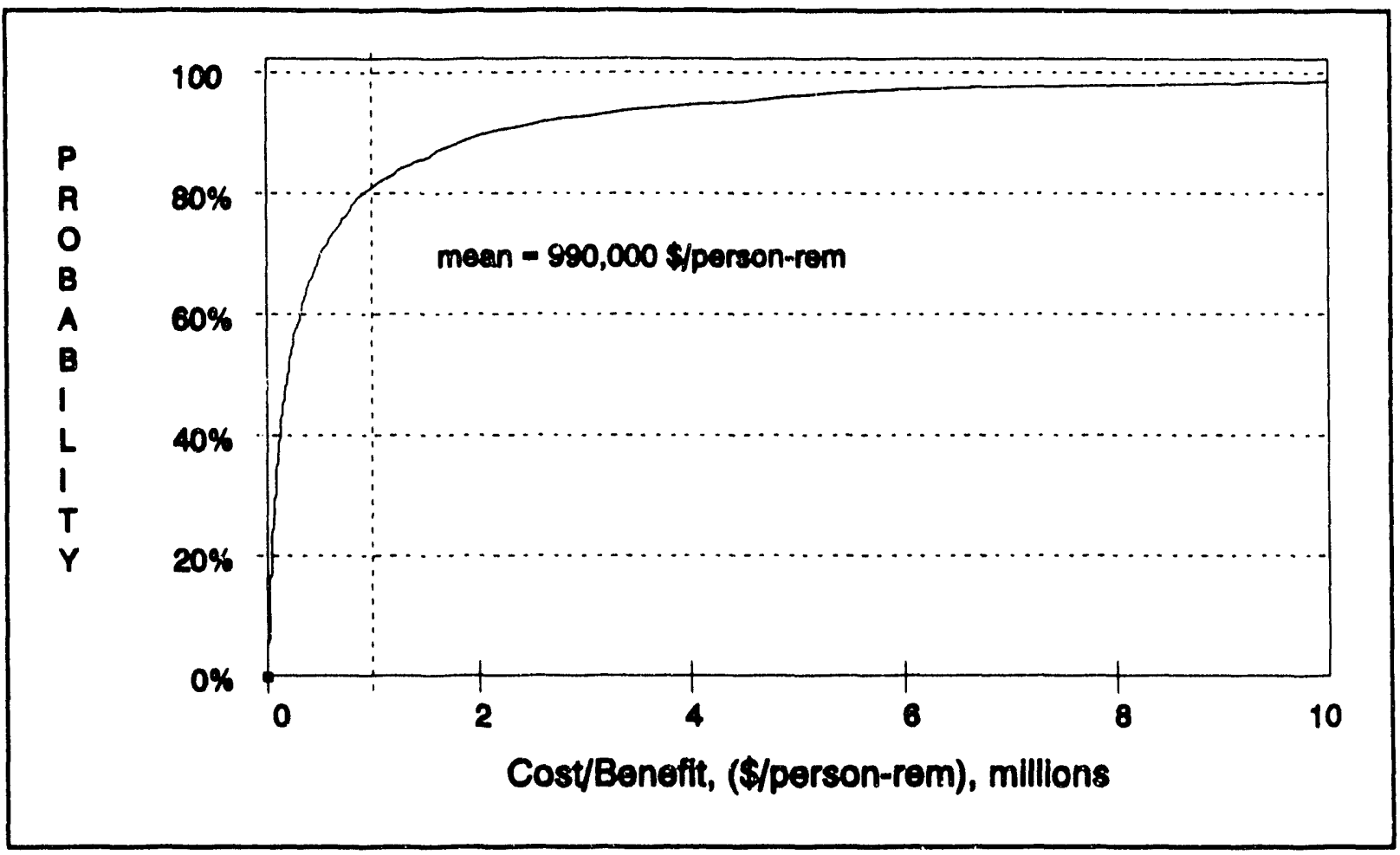

Figure F-15. Configuration IV (modification 3) cost/benefit CDF.

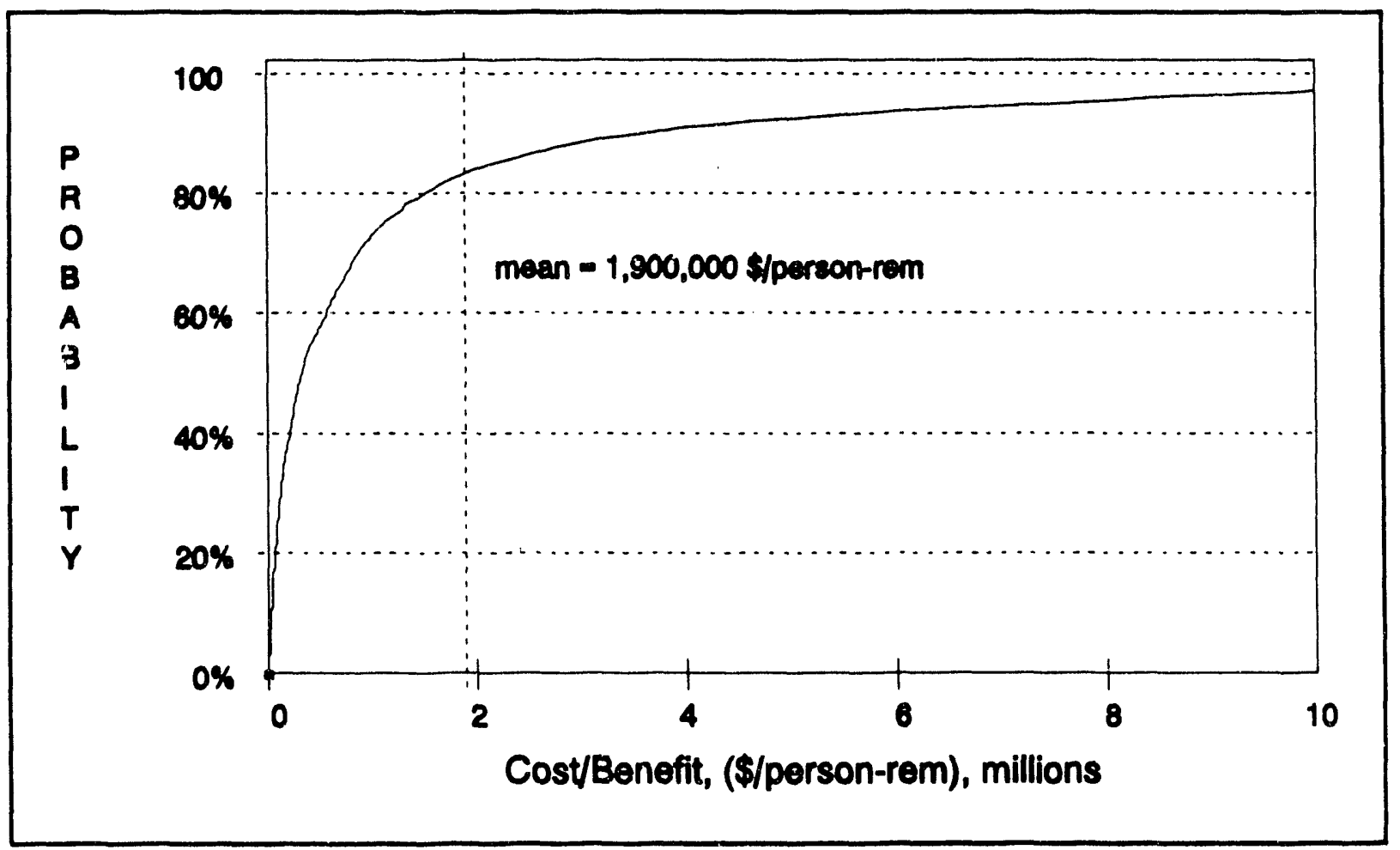

Figure F-16. Configuration V (modification 3) cost/benefit CDF.

\section{F-11}




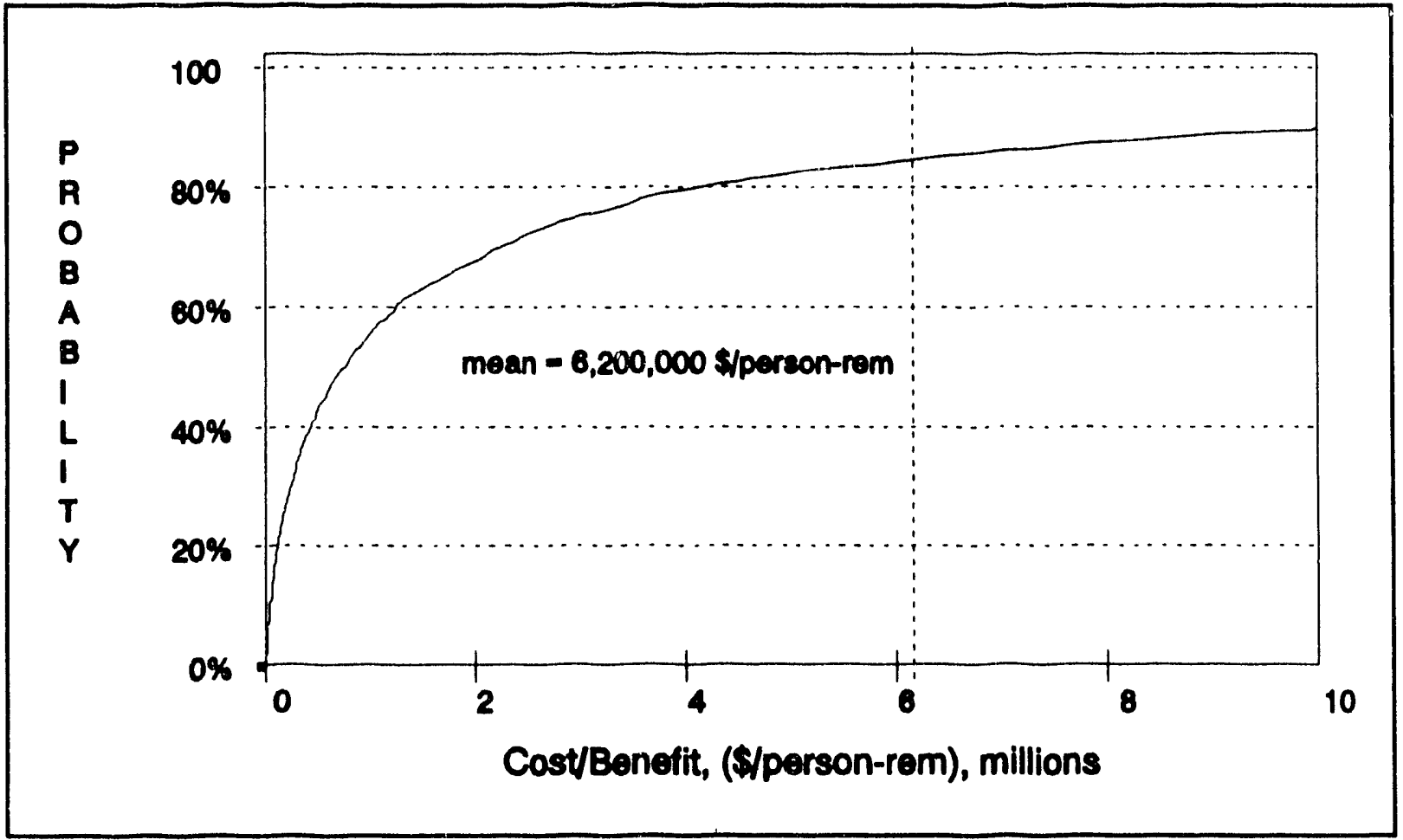

Figure F-17. Configuration VI (modification 3) cost/benefit CDF.

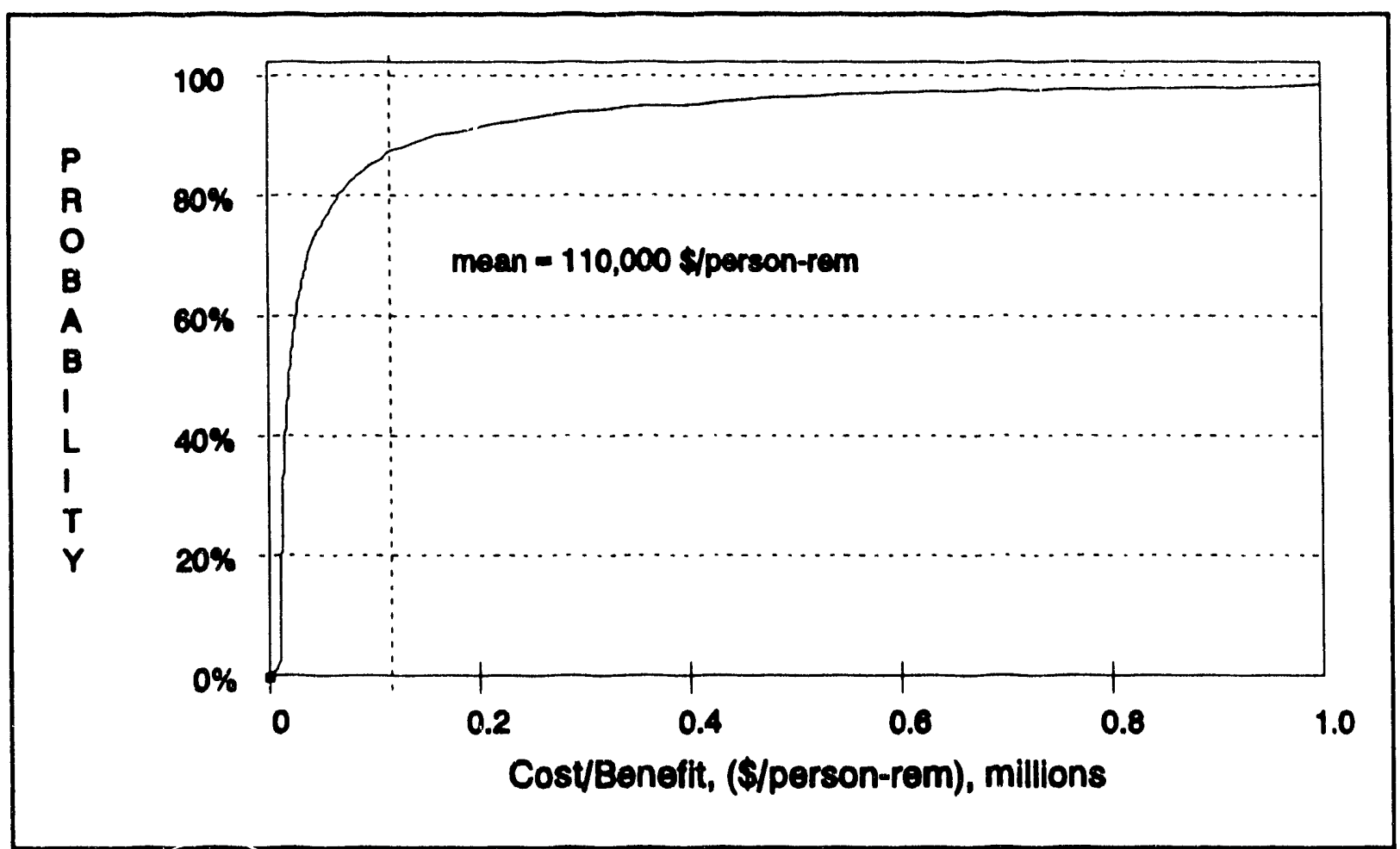

Figure F-18. Configuration VII (modification 3) cost/benefit CDF. 


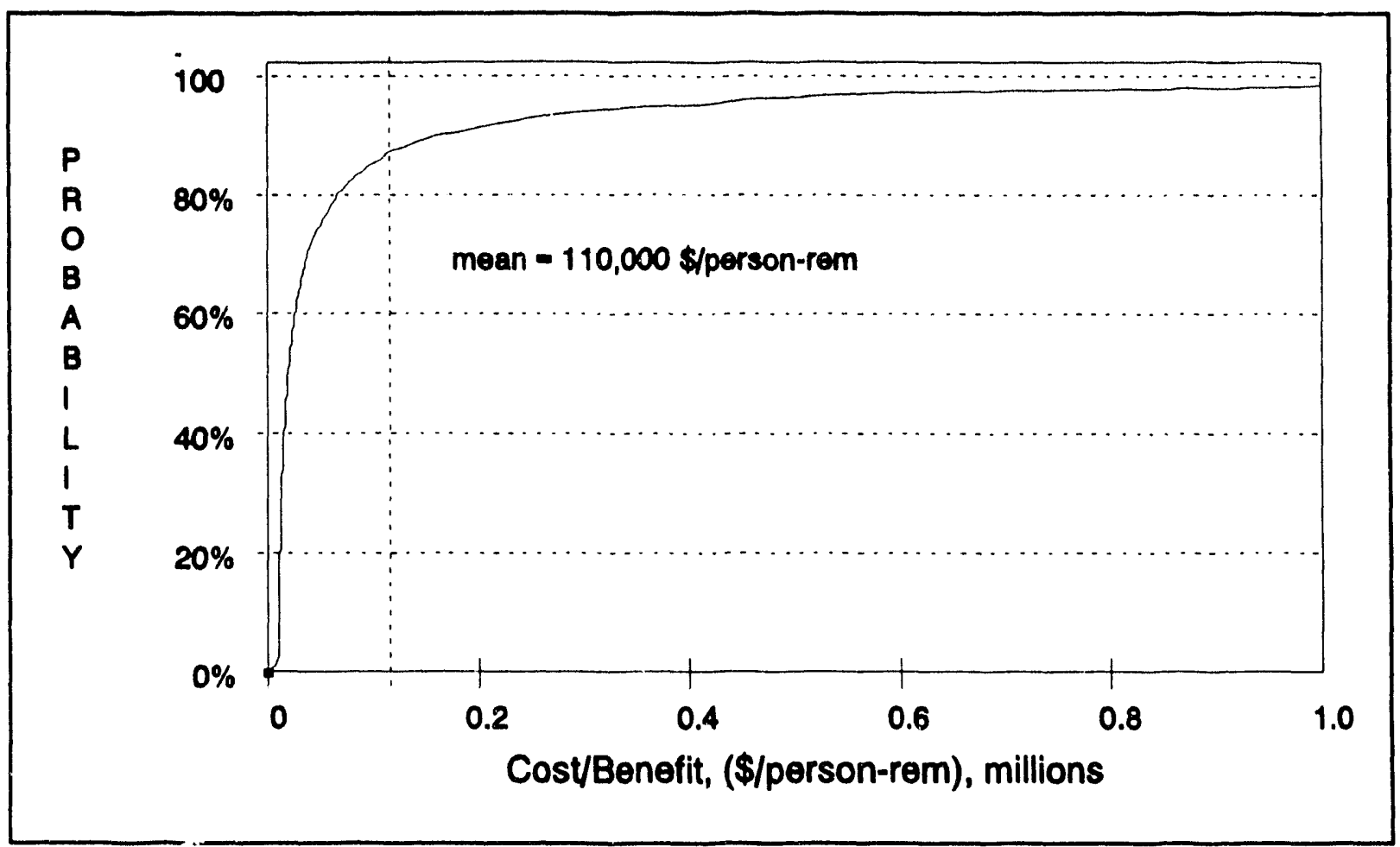

Figure F-19. Configuration VIII (modification 3) cost/benefit CDF.

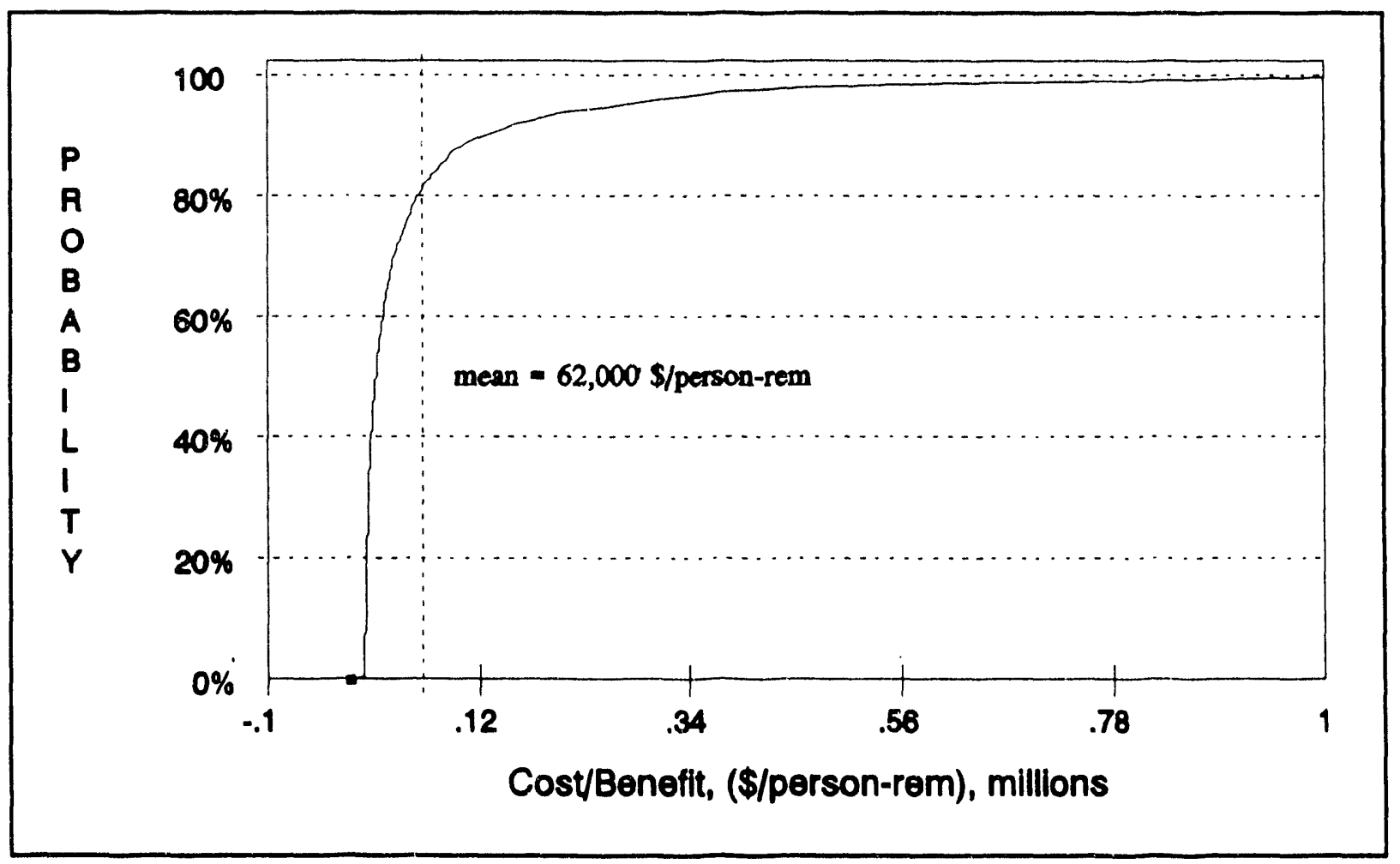

Figure F-20. Base Case (modification 1) cost/benefit CDF.

\section{F-13}




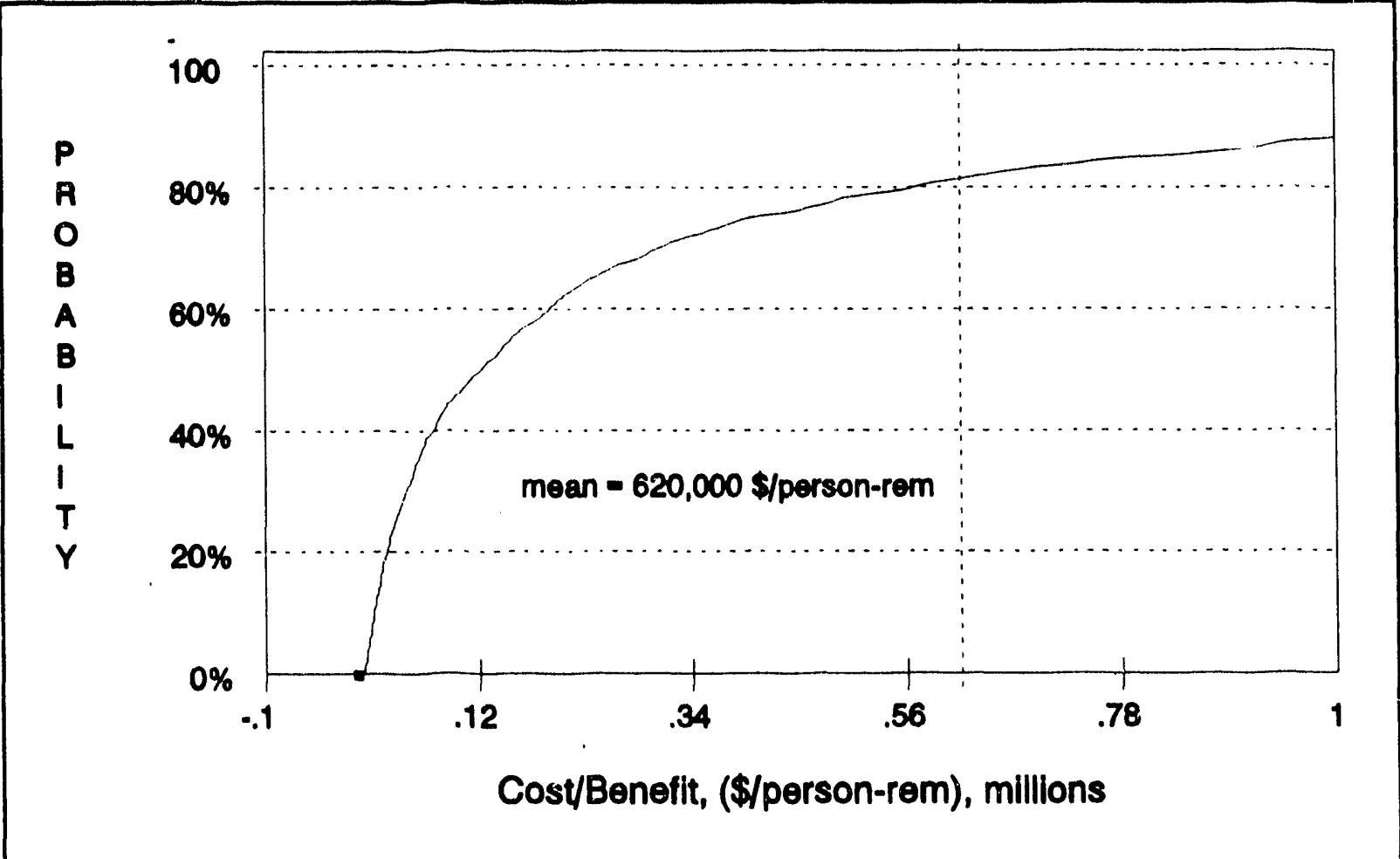

Figure F-21. Base Case (modification 2) cost/benefit CDF.

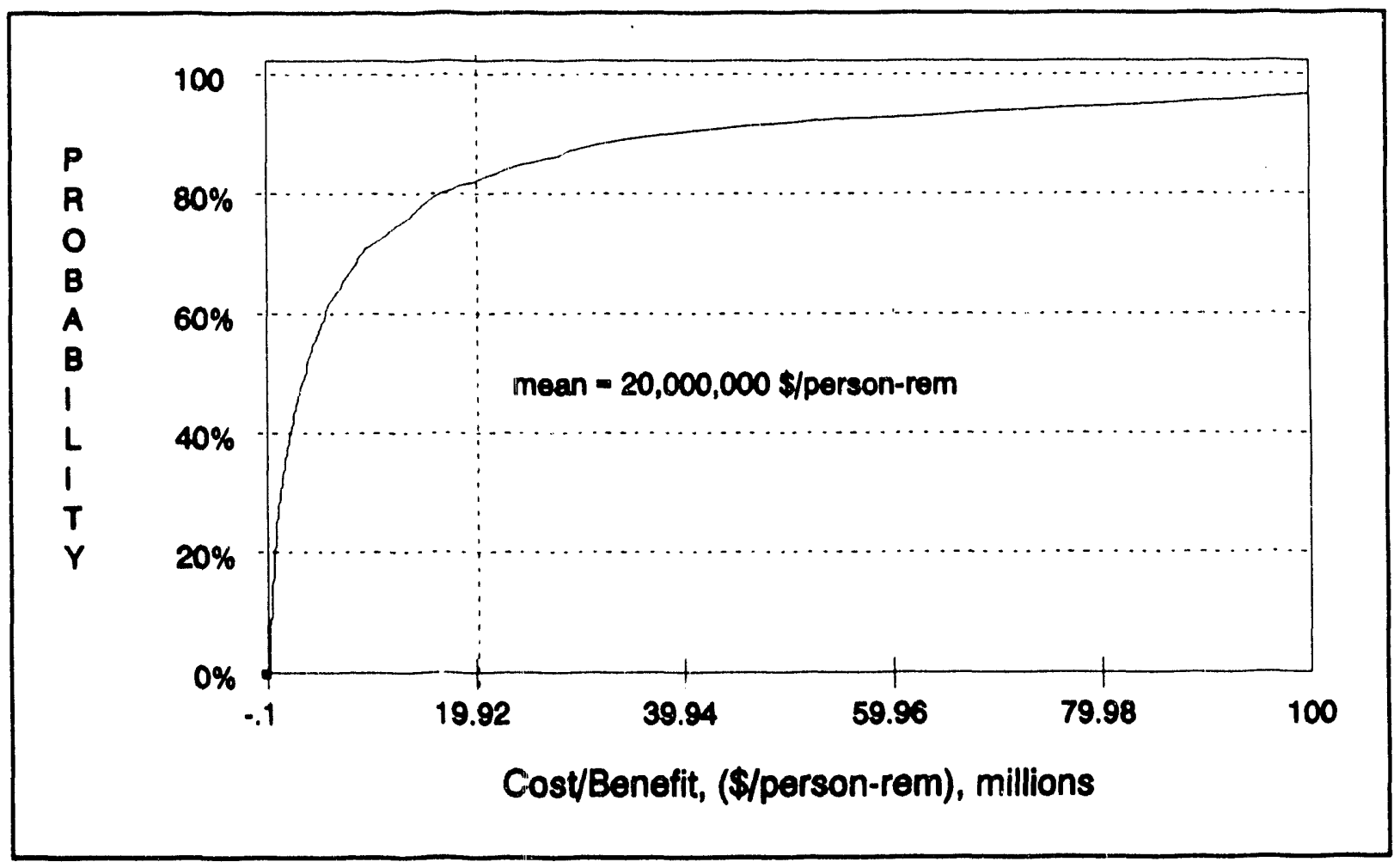

Figure F-22. Base Case (modification 3) cost/benefit CDF.

F-14 


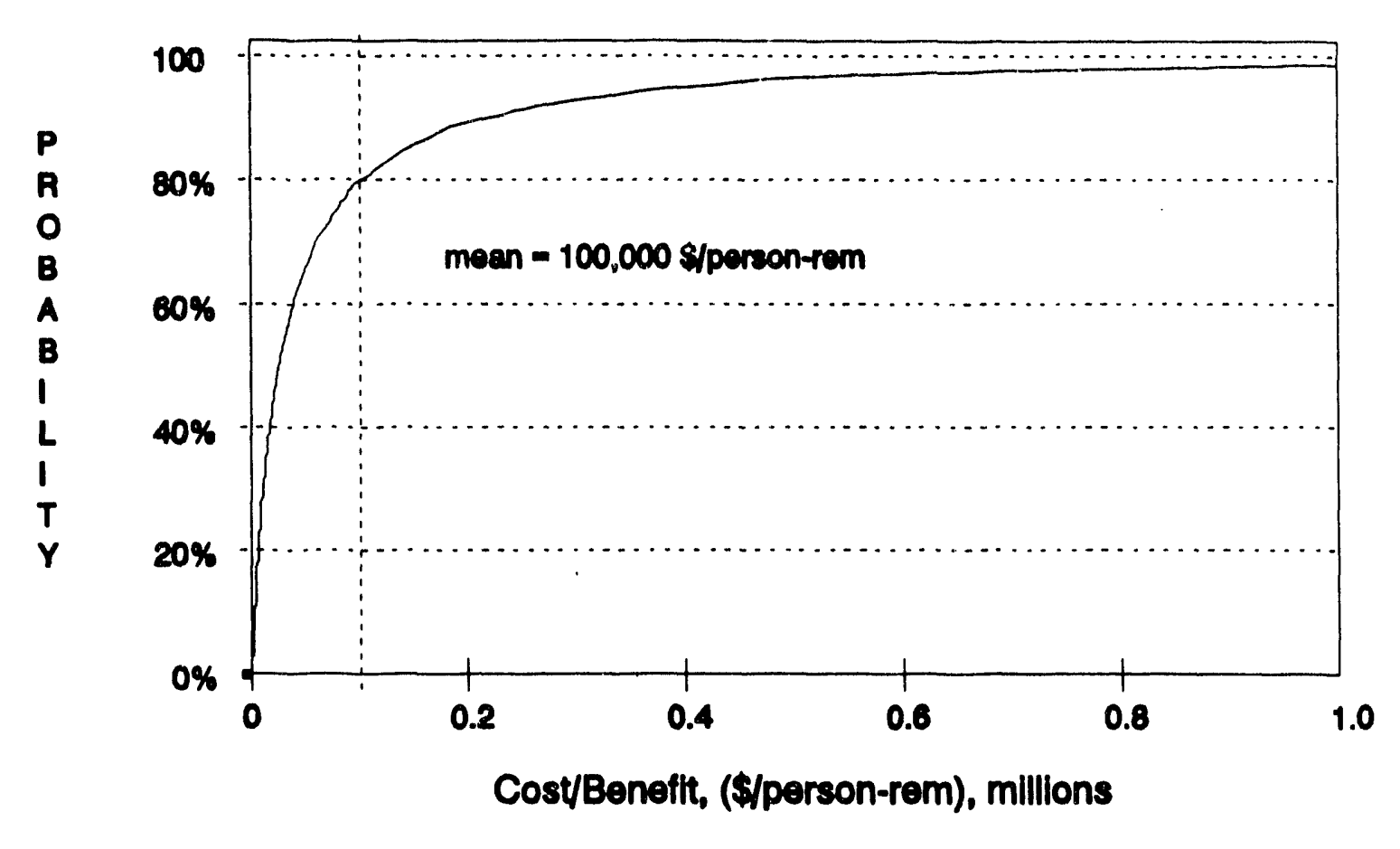

Figure F-23. Plant A (modification 1) cost/benefit CDF.

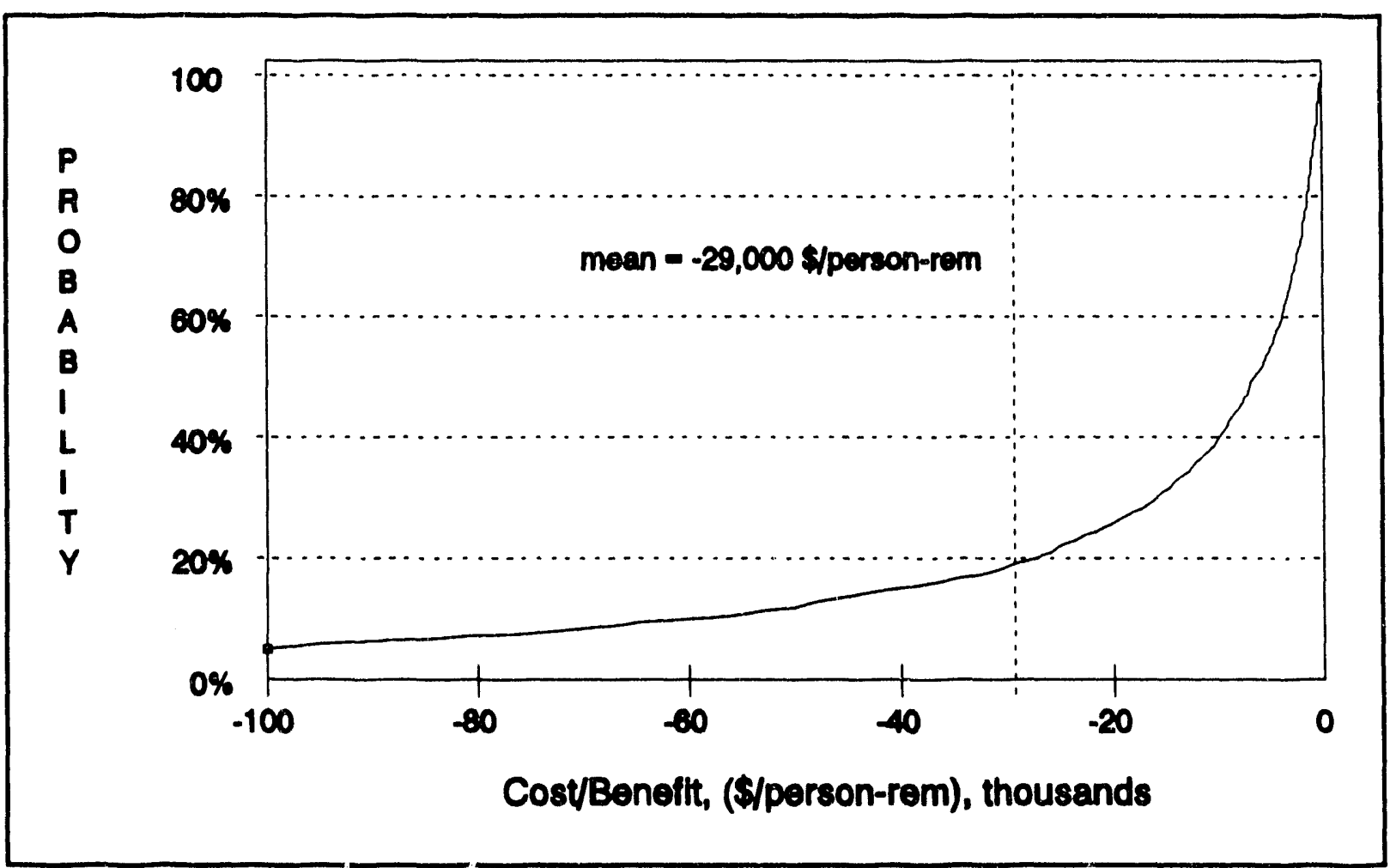

Figure F-24. Plant A (modification 2) cost/benefit CDF.

F-15 


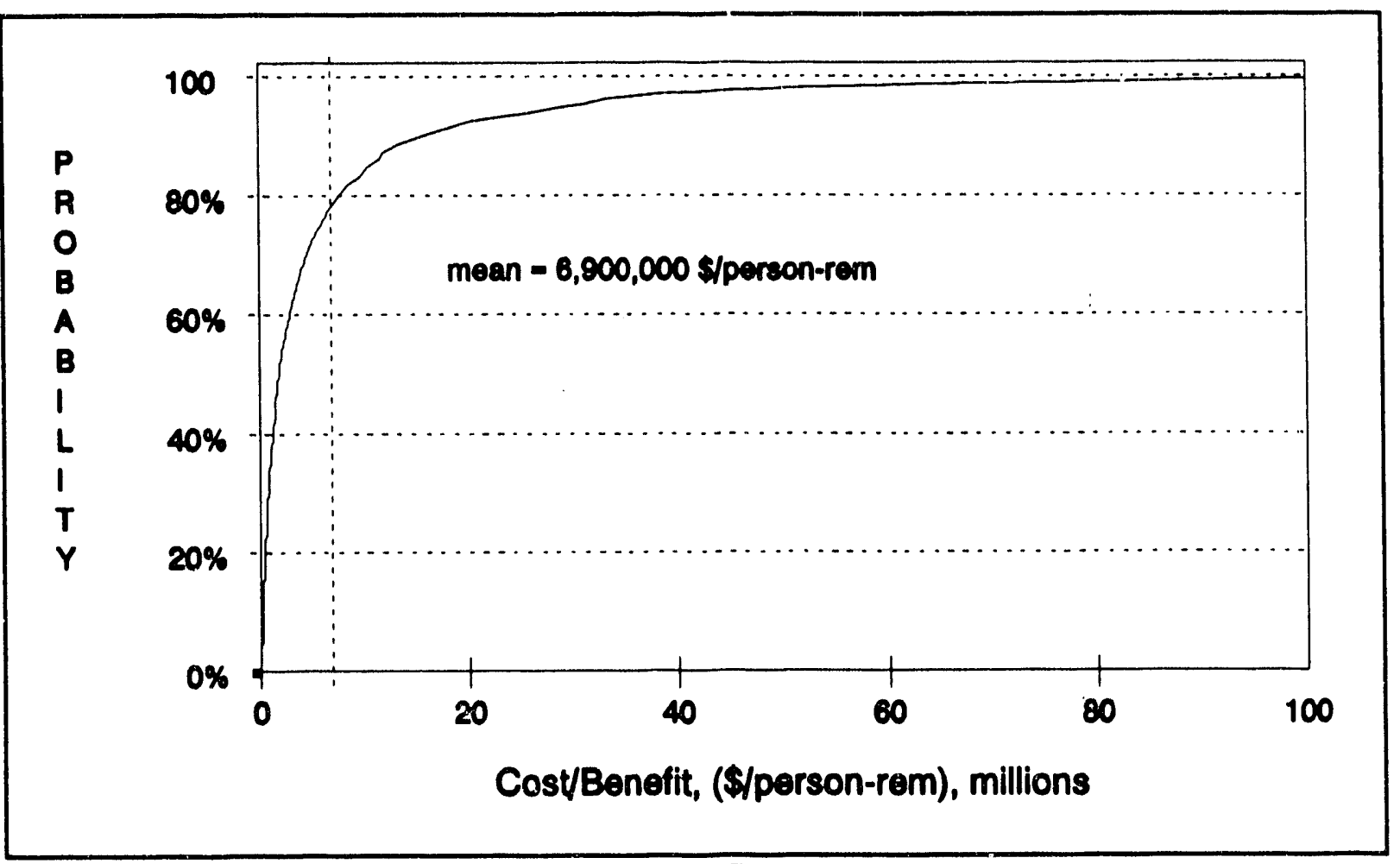

Figure F-25. Plant A (modification 3) cost/benefit CDF.

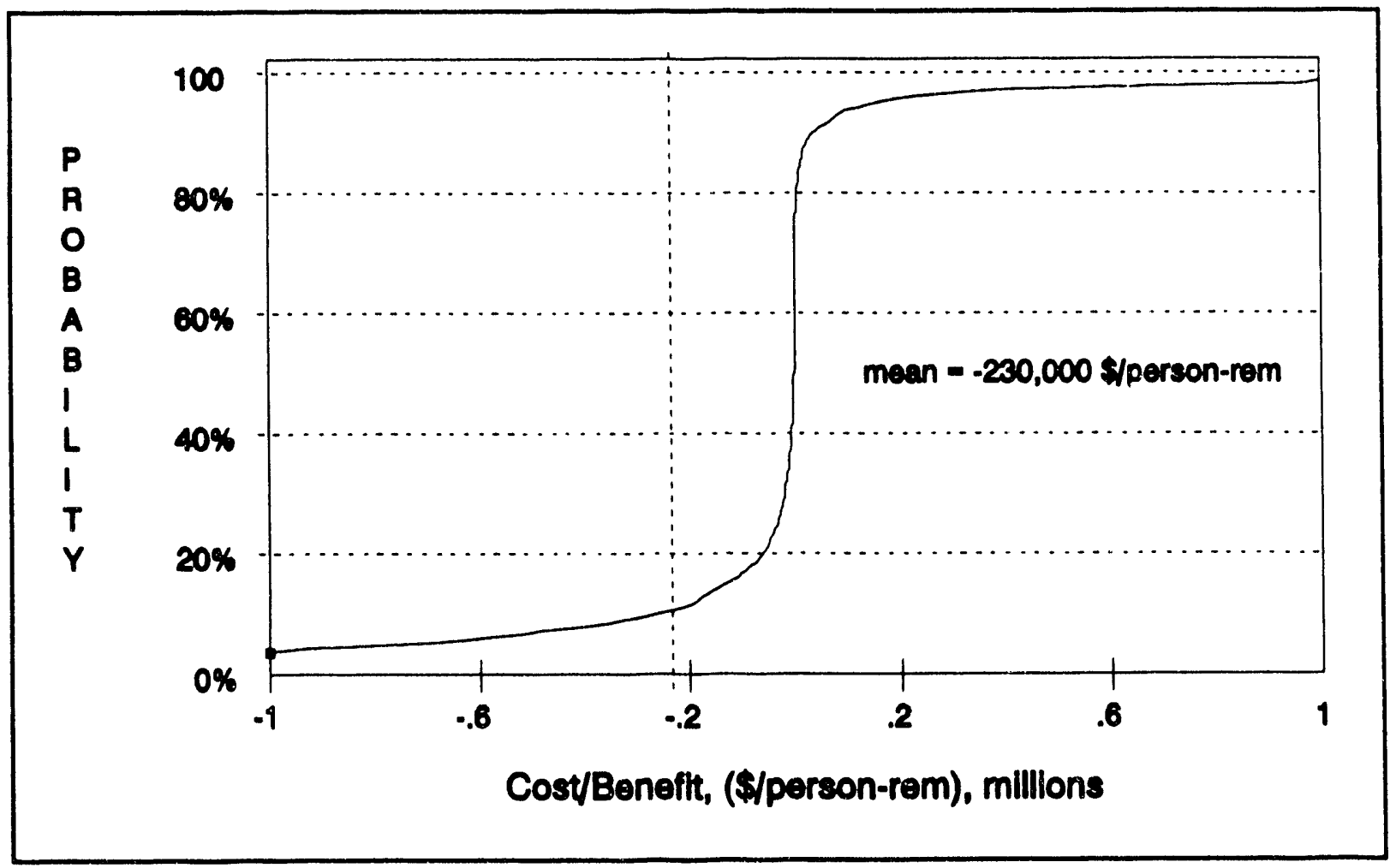

Figure F-26. Plant B (modification 1) cost/benefit CDF. 


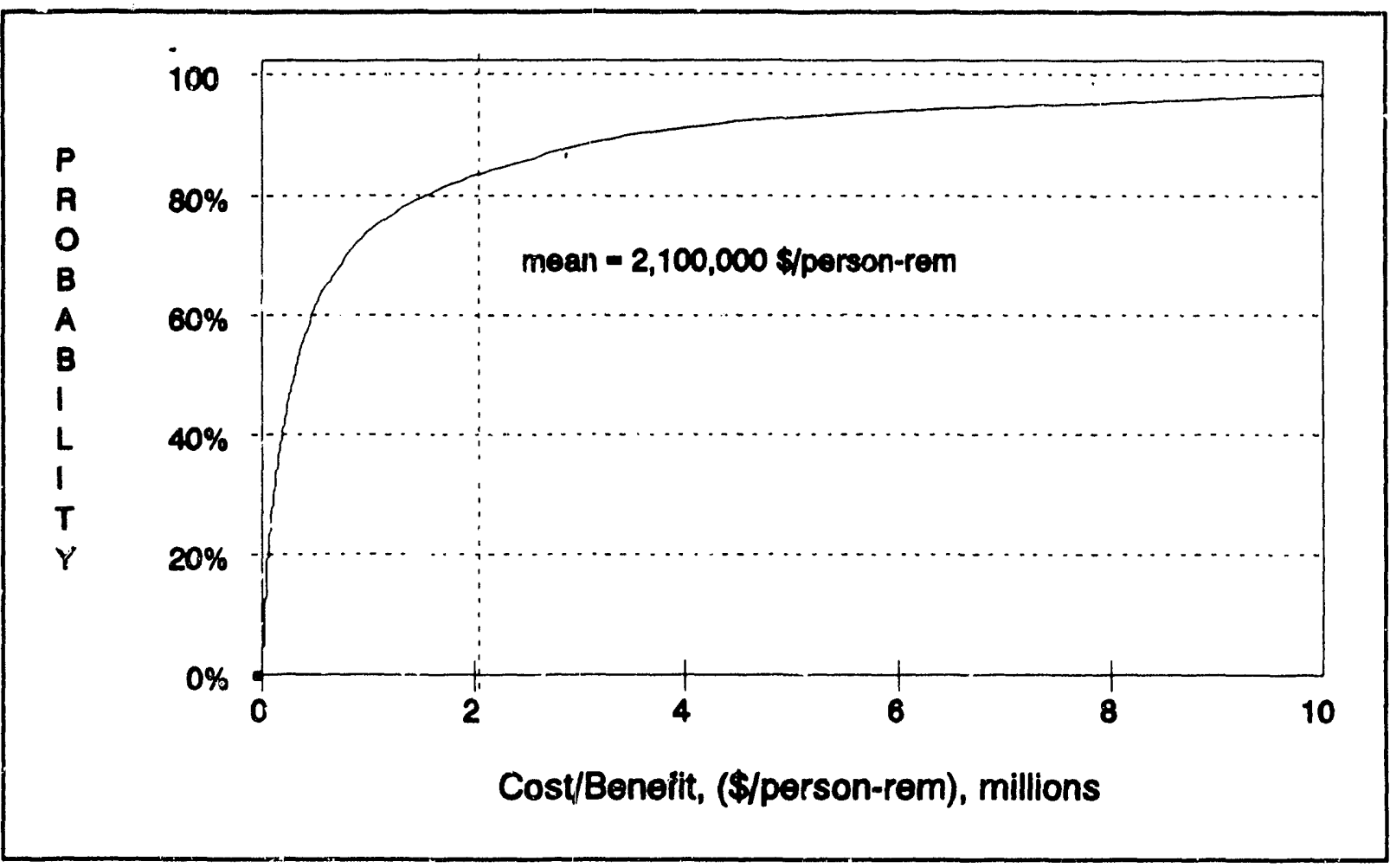

Figure F-27. Plant B (modification 3) cost/benefit CDF.

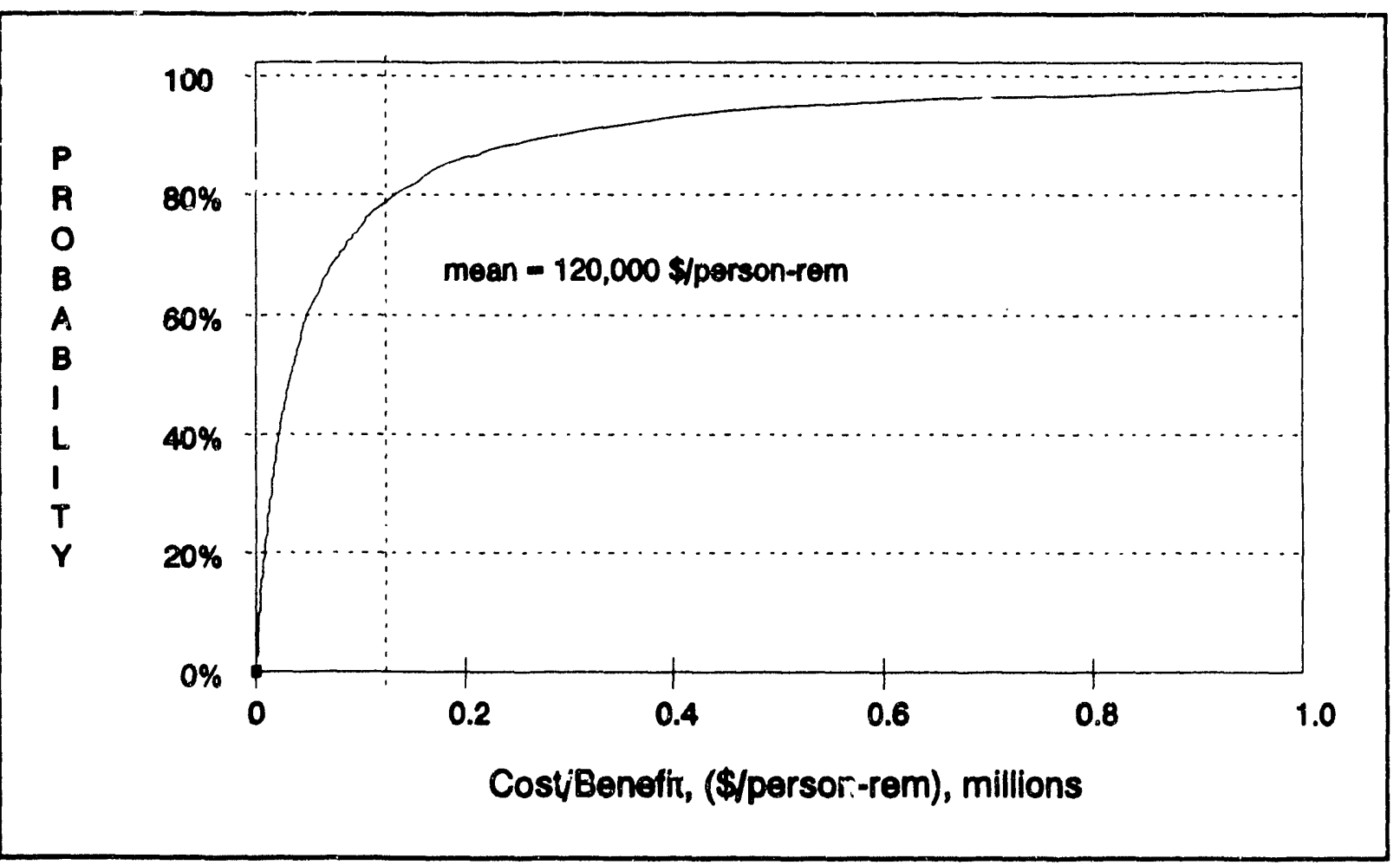

Figure F-26. Plant C (modification 3) cost/benefit CDF. 

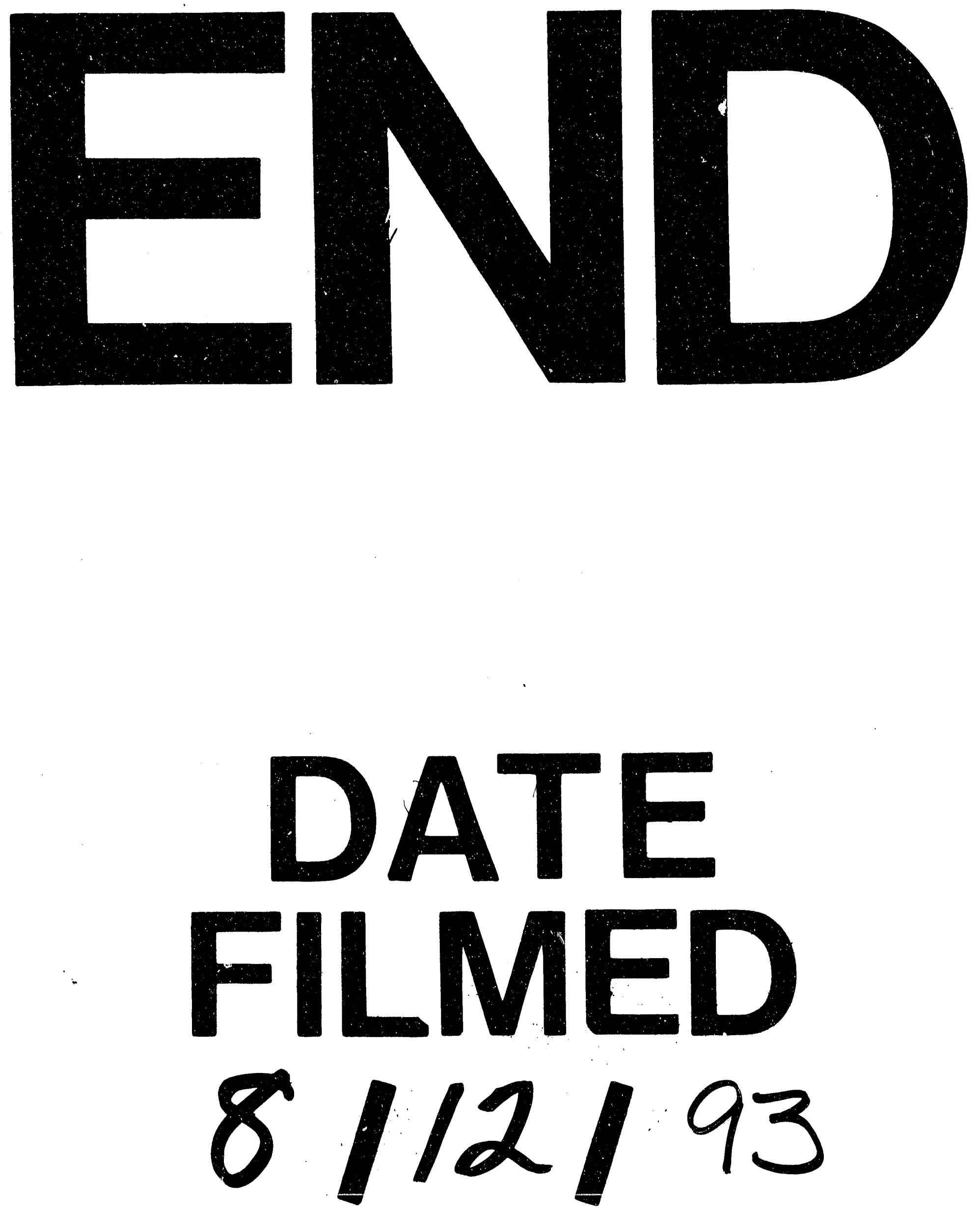


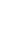

